\title{
Zur Staats- und Ideologietheorie im strukturalistischen Marxismus
}

\author{
Dissertation \\ zur Erlangung des sozialwissenschaftlichen Doktorgrades der \\ Sozialwissenschaftlichen Fakultät der Universität Göttingen
}

\author{
vorgelegt \\ von
}

Stefan von Brauk aus Lübbecke/Westf.

Göttingen 2002 
1. Gutachter/in: Prof. Dr. Walter Euchner

2. Gutachter/in: Prof. Dr. Wolf-Sighard Rosenbaum

3. Gutachter/in: Prof. Dr. Walter Reese-Schäfer

Tag der mündlichen Prüfung: 30.04.2002

Gleichzeitig erschienen in (bei):

Bd. Heft Seite

(Ort) (Datum) 
Keine Zukunft ohne Marx. [...] Jedenfalls nicht ohne einen bestimmten Marx, sein Genie, wenigstens einen seiner Geister. [...] Es gibt mehr als einen davon, es muss mehr als einen davon geben.

Jaques Derrida 



\section{Gliederung}

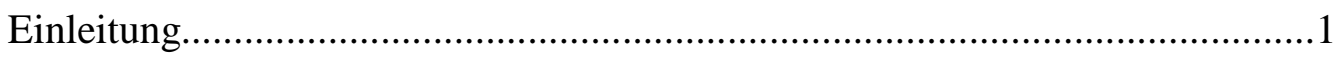

Kapitel 1: Marxismus und Epistemologie...................................................6

1. Realobjekt - Erkenntnisobjekt......................................................... 10

2. Theorie und theoretische Praxis.............................................................14

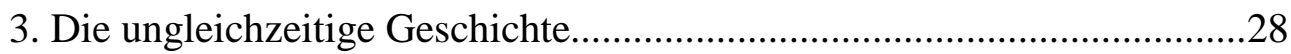

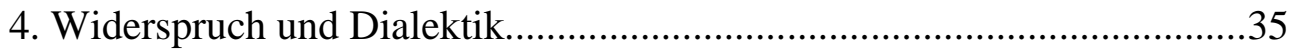

5. Geschichte ohne Subjekt: der epistemologische Einschnitt bei Marx......43

6. Philosophie und Wissenschaft - Althussers Selbstkritik.........................55

Kapitel 2: Zur Staats- und Ideologietheorie................................................62

1. Das automatische Subjekt................................................................64

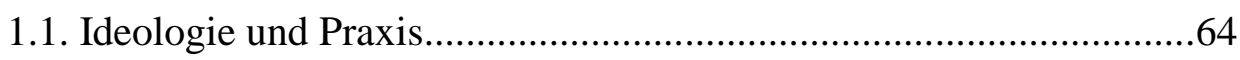

1.2. Ideologie als Staatsapparat........................................................ 71

1.2.1. Gramsci-Exkurs I: Hegemonie und hegemoniale Apparate......72

1.2.1.1. Der Hegemoniebegriff bei Gramsci..................................72

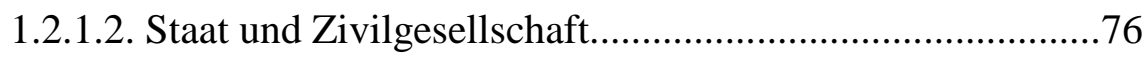

1.2.2. Ideologie und Reproduktion der Produktionsverhältnisse........83

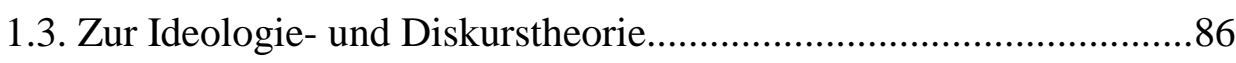

2. Der Staat - materielle Verdichtung eines Kräfteverhältnisses..................95

2.1. Zur theoretischen Konstitution des Politischen..............................95

2.2. Produktionsverhältnisse, Klassen und Klassenkampf....................100

2.3. Der Staat als soziales Verhältnis...............................................107

2.4. Staat und gesellschaftliche Macht................................................116

2.5. Die Materialität des Staates.............................................................123

2.5.1. Macht und Wissen.................................................................123

2.5.1.1. Gramsci-Exkurs II: Die Intellektuellen...........................125

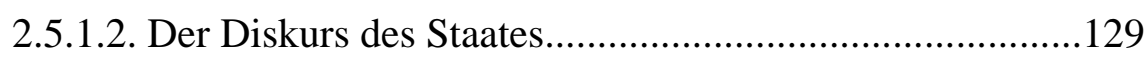

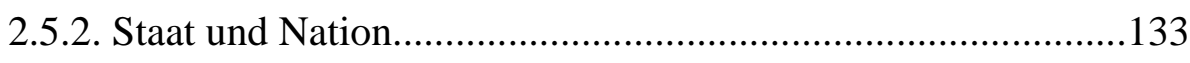

2.5.2.1. Die kapitalistische Raummatrix.....................................135

2.5.2.2. Die kapitalistische Zeitmatrix........................................138

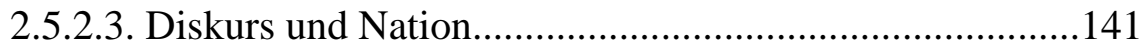

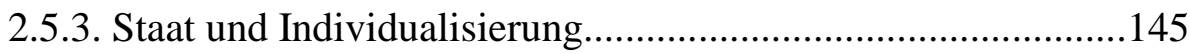

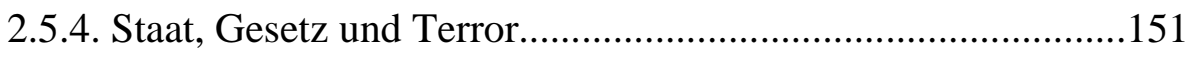

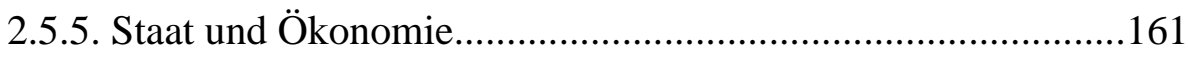


2.6. Der moderne Staat - Autoritärer Etatismus...................................180

2.6.1. Autoritärer Etatismus, Totalitarismus, Faschismus.................180

2.6.2. Autoritärer Etatismus und Bürokratie...................................183

2.6.3. Die Staatspartei im autoritären Etatismus.............................187

2.6.4. Autoritärer Etatismus als selbstnegatorischer Prozess?..........191

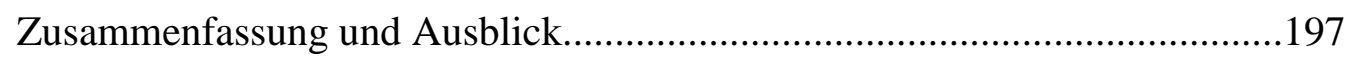

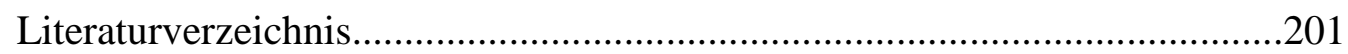

Hervorhebungen innerhalb von Zitaten beruhen - soweit nicht anders gekennzeichnet - im Folgenden immer auf der Fundstelle. Die Rechtschreibung der Zitate wurde (mit Ausnahme der Zitate von Marx und Engels) an die aktuelle Rechtschreibung angepasst. Eckige Klammern kennzeichnen vom Autor vorgenommene Auslassungen oder Ergänzungen in Zitaten bzw. Auslassungen oder Ergänzungen in zitierten einzelnen Wörtern.

Fundstellen aus Für Marx und Das Kapital lesen werden im Zweifel aus dem französischen Originaltexten wiedergegeben; zur Problematik der Qualität der deutschen Übersetzungen dieser Texte siehe Schöttlers Anmerkungen in Althusser 1975a, S. $16 \mathrm{ff}$. 


\section{Siglen und Abkürzungen}

Aufl. Auflage

Bd. Band

bzgl. bezüglich

bzw. beziehungsweise

d. h. das heißt

Diss. Dissertation

DKL Das Kapital lesen, Althusser/Balibar 1972

E-Bd. Ergänzungsband

ebd. ebenda

evtl. eventuell

f. folgende

ff. fortfolgende

FM Für Marx, Althusser 1968

Fn. $\quad$ Fußnote

F\&E Forschung und Entwicklung

GG Grundgesetz

Gh Gefängnishefte, Gramsci $1991 \mathrm{ff}$.

Hrsg. Herausgeber

i. d. R. in der Regel

insb. insbesondere

IISA Ideologie und Ideologische Staatsapparate, Althusser 1977

ISA ideologische Staatsapparate

IWF Internationaler Währungsfonds

LLC $\quad$ Lire le Capital, Althusser/Balibar 1969

LW Lenin-Werke, Lenin 1956 ff.

m. E. meines Erachtens

MEW Marx-Engels-Werke, Marx/Engels 1956 ff.

NAFTA North America Free Trade Agreement

NATO North Atlantic Treaty Organization

NGO Non Government Organization

o. ä. oder ähnliches

o. O. ohne Ort

o. J. ohne Jahrgang 
PCF Parti Communiste Française

PM Pour Marx, Althusser 1974b

ProKla Probleme des Klassenkampfs

RSA repressive Staatsapparate

S. Seite

St Staatstheorie, Poulantzas 1978a

s. o. siehe oben

s. u. siehe unten

u. a. unter anderem

usf. und so fort

usw. und so weiter

ÜuS Überwachen und Strafen, Foucault 1994

vgl. vergleiche

WTO World Trade Organization

z. B. zum Beispiel

zit. zitiert

z. T. zum Teil 


\section{Personenverzeichnis}

(Marx, Althusser und Poulantzas werden nicht aufgeführt)

Adorno, T. W

$25,59,88$

Descombes, V.

$19,38,60$

Agnoli, J. $188,189,195$

Dosse, F. 2 2, 4, 38, 44, 48, 59, 84, 195

Anderson, P. 3, 12, 25, 72, 74, 75, 77-79, 81,82

Engels, F.

$2,19,54,62,99,198$

Establet, R.

45

Bachelard, G.

$5,23,24,61$

Euchner, W. 51

Backhaus, H.-G.

25,27

Fetscher, I.

9

Balibar, É. 4, 9, 23, 50, 55, 60, 83, 95-97, $102,108,129,141-144,148$

Feuerbach, L.

$10,41,42,51,67$

Balibar, R.

Fichant, M.

Barthes, R.

Foucault, M. $\quad 2,4,5,10,22,23,43,50$,

2,10

Bauer, O.

Berthold, J.

Bettelheim, C.

Bischoff, J.

62

64

4

126

Böke, $\mathrm{H}$.

Bordiga, A. $49,57-59$

78

Bourdieu, P. 21, 44, 48, 51, 52, 94, 101, 152

Brentel, $\mathrm{H}$.

Brühmann, $\mathrm{H}$.

Bucharin, $\mathrm{N}$.

Buci-Glucksmann, C.

Butler, J.

Buttler, J.

Canguilhem, G.

Châtelet, F.

Courtois, S.

Croce, B.

Dahrendorf, R.

Deleuze, G. $5,50,56,57,115-119,131$, 136, 161, 169

Della Volpe, G.

Demirovic, A. $3,4,87,88,93,105,157$

Derrida, J. $3,4,54,55,60,89,217$

de Saussure, F.

$5,17,26-28$

Hes
52, 55, 58, 65, 86, 87, 89-91, 93, $116-119,121,129,139,141,145-$ 148, 152-154, 159, 172, 180

Freud, S.

$8,10,18,21,39,47,66$

Friedrich, C. J.

182

Garaudy, R.

2, 45

Godelier, $\mathrm{M}$.

Gramsci, A. 4, 5, 33, 39, 62, 64, 71-79, $81,82,89,90,106,124,125,127$, $129,153,172$

Guattari, F. 115, 117, 131, 136, 161, 169

Habermas, J. 59, 91, 93, 187, 193, 199

Harms, A.

62

Hauck, G.

91

Hegel, G. W. F. $8-10,12,19,23,25,29-$ 31, 35-38, 40-42, 51, 55, 57, 76, 88,109

Heidegger, $M$.

59

Heinrich, M. $27,59,61$

Heisenberg, W. 26

Hess, $\mathrm{M}$. 51

Hirsch, J. 3, 62, 106-108, 112, 113, 135 , 141, 166, 169, 174, 177, 179, 195, 199

Hobsbawm, E.

Honneth, A. 
Hund, W. D.

Jaeggi, U.

Jäger, M.

Jessop, B.

Kammler, C.

Karsz, S.

Kebir, S.

Kristeva, J.

Kurz, R.

Labica, G.

Labriola, A.

Lacan, J.

Laclau, E.

Lecourt, D.

Lefebvre, $\mathrm{H}$.

Lenin, W. I. 198

Lévi-Strauss, C.

Lewis, J.

Lipietz, A.

Luhmann, N.

Lukács, G.

Lyotard, J.-F.

Macherey, P.

Mandel, E.

Mao Tsetung

Marcuse, $\mathrm{H}$.

Meillassoux, C.

Milliband, R.

Mouffe, C.

Nietzsche, F. W.

$4,10,18,22,56,65,70$

$87,88,92$

59,90

52

$3,62,72-74,76,78,133$,

33 ,

S

Sch

2, 30, 38

45

3, 108

$1,93,152,181$

$14,19,33,44,50,53,65$

2,123

4,59

$17,167,183,185$

35

152

45

85

$87,88,92$

116

Offe, C. 98, 100, 101, 104, 108, 109, 114, 181, 186, 193, 194

Owen, R.

Panne, J.-L.

Parsons, T.

16

182

1,181
Pascal, B.

64

Paschukanis, E.

62

Pêcheux, M.

4, 59, 69

12,72

Plechanow, G. W.

Plumpe, G.

Poster, M.

Priester, K.

Proudhon, P. J.

Rancière, J.

Reichelt, $\mathrm{H}$.

Rheinberger, H. J.

Ricardo, D.

Roth, G.

Samuelson, P. A.

Sartre, J.-P.

Schaff, A.

Schmidt, A.

Schoch, B.

Schöttler, P.

Schumpeter, B.

Sève, L.

Smith, A.

Spiegel, H.

Spinoza, B.

Sprinkler, M.

Stalin, J.

Terray, E.

Thieme, K. 14, 16, 20, 30, 40, 43, 44, 4850

Trenkle, N.

4,53

Turchetto, $\mathrm{M}$.

19,57

Wallerstein, I.

141-144

Weber, $\mathrm{M}$.

$86,105,109,152,187$

Werth, N.

182

Zizek, S.
$45,64,69,91$

86,93

125

31

55

9,27

10

128

52

$2,5,30$

9

$10,24,25$

47,54

52

45, 46

16

33

12

54

9, 134

4, 38, 45 


\section{Einleitung}

a) Marxistische Theorie auch im 21. Jahrhundert zu betreiben mag vielleicht angesichts des Untergangs der Gesellschaften sowjetischen Typs und dem danach ausgerufenen „Ende der Geschichte“ (Fukuyama) verwundern; allerdings haben die sich seit diesem Zeitpunkt abzeichnenden politischen und ökonomischen Tendenzen gezeigt, dass von diesem „Ende der Geschichte“ wohl keine Rede sein kann. Statt dessen werden sowohl vom bürgerlichen Feuilleton als auch von linken und rechten politischen Strömungen die gleichen Schlagwörter („Globalisierung“, „Clash of Civilizations“) bemüht, um die aktuellen Veränderungen in den ökonomischen, politischen und ideologischen Verhältnissen zu artikulieren: ein sicheres Indiz, dass eben diese Veränderungen theoretisch ,,unverdaut" geblieben sind.

Einhergehend mit dem Verschwinden des „Ende der Geschichte“ ist aber auch eine weiterer Abgang zu verzeichnen: die sogenannte Postmoderne hat sich verabschiedet, allerdings ohne dass sie jemals - wie der Name suggeriert die Moderne tatsächlich abgelöst hätte. Im Gegenteil wird bei der vorliegenden Arbeit davon ausgegangen, dass sich die „Manifestationsformen“ (Offe) der kapitalistischen Gesellschaftsformationen zwar erheblich verändert haben, dass aber die für diese Gesellschaftsformationen fundamentalen Mechanismen (Warenproduktion, Trennung der Gesellschaft in Klassen, Akkumulation von Mehrwert etc.) weiter bestehen. Für sozialwissenschaftliche Theorie - so sie nicht an der gesellschaftlichen Ideologieproduktion teilnimmt (sei es als ehemalige „sozialistische Wissenschaft“, sei es als Vehikel der politischen und ökonomischen Herrschaft im Sinne des „Social Engineering“) - besteht also weiterhin durchaus Grund $\mathrm{zu}$ der Annahme, dass jenseits der konkreten sozialen Oberfläche einer Gesellschaft Mechanismen, Kräfte oder Funktionsweisen existieren, die die ökonomischen, politischen und ideologischen Verhältnisse einer Gesellschaft beherrschen. Wird dabei ein theoretischer Ansatz verfolgt, der - anders als beispielsweise die Systemtheorie Luhmanns oder Parsons - das Gesellschaftssystem begreift als durch die jeweilige gesellschaftliche Produktionweise beherrscht, stellt sich damit wieder die Frage nach dem historischen Materialismus, oder mit anderen Worten: dem Marxismus. 
b) Im Folgenden werden Aspekte einer „Spielart“ des Marxismus untersucht, die den klassischen Marxismus mit dem sogenannten Strukturalismus zu verbinden sucht. Der maßgeblich von Claude Lévi-Strauss initiierte Strukturalismus ${ }^{1}$ löste in Frankreich Mitte der 50er Jahre des zwanzigsten Jahrhunderts bei den Intellektuellen den marxistisch geprägten Existentialismus Sartres in seiner dominierenden Position ab, ebenso unterminierte er den Einfluss des von der „Parti Communiste Française“ (PCF) dogmatisierten Marxismus. Der Strukturalismus gewann in der Folge so sehr an Popularität, dass selbst der Trainer der französischen Fußballnationalmannschaft die Absicht bekundete, bei seiner Mannschaft eine strukturalistische Reorganisation vorzunehmen [Dosse 1999, Bd. 1, S. 9]².

Der Siegeszug des Strukturalismus bedeutete nicht nur, dass die moskautreue PCF ihren vormals erheblichen Einfluss unter den Intellektuellen verlor ${ }^{3}$, auch in den Reihen der Partei bildete sich zunehmend eine Opposition zu einer dogmatischen Interpretation des Werkes von Karl Marx und Friedrich Engels. Gerade zu dem Zeitpunkt, an dem die offiziellen sowjetischen Interpreten das Jugendwerk Marx' (wieder-) entdeckten und (politisch nicht unmotiviert) den humanistischen Gehalt des Marxismus hervorhoben ${ }^{4}$, versuchte eine Gruppe von Wissenschaftlern und Philosophen um Louis Althusser eine neue strukturalistisch inspirierte Lektüre der Marx'schen Schriften, die in der Deklaration eines ,theoretischen Antihumanismus“ einen ihrer Höhepunkte fand ${ }^{5}$. Diese neue Lektüre versuchte nicht nur den Marxismus zu modernisieren, sondern sie ist auch den großen Themen des Strukturalismus verpflichtet: Diskurstheorie, Epistemologie, Fragen der wissenschaftlichen Methodologie usw. finden in dieser Lektüre Berücksichtigung, welche insoweit zu einer vollkommen neuen

1 Zur Geschichte der verschiedenen Spielarten des Strukturalismus siehe die hervorragende Darstellung Geschichte des Strukturalismus [Dosse 1999].

2 Auch wenn sich der Strukturalismus als das „,neue Denken“ gerierte, sollte im Folgenen immer Berücksichtigt werden, dass die Quellen, auf die sich strukturalistische Autoren regelmäßig berufen, wie z. B. Marx, Nietzsche, Freud, de Saussure, Durkheim oder Mauss, größtenteils noch dem 19. Jahrhundert entstammen.

3 Neben Jean-Paul Sartre verstanden sich zu diesem Zeitpunkt beispielsweise auch Roland Barthes und Jean-François Lyotard als marxistisch, selbst Michel Foucault war kurzfristig Mitglied der PCF [Foucault 1973b, S. 181].

4 Diese Interpretation wurde in den 60er Jahren vom „nachstalinschen Stalinismus“ (Foucault) der PCF übernommen und insbesondere von R. Garaudy vertreten, vgl. insbesondere Garaudy 1969a.

5 Die kontroversen (und z. T. absurden) Diskussionen über die Arbeiten der Gruppe um Althusser dokumentiert anschaulich Autorenkollektiv 1976. 
Bestimmung des Marxismus führt, als dass sie versucht, die Bewusstseinsphilosophie aus dem Marxismus zu „exorzieren“ und anhand der Lektüre von Das Kapital den wissenschaftlichen Charakter des historischen Materialismus $\mathrm{zu}$ belegen. Im Zuge dieser neuen Lektüre wurden nahezu alle zentralen Begriffe des Marxismus wie (geschichtliche) Dialektik, gesellschaftliche Totalität, Basis/Überbau, Klassenkampf etc. zwar nicht durchweg revidiert, aber immer zumindest einer kritischen Betrachtung unterzogen.

Im Ergebnis stellt sich eine Interpretation des Marxismus dar, die nicht nur dem kanonisierten „Marxismus-Leninismus“ diametral gegenübersteht (wenn auch die theoretischen Arbeiten Lenins gewürdigt werden ${ }^{6}$ ), sondern sich ebenso in Opposition zu verschiedenen Richtungen des sogenannten „westlichen Marxismus“ (Perry Anderson), wie beispielsweise der Frankfurter Schule, begibt. Mit diesen theoretischen Entwicklungen des Marxismus teilt aber diese Interpretation (im Folgenden in Anlehnung an den angelsächsischen Sprachraum - keineswegs abwertend - „strukturalistischer Marxismus“ genannt) vor dem Hintergrund der Geschichte des zwanzigsten Jahrhunderts die Ablehnung einer positiv besetzten Geschichtsdialektik, und wie diese rückt sie die Theoretisierung der sogenannten Überbauten, insbesondere Ideologie und Staat, in das Zentrum ihres Denkens [Anderson 1978, S. 111].

Diese Lektüre Marx' ist heute noch dahingehend von Relevanz, da sie aktuell zwar nicht mehr als „Althusser-Schule“ auftritt, aber die Aneignung Marx' von zahlreichen derzeit aktiven oder stark rezipierten Wissenschaftler und Philosophen stark beeinflusst hat, hierzu können beispielsweise Derrida, Buttler, Zizek, gezählt werden. Desweiteren hat die die sich daran anschließende Ideologie- und Staatstheorie auch Einfluss auf die Entwicklung der Regulationstheorie (Autoren, die sich mit mehr oder weniger großen Einschränkungen auf die im Folgenden vorgestellten Theoreme berufen sind u. a. Hirsch, Lipietz, Demirović).

c) Wenn diese Arbeit mit dem Titel „Zur Ideologie und Staatstheorie im strukturalistischen Marxismus“ versehen ist, also nahe legt, dass diese Theorie von einer gesamten „Schule“ entwickelt und vertreten wurde, muss dies insoweit eingeschränkt werden, als bezüglich einer Theorie des Staates im Folgenden

6 Was natürlich auch als politisches Manöver gegenüber der PCF gedeutet werden kann. 
die Arbeiten Nicos Poulantzas ${ }^{7}$ im Mittelpunkt stehen und die zahlreichen Arbeiten anderer Autoren, die positiv auf die Arbeiten Althussers zurückgriffen - erst recht, wenn sie den Bereich der Ideologie- und Staatstheorie im engeren Sinn nicht betreffen - nicht berücksichtigt werden ${ }^{8}$.

Bei der Darstellung der Staatstheorie Poulantzas' wird davon ausgegangen, dass die Entwicklung seiner theoretischen Ansätze von drei verschiedenen Positionen aus beeinflusst wurde:

1. Der Althusser'schen Epistemologie und Ideologietheorie,

2. den politiktheoretischen Arbeiten Antonio Gramscis,

3. und schließlich die den Machtbegriff betreffenden Analysen Foucaults.

Die Darstellung dieser Einflüsse folgt jeweils verschiedenen Strategien. Der Althusser'schen Epistemologie wird, da sie - wie oben bereits angedeutet einen nicht unerheblichen Einschnitt im marxistischen Diskurs darstellt, der erste Teil dieser Arbeit gewidmet. Hier soll das ,große Projekt“ Althussers, die vollständige „Befreiung“ des Marxismus von der klassischen (bzw. vorMarx'schen) Philosophie (und vor allem die Eliminierung jeglicher Reste des

7 Zu biographischen Daten Poulantzas' siehe Demirović 1987, zu Althusser siehe dessen Autobiographie [Althusser 1998].

8 Das betrifft vor allem theoretische Arbeiten Balibars zur Analyse der politökonomischen Begrifflichkeiten Marx' in Das Kapital lesen, zur Wissenschaftsgeschichte [Fichant/ Pêcheux 1977, Macherey 1964], zur Anthropologie [Terray 1974] und zur Literaturtheorie, vgl. z. B. Althusser 1974b, Balibar et. al. 1975, Balibar/Macherey 1974, Macherey 1973, Pêcheux/Fuchs 1975, Pêcheux 1982. In der Geschichtsschreibung hat sich des weiteren die dritte Annales-Generation unter den Einflüssen Althussers gebildet, in der Literatur stand die von Julia Kristeva beherrsche Tel Quel-Gruppe den Ansätzen Althussers nahe. In der Ökonomie standen die ökonomischen Arbeiten Bettelheims [vgl. Bettelheim 1970b, S. 7 ff.] unter direktem Einfluss Althussers Arbeiten.

Die hiermit angedeutete theoretische Offenheit des strukturalistischen Marxismus bedingt aber auch, dass einige Autoren nicht umhin kommen, Althusser zum Vorwurf zu machen, mit dem sogenannten Poststrukturalismus/der „Postmoderne“ in Verbindung zu stehen [Trenkle 1999; Kurz 1999, S. 36]. Diese Nähe ist natürlich nicht von der Hand zu weisen, denn einerseits versuchte Althusser, Derrida und Foucault im Pariser Wissenschaftsbetrieb zu protegieren, andererseits war sein theoretischer „Ausbruch“ aus dem Parteimarxismus für diese Autoren sicher ermutigend, gegen die Hegemonie der PCF im wissenschaftlichen Apparat Theorie zu betreiben; die theoretische Produktion Althussers selbst hat zumindest Einfluss auf Foucaults Theoriebildung (beispielsweise äußert Balibar im Gespräch mit Dosse, dass Foucaults Einschätzung Marx' in der Archäologie des Wissens von Althussers Marx-Lektüre geprägt sei und sich von der in Die Ordnung der Dinge dargelegten unterscheide [Dosse 1999, Bd. 1, S. 491]).

Von besonderem Interesse (und von besonderer Brisanz) scheint im Zusammenhang mit der Postmoderne aber die Verbindung von strukturalistischer Marx-Lektüre (und dem dort entwickelten theoretischen Anti-Humanismus), der von Lacan beeinflussten Ideologie- und Subjekttheorie Althussers (die auch Einfluss auf die feministische Theorie Judith Butlers hatte) und der - Foucault und Gramsci aufnehmenden - Staatstheorie Poulantzas, denn im „Zentrum“ dieser Felder steht ein Erkenntnisobjekt, dass auch von den Postmodernen (freilich fast immer nur affirmativ) ,,bearbeitet“ wird: das ,dezentrierte Subjekt“ (s.u). 
Hegelianismus aus dem marxistischen Denken) und die von ihm betriebene (Re-) Konstituierung des historischen Materialismus als Wissenschaft dargelegt werden. Dabei sollen in erster Linie die Einflüsse und Parallelen zu ,strukturalistischen" Philosophen und Wissenschaftlern, z. B. Gaston Bachelard, aber auch Ferdinand de Saussure aufgezeigt werden ${ }^{9}$. Ebenso sollen hier die Vorwürfe, denen Althusser ausgesetzt war (die im wesentlichen mit denen identisch waren, die gegen den Strukturalismus im allgemeinen vorgebracht wurden, z. B. Geschichtslosigkeit, „Tod des Subjekts“), kurz untersucht werden.

Der zweite Teil ist der Darstellung der eigentlichen Ideologie- und Staatstheorie gewidmet, hierbei werden die in diesem Zusammenhang zentralen theoretischen Arbeiten Gramscis als Exkurse vorgestellt. Ausgehend von der Althusser'schen theoretischen Verbindung von Staat, Subjekt und Ideologie wird anschließend die von Poulantzas entwickelte Staatstheorie erläutert, hierbei steht vor allem dessen Werk Staatstheorie [Poulantzas 1978] im Mittelpunkt ${ }^{10}$. Dabei soll gezeigt werden, dass von Poulantzas in diesem Bereich zahlreiche Themen und Theorien Foucaults aufgegriffen wurden.

9 Wie andere Autoren (z.B. Foucault) lehnte auch Althusser die Bezeichnung „strukturalistisch“ für sich selbst ab. Werden zur Einordnung dieser Autoren die Kategorien von Deleuze herangezogen [Deleuze 1992], müssen vor allem die „Frühwerke“ von Foucault und Althusser als, wenn auch z. T. atypisch, strukturalistisch bezeichnet werden (s. u., insb. S. 56 ff.).

10 Insbesondere die frühen Arbeiten von Poulantzas, die noch unter erheblichen Einfluss von Sartre standen, werden nicht berücksichtigt; zur historischen Entwicklung der Theorien Poulantzas' vergleiche Jessop 1985. 


\title{
Kapitel 1: Marxismus und Epistemologie
}

\begin{abstract}
Indem wir genau die Punkte bestimmen, an denen die Strenge des Marx'schen Diskurses nachlässt, entdecken wir diese Strenge wieder: Sie selbst ist es, die uns auf das Nachlassen hinweist. Wir aber tun nichts anderes, als Marx in den Augenblicken seines vorläufigen Schweigens zu dem ihm eigenen Sprechen zu bringen.
\end{abstract}

Louis Althusser

a) Althusser und seine Mitarbeiter nehmen für ihre Neulektüre des Marx'schen Werkes ${ }^{11}$ nicht in Anspruch, eine ,authentische“ oder „wahre“ Interpretation vorgenommen zu haben, vielmehr eröffnet Althusser seine Lektüre von Das Kapital, indem er die „Interpretation“ in Form der Lektüre selbst problematisiert. Der Akt der Lektüre, der Leseprozess, ist für ihn alles andere als ein neutrales Aufnehmen von Informationen aus dem Text, keine ,unschuldige Lektüre“, sondern ein Akt der Produktion des Textes. Ein Text ist nicht in dem Sinne transparent, dass er als passiver Reflex angeeignet werden könne,

es gibt keine unschuldige, voraussetzungslose, authentische Lektüre: Der Sinn eines Textes ist keine unwandelbare Essenz, die in ihm enthalten wäre wie der Kern in der Frucht. Die Annäherung an einen Text ist immer schon ein Umweg, der durchlaufen werden muss, um das Gelände der Ideologien, Wissenschaften und Philosophien zu vermessen, in dem jeder Diskurs angesiedelt ist. [Brühmann 1980, S. 225; Hervorhebung S.v.B.]

Der Text muss somit durch den Leser decodiert, „zum Funktionieren“ gebracht werden. Gegenüber einer „buchstabengetreuen“ Lektüre, welche vorgibt, reine Information zu sein, also einen anderen Text authentisch zu reproduzieren oder diesen gar weiterzuentwickeln, stellt Althusser die symptomatische Lektüre [DKL, Bd. 1, S. 32].

Althusser versucht, die symptomatische Lektüre an einem Beispiel zu verdeutlichen: Als Antwort auf die Frage bezüglich des Wertes der Arbeit lehnt

11 Wie bei (leider) zahlreichen anderen Autoren auch werden bei der Lektüre Althussers die Beiträge Friederich Engels zum Marxismus ,unter Wert“ gehandelt. U. a. Labica weist in aller Deutlichkeit auf den Einfluss von Engels hin: „Von wem stammt der Marxismus? Schulden wir davon Friederich Engels nichts? Ist es nicht der junge Engels, der Marx beständig beeinflusst; ihm in jedem Augenblick zeigt, wohin er sich wenden soll: zu Feuerbach, Hegel, Hess; was er sich aneignen soll: die politische Ökonomie, die 'wirkliche' Geschichte, die des Klassenkampfs; und sogar wen es zu verreißen gilt: Stirner, Proudhon, Smith?“ [Labica 1976, S. 189]. 
David Ricardo bekanntlich das Spiel von Angebot und Nachfrage ab. Der Wert der Arbeit sei vielmehr durch den Wert der lebensnotwendigen Güter, die zur Reproduktion der Arbeitskraft erforderlich sind, bestimmt. Kennzeichnend für Ricardos Antwort ist vor allem, dass sie zwar wissenschaftlich korrekt ist, da aber Arbeit und Arbeitskraft nicht identisch sind, antwortet sie auf eine Frage, die von ihm überhaupt nicht gestellt wurde: Welchen Wert hat die Arbeitskraft? [DKL, Bd. 1, S. 23 ff.] Wenn Marx nun auf Ricardos Antwort die richtige Frage formuliert, sei dies nicht lediglich Wortklauberei, sondern mit der gegebenen Antwort und der neu gestellten Frage habe sich der gesamte Untersuchungsbereich von der Arbeit hin zum Arbeiter (und zum Arbeitsprozess) verschoben. Marx sei sich dieser Verschiebung bewusst geworden, so dass er selbst behaupten könne, nicht die Lösung des Problems sei gelungen, sondern die Begriffe hätten sich vollständig verändert [DKL, Bd. 1, S. 25].

Aus der Veränderung der Begriffe ergeben sich aber wesentliche theoretische Problematiken: Da Ricardo behauptet, dass der Wert der Arbeit identisch mit den Reproduktionskosten der Arbeitskraft ist, also der Lohn gleich dem mit dem im Arbeitsprozess produzierten Wert ist, kann er nicht bestimmen, woher der Gewinn stammt, der als Kapital- und Rentenzins erzielt wird. Dies impliziert eine weit reichende Konsequenz in der Theorie: Wenn die politische Ökonomie die Differenz zwischen dem Wert der Arbeit und der Wert der Arbeitskraft nicht erkennt, kann sie auch nicht den Mehrwert erkennen [vgl. Karsz 1976, S. 18]. Mit dem Nicht-Sehen (und umgekehrt dem Sehen) des Mehrwerts ist in der Folge eine theoretische - aber auch eine politische Disposition verbunden. Indem Marx den Mehrwert als Teil des Wertes der Arbeit bestimmt, eröffnet sich ihm einerseits in der (ökonomischen) Theorie ein vollständig neuer methodologischer Raum. Mit der theoretischen Bestimmung des Mehrwerts fällt aber auch der Begriff der Ausbeutung und der gesellschaftlichen Klassen, schließlich der Klassenkampf zusammen. Indem also der politischen Ökonomie durch Marx ein fehlender Begriff hinzugefügt wurde, hat sich dadurch ein kompletter „Terrainwechsel“ vollzogen [DKL, Bd. 1, S. 27]. Das bedeutet für Althusser, dass das Erkennen des fehlenden Begriffs, der leeren Stellen in den Texten der politischen Ökonomie, der gegebenen Antworten ohne gestellten Fragen bereits eines ,wissenden Blicks“ bedarf, der diese leeren Stellen und Abwesenheiten von Begriffen identifizieren kann. 
Diese Lektüre ist insoweit symptomatisch, als sie zwei Texte aufeinander bezieht, aneinander misst, wobei sich der zweite Text durch die leeren Stellen innerhalb des ersten Textes selbst produziert [DKL, Bd. 1, S. 32].

Im Gegensatz zur symptomatischen Lektüre kann die „,authentische“, buchstabengetreue (oder hermeneutische) Lektüre leere Stellen, Brüche innerhalb eines textuellen Gesamtwerkes entweder nicht wahrnehmen oder muss diese nivellieren. Bezogen auf das Marx'sche Werk selbst muss also eine buchstabengetreue Lektüre behaupten, dass in den Ökonomisch-philosophischen Manuskripten von 1844 [MEW, E-Bd. 1, S. 465 ff.] schon die Logik des Kapitals enthalten sei, oder, polemisch ausgedrückt, jeder Marx'sche Text muss marxistisch sein, eben weil er von Marx verfasst ist [vgl. Karsz 1976, S. 21]. Wenn Marx behauptet, dass er die Hegel'sche Dialektik umgestülpt habe, muss die buchstabengetreue Lektüre diese Aussage für bare Münze nehmen und als Monstranz vor sich her tragen und kann überhaupt nicht erkennen, ob sich in einem Text eine andere Theorie in ,geborgten Begriffen“ entfaltet ${ }^{12}$. Die symptomatische Lektüre soll dagegen einen Text auf seine eigene Aussage hin „testen“, also beispielsweise in Bezug auf die Marx'sche Aussage Das Kapital dahingehend untersuchen, ob Marx tatsächlich mit dieser „umgestülpten Dialektik“ gearbeitet hat, oder ob sich in Marx' Hauptwerk nicht eine völlige Verschiebung des Diskurses vollzogen hat [DKL, Bd. 1, S. 39 f.].

Das Aufspüren von Brüchen innerhalb eines Textes, das Identifizieren von Fragen ohne Antworten und Antworten ohne Fragen ist aber nicht das aufspüren der „Wahrheit“ eines Textes, ist keine Textinterpretation oder Inhaltsanalyse; eine ,authentische Lektüre“ im Sinne eines Erkennens des „echten“ Autoren-Subjekts (wie es Parolen wie „Zurück zu Marx“ oder „Zurück zu Freud“ implizieren) ist demzufolge ein Mythos ${ }^{13}$. Georges Labica unterscheidet im Anschluss an Althusser innerhalb der buchstabengetreuen/hermeneutischen Lektüre zwei Unterformen:

1. Die apriorische Lektüre, die ein fertiges Schema (cadre) auf einen Text legt, um Überraschungen bei der Lektüre zu vermeiden. Als Beispiel für die apri-

12 Nach Althusser haben Marx wie auch auch Freud vor der Problematik gestanden, die neue Theorie mit den bereits vorhanden Begriffen zu explizieren [Althusser/Tort 1976, S. 10].

13 Ebenso die vielbeschworene „Rekonstruktion“ des Marx'schen Denkens: Eine solche hält Althusser weder für möglich noch für sinnvoll; wie noch zu sehen sein wird, entwickelt Althusser seine Theorien partiell auch gegen Marx. 
orische Lektüre zieht Labica einen Text von I. Fetscher heran, in dem dieser ausführt, dass Marx „ebensosehr Schüler wie kritischer Fortführer Hegels“ sei $^{14}$ [Labica 1976, S. 191; vgl. Fetscher 1967, S. 49].

2. Die talmudistische Lektüre, für die das Marx'sche Werk schon fertig interpretiert ist: „,vier Gesetze der Dialektik, fünft Typen von Produktionsverhältnissen“ [Labica 1976, S. 191] - eine Lektüre, die vor allem den Dogmatismus des Marxismus-Leninismus kennzeichnet (insbesondere, wenn sie von Stalins Grundlagen des Leninismus geprägt ist) ${ }^{15}$.

b) Sowohl die symptomatische als auch die buchstabengetreue Lektüre arbeiten an einem Text mit einer gegebenen Zahl methodischer und politischer Dispositionen, die Differenz zwischen den beiden Arten der Lektüre ist dabei, dass sich die symptomatische Lektüre ihrer Operationen bewusst ist und insoweit objektive Methode ist, da sie die vorgenommenen Operationen rechtfertigen kann [Karsz 1976, S. 25]. Althusser gibt deshalb auch unumwunden zu, dass er dem Diskurs Marx' neues hinzufügt, gleichzeitig kann er aber auch behaupten, dass nicht „er“ - Althusser - spricht, sondern dass sein Text (Das Kapital lesen) von jedem anderen hätte verfasst werden können [Althusser 1975a, S. 99].

Althusser und Balibar betrachten ihre Interpretationen vor allem als individuelle Lektüreprotokolle [DKL, Bd. 1, S. 12], die von den an den Text herangetragenen Erkenntnisinteressen geleitet werden. Althusser stellt in diesem Zusammenhang fest, dass Marx' Hauptwerk bisher vor allem philosophisch gelesen wurde und damit die Beziehung zwischen dem Gegenstand und der Darstellung innerhalb dieses Werkes im Vordergrund der Lektüre gestanden habe; es sei aber genauso möglich, Das Kapital unter historischen, logischen oder ökonomischen Gesichtspunkten zu studieren. Allerdings sei eine philoso-

14 Exemplarisch für die ,apriorische“ Lektüre ist, gerade in diesem Zusammenhang, Zur logischen Struktur des Kapitalbegriffs bei Karl Marx zu nennen. Der Autor ist angesichts der Tatsache, dass der Begriff der Entfremdung - eine Schlüsselkategorie der Ökonomisch-philosophischen Manuskripte - in späteren Werken Marx' expressis verbis kaum Verwendung findet, dazu genötigt, zu erklären, wie Marx hätte argumentieren müssen [Reichelt 1973, S. 23], und schließlich entfremdete Arbeit mit dem Begriff der Arbeitsteilung gleichsetzen muss [ebd., S. 49], um die behauptete Identität der Marx'schen Methode im Kapital mit der Hegel'schen Logik nachzuweisen.

15 Eine „talmudistische“ Rezeption par excellence (des Althusser'schen Werks) stellt wohl Marxismus und Strukturalismus [Schaff 1974] dar, in dem Althussers Theorien als „Pseudo-Marxismus“, „Pseudo-Strukturalismus“, „Eleatismus“ und „Anti-Marxismus“ bezeichnet werden, kurzum nahe legt, dass die „Ausdeutung“ der Werke Marx und Engels endgültig abgeschlossen ist (falls es einer solchen Ausdeutung je bedurft hätte). 
phische Lektüre des Kapitals, die zum Ziel habe, die Philosophie Marx' zu „entdecken“, ein Paradoxon, denn diese Lektüre setze Kriterien voraus, die erst die Lektüre selbst liefern könne. Die Lektüre ist demnach ein Produzieren des Textes, nicht ein Entdecken des im Text „Verborgenen“ [DKL, Bd. 1, S. 42] ${ }^{16}$.

\section{Realobjekt - Erkenntnisobjekt}

\begin{abstract}
Das Ziel jeder strukturalistischen Tätigkeit, sei sie nun reflexiv oder poetisch, besteht darin, ein "Objekt" derart zu rekonstruieren, dass in dieser Rekonstruktion zutage tritt, nach welchen Regeln es funktioniert.
\end{abstract}

Roland Barthes dieses sowohl von einer „ideologisch-philosophischen“ wie auch eine streng wissenschaftlichen Komponente geprägt sei. Diese Problematik entwickelt Althusser bezüglich der „Umstülpung“"18 der Hegel'schen Dialektik durch Marx [FM, S. 121]. Die Hegel'sche Dialektik ${ }^{19}$ sei nicht nur durch eine spekulative Illusion geprägt, die - wie von Feuerbach kritisiert - sich durch die „Identifikation des Denkens mit dem Sein, des Prozesses des Denkens mit dem Prozess des Seins, des 'gedachten' Konkreten mit dem 'tatsächlichen' Konkreten“ [FM, S. 132] auszeichne. Die „Umstülpung“ der Hegel'schen Dialektik, wie sie von Feuerbach und vom frühen Marx vorgenommen wurde, sei dadurch geprägt, dass sie als „gute Abstraktion“ die Verhältnisse zwischen „Sein“ und „Denken“

16 Beispielhaft für die symptomatische Lektüre zu nennen ist neben Das Kapital lesen selbst vor allem Foucaults Die Geburt der Klinik [Foucault 1988]. Weiterhin sind die Arbeiten Lacans zu diesen zu zählen [Lacan 1986]; Althusser konstatiert, dass Lacan durch eine symptomatische Lektüre den wissenschaftlichen Charakter des Freudschen Werks herausgearbeitet habe [Althusser/Tort 1976, S. 7].

17 Zur deutschsprachigen zeitgenössischen (überwiegend kritischen) Rezeption der Epistemologie Althussers vgl. vor allem Hund 1973, Jaeggi 1968, ders. 1975, ders. 1976, Schmidt 1972, Rheinberger 1975.

18 So Marx: „Die Mystifikation, welche die Dialektik in Hegels Händen erleidet, verhindert in keiner Weise, daß er ihre allgemeinen Bewegungsformen zuerst in umfassender und bewußter Weise dargestellt hat. Sie steht bei ihm auf dem Kopf. Man muß sie umstülpen, um den rationellen Kern in der mystischen Hülle zu entdecken“ [MEW, Bd. 23, S. 27]

19 Die Hegel-Rezeption durch Althusser ist generell als problematisch einzustufen, oft wirkt diese sehr verflacht; evtl. ist dies dem ebenso problematischen Hegel-Kommentar von Kojève [Kojève 1975] anzulasten, der maßgeblich die Hegel-Interpretation in Frankreich beeinflusst hat. 
in dem Sinne umkehrt, dass das „Sein“ das „Denken“ produziert, somit dass „Denken“ und „Sein“ immer noch eine Einheit bilden, in der das „Sein“ seinen abstrakten Begriff hervorbringt.

Für Althusser ist kennzeichnend für den Prozess der empiristischen Erkenntnis das Setzen eines zu erkennenden Objekts und eines erkenntnisfähigen Subjekts (wobei diese Konzeption den meisten idealistischen wie materialistischen Erkenntnistheorien zu Grunde liegt [Thieme 1982, S. 14]). Unbeachtlich sei in der Logik dieser Konzeption, ob es sich dabei um ein historisches, psychologisches oder anders geartetes Subjekt handelt, ebenso wenig werde in der Konzeption die Natur des Objekts (kontinuierlich oder diskontinuierlich, fix oder beweglich) berücksichtigt. Der Erkenntnisprozess beginne in dieser Konzeption mit dem Vorgang der Abstraktion: „Erkennen heißt: dem Realobjekt das Wesen entziehen (abstrahieren)“ [DKL, Bd. 1, S. 44]. Die aus dem Realobjekt gewonnene (reale) Abstraktion müsse demnach schon essenziell in dem Erkenntnisobjekt selbst existieren. Die Erkenntnis eines Objekts existiere somit als „Wesen des Realen als reales Wesen in dem Realen, das es umschließt“" [ebd.]. Das Reale bestehe somit aus zwei Essenzen, nämlich dem Wesen des Objekts, das es durch die Operation der Abstraktion zu erkennen gelte und einer realen Hülle, die dieser Erkenntnis entgegenstehe und damit die Abstraktion erst erforderlich mache [DKL, Bd. 1, S. 44 f.], folglich bilden wesentliches und unwesentliches die Struktur des zu erkennenden Objekts.

Der Prozess der Erkenntnis in einer solchen Konzeption wäre demnach, die beiden Teile des Realobjekts - Essenz und Inessenzielles - zu trennen bzw. das Inessenzielle zu eliminieren, damit das erkennende Subjekt nur der ,realen Essenz des Realen“ [DKL, Bd. 1, S. 45] gegenübersteht. Die Struktur des Realobjekts wird also in der empiristischen Erkenntniskonzeption als Einheit von Essenz und Inessenziellem gedacht, die in ihrer Gesamtheit das Realobjekt bilden. Die Notwendigkeit der Abstraktion/Freilegung ergibt sich aber aus der Struktur des Realobjekts selbst, da das Inessenzielle die „Außenseite“ bilde und das Essenzielle des Realobjekts (im wahrsten Sinne des Wortes) verhülle [DKL, Bd. 1, S. 46]. Allerdings ist der beschriebene Erkenntnisvorgang nach Althusser „,der Akt der Abstraktion, der aus konkreten Individuen ihr reines Wesen herauslösen würde, [...] ein ideologischer Mythos “ [FM, S. 135], der auf einer zweifelhaften Konzeption des Objekts beruht. Aber die Anordnung 
der komplementären Teile (außen/innen, sichtbar/unsichtbar) bezieht sich nach Althusser in der empiristischen Erkenntniskonzeption nicht nur auf das Objekt der Erkenntnis, sondern ebenso auf die Erkenntnistätigkeit selbst: Diese Konzeption zeichne sich vor allem dadurch aus, dass

die gesamte Erkenntnis: das Objekt als die Erkenntnistätigkeit im Unterschied zum Realobjekt, das erkannt werden soll, mit vollem Recht der Realstruktur des Realobjekts zugerechnet und als ihr Bestandteil gedacht wird [DKL, Bd. 1, S. 49],

das Realobjekt somit selbst seine Erkenntnis in sich trägt. Damit offenbare der Empirismus eine erstaunliche Inkonsequenz:

Wenn der Empirismus sein Erkenntnisobjekt in der Essenz sieht, so behauptet er etwas sehr Entscheidendes, das er im selben Moment leugnet: er behauptet, dass das Erkenntnisobjekt mit dem Realobjekt nicht identisch ist, denn er bezeichnet es als einen Bestandteil des Realobjekts. Zugleich leugnet er diese Behauptung, indem er die Differenz zwischen zwei Objekten, dem Erkenntnisobjekt und dem Realobjekt, auf eine einfache Differenz zwischen verschiedenen Bestandteilen eines einzigen Objekts - des Realobjekts - reduziert. [DKL, Bd. 1, S. 50 f.]

D. h. die ursprüngliche Einheit des Objekts aus inessenziellem und essentiellem wird zugunsten des Essentiellem aufgelöst - die Differenz des so kreierten „erkannten Objekts“/Erkenntnisobjekts zum Realobjekts durch das Eliminieren des Inessentiellem wird aber verschwiegen, ,,in der Negierung gibt es nur noch ein einziges Objekt: das Realobjekt“ [DKL, Bd. 1, S. 51].

Mit Marx verwirft Althusser die Gleichsetzung/Vermischung von Realobjekt und Erkenntnisobjekt und besteht auf deren Differenz ${ }^{20}$ [ebd., S. 51 f.], Marx schreibt selber zum Verhältnis von Realen und Erkenntnisobjekt:

Hegel geriet daher auf die Illusion, das Reale als Resultat des sich in sich zusammenfassenden, in sich vertiefenden und aus sich selbst sich bewegenden Denkens zu fassen, während die Methode, vom Abstrakten zum Konkreten aufzusteigen, nur die Art für das Denken ist, sich das Konkrete anzueignen, es als ein geistig Konkretes zu reproduzieren. [MEW, Bd. 13, S. 632]

Althusser verweist darauf, dass Marx in dem Abschnitt Die Methode der politischen Ökonomie [MEW, Bd. 13, S. 631 ff.] zum einen die absolute Differenz zwischen dem Realobjekt (,das Konkret-Reale, die reale Totalität“ [DKL,

20 Diese Differenz entnimmt Althusser bei Spinoza [DKL, Bd. 1, S. 51], wie er auch Spinoza (und nicht Marx oder Hegel) als den größten Einschnitt im philosophischen Diskurs klassifiziert [DKL, Bd. 1, S. 134] und dabei Marx mit Spinoza in Verbindung bringt. Die genealogische „Verwandtschaft" von Marx und Spinoza hat vor Althusser bereits Plechanow behauptet [Anderson 1978, S. 97, Fn. 30]. 
Bd. 1, S. 52]) und dem Erkenntnisobjekt („Produkt des Gedankens, der es als Gedankenkonkretum produziert“ [ebd.]) behauptet. Ebenso unterscheide Marx auch die Konstitutionsprozesse der jeweiligen Objekte; im Gegensatz zum Realobjekt, dessen Entstehung nach „der realen Gesetzmäßigkeit der realen Entwicklung“ [ebd.] verlaufe, konstituiert sich das Erkenntnisobjekt in gedachten Kategorien, die die realen Kategorien reproduzieren. Dabei folge diese Konstitution aber anderen Gesetzmäßigkeiten, die einen Stellenwert haben, der ihnen durch ihre Funktion im Prozess der Erkenntnisproduktion zugewiesen werde [ebd.]; die Konstitution des Gedankenobjekts erfolgt somit nicht-identisch zu dem Realobjekt.

b) Wenn Marx also behauptet, dass die Erkenntnis sich in den Gedanken vollzieht, als „Produkt des denkenden Kopfes“ [MEW, Bd. 13, S. 633], bedeutet das für Althusser aber nicht einen Rückfall in einen Idealismus, der das Denken als Fähigkeit eines transzendentalen Subjekts begreift oder einem Dualismus Bewusstsein/materielle Welt huldigt. Vielmehr ist für Althusser das Denken das

historisch konstituierte System eines Denkapparats. [...] Es ist bestimmt vom System der realen Bedingungen, die es [...] zu einer bestimmten Produktionsweise von Erkenntnissen machen. Als solche ist es durch eine Struktur konstituiert, die eine Verbindung darstellt zwischen dem Objekttyp [matière première; LLC, Bd. 1, S. 47], auf dessen Grundlage sie tätig ist, den theoretischen Produktionsmitteln, über die sie verfügt [...] und den zugleich theoretischen, ideologischen und gesellschaftlichen historischen Beziehungen, innerhalb derer eine Erkenntnis produziert wird. [DKL, Bd. 1, S. 53]

Dieser „Denkapparat“ besitzt laut Althusser eine genau bestimmbare objektive Realität. Sie weise dem ,einzelnen denkenden Subjekt“ [ebd.] dessen Stellung und Funktion in dem Produktionsvorgang der Erkenntnis zu; sie setze ,die Denkkraft ins Werk, so wie die Struktur einer ökonomischen Produktionsweise die Arbeitskraft der unmittelbaren Produzenten ins Werk setzt“" [ebd.]. Mit der Behauptung, dass das Denken ein Akt der Produktion ist, grenzt sich Althusser von jeder Form von Widerspiegelungs- oder Abbildtheorien ab, allerdings eröffnet sich so die Perspektive, dass das Denken und das Gedachte nicht übereinstimmen müssen, es also keine Garantie für diese Übereinstimmung gibt (die Annahme dieser Übereinstimmung sei kennzeichnend für die empiristische Erkenntnistheorie). Vielmehr sei grundsätzlich eine Diskrepanz zwischen dem 
„Denken“ und dem „Realen“ anzunehmen, da das Denken selbst schon nicht mehr an einem Realobjekt arbeitet:

La connaissance travaillant sur son „objet“, ne travaille pas alors sur l'objet réel, mais sur sa propre matière première, qui constitue, au sens rigoureux du terme, son „objet“ (de connaissance), qui est, dés les formes les plus rudimentaires de la connaissance, distinct de l'objet réel, [...] comme l'objet qu'elle va transformer, dont elle va modifier les formes, au cours de son processus développement, pour produire des connaissances sans cesse transformées, mais qui ne cesseront jamais de porter sur son objet, au sens d'objet de connaissance. [LLC, Bd. 1, S. 49 f.]

Die verschiedenen Modi der Aneignung des Realen - nach Althusser Ideologie und Wissenschaft - bearbeiten/erkennen demnach nicht das Realobjekt, sondern ein immer schon durch Wahrnehmungs-, Sprach- und Bearbeitungsprozesse transformiertes Erkenntnisobjekt [Thieme 1982, S. 16] ${ }^{21}$, das Denken ist durch seine Arbeit an einem aus dem Denken selbst entstandenem Erkenntnisobjekt selbstreferenziell.

\section{Theorie und theoretische Praxis}

a) Entscheidend für die Bestimmung der Wissenschaft als privilegierte Form der Erkenntnis ist für Althusser der Begriff der theoretischen Praxis. Wie andere Formen der gesellschaftlichen Arbeit stelle die Wissenschaft einen Veränderungsprozess dar, in denen die vier Grundelemente der Produktion (Grundstoff, Arbeitskraft, Produktionsmittel, Produkt) kombiniert werden [FM, S. 104]. Diese Elemente bilden die Grundlager einer „Praxis im allgemeinen“, auf deren Basis sich eine ökonomische, technische, künstlerische usw. Praxis analysieren lässt. Jede dieser Praxen erhält ihre spezifische Ausprägung durch ihre Differenz zu anderen Praxen, die sich aus der Differenz der Regeln der Verknüpfung der Grundelemente als auch aus der Diffrenz der Grundelemente selbst ergibt.

Gleichzeitig sind die verschiedenen Praxen nicht vollkommen voneinander verschieden oder hermetisch abgeriegelt, sondern sie bilden zusammen die gesellschaftliche Praxis, vor deren Hintergrund jede der spezifischen

21 Ähnlich argumentiert Georg Lukács, wenn er zwischen Erscheinungsform/V orstellungen und Begriff/K ern der "W irklichkeit" unterscheidet [Lukács 1970, S. 68 f.]. 
Praxen ausgeübt wird. Theorie ist demzufolge selbst eine spezifische Praxisform, die „ebenfalls zur komplexen Einheit der 'sozialen Praxis' einer bestimmten menschlichen Gesellschaft gehört. Die theoretische Praxis geht ein in die allgemeine Definition der Praxis“ [FM, S. 105].

Die verschiedenen Praxisformen würden jeweils nicht autonom und abgeschlossen existieren, sie besäßen aber in ihrem jeweils spezifischen Feld eine relative Autonomie. Gleichzeitig konstituieren die Praxen durch ihre Verbindung zu den anderen Praxen erst die gesellschaftliche Praxis als solche die gesellschaftliche Praxis ist kein fest umrissener Ort, sondern ein System von Beziehungen [Karsz 1976, S. 43]. Innerhalb dieser gesellschaftlichen Praxis ist das wissenschaftliche

Denken ein eigenes Realitätssystem auf der Basis der realen Welt einer gegebenen geschichtlichen Gesellschaft, die eine bestimmte Weise des Stoffwechsels mit der Natur reproduziert; es ist ein spezifisches System, bestimmt durch die Bedingungen seiner Existenz und seiner Praxis, d. h. durch eine eigene Struktur, einen bestimmten Typ der Verbindung zwischen seinem Grundstoff (dem Gegenstand der theoretischen Praxis), seinen Produktionsmitteln und seinen Beziehungen zu anderen Strukturen der Gesellschaft. [DKL, Bd. 1, S. 53]

Die Differenz der verschiedenen Praxen situiert diese zeitlich und räumlich und stellt sie in einen gesellschaftlichen Kontext, also setzt sie in Beziehung zu den materiellen, objektiven und gesellschaftlichen Charakter der historischen Bedingungen, unter denen die verschiedenen Praxisarten ausgeübt werden [Karsz 1976, S. 41]. Diese historischen Bedingungen sind für die Untersuchung der theoretischen Praxis in zweierlei Hinsicht von Bedeutung:

1. Im Verhältnis von Theorie und Praxis gibt es kein Primat der Theorie über der Praxis oder Primat der Praxis über die Theorie, beide zusammen bilden einen Prozess. Die Theorie greift dabei in ihre Praxis ein und ist nicht lediglich deren Reflex, gleichzeitig ist die Praxis die Kritik der Theorie, wenngleich die Praxis alleine die Theorie nicht widerlegen, aber auch nicht verifizieren kann. [Karsz 1976, S. 44].

2. In der Bewegung des Prozesses der wissenschaftlichen Praxis verändert sich die Theorie, indem sie Elemente ihrer selbst abspaltet und als ideologische Irrtümer zurücklässt.

Die Existenz solcher ideologischen Irrtümer innerhalb ihrer theoretischen Praxis sowie die Verschränkung der theoretischen Praxis mit anderen Praxen 
(insbesondere der ideologischen Praxis) bedeutet nach Althusser, dass es eine „reine“ Wissenschaft nicht gibt, sondern das die Wissenschaften mit den verschiedensten Ideologien, politischen Positionen und Philosophien durchsetzt sind und ebenso wie Philosophie, Ideologie und Politik „Kampfplatz“ ist [FM, S. 109 ff.]. Theoretische Praxis lässt sich demnach als ein Typ von Veränderung definieren, der

mit Hilfe eines begrifflichen Instrumentariums (Analyse, Definition, Experiment, Methode) in einem Prozess ununterbrochener Forschung und Konfrontation auf einen Grundstoff - schon bestehende Evidenzen, Begriffe, Vorstellungen, Thesen, Theorien und Doktrinen - mit dem Ziel einwirkt, einen theoretischen Effekt zu produzieren, der sowohl in einer wissenschaftlichen Theorie als auch in einem ideologischen Korpus oder einer philosophischen Position bestehen kann. [Karsz 1976, S. 48; Hervorhebung S.v.B.]

Aufgrund der Bestimmung des Erkennens als Produktion, die auf bestimmte Produktionsmittel angewiesen ist und die in einer Beziehung zum Realobjekt steht, aber dieses nicht direkt bearbeitet, sondern sich an der Erkenntnis selbst abarbeitet, kann Althusser eine erste Abgrenzung der Wissenschaft von der Ideologie definieren: Wissenschaft als Prozess der theoretischen Praxis konstituiert sich selbst als Wissenschaft, indem sie beginnt, sich ihre eigenen wissenschaftlichen Tatsachen auszuarbeiten und die vorhergehende Praxis als ideologisch kritisiert.

Dies heißt natürlich nicht, dass die Wissenschaft an reinen, objektiven Gegenständen abarbeitet, sondern sie erarbeitet Theorien, die nur innerhalb des Feldes ihrer theoretischen Praxis identifiziert werden können [FM, S. 125 f.]. Für Althusser bedeutet das, dass es mehrere Felder von Allgemeinheiten gibt, innerhalb derer sich wissenschaftliche Praxis vollzieht:

1. Die Allgemeinheit I wird durch die Grundmaterie/Rohstoff (matière première) gebildet. Sie besteht aus ideologischen, philosophischen und/oder wissenschaftlichen Vorstellungen (,ideologische Tatsachen“) und bildet das Objekt wissenschaftlicher Arbeit (im Fall der Marx'schen Kritik der politischen Ökonomie stellen also die Arbeiten von Smith, Owen und Ricardo den Rohstoff dar). [Thieme 1982, S. 17]

2. Die wissenschaftliche Praxis basiert auf einer Arbeit mit einem „Gebäude von Begriffen“ [FM, S. 126], das in einer mehr oder weniger widersprüch- 
lichen Einheit die „Theorie“ der jeweiligen Wissenschaft bildet, diese stellen die Produktionsmittel der Wissenschaft dar (Allgemeinheit II ).

3. Die Allgemeinheit III ist schließlich die wissenschaftliche Erkenntnis in Form einer neuen Theorie bzw. eines neuen Begriffssystems.

Der Prozess der wissenschaftlichen Erkenntnis verläuft innerhalb dieser Allgemeinheiten, indem „Vorstellungen“ der Allgemeinheit I mit Methoden (Produktionsmitteln) der Allgemeinheit II bearbeitet und neue wissenschaftliche Theorien und Begriffe erarbeitet werden und diese in die Allgemeinheit III übergehen - dementsprechend ist wissenschaftliche Erkenntnis nicht (Wider-) Erkennen, sonder Produktion einer Erkenntnis auf der Basis bereits erarbeiteter Erkenntnisse und Theorien. Überwundene wissenschaftliche Erkenntnisse werden somit im Laufe der wissenschaftlichen Praxis von einer Allgemeinheit III zu einer Allgemeinheit I überführt, dieser Gesamtvorgang stellt für Althusser die Arbeit und Produktion der Wissenschaft dar [FM, S. 125 ff.].

Die wissenschaftliche Begriffsbildung ist folglich keine „Übersetzung“ des Realen, sondern es wird ein theoretisches Objekt - bestehend aus Begriffen und Beziehungen zwischen diesen - konstruiert, das grundsätzlich von „dem Realen“/dem Realobjekt verschieden ist. Durch diese wissenschaftliche Praxis besteht auch ein notwendiger Zusammenhang zwischen Erkenntnis- und Realobjekt $^{22}$; Wissenschaft ist „begriffliche Inbesitznahme der realen Welt“ [DKL, Bd. 1, S. 71], indem ein Begriffssystem konstruiert und in ein „Gedankenganzes“ (Marx) verwandelt wird. Mit der Unterscheidung zwischen dem Realobjekt und dem theoretischen Objekt ${ }^{23}$ fällt eine (kognitive) Veränderung

22 Die Verknüpfung der Allgemeinheiten durch die wissenschaftliche Praxis beinhaltet die Verknüpfung von Erkenntnisobjekt und Realobjekt; von einem idealistischen Dualismus von Erkenntnis- und Realobjekt, wie z. B. von Mandel behauptet [Mandel 1974, S. 17], kann somit keine Rede sein.

23 Die Unterscheidung von „Realobjekt“ und „Erkenntnisobjekt“, d. h. zwischen dem zu erkennenden Objekt und seinem wissenschaftlichen Begriff scheint sich Althussers Argumentation an de Saussures Theorie bezüglich ,Signifikant/Signifikat“ zu orientieren: in seiner Sprachtheorie geht de Saussure davon aus, dass zwischen dem sprachlichen Zeichen einer Sache (Signifikant) und der dadurch bezeichneten Sache (Signifikat) keinerlei „natürlicher“ Zusammenhang besteht, das sprachliches Zeichen einer Sache ist diesem gegenüber vollständig beliebig [de Saussure 1931, S. 79] und beruht nur auf historisch gewachsenen gesellschaftlichen Konventionen [de Saussure 1931, S. 83 f.]. Der Sinn/die Bedeutung eines Zeichens ist in diesem Sinne nicht „natürlich“, dass das Bezeichnete seine Bezeichnung hervorbringt. Im Gegenteil stellt de Saussure fest, dass die Decodierung des Signifikats durch den Signifikanten nur dadurch möglich ist, dass kein anderer Signifikant diese Sache bezeichnet. Analog bringt das Realobjekt seinen Begriff nicht selbst hervor, sondern dieser kann nur im Gesamtsystem der Signifikanten (in der theoretischen Ordnung) konstituiert und so seine Funktion identifiziert werden. Für Althusser 
der Wirklichkeit zusammen, da Realobjekt und theoretisches Objekt nicht identisch sind. Die wissenschaftliche Abstraktion, verstanden als Konstruktion von Begriffen und nicht als „Herausschälen“ von Essenzen, wäre somit die grundlegende Bewegung jeder wissenschaftlichen Praxis. Ein Zurückgreifen auf (vermeintliche) Evidenzen und sogenannte „Tatsachen“ zeige dann innerhalb der wissenschaftlichen Praxis an, wann diese auf das Niveau der Ideologie zurückfällt. [vgl. Karsz 1976, S. 56 ff.] Für Althusser stellt sich die Frage, wie Erkenntnis produziert (im Sinne von Aneignung) wird, also die Frage nach einem Mechanismus, „durch den die Produktion eines Erkenntnisobjekts die gedankliche Aneignung eines Realobjekts produziert“ [DKL, Bd. 1, S. 74]. Das grundlegende Schema des Prozesses der theoretischen Praxis ist nach Althusser, das gedanklich Abstrakte (die Allgemeinheit I) in ein gedanklich Konkretes (Allgemeinheit III) zu transformieren [FM, S. 129], diese Transformation bestehe in der Theoretisierung der Allgemeinheit I.

Vor dem bisher dargestellten Sachverhalt entfaltet sich natürlich die Problematik, wann eine Erkenntnis als wissenschaftlich bzw. als ideologisch (nicht-wissenschaftlich) einzuordnen ist. Althusser nennt zwei Merkmale, die die Wissenschaft von der Ideologie trennt:

1. Die Konstruktion der theoretischen Begriffe erfolgt innerhalb des Kontextes einer spezifischen Wissenschaft, durch die eine Kontrolle der konstruierten Begriffe hinsichtlich der Kohärenz derselben unter expliziten (und damit redivierbaren) Regeln erfolgt [vgl. Karsz 1976, S. 61 f.].

2. Jede Wissenschaft ist in dem Sinn ein System, indem sie ihre theoretischen Objekte und spezifischen Methoden zu einem verknüpften, hierarchischen Ganzen organisiert. Im Gegensatz zu einer ideologischen Ordnung schafft es die wissenschaftliche Ordnung, alle ihre theoretischen Objekte zu erfassen und einzuordnen, ohne auf Analogismen und Metaphern zurückzugreifen ${ }^{24}$.

stellt die - auf dieser Begrifflichkeit aufbauende - strukturale Linguistik die Methoden bereit, mit denen Lacan an Freud anknüpfen konnte [Althusser/Tort 1976, S. 23].

24 Dies ist natürlich als Typisieruung des Idealzustandes zu begreifen, denn einerseits konstatiert Althusser, dass sich Marx des öfteren Metaphern bedient [DKL, Bd. 1, 27; S. 62 f.], Althusser selbst aber auch Metaphern benutzt und dies auch unumwunden zugibt, z. B. wenn er die Metapher des ,theoretischen Feldes“ benutzt [DKL, Bd. 1, S. 30] oder mit der Theater-Metapher („Bühne“, „Auftritt“) arbeitet [DKL, Bd. 1, S. 71]. Zweifellos ist aber auch Althusser der Ansicht, dass die besagten Knotenpunkte in der wissenschaftlichen Theorie nur von ,reinen“ Begriffen besetzt werden können, beispielsweise in der Marx'schen der Begriff des „Mehrwerts“ [DKL, Bd. 1, S. 195]. 
Indem Wissenschaft das theoretische Objekt vor dem Hintergrund ihres Systems konstruiert und in dieses einordnet, vollzieht sie eine Totalisierung desselben:

Eine Wissenschaft [wie der historische Materialismus] ist eine systematische Theorie, die ihren Gegenstand in seiner Totalität erfasst und damit das ,,innere Band“ begreift, das die (reduzierten) Wesenheiten mit allen ökonomischen Erscheinungen verknüpft. [DKL, Bd. 1, S. 108]

Objektivität erreicht eine Wissenschaft damit erst dann, wenn es ihr gelingt, Erklärungen und Auskünfte über ein Element ihres Systems aus dem theoretischen System, der funktionalen Anordnung der Begriffe selbst heraus abzugeben. Das wissenschaftliche theoretische System ist in dem Sinn die Totalität, in der „eine Erkenntnis der Tatsachen, als Erkenntnis der Wirklichkeit möglich“ ist [Lukács 1970, S. 69]. Für den strukturalen Marxismus muss dies aber gelingen, ohne auf irgendeine Form von Bewusstseinsphilosophie zurückzugreifen.

Der „Wahrheitsgehalt“ einer Wissenschaft ist demnach auch nicht durch Empirie zu klären, sondern die Wissenschaft muss allein internen Anforderungen genügen [Descombes 1981, S. 148]. Folglich ist die pragmatische Antwort auf den Erkenntnisgehalt einer Wissenschaft, nämlich dass die gesellschaftliche Praxis der Menschheit (nach Althusser „eine Nacht, in der jede Praxis grau ist“ [DKL, Bd. 1, S. 75]) das Kriterium der „Wahrheit“" wäre bzw. die Probe eines Puddings darin bestehe, dass man ihn esse (Engels), ebenso entschieden zurückzuweisen wie das Mysterium der Hegel'schen Dialektik, das die Übereinstimmung von Theorie und Praxis herstellt. Wenn die Wissenschaftlichkeit einer Wissenschaft im Zentrum der Untersuchung steht, muss deren Praxis untersucht werden, innerhalb derer das Wissen produziert wird; allerdings nicht die „handwerkliche“ Praxis (Experiment), sondern die Praxis der theoretischen Produktion.

Wir behaupten theoretisch den Primat der Praxis, indem wir zeigen, dass alle Ebenen des gesellschaftlichen Seins die Stellen verschiedener Praxisformen sind: die ökonomische, politische, ideologische, technische, wissenschaftliche (oder theoretische) Praxis. [DKL, Bd. 1, S. 77] $]^{25}$

Die Struktur jeder Praxis ist demnach die Struktur einer Produktion, in der mittels bestimmter Produktionsmittel ein Rohstoff zu einem Produkt (hier:

25 Althusser gelingt es so mit der Analyse der theoretischen Praxis auch, die Dichotomie zwischen „Theorie“ und „Praxis“ aufzulösen, vgl. Turchetto 1994, S. 52. 
wissenschaftliche Erkenntnis) umgewandelt wird [Thieme 1982, S. 23], das Ergebnis dieser Produktion (die Theorie) ist dabei aber allein in der Lage, dem gesamten Prozess den Status der Wissenschaftlichkeit zu geben [vgl. Karsz 1976, S. 70] ${ }^{26}$. Folglich ermöglicht allein die Theorie im strengen Sinn die Durchführung empirischer (nicht empiristischer) Forschung ${ }^{27}$, da erst sie den wissenschaftlichen Konstitutionsrahmen bildet, ein empirisches Datum einzuordnen und $\mathrm{zu}$ bewerten - das empirische Datum selbst hat keinen wissenschaftlich erklärenden Gehalt.

b) In dem Prozess der wissenschaftlichen Praxis ist also die Theorie die Schlüsselkategorie, da alle Phasen der wissenschaftlichen Praxis von dieser abhängen. Hierbei ist unter Theorie einmal eine Theorie im strengen Sinn zu verstehen, die sich auf ,abstrakt-formale“ Gegenstände bezieht (z. B. Produktionsweise/Produktionsverhältnisse). Zum anderen ist unter Theorie auch eine „empirisch-theoretische“ Theorie von weniger weit greifender Bedeutung zu fassen, sie stellt quasi eine Sub-Theorie dar, die an die Theorie im strengen Sinn anknüpft und örtlich lokale Beziehungen im wissenschaftlichen System untersucht oder zeitlich begrenzte Erscheinungen zum Gegenstand hat (konkret-wirkliche Gegenstände) [vgl. Karsz 1976, S. 68 f.]. Die Theorie im strengen Sinn bildet allerdings keine Axiomatik im klassischen Sinn: sie ist

26 Die „Wissenschaftlichkeit einer Wissenschaft“ definiert sich also nicht darüber, welche (vermeintlich wissenschaftlichen) Methoden sie benutzt, sondern nur über die Strenge der Entwicklung ihres Begriffsapparates. Beispielsweise ist die Mathematik als Wissenschaft völlig unabhängig davon, ob ihre Methoden in der Physik Verwendung finden und dort „funktionieren“ [DKL, Bd. 1, S. 78]. Umgekehrt kann eine Wissenschaft ihre Wissenschaftlichkeit nicht dadurch begründen, dass sie mathematische Methoden benutzt; im Gegenteil müsste sie zuvor in der Lage sein, aus ihrem Begriffsapparat heraus darzustellen, warum überhaupt mathematische Methoden innerhalb ihres Wissenschaftsgebietes angewendet werden dürfen und müssen.

27 Den Status eines so verstandenen wissenschaftlichen Begriffs lässt sich am Beispiel des marxistischen Klassenbegriffs demonstrieren: Der Begriff basiert in der marxistischen Definition vollständig auf dem Begriff des Mehrwerts und ist funktional voll von diesem abhängig. Die Existenz gesellschaftlicher Klassen ist innerhalb des Marxismus nur durch die Produktion von Mehrwert erklärbar, dies bedeutet für den historischen Materialismus, dass es per definitionem solange gesellschaftliche Klassen gibt wie Mehrwert produziert wird, die Definition der Klassen wie die Zurechnung gesellschaftlicher Gruppen zu den verschiedenen Klassen ist dabei immer anhand der Mehrwertproduktion und -verteilung zu bestimmen. Vollkommen unerheblich ist dabei, ob sich gesellschaftliche Gruppen oder Individuen selbst gesellschaftlichen Klassen zuordnen/,Klassenbewusstsein“ entwickeln (als „Klasse für sich“) oder politische oder habituelle Merkmale aufweisen, die einer bestimmten gesellschaftlichen Klasse zuzuordnen sind. Die grundsätzliche wissenschaftliche Problematik solcher Zuordnungen offenbart sich, wenn in diesem Zusammenhang das Ende der Klassengesellschaft ausgerufen wird, weil sich traditionelle soziologische und/oder politische Formen des „Klassenbewusstseins“ auflösen. 
selbst wiederum Resultat einer theoretischen Praxis. Die großen Durchbrüche in der Wissenschaftsgeschichte sind somit weniger auf die Genialität der Personen zurückzuführen, mit denen diese Durchbrüche namentlich verbunden sind, wie z. B. Galilei/Newton/Marx/Freud, sondern nahezu zwangsläufige Resultate des wissenschaftlichen Diskurses. Dies gilt um so mehr, da Althusser die Subjekt-Objekt-Dichotomie in seiner Epistemologie nicht weiterverfolgt, sondern dieses Konzept zugunsten einer strukturalistischen Konstruktion aufgibt: der Prozess der wissenschaftlichen Erkenntnis - der wissenschaftliche Diskurs - weist dem Wissenschaftler-,,Subjekt“" seinen Platz und seine Funktion zu; die Struktur der wissenschaftlichen Praxis, die selbst ,auf der bestehenden ökonomischen, politischen, ideologischen Praxis gründet“, beherrscht das Denken des Wissenschaftler-Individuums [DKL, Bd. 1, S. 53] ${ }^{28}$. Ebenso bearbeitet der wissenschaftliche Diskurs nicht ein ihm äußerliches Realobjekt, sondern die „Erkenntnis“ bearbeitet immer ein durch diesen Diskurs konstituiertes Objekt, ein bereits formierter Stoff,

une matière première, c'est-à-dire une matière déjà élaborée, déjà transformée, précisément par l'imposition de la structure complexe (sensible-technique-idéologique) qui la constitue comme objet de la connaissance, même la fruste. [LLC, Bd. 1, S. 49]

Wissenschaftliche Diskurse bilden somit die „Produktionsverhältnisse“ der Produktion des wissenschaftlichen Wissens ${ }^{29}$. Aber wie auch die ökonomischen Produktionsverhältnisse nicht „,rein“ erscheinen (sondern nur als Überlagerung verschiedener Produktionsverhältnisse existieren, siehe dazu S. 95 ff.) überlagern sich auch wissenschaftliche Diskurse, die an der Ablösung des herrschenden wissenschaftlichen Diskurses arbeiten.

c) In Abgrenzung zur wissenschaftlichen Praxis könnte eine vorsichtige, rein epistemologische Definition der Ideologie sein, dass sie wie die wissenschaftli-

28 Bourdieu ist insoweit Recht zu geben, wenn er anmerkt, dass die Konzeption der wissenschaftlichen Erkenntnis bei Althusser einen subjektlosen Prozess bildet [Bourdieu 1997b, S. 78; 1999, S. 358]. Der darin vorliegenden Vorwurf, dass die wissenschaftliche Erkenntnis bei Althusser eine universelle objektive Erkenntnis sei oder dieser das Feld verkenne/ missachte, innerhalb derer die wissenschaftliche Erkenntnis produziert werde (welches somit bestimmte Dispositionen für das erkennende „Subjekt“ - den Wissenschaftler enthalte), muss Angesichts des Beharrens Althussers auf der Analyse der wissenschaftlichen Praxis als diskursive Praxis im Foucault'schen Sinn wohl zurückgewiesen werden (siehe unten).

29 Wenn wissenschaftliche Diskurse als „Produktionsverhältnisse“ Begriffen werden, impliziert das natürlich auch, dass hier spezifische politische Rahmenbedingungen existieren, hierauf wird im Folgenden noch zurückzukommen. 
che Praxis eine Form der Aneignung des Realen ist, aber eine von der wissenschaftlichen Erkenntnis differente Praxis besitzt: während die ideologische Aneignung des Realen unmittelbar - aber dabei schon gebrochen durch andere gesellschaftliche Strukturen (siehe dazu unten) - als Teil der Allgemeinheit I erfolgt, produziert die Wissenschaft die Erkenntnis mit einen spezifischen Produktionsapparat in einem spezifischen Begriffssystem ${ }^{30}$ - schon vor dem Hintergrund einer Theorie, die sich in ihrer Praxis selbst überprüft.

Allerdings ist die Bestimmung der Wissenschaft in der oben dargelegten Form für Althusser nicht ausreichend, sondern es ist zusätzlich die Geschichte der Wissenschaft - genauer: die Geschichte der theoretischer Produktion näher zu untersuchen. Dies ist schon deshalb notwendig, da der Modus der Althusser'schen Epistemologie einen spezifischen Begriff der Wissenschaftsgeschichte impliziert: Die Bewegung von Allgemeinheit I zu Allgemeinheit III unter Anwendung der Allgemeinheit II ist nach Althusser ein dialektischer Prozess, in dem die ideologischen Irrtümer der Wissenschaft abgespalten werden. Die theoretische Praxis produziert somit die das Konkret-Gedankliche als Erkenntnis des Gegenstands (Konkret-Wirkliches) ${ }^{31}$ - es besteht somit immer eine Differenz zwischen den Allgemeinheiten (und das Bestreiten dieser Differenz mache genau den Kern des Hegel'schen Idealismus aus) [FM, S. 135].

Das heißt aber auch, dass dieser Prozess endlos ist, die Geschichte einer Wissenschaft ist vor allem die Geschichte von Einschnitten innerhalb ihrer Praxis; diese Geschichte wird für Althusser (hierin mit Foucault übereinstimmend $^{32}$ ) zur Schlüsselkategorie der Erkenntnis der theoretischen Praxis:

Pour aller au-delà du simple concept formel de la structure de la pratique théorique, c'est-a-dire de la production des connaissance, nous devons élaborer le concept de l'histoire de la connaissance, et élaborer les concepts des différents modes de production théorique (au premier chef les concepts du mode de production théorique de l'idéologie, et de la science), ainsi que les concepts propres des différentes branches de la production théorique, et des leurs rapports (les différentes sciences et les

30 Auch hier wird die Nähe Althussers zu Lacan deutlich: die Anordnung der Begriffe Wissenschaft/Ideologie/Reales verläuft weitgehend analog zu den Lacan'schen drei Ebenen des Symbolischen/Imaginären/Realen, siehe dazu auch S. 64 ff.

31 Marx sei demnach vollkommen zuzustimmen, wenn er behauptet, dass die ,konkrete Totalität als Gedankentotalität, als ein Gedankenkonkretum, in fact ein Produkt des Denkens, des Begreifens ist" [MEW, Bd. 13, S. 632].

32 Althusser hebt vor allem Foucaults Wahnsinn und Gesellschaft [Foucault 1996] hervor, vgl. DKL, Bd. 1, S. 30; 58. 
types spécifiques de leurs dépendance, indépendance et articulation). [LLC, Bd. 1, S. 50]

Wenn auch der ideologische Irrtum „Vorbedingung“ einer wissenschaftlichen Erkenntnis ist, die auf diesen Irrtum folgt/folgen kann, heißt dies nicht, dass Althusser dem Positivismus anheim gefallen ist, also dass die Geschichte der Wissenschaften eine Geschichte des kontinuierlichen Fortschritts ist ${ }^{33}$. Um die Geschichte der theoretischen Erkenntnis zu untersuchen, ist nach Althusser ein bloßes empirisches Erfassen von „Tatsachen“ und Präsentieren chronologischer Abläufe, wie sie im herrschenden Wissenschaftsbetrieb die Regel seien, nicht ausreichend $^{34}$. Diesem ,teleologische[n] und daher idealistische[n] Rationalismus“ [DKL, Bd. 1, S. 56] sei eine Konzeption entgegenzusetzen, die nicht auf die Ideologie der linear fortschreitenden Aufdeckung der Wirklichkeit oder der Aufklärungsphilosophie zurückgreift. Es sei vielmehr davon auszugehen, dass

die Geschichte des menschlichen Geistes weder die lineare Geschichte einer kontinuierlichen Entwicklung ist, noch, in ihrer Kontinuität, die Geschichte der fortschreitenden Manifestation oder Bewusstwerdung einer Vernunft, die bereits völlig in den den keimhaften Ursprüngen der Geschichte angelegt wäre und im Verlauf ihrer Geschichte nur zu voller Entfaltung gebracht würde. [DKL, Bd. 1, S. 56 f.]

Statt weiterhin dem Hegel'schen Triumph der Vernunft verpflichtet zu sein, gelte es vielmehr, die Wissenschaftsgeschichte

$\mathrm{zu}$ begreifen als eine ständig unterbrochene Geschichte tief greifender Diskontinuitäten, (z. B. die Trennung einer neuen Wissenschaft von der Grundlage älterer ideologischer Formationen), tiefer Umbrüche, die, selbst wenn sie die kontinuierliche Existenz der Erkenntnisbereiche nicht antasten [...] doch in ihrem Bruch mit vergangenen Formationen das Herrschen einer neuen Logik ankündigen, die - weit davon entfernt, nur die einfache Entwicklung der „Wahrheit“ oder die „Umwälzung“ der alten Logik zu sein - vielmehr im vollen Sinne des Wortes deren Platz einnimmt. [DKL, Bd. 1, S. 57]

Die Diskontinuitäten und Brüche in der Entwicklung der Wissenschaften sind also Kennzeichnen für die Verschiebung innerhalb der Wissenschaft (ihrer Logik/ihres Gegenstandes) selbst ${ }^{35}$. Sie sind Punkte, an denen die bereits ange-

33 Ebenso wenig kann davon gesprochen werden, dass der strukturalistische Marxismus eine Form des Rationalismus darstellt, denn dieser akzeptiert keinen a priori gesetzten, „natürlichen“ Vernunftbegriff, der außerhalb der Klassenbeziehungen existieren würde [Balibar 1977b, S. 231], vgl. dazu auch S. 55 ff.

34 Althusser hebt in diesem Zusammenhang die Ausnahmeposition der Strukturalisten, die eben in diese Richtung arbeiteten wie Foucault, Bachelard, Cavalliès, Canguilhem und Koyré hervor [DKL, Bd. 1, S. 56].

35 Siehe hierzu Fichant/Pêcheux 1977, S. 44 ff.. 
sprochenen Allgemeinheiten der Wissenschaft sich transformieren, indem sie sich von dem bisherigen wissenschaftlichen Erkenntnisstand (nunmehr als „ideologische Tatsache“ einzuordnen) trennen - sich also nun die Produktion einer neuen Allgemeinheit III ankündigt ${ }^{36}$.

Hierbei bestehe die Problematik, das die Produktion von wissenschaftlichen Erkenntnissen noch im ideologischen Raum beginnt, sie folglich ,zur Geschichte eines noch ideologischen Erkenntnisbereichs gehören, der sich als Wissenschaft zu begründen sucht oder sich bereits als Wissenschaft etabliert hat" [ebd.]. Die Diskontinuitäten und Verschiebungen in der Geschichte der Erkenntnis bedeuten auch, dass diese Geschichte der Wissenschaft(en) keine lineare Geschichte der Vernunft ist:

Par là nous est imposée l'obligation de renoncer à toute téléologie de la raison, et de concevoir le rapport historique d'un résultat à ses conditions comme un rapport de production, et non d'expression, donc ce que nous pourrions appeler, d'un mot qui jure avec le système des catégories classiques, et exige le remplacement des ces catégories elles-mêmes, la nécessite de sa contingence. [LLC, Bd. 1, S. 52]

Vor diesem Hintergrund müsse die Differenzierung zwischen Ideologie und Wissenschaft zur Folge haben, dass die Ideologie selbst ,als wirkliche Geschichte mit eigener Gesetzlichkeit und zugleich als wirkliche Vorgeschichte“ [DKL, Bd. 1, S. 58] behandelt werden müsse. Althusser stellt bezüglich des Verhältnisses von wissenschaftlicher und ideologischer Erkenntnis zwei Behauptungen auf:

1. Der Übergangsprozess von der Allgemeinheit I zur Allgemeinheit III vollzieht sich allein in der theoretischen Praxis [FM, S. 127].

2. Wenn die Wissenschaft die Allgemeinheit I in die Allgemeinheit III transformiert, kann dies zum einen eine Produktion einer wissenschaftlichen Allgemeinheit sein, ,die die alte [Allgemeinheit] zurückweist, indem sie sie sich gleichzeitig 'einverleibt'“ [FM, S. 127] oder die Transformation einer ideologischen Allgemeinheit in ein wissenschaftliche Allgemeinheit sein. Diesen Vorgang bezeichnet Althusser mit dem - von Bachelard entliehenen $^{37}$ - Begriffs des epistemologischen Bruchs (epistemologischen

36 Beispielhaft für einen solchen epistemologischen Einschnitt in den Naturwissenschaften sind die Erfolge von Einstein und Mendel.

37 Zur ausführlicheren Darstellung der Einflüsse Bachelards auf Althusser vgl. Brühmann 1980 und Schmidt 1972b, S. 107 ff. 
Einschnitts). Die Identifizierung eines solchen epistemologischen Bruchs ist eben Zielsetzung der symptomatischen Lektüre [Althusser/Tort 1976, S. 47].

d) Aufbauend auf der skizzierten Epistemologie problematisiert Althusser die Frage der Begriffsbildung bei Marx. Die Kontroversen bezüglich der Entwicklung und der Anordnung der Kategorien im Kapital, also die „historische“ oder die „logische“ Entwicklung der Kategorien, die Frage der „Identität oder NichtIdentität von 'logischer' und 'historischer' Ordnung“ [DKL, Bd. 1, S. 60] sei durch Das Kapital selbst beantwortet: Im Gegensatz zu einem vor allem durch Hegel geprägten Marxismus, der die Identität von historischer/realer und logischer Ordnung annehme und sich deshalb ,gewaltsam über bestimmte Antworten von Marx hinwegsetzen“ [ebd.] müsse, sei nur das Anerkennen der Differenz von Real- und Erkenntnisobjekt akzeptabel.

Demnach sei die Unterscheidung zwischen logischer und historischer Ordnung, der radikalen Trennung von historischer Entwicklung und wissenschaftlicher Begriffsbildung vor dem Hintergrund der Trennung von Erkenntnis- und Realobjekt nur ein Scheinproblem und als solches nur innerhalb einer Hegel'schen Erkenntnistheorie stellbar. Vielmehr sei in den Antworten von Marx ein „Ineinander von Übereinstimmungen und Nichtübereinstimmungen zwischen 'logischer' und 'realer' Ordnung“ [DKL, Bd. 1, S. 67] zu konstatieren. Das heißt für Althusser aber auch (in Abgrenzung zu Della Volpe), dass eine bloße Umkehrung des Verhältnisses von logischer und historischer Ordnungen ebenso zurückzuweisen ist [DKL, Bd. 1, S. 60 f. $]^{38}$. Althusser greift in seiner Argumentation eine Textstelle aus der Einleitung zur Kritik der politischen Ökonomie auf, in der Marx explizit ausführt, dass in der Entwicklung der Kategorien das Kapital „Ausgangspunkt wie Endpunkt“ bilden müsse, die Entwicklung der gedanklichen Kategorien sei also nicht in der Reihenfolge ihrer historischen Erscheinung zu entwickeln:

38 Backhaus weist zurecht darauf hin, dass an diesem Punkt Althusser und die „Frankfurter Schule" konvergieren, beide Konzeptionen würden davon ausgehen, dass die innere Systematik der Marx'schen Begriffe nur partiell mit der Darstellungsform übereinstimmen würde [Backhaus 1997, S. 206 f.]. Anzumerken ist dabei, dass diese Problematik der Differenz von bewusster Darstellung und innertheoretischer Systematik Marx selbst wohl bekannt war [Schmidt 1972a, S. 32, Fn. 5]. Weiterhin weist auch Anderson darauf hin, dass in Adornos Negative Dialektik - die nach Für Marx und Das Kapital lesen erschien zahlreiche Thesen Althussers Epistemologie auftauchen [Anderson 1978, S. 108 ff.] 
Es wäre also untubar und falsch, die ökonomischen Kategorien in der Folge aufeinander folgen $\mathrm{zu}$ lassen, in der sie historisch die bestimmenden waren. Vielmehr ist ihre Reihenfolge bestimmt durch die Beziehung, die sie in der modernen bürgerlichen Gesellschaft aufeinander haben, und die genau das umgekehrte von dem ist, was als ihre naturgemäße erscheint oder der Reihe der historischen Entwicklung entspricht. Es handelt sich nicht um das Verhältnis, das die ökonomischen Verhältnisse in der Aufeinanderfolge verschiedener Gesellschaftsformen historisch einnehmen. Noch weniger um ihre Reihenfolge ,in der Idee“ [...]. Sondern um ihre Gliederung innerhalb der modernen bürgerlichen Gesellschaft. [MEW, Bd. 13, S. 638]

Die bei Marx skizzierte Entwicklung der Kategorien aus ihrer funktionalen Anordnung heraus im Gegensatz zu einer historischen Entwicklung ähnelt der Konzeption Ferdinand de Saussures. Dieser stellte Anfangs des 20. Jahrhunderts innerhalb der Sprachwissenschaften fest, dass grundsätzlich zwei Methoden der Analyse des Erkenntnisgegenstandes voneinander unterschieden werden müssen. Die diachronische Sprachwissenschaft habe die historische Entwicklung der Elemente der Sprache als Gegenstand während die synchronische Sprachwissenschaft den statischen Zustand des Sprachsystems und die Beziehungen der einzelnen Elemente untereinander $\mathrm{zu}$ untersuchen versuche [de Saussure 1931, S. 96]. In dieser später den Strukturalismus prägenden Unterscheidung kommt nach de Saussure der Synchronie überragende Bedeutung zu. Während eine diachronische Erscheinung ein Einzelereignis darstellt, das keine unmittelbare Veränderung des Gesamtsystems nach sich zieht, ist die „synchronische Tatsache [...] stets bedeutungsvoll, sie bezieht sich stets auf zwei gleichzeitige Glieder“ [ebd., S. 101]. Das bedeute für die Sprachwissenschaft, dass die Sprache ein System ist, das sich in der historischen Entwicklung verändert, aber ein Mechanismus ist, „der trotz des Verfalls, der stattfindet, nicht aufhört zu funktionieren“ [de Saussure 1931, S. 103], „, die Sprache ist ein System, dessen Teile in ihrer synchronischen Wechselbeziehung betrachtet werden können und müssen“" [ebd.].

Die Konzeption von Diachronie/Synchronie innerhalb der Betrachtung eines wissenschaftlichen Systems stellt, so sie nicht nur innerhalb der Linguistik angewandt wird, sondern auf andere Wissenschaftsgebiete übertragen wird, in einem gewissen Sinn die Heisenberg'sche Unschärferelation der Gesellschaftswissenschaften dar; sie unterstellt, dass es nicht möglich ist, die spezifische Geschichte und die Relationalität der theoretischen Elemente gleichzeitig zu bestimmen bzw. die Anordnung eines Elementes in dem System 
aus seiner spezifischen Geschichte heraus zu bestimmen. Die Terminologie de Saussures auf die Marx'sche Konzeption der Entwicklung der Kategorien angewandt bedeutet, dass der Marx'schen Analyse einer Gesellschaftsformation eine synchronische Konzeption zugrunde liegt ${ }^{39}$. Dies bedeutet nicht, die historische Genese der Gesellschaftsformation $\mathrm{zu}$ bestreiten, allerdings ist die diachronische Entwicklung für die Ausarbeitung der theoretischen Kategorien und ihrer Verbindungen untereinander von untergeordneter Bedeutung ${ }^{40}$. Die synchronische Gliederung des theoretischen Gegenstand ist für Althusser auch für die Analyse der bürgerlichen Gesellschaft ausschlaggebend:

C'est justement cette Gliederung, cette totalité-articulée-de-pensée qu'il s'agit de produire dans la connaissance comme objecte de la connaissance pour parvenir a la connaissance de la Gliederung réelle, de la totalitéarticulée-de-pensée, qui constitue l'existence de la société bourgeoise. [LLC Bd. 1, 56]

D. h. die Ordnung der Kategorien und derer Verbindungen im Kapital ist notwendig für die „Produktion jener konkreten Gedankentotalität, welche die Theorie des 'Kapital' bildet" [DKL, Bd. 1, S. 62], eine direkte und wechselseitige Beziehung zwischen der Ordnung der Gedankentotalität und der Ordnung der realen Totalität existiert demnach nicht zwangsläufig; zwar kann es Berührungen, partielle Übereinstimmungen der beiden Ordnungen geben, jedoch sei dies ,kein Beweis für die Übereinstimmung beider Ordnungen oder gar eine Antwort auf die Frage nach dieser Übereinstimmung, sondern ein neues Problem“ [ebd.].

Althusser rekurriert auf die Anordnung von Synchronie und Diachronie explizit im Bezug auf den wissenschaftlichen Diskurs: Synchronie stelle die Struktur der Begriffe in ihrer Gedankentotalität/dem wissenschaftlichen System dar, während die Diachronie als „,die Bewegung der begrifflichen Abfolge im geregelten Diskurs wissenschaftlicher Demonstration“ [DKL, Bd. 1, S. 91] zu

39 Diese Annahme ist im akademischen marxistischen Diskurs alles andere als unumstritten. Zur ausführlichen Darstellung der Diskussion um die „logische“ respektive „logischhistorische“ Interpretation der Arbeiten Marx' vgl. Backhaus 1997, zur „,wissenschaftstheoretischen“ Analyse des Kapitals in der BRD siehe auch Brentel 1989, Heinrich 1991, Reichelt 1973.

40 Anders ausgedrückt: die Beschreibung der historischen Bewegung einer Gesellschaftsformation (diachronischer Verlauf) kann nur durch den Vergleich zweier synchronischer Zustände dieser Gesellschaft erfolgen. 
begreifen sei. Wie für de Saussure kommt bei Althusser der Synchronie im Vergleich zur Diachronie die vorrangige Position $\mathrm{zu}^{41}$ :

1. Die Definition eines Begriffes bestimmt die Funktion und seinen Stellenwert im gesamten Begriffssystem:

Diese Definition des Stellenwertes und der Funktion des Begriffs in der Totalität des Systems zeigt sich in dem Sinn, der einem Begriff immanent ist, wenn wir ihn in eine wechselseitig eindeutige (biunivoque) Beziehung zu seiner realen Kategorie setzten. [ebd.]

2. Die historische Entwicklung der Begriffe erfolgt immer schon vor dem Hintergrund einer begrifflichen Synchronie, „das System der Begriffshierarchie [bestimmt] die 'diachronische' Ordnung ihres Auftretens im wissenschaftlichen Diskurs“ [ebd.].

\section{Die ungleichzeitige Geschichte}

Wir betrachten das Resultat ohne sein Werden und sind bereit, uns der Anklage eines Verbrechens am Hegelianismus und der Entwicklungslehre zu stellen; denn dieses doppelte Verbrechen ist für uns ein Gewinn: es befreit uns von der empiristischen Ideologie der Geschichte.

Louis Althusser

a) An der dargelegten Kritik der Darstellung der Wissenschaftsgeschichte als lineare Entwicklung des Wissens ${ }^{42}$ schließt Althusser eine Kritik der (marxistischen) Geschichtsphilosophie an: „die“ Geschichte als monolithische Einheit, als expressive Totalität, sei ein Mythos. Um dies zu belegen, problematisiert Althusser die Historizität in der Marx'schen Konzeption.

Ein Vorwurf, den Marx der klassischen Ökonomie mache, sei, dass die von dieser entwickelten Kategorien ahistorisch, fix konzeptioniert erscheinen,

41 Die synchronische Theoriebildung attestiert Althusser auch bei Marx: Die ,paradoxe Situation“, vor die Marx gestellt sei, ist dass das Erkenntnisobjekt, die bürgerliche Gesellschaft, schon selbst Resultat einer historischen Entwicklung ist. Für Marx bedeute dies jedoch nicht, eben diese historische Entwicklung zu verfolgen. „Die Erkenntnis dieser Gesellschaft wird nicht durch die Theorie von der Entwicklung dieses Resultats vermittelt, sondern ausschließlich durch die Theorie vom 'Gesellschaftskörper', d. h. von der aktuellen Struktur der Gesellschaft aus, ohne dass deren Genese zu welchem Zweck auch immer in Erscheinung träte." [DKL, Bd. 1, S. 86]

42 Vgl. Seite $23 \mathrm{ff}$. 
dadurch die Bedingungen der kapitalistischen Produktionsweise als Bedingungen jeglicher Produktionsweise erscheinen. Demgegenüber gelte es für Marx, diese Kategorien zu historisieren, um ihre Relativität und Vergänglichkeit begreiflich zu machen [DKL, Bd. 1, S. 119 f.; vgl. MEW Bd. 4, S. 126, 130]. Nach Althusser ist die Kritik Marx' an diesem Punkt auf halben Wege stecken geblieben und liefere dadurch einer historizistischen Interpretation des Werkes Marx' Vorschub. Die Historisierung der ökonomischen Kategorien und ihre Gleichsetzung mit der realen Geschichte, die eine solche historizistische Interpretation betreiben müsse, würde darauf hinauslaufen, dass die Kombination der Kategorien Ricardos mit der Hegel'schen Dialektik Marx' Hauptverdienst wäre. Eine solche Interpretation verdecke aber ein zentrales Problem: „die allgemeine Konfusion in Bezug auf den Geschichtsbegriff“ [DKL, Bd. 1, S. 121].

In der Kritik der überzeitlichen Argumentation der politischen Ökonomie würden alle Interpretationen einen Geschichtsbegriff in Anschlag bringen, der entweder ungeprüft der empiristischen Geschichtsschreibung entliehen sei oder einen durch Hegel geprägten Geschichtsbegriff akzeptieren. Allerdings sei zu fragen, welchen „Gehalt der Geschichtsbegriff haben muss, den die theoretische Problematik von Marx verlangt“ [DKL, Bd. 1, S. 122]. Der Begriff der Geschichte ist folglich für Althusser keine Evidenz, sondern ein theoretisches Problem, welches selbst wiederum auf eine andere Problematik verweist: Den Begriff der geschichtlichen Zeit. Der Hegel'sche Begriff der geschichtlichen Zeit, in der Phänomenologie des Geistes als „,daseiender Begriff“ geprägt [vgl. Hegel 1952, S. 558], zeichne sich durch zwei Eigenschaften aus:

1. Die Zeit besitze in dieser Konzeption eine homogene Kontinuität, d. h. dass die dialektische Selbstentwicklung der Begriffe kontinuierlich verläuft, jeweils aufeinander folgend. Die gesamte Entwicklung folgt dabei einem „Plan“ (der absoluten Idee), der den Rahmen der Entwicklung absteckt und die Homogenität der sich entwickelnden Begriffe garantiert - Momente der Entwicklung, die diesen Rahmen überschreiten, müssen „unter den Tisch fallen“ [Karsz 1976, S. 272]. Die Geschichtswissenschaft wäre demgemäß auf die Periodisierung dieser Kontinuität, also auf die Spezifizierung der jeweiligen dialektischen Totalitäten innerhalb dieses Kontinuums zu reduzieren. 
2. Die Gleichzeitigkeit der Zeit oder die Kategorie der gegenwärtigen Geschichte als Bedingung der homogenen Kontinuität:

Die Tatsache, dass die Beziehung der gesellschaftlichen Totalität zu ihrer geschichtlichen Existenz die Beziehung zu einer unmittelbaren Existenz ist, schließt die Unmittelbarkeit dieser Beziehung selbst ein. [DKL, Bd. 1, S. 123]

Dementsprechend könnte man formulieren, dass es in der Hegel'schen Konzeption nur eine geschichtliche Zeit gibt (,,weil es nur ein Prinzip gibt“" [Thieme 1982, S. 31]), in der die Kategorien in der dialektischen Entwicklung jeweils im historischen Gleichschritt erscheinen. Die gleichzeitige Existenz der Elemente und ihrer Beziehungen untereinander in der Struktur der geschichtlichen Existenz der Hegel'schen gesellschaftlichen Totalität mache es demnach möglich, einen „essenziellen Einschnitt“ (coupe d'essence) vorzunehmen, eine

opération intellectuelle par laquelle on opère a n'importe quel moment du temps historique une coupure verticale, une coupure du présent telle que tous les éléments de tout révèles par cette coup soient entre eux dans un rapport immédiat, qui exprime immédiatement leur essence interne. [LLC, Bd. 1, 116 f.]

b) Die Möglichkeit dieses essenziellen Einschnitts, die die „unmittelbare Lesbarkeit“" des Ganzen garantiere, sei auf die Konzeption der geschichtlichen Zeit (und damit der spezifischen Struktur der gesellschaftlichen Totalität Hegels) zurückzuführen: „Jedes Teil enthüllt in der unmittelbaren Form seines Ausdrucks das Wesen der Totalität selbst“ [DKL, Bd. 1, S. 124] ${ }^{43}$, jedes Teil reflektiert die absolute Idee. Der Hegel'schen Konzeption der geschichtlichen Zeit versucht Althusser eine marxistische Konstruktion dieses Begriffes entgegenzustellen. Der Totalitätsbegriff Marx' sei, durch die Differenz zu dem Begriff der geschichtlichen Zeit Hegels (gekennzeichnet durch dessen Linearität und Homogenität), sehr genau von Hegels Begriff der Totalität zu unterscheiden. Während Hegel die Totalität als einheitliches Ganzes denke, sei diese

43 Die Kritik des Hegel'schen Zeitbegriffes überträgt Althusser aber auch auf die Konzeption der Synchronie/Diachronie (wenn sie auf die Geschichte angewandt wird, wie Althusser Lévi-Strauss unterstellt). Dieser liege ebenso eine ideologische Geschichtskonzeption, eine zeitlich kontinuierliche Abfolge von geschichtlichen Ereignissen, zugrunde, „das Hegel'sche Gegenmodell ist also durchaus relevant, denn es ist repräsentativ für die naiven ideologischen Wahnvorstellungen der herrschenden Praxis allgemein und der Praxis der Historiker im besonderen“ [DKL, Bd. 1, S. 126]. Diese Kritik ist, wenn sie auf LéviStrauss zielt, ungerechtfertigt: Lévi-Strauss kritisiert selbst (gegen Sartre gerichtet) eine Geschichtskonzeption, die „das historische Werden als einen kontinuierlichen Ablauf“ begreift [Lévi-Strauss 1997, S. 299]. 
bei Marx durch Komplexität gekennzeichnet. So schreibt Marx in Das Elend der Philosophie:

Die Produktionsverhältnisse jeder Gesellschaft bilden ein Ganzes. Herr Proudhon betrachtet die ökonomischen Verhältnisse als ebenso viele soziale Phasen, die einander erzeugen, von denen die eine aus der anderen sich ergibt, wie die Antithese aus der These, und die in ihrer logischen Aufeinanderfolge die unpersönliche Vernunft der Menschheit verwirklichen.

Der einzige Übelstand bei dieser Methode ist der, daß Herr Proudhon, sobald er eine einzelne dieser Phasen getrennt untersuchen will, er sie nicht erklären kann, ohne auf die anderen gesellschaftlichen Verhältnisse zurückzukommen, obwohl er diese Verhältnisse noch nicht vermittels seiner dialektischen Bewegung hat entstehen lassen. Wenn Herr Proudhon dann mittels der reinen Vernunft zur Erzeugung der anderen Phasen übergeht, so stellt er sich, als ob er neugeborene Kinder vor sich habe, und vergißt, daß sie ebenso alt sind wie die erste. [...]

Sobald man mit den Kategorien der politischen Ökonomie das Gebäude eines ideologischen Systems errichtet, verrenkt man die Glieder des gesellschaftlichen Systems. Man verwandelt die verschiedenen Teilstücke der Gesellschaft in ebenso viele Gesellschaften für sich, von denen eine nach der anderen auftritt. Wie kann in der Tat die logische Formel der Bewegung, der Aufeinanderfolge, der Zeit allein den Gesellschaftskörper erklären, in dem alle Beziehungen gleichzeitig existieren und einander stützen? [MEW, Bd. 4, S. 130 f.; Hervorhebung S.v.B.]

Das Problem, die Beziehung verschiedener gesellschaftlicher Strukturen zu erklären, ist folglich nicht durch die Hegel'sche Dialektik des „Eins teilt sich in Zwei“ zu bewältigen. Die Beziehungen der Teile des Gesellschaftskörpers, die „gleichzeitig existieren und einander stützen“, würden nicht in dieser Kausalitätsfolge erscheinen, sondern sie stellen eine entwickelte gesellschaftliche Totalität dar, die Marx skizziere als

l'unité d'un tout structuré, comportant ce que l'on peut appeler des niveaux ou instances distincts et 'relativement autonomes', qui coexistent dans cette unité structurale complexe, en s'articulant les uns sur les autres selon les modes de détermination spécifiques, fixés en dernière instance par le niveau ou instance de l'économie. [LLC, Bd. 1, S. 121].

Die Marx'sche gesellschaftliche Totalität (von Althusser in Abgrenzung zur Hegel'schen Totalität auch als „,soziales Ganzes“ bezeichnet [IISA, S. 113]) sei demnach wie folgt gekennzeichnet:

1. Die Gesellschaft besteht aus verschiedenen Instanzen/Ebenen, die sich zu einer Gesamtstruktur zusammenfügen.

2. Die verschiedenen gesellschaftlichen Instanzen (Ökonomie/Staat/Ideologie) besitzen innerhalb der Gesamtstruktur eine relative Autonomie. 
3. Die Grad der Autonomie der Ebenen wird in letzter Instanz durch die Ökonomie determiniert.

Althusser führt diese strukturale Totalität - bestehend aus verschiedenen gesellschaftlichen Instanzen, die durch die Ökonomie determiniert zu der Einheit der Produktionsweise zusammengefügt werden ${ }^{44}$ - auf die verschiedenen gesellschaftlichen Praxisformen zurück. Wie oben bereits angeführt existiert nicht eine gesellschaftliche Praxis an sich, sondern verschiedene Praxisformen (ökonomische, politische, theoretische, ideologische, künstlerische Praxis), denen verschiedene gesellschaftliche Orte entsprechen. Den differenten Praxisformen ist nach Althusser aber gemein, dass sie in ihrer theoretischen Struktur aus menschlicher Arbeit, (Produktions-) Mittel und technischer Anwendung der Mittel bestehen, wobei das Moment der Veränderungsarbeit auf ein Objekt selbst im Mittelpunkt der jeweiligen Praxis steht.

Diese allgemeine Definition der Praxis schließt die Möglichkeit der Partikularität in sich ein: Es existieren verschiedene, tatsächlich unterschiedliche Praxis-Arten, obwohl sie organisch ein und derselben komplexen Totalität angehören. [FM, S. 104]

Wenn auch die ökonomische Praxis für die Gesellschaft von grundlegender Bedeutung ist, kann sie nicht allein als konstitutiv begriffen werden: erst die Verknüpfungen der verschiedenen Praxisformen und ihrer sozialen Orte zu einer konkreten Gesellschaft bildet eine Produktionsweise; hierbei wird aber die organische Verbindung zu einer gesellschaftlichen Totalität durch die ökonomische Praxis gebildet. Das bedeutet in der Folge, dass z. B. die „Überbauten“ nicht lediglich in einer (historischen oder funktionalen) Ausdrucksbeziehung zur ökonomischen Basis stehen, sondern „die Beeinflussung des Überbaus durch die ökonomische Basis“ kann als „Eingrenzung der Überbaufunktionen durch die ökonomische Struktur“" interpretiert werden [Honneth 1977, S. 424], Gesellschaftsformationen werden folglich als „hierarchische Relationsgefüge“ [ebd.] analysiert. Eine Interpretation Althussers, nach der die „nicht-ökonomische Teilbereiche wohl in ihrem Einflussumfang, nicht aber in ihrer inneren Funktionsweise“ von der ökonomischen Struktur determiniert

44 Mit der Bestimmung der nicht-ökonomischen Ebenen als strukturell von der Ökonomie abhängige kann sich Althusser durchaus auf Marx berufen: „In allen Gesellschaftsformen ist es eine bestimmte Produktion, die allen übrigen, und deren Verhältnisse daher auch allen übrigen, Rang und Einfluß anweist.“ [MEW, Bd. 13, S. 637] 
sind [ebd.], muss aber als verkürzt zurückgewiesen werden, denn die verschiedenen Praxisformen bedingen in ihrer konkreten Verknüpfung zu einer Produktionsweise auch spezifische Interdependenzen, die von der ökonomischen Praxis in letzter Instanz determiniert werden.

Wenn die gesellschaftlichen Überbauten also nicht als reine Erscheinungen der Basis zu betrachten sind, sondern eine spezifische und autonome Form (also eine ebenso spezifische - wenn auch begrenzte - Unabhängigkeit von der ökonomischen Struktur) haben, ist nach Althusser eine „Theorie der spezifischen Wirksamkeit der Überbauten und andere[r] 'Umstände' zum großen Teil noch zu erarbeiten" [FM, S. 82]. Für Althusser hat Antonio Gramsci die Basis für diese theoretische Arbeit gelegt ${ }^{45}$, in dessen theoretischer Konzeption eine relative Autonomie der „Überbauten“ von der Basis/Struktur als Kritik des marxistischen Ökonomismus und Mechanismus - bereits angelegt ist. Wird also den verschiedenen gesellschaftlichen Ebene eine relative Autonomie zugesprochen, bedeutet das für Althusser auch, diese Autonomie auf die historische Entwicklung der gesellschaftlichen Ebenen hin auszuweiten:

la coexistence des différents niveaux structures, l'économique, le politique et l'idéologique, etc., donc de l'infrastructure économique, de la superstructure juridique et politique, des idéologies et des formations théoriques (philosophie, sciences) ne peut plus être pensée dans la coexistence du présent hégélien, de ce présent idéologique où coïncident la présence temporelle et la présence de l'essence à ses phénomènes. [LLC, Bd. 1, 123]

Die Konzeption einer kontinuierlichen und homogenen Zeit, der alle Strukturebenen in ihrer Entwicklung folgen, ist demnach zurückzuweisen ${ }^{46}$. Vielmehr

45 Weitaus kritischer ist die philosophische Gramsci-Rezeption Althussers. Gramsci bezeichnete den Marxismus, selbst von Labriola und Croce geprägt, als ,absoluten Historizismus“. Diese Position kann Althusser unmöglich akzeptieren, Gramsci's Definition des Marxismus als „Philosophie der Praxis“ [Gh, Bd. 6] sei radikal zurückzuweisen: „Zu der Annahme, der Marxismus sei eine neue Philosophie, eine Philosophie der Praxis, haben wir heute weniger Grund denn je. Im Zentrum der marxistischen Theorie ist eine Wissenschaft verborgen, eine absolut einzigartige Wissenschaft, aber eine Wissenschaft. Was der Marxismus an Neuem in die Philosophie einbringt, ist eine neue Praxis der Philosophie. Der Marxismus ist keine (neue) Philosophie der Praxis, sondern eine (neue) Praxis der Philosophie" [Althusser 1974, S. 44]. Zur Kritik der Gramsci-Rezeption durch Althusser siehe Spiegel 1983, zur Kritik der hier dargelegten Althusser'schen Konzeption von Marxismus und Philosophie s. u.

46 In diese Richtung tendiert beispielsweise Lukács, wenn er vollkommen zurecht den herrschenden Empirismus kritisiert, diesem aber eine Konzeption entgegenstellt, die alle gesellschaftlichen Phänomene auf die ökonomische Struktur - Arbeitsteilung, Warenfetischismus etc. - zurückbezieht und die historische Bedingtheit der verschiedenen Felder allein auf die geschichtliche Entwicklung der Ökonomie bezieht [Lukács 1970, S. 66 ff.]. 
müsse jeder Ebene eine eigene Zeit zugesprochen werden, die selbst nicht von einem Prinzip ableitbar ist, sondern

die relativ autonom, also selbst in ihrer Abhängigkeit von den „Zeiten“ anderer Ebenen relativ unabhängig ist. [...] Jede Produktionsweise hat ihre eigene Zeit und ihre eigene Geschichte, die auf besondere Weise von der Entwicklung der Produktivkräfte geprägt sind. Ebenso gibt es eine eigene Zeit und eine eigene Geschichte der Produktionsverhältnisse, die auch auf besondere Weise geprägt sind; ferner eine Zeit und Geschichte der politischen Suprastruktur, eine Zeit und Geschichte der Philosophie; der ästhetischen Produktion; der wissenschaftlichen Formationen usw. Jeder dieser „eigenen“ Geschichtsabläufe ist von einem besonderen Rhythmus geprägt und kann nur unter der Bedingung erkannt werden, dass man den Begriff der Besonderheit seiner geschichtlichen Zeitlichkeit und seiner Prägungen (kontinuierliche Entwicklung, Revolutionen, Einschnitte usw.) bestimmt hat. [DKL, Bd. 1, S. $130 \mathrm{f}$.]

Das bedeutet für eine marxistische Gesellschaftstheorie, dass sie sich von einem Geschichtsbegriff verabschieden muss, der die Geschichte einer Gesellschaftsformation auf die Existenz einer Produktionsweise reduziert und die gesellschaftliche Totalität durch die direkte Ableitung von dieser Produktionsweise gewinnt ${ }^{47}$. Folglich ist auch der lineare Prozess des Widerspruchs und die dialektische Synthese, wie sie bei Hegel angelegt ist, zu kritisieren.

47 Im zweiten Teil dieser Arbeit wird dargelegt, wie Poulantzas eine Konzeption erarbeitet, die u. a. durch die historisch gleichzeitige Existenz verschiedener Produktionsweisen gekennzeichnet ist, vgl. S. 95 ff. 


\title{
4. Widerspruch und Dialektik
}

\begin{abstract}
Jeder Widerspruch, jede wesentliche Gliederung der Struktur und das allgemeine Gliederungsverhältnis in der Struktur mit Dominante bilden ebenso viele Existenzbedingungen des komplexen Ganzen selbst.
\end{abstract}

Louis Althusser

Die Konzeption der gesellschaftlichen Totalität als strukturiertes Ganzes mit in letzter Instanz durch die Ökonomie determinierten Ebenen ist also auf eine Kritik des bisher im Marxismus vertretenen Modells der historischen Dialektik und des von Hegel übernommenen Begriffs des Widerspruchs zurückzuführen $^{48}$. Der Hegel'sche Widerspruch ist Althusser zufolge auf ein „Grundmodell“" zurückzuführen, in dem sich eine Einheit in zwei widersprüchliche Teile trennt. Demgegenüber postuliert Althusser (mit Mao) dass es in der Marx'schen Dialektik nicht einen einfachen und reinen Widerspruch gebe, sondern dass der Widerspruch dadurch gekennzeichnet sei, dass es

1. Haupt- und Nebenwidersprüche,

2. Haupt- und Nebenaspekte des Widerspruchs

3. und eine ungleichmäßige Entwicklung des Widerspruchs

gebe [FM, S. 138 f.]. Hierbei ist eine Reduzierung von Widersprüchen auf einen Hauptwiderspruch, von welchem alle anderen Widersprüche abgeleitet werden, für Althusser unzulässig, dieses würde eine Rückkehr zum Grundmodell des Hegel'schen Widerspruchs bedeuten. Ein komplexer Prozess wie die Entwicklung einer modernen Gesellschaft ist nicht reduzierbar auf einen (ursprünglichen) Widerspruch innerhalb des Prozesses, auf zwei diesem Widerspruch entspringenden Gegensätze, die allein die Entwicklung des Prozesses bestimmen. Im Gegenteil sei davon auszugehen, dass in einem komplexen Prozess eine ebenso komplexe Beziehung von Widersprüchen besteht [FM, S. 139]. Althusser versucht hierbei zu zeigen, dass auch im Marx'schen Werk eine solche Reduktion auf einen Grundwiderspruch nicht gegeben ist. Beispielsweise sei der Begriff der Produktion nicht universal zu definieren, sondern

48 Eine strukturalistisch motivierte, aber von Althusser unabhängig durchgeführte marxistische Analyse von Das Kapital kommt zu ähnlichen Ergebnissen wie die hier vorgestellten, vgl. Godelier 1970. 
könne immer nur vor dem Hintergrund einer spezifischen Gesellschaftsformation entwickelt werden. Althusser stützt sich hierbei wiederum auf die Einleitung zur Kritik der Politischen Ökonomie, in der Marx ausführt:

Wenn also von Produktion die Rede ist, ist immer die Rede von Produktion auf einer bestimmten gesellschaftlichen Entwicklungsstufe von der Produktion gesellschaftlicher Individuen [MEW, Bd. 13, S. 616]

Demzufolge sei es in der Entwicklung der Theorie unmöglich, hinter das gegebene strukturierte soziale Ganze zurückzugehen. Jede bei Marx entwickelte einfache Kategorie weise nicht auf etwas Ursprüngliches zurück, sondern stehe nur in Beziehung zu Elementen der gegebenen gesellschaftlichen Struktur. Dementsprechend sind für Althusser die einfachen Kategorien, die Marx analysiert, wie Ware, Geld etc. nicht in dem Sinne einfach, dass sie ein (soziales) System konstituierende Basiskategorien seien. Sie stellen vielmehr das Produkt eines komplexen (gesellschaftlichen) Prozesses dar, nur aufgrund dieser Tatsache können sie überhaupt in ihrer Einfachheit innerhalb eines komplexen Ganzen entwickelt werden [FM, S. 140 f.]. Die Begriffe/Kategorien sind somit von der Struktur präformiert, wie bereits Marx in der Einleitung zur Kritik der politischen Ökonomie anmerkt: „Er [der Begriff] kann nie existieren außer als abstrakte, einseitige Beziehung eines schon gegebenen konkreten, lebendigen Ganzen“" [MEW, Bd. 13, S. 632]. Erhalten so die einzelnen Begriffe erst vor dem Hintergrund der Gesamtstruktur ihren Sinn, müsse das Hegel'sche Grundmodell der Dialektik zurückgewiesen werden, da die Widersprüche nicht auf einer ursprünglichen Einheit selbst basieren, sondern vielmehr in den grundlegenden Strukturbeziehungen zu lokalisieren sind. Strukturen im Sinne von „Basis“ und „Überbau“ sind hierbei nicht als Hegel'sche (stillschweigende) Identitäten gedacht, sondern es erscheint das Verhältnis der „determinierenden Instanzen“ in den Strukturbeziehungen [FM, S. 78 f.].

Durch die Bestimmung der Ökonomie als ,,in letzter Instanz“ determinierend - und keineswegs einzige bestimmende - Instanz entsteht aber auch der Raum der relativen Autonomie der determinierten Strukturen und deren spezifische Wirksamkeit [FM, S. 79]. Der Marxismus ersetzt für Althusser demnach den „ideologischen Mythos einer ursprünglichen Philosophie des Ursprungs“ [FM, S. 143] mit der Anerkennung einer gegebenen komplexen Struktur, die „sowohl die Entwicklung des Gegenstandes als auch die Entwicklung der theoretischen Praxis, die seine Erkenntnis produziert" [ebd.]. Wird diese 
Ablehnung der ursprünglichen Einheit zugunsten einer strukturierten komplexen Einheit aufgegeben, bedeutet das aber, dass die zentralen

Kategorien, die das Thema der ursprünglichen einfachen Einheit prägen, d. h. die „Spaltung“ des Einheitlichen, die Entfremdung, die Abstraktion (im Hegel'schen Sinne), die die Gegensätze vereint, die Negation der Negation, die Aufhebung etc. [FM, S. 144]

in der entwickelten Marx'schen Theorie keine Bedeutung mehr haben und von Marx in seinem Spätwerk nicht mehr herangezogen werden würden [FM, S. 145, Fn. 40; z. T. relativierend in Arentz/Bischoff/Jaeggi 1973, S. 69]. Die Ablehnung der Annahme eines „Ursprünglichen“ und die Akzeptanz der ungleichen Entwicklung der Widersprüche bedeutet für die Konzeption von Hauptund Nebenwiderspruch nicht, dass die Nebenwidersprüche wiederum selbst vom Hauptwiderspruch ,abgeleitet“ sind, lediglich als Erscheinung des Hauptwiderspruchs auftreten und so wieder auf ein „ursprüngliches“ verweisen. Allerdings ist anzunehmen, dass die verschiedenen Widersprüche sich nicht unabhängig voneinander entwickeln, sondern von einem Widerspruch beherrscht werden:

Dass ein Widerspruch die anderen beherrscht, setzt voraus, dass die Komplexität, in der er erscheint, eine strukturierte Einheit ist und dass diese Struktur das zwischen den Widersprüchen aufgezeigte Verhältnis von Herrschaft-Unterwerfung einschließt. [...] In diesem komplexen Ganzen [...] findet man nicht einen Widerspruch, der die anderen beherrscht, wie auf der Tribüne eines Stadions der größte Zuschauer, der einen Kopf größer ist als die anderen. Die Herrschaft ist nicht eine einfache, unwichtige Tatsache, sie ist eine für die Komplexität selbst wesentliche Tatsache. Deshalb schließt die Komplexität die Herrschaft als für sich wesentlich ein: Sie ist in ihre Struktur eingeschrieben. [FM, S. 146 f.]

D. h. die Einheit einer gegebenen sozialen Struktur ist gerade auf die Existenz von verschiedenen Widersprüchen zurückzuführen, so

dass die Einheit, von der der Marxismus spricht, die Einheit der Komplexität selbst ist, dass die Organisations- und Artikulationsart der Komplexität eben gerade seine Einheit bildet. Das heißt behaupten, dass das komplexe Ganze die Einheit einer gegliederten Struktur mit einer Dominante besitzt. [FM, S. 148]

Die strukturierte Einheit eines komplexen Ganzen ist dabei nicht mit der Hegel'schen Totalität gleichzusetzen; weder ist die strukturierte Einheit auf die Entwicklung eines einzigen Wesens reduzierbar noch ist in der Hegel' schen Totalität ein Moment enthalten, in dem ein Widerspruch vorherrschend ist, vielmehr sind dort die „Sphären“, auf das innere Prinzip ihrer Entwicklung 
bezogen, gleichermaßen indifferent [FM, S. 148 f.]. Wenn Althusser die Konzeption zurückweist, nach der die Überbauten Ausdruck der Basis sind und statt dessen die relative Autonomie der verschiedenen gesellschaftlichen Strukturen behauptet, stellt sich aber die Problematik der Einheit der gesellschaftlichen Struktur. Wird in der Hegel'schen Totalität die Einheit der Gesellschaft durch die Dialektik garantiert ${ }^{50}$, muss in der komplexen Struktur die Einheit der Gesellschaft organisiert (besser noch: produziert) werden, ,der Überbau ist nicht das reine Phänomen der Struktur, er ist auch ihre Existenzbedingung“ $[\mathrm{FM}, \mathrm{S} .151]^{51}$.

Die von der determinierenden Instanz unterschiedene dominierende Instanz ist bezüglich dieser Organisation der Einheit von maßgebender Bedeutung. Die Existenz einer determinierenden Instanz ${ }^{52}$ bedeutet nämlich nicht, dass diese auch die Dominierende ist, sondern die Rolle einer dominierenden Instanz wird von der determinierenden Instanz einer bestimmten gesellschaftlichen Struktur zugewiesen (die determinierende Instanz kann aber auch die Rolle der dominierende Instanz innehaben). Die Gesellschaft als soziales strukturiertes Ganzes produziere hierbei nicht nur verschiedene Formen von

50 Ebenso gilt dies für die „umgestülpte“, „,materialistische“ Dialektik.

51 Problematisch ist die Trennung der verschiedenen gesellschaftlichen Ebenen, wenn sie bei Althusser in Konfrontation zu seiner politischen Überzeugung gerät: in der Kritik des Stalinismus behauptet er, „dass die sozialistische Basis im wesentlichen sich ohne Schaden entwickeln konnte während dieser Periode von Irrtümern, die den Überbau angingen“ [FM, S. 193]. Weniger erstaunt, dass hier unkommentiert die Basis-Überbau-Dichotomie wieder eingeführt wird (zum Basis-Überbau-Schema s. u.), sondern die Naivität des politischen Machtbegriffs, der vollkommen aus dem Überbau abgeleitet wird, so dass Althusser zwar von Repression, nicht aber von Ausbeutung spricht [Descombes 1981, S. 153].

52 An diesem Punkt ist eine Unterscheidung zwischen Strukturalismus und Marxismus Althusser'scher Prägung erkennbar: Grundsätzlich ist der Strukturalismus durch die Anordnung der Elemente isomorph, da die Elemente allein durch ihre Relationalität innerhalb eines Systems eine bestimmte Funktion, einen Sinn erhalten (dieser also konstruiert und keineswegs gegeben ist), es ist kein Element im Verhältnis zu den anderen ,privilegiert“. Die Anordnung der Elemente Althusser ,verstößt“ insoweit gegen diese strukturalistische Konzeption, da sie nicht isomorph ist, sondern alle gesellschaftlichen Ebenen von einer Ebene, wenn auch nur in letzter Instanz, abhängig sind. Allerdings gehen auch andere Strukturalisten (z. B. Lévi-Strauss) von der Annahme aus, das der Ökonomie eine besondere Rolle zukommt.

Hierbei ist Anzumerken, dass die Ökonomie in Lévi-Strauss' Arbeiten auf Tauschhandlungen reduziert wird, die Produktion aber nicht berücksichtigt werden kann. Dies führt Terray darauf zurück, dass Lévi-Strauss die Gesellschaft mit der Repräsentationsebene gleichsetzt und somit nicht die Praxis untersuchen könne. Dies führe auch dazu, dass der Bereich der Machtphänomene bei Lévi-Strauss nicht berücksichtigt werden. Aber genau diese beiden „blinden Flecken“ würden durch die Integration der marxistischen Theorie (in der Althusser'schen Lesart) innerhalb des Strukturalismus beseitigt. [Dosse 1999, Bd. 2, S. 209] 
Widersprüchen, sondern ihre Existenz als Gesellschaftsformation ist ebenso auf die Existenz von Widersprüchen zurückzuführen:

Si tout contradiction l'est d'un tout complexe structuré à dominante, on ne peut envisager le tout complexe hors ses contradictions, hors leur rapport d'inégalité fondamental. Autrement dit, chaque contradiction, chaque articulation essentielle de la structure à dominante, constituent autant de conditions d'existence du tout complexe lui-même. [PM, S. 210]

Die Nebenwidersprüche sind dabei nicht „Phänomene“ des Hauptwiderspruchs, sondern ein Hauptwiderspruch kann nicht ohne Nebenwiderspruch existieren, letztere sind ebenso Existenzbedingung für den Hauptwiderspruch wie dieser für den Nebenwiderspruch. So seien in der Marx'schen Theorie die Produktionsverhältnisse nicht das reine Phänomen der Produktivkräfte, sondern ebenso deren Existenzbedingung, der Überbau nicht nur Ausdruck der Basis, sondern ebenso deren Voraussetzung - Produktivkräfte und Produktionsverhältnisse sind in ihrer begrifflichen Anordnung also gegenseitig konstituierend [FM, S. 151 f.]. Dieser offensichtliche Zirkel hebe aber nicht die Struktur mit Dominante auf, beseitige nicht die Herrschaftsstruktur, sondern

il est, à l'intérieur même de la réalité des conditions d'existence de chaque contradiction, la manifestation de cette structure à dominante qui fait l'unité du tout. [PM, S. 211 f.]

Diese Reflexion, die im Gegensatz zur Idee eines „einfachen und reinen Widerspruchs“ als einfacher Determinante, von der alle anderen Widersprüche aus entwickelt werden, stehe, bezeichnet Althusser mit dem (von Freud entliehenen) Begriff der Überdetermination. Mit „Überdetermination“ versucht Althusser auf dem Gebiet der Gesellschaftstheorie den Umstand zu fassen, den schon Gramsci konstatierte: dass zum einen zwischen Basis und Überbau eine Wechselwirkung besteht, zum zweiten, dass eine (revolutionäre) Veränderung in der Produktionsweise nicht zwangsläufig eine ebensolche Veränderung in den Überbauten nach sich zieht, sondern drittens im Gegenteil (vor allem auf dem Gebiet der Ideologie) eine „Reaktivierung der alten Elemente“ (Gramsci), also eine wiederkehrende Virulenz überwunden geglaubter Ideologien hervorrufen kann und viertens dass bei gleicher Produktionsweise (national) verschiedene Formen der Überbauten existieren [FM, S. 84 f.].

La surdétermination désigne dans la contradiction même, de ses conditions d'existence, c'est-à-dire de sa situation dans la structure a dominante du tout complexe. Cette „situation“ n'est pas univoque. Elle n'est ni sa seule situation ,de droit““ [...] ni sa seule situation , ,de fait“ $[\ldots]$ 
mais le rapport de cette situation de fait a cette situation de droit, c'est-àdire le rapport même qui fait de cette situation de fait une „variation“ de la structure, a dominante, ,invariant" de la totalité. [...] Tout au contraire cessant d'entre univoque, donc déterminée une fois pour toutes, au gardeà-vous dans son rôle et son essence, elle se révèle déterminée par la complexité structurée qui lui assigne don rôle, comme [...] complexement-structuralement-inégalitairement-déterminée. [PM, 215]

Überdetermination ist für Althusser das Kennzeichen des marxistischen Widerspruchs und bedeutet für ihn, dass es einen „einfachen“ Widerspruch nicht gibt, sondern dass alle Elemente in ein Netz von Haupt- und Nebenwidersprüchen eingegliedert sind. Damit ist Althusser gezwungen, auch den Hegel'schen Begriff der Totalität zu verwerfen, welcher eben auf einem reinen Widerspruch, einer einfachen „Entgegen-Setzung“ [Thieme 1982, S. 29] beruht.

Das Konzept der Überdetermination versucht Althusser an der Frage zu verdeutlichen, wann innerhalb der Gesellschaftsformation ein revolutionärer Bruch möglich ist, konkreter: warum in Russland mit der bekannten ökonomischen wie politischen Rückständigkeit 1917 eine Revolution stattfand und warum diese in Deutschland mit seiner stark entwickelten Arbeiterbewegung ausblieb. Zwei klassische „Theorien“ dieses historischen Verlaufs müssen dabei von vornherein ausgeschlossen werden:

1. Die ökonomistische Theorie, nach welcher die ökonomische Rückständigkeit in Russland Auslöser für die Revolution war und Russland damit auf den Weg der „,nachholenden Modernisierung“ gebracht wurde.

2. Die politizistische Theorie, nach der die Arbeiterbewegung „reif“ für die Revolution gewesen sei, durch die (,verräterische“) reformistische Politik der Sozialdemokratie die Revolution in Deutschland aber verhindert worden sei.

Die in diesen Theorien enthaltenen einfachen Widersprüche weisen wiederum auf einen „Hauptwiderspruch“ zurück, von dem aber keinesfalls behauptet werden könne, dass dieser alleiniger Auslöser einer Revolution sein könne, nach Althusser beweise vielmehr die ganze marxistische Erfahrung,

dass, wenn der Widerspruch im allgemeinen [...] ausreicht, um eine Situation zu definieren, in der die Revolution ,auf der Tagesordnung“ steht, er jedoch nicht durch seine direkte, einfache Kraft eine „revolutionäre Situation“ und mit noch weniger Wahrscheinlichkeit eine Situation des revolutionären Bruchs und den Triumph der Revolution auslösen kann. Damit dieser Widerspruch „aktiv“ werden kann im starken Sinn, Prinzip des Bruchs, bedarf es einer derartigen Anhäufung 
von „Umständen“ und „Strömungen“, dass diese, welchen Ursprungs und welcher Richtung sie auch sein mögen (und viele von ihnen sind notwendigerweise, aufgrund ihres Ursprungs und ihrer Richtung, und paradoxerweise der Revolution fremd, ja sogar ,absolut entgegengesetzt“), zu einer Einheit des Bruchs „zusammenfließen“ [,,ils 'fusionnent' en une unité de rupture"] [FM, S. 63].

Die russische Revolution sei somit der Kulminationspunkt unzähliger angehäufter, gegenseitig überlagernder und „verschmolzener“ Widersprüche einer Gesellschaft; diese Situation stelle sich dermaßen überdeterminiert dar, dass die Widersprüche nicht mehr gelöst werden können und die Einheit des gesellschaftlichen Ganzen (partiell) zerfalle.

Wenn Althusser den „einfachen Widerspruch“ Hegels zurückweist und durch die Überdetermination ersetzt, ist er damit natürlich auch gezwungen, in Abgrenzung zu Hegels Dialektik das Spezifikum der Marx'schen Dialektik herauszuarbeiten. Entscheidend ist in diesem Zusammenhang, wie Marx Ausspruch zu bewerten sei, dass er die Hegel'sche Dialektik „umgestülpt“ habe [MEW, Bd. 23, S. 27]. Nach Althusser betrachtet eine auf der Hegel'schen Dialektik bezogene Gesellschaftstheorie

jede Gesellschaft [...] als durch zwei Gesellschaften konstituiert [...]: durch die Gesellschaft der Bedürfnisse oder die bürgerliche Gesellschaft, und die politische Gesellschaft oder der Staat samt allem, was sich im Staat verkörpert: Religion, Philosophie, kurz das Selbstbewusstsein einer Zeit. [...] Für Hegel ist das materielle Leben [...] nur List der Vernunft, es wird unter dem Anschein der Autonomie durch ein ihm fremdes Gesetz bewegt. [FM, S. 74]

Die „List der Vernunft“ bestehe also darin, dass das Bewusstsein und das materielle Dasein der Gesellschaft zur Deckung gebracht werden, also das Bewusstsein das Wesen des Materiellen darstellt. Eine Feuerbach'sche „Umstülpung“, verstanden als bloße Umkehrung dieses Schemas (und nun als materialistische Dialektik bezeichnet) ließe sich dann darauf reduzieren, dass die Hegel'sche Entsprechung des „Politisch-Ideologischen“ durch die Ökonomie sich dahin wandelt, dass bei Marx das Ökonomische das ganze Wesen des Politisch-Ideologischen ausmacht. Das Politische und das Ideologische wären dann nur die reine Erscheinung des Ökonomischen, das deren „Wahrheit“ wäre [FM, S. 75]. Diese Umstülpung ist für Althusser das Charakteristikum des Ökonomismus, sie reduziert im Endeffekt die Dialektik der Geschichte auf eine Dialektik aufeinander folgender Produktionsweisen [ebd.]. Allerdings erscheint 
nach Althusser eine solche ökonomische Dialektik in der Geschichte nie „,im reinen Zustand“, so dass man

in der Geschichte nie sieht, dass diese Instanzen, die Überbauten etc., sich respektvoll zurückziehen, wenn sie ihr Werk vollbracht haben oder sich auflösen wie ihre reine Erscheinung, um auf dem königlichen Weg der Dialektik ihre Majestät die Ökonomie voranschreiten zu lassen, weil ihre Zeit gekommen wäre. Die einsame Stunde der „letzten Instanz“ schlägt nie, weder im ersten noch im letzten Augenblick. [FM, S. 81]

Was der Marxismus verweigert, das ist der philosophische (ideologische) Anspruch, erschöpfend mit einem „radikalen Ursprung“ übereinzustimmen, welche Form auch immer er haben möge (die Tabula rasa, der Nullpunkt eines Prozesses; der Naturzustand, der Begriff des Beginns [...]); daher verwirft er den Hegel'schen philosophischen Anspruch, der sich diese ursprüngliche einfache (in jedem Augenblick des Prozesses wieder produzierte) Einheit gibt, die dann durch ihre Selbstentwicklung die ganze Komplexität des Prozesses produzieren wird, aber ohne sich jemals selbst darin zu verlieren, ohne darin die Einfachheit oder ihre Einheit zu verlieren, - da die Pluralität und die Komplexität immer nur ihr eigenes „Phänomen“ sein werden, damit beauftragt, ihr eigenes Wesen zu manifestieren. [FM, 142 f.]

Althusser weist folglich die Hegel'sche wie die Feuerbach'sche („materialistische") Konzeption zurück, er geht vielmehr davon aus, dass die Struktur der Marx'schen Dialektik von diesen beiden vollkommen verschieden ist [FM, S. 56]. Für Althusser trennt sich der Marxismus strikt von jeder Philosophie des Ursprungs, des metaphysischen „Am Anfang war“, statt dessen untersucht der Marxismus das Resultat eines Prozesses [DKL, Bd. 1, S. 87]. Folglich bestehen für Althusser zwischen den gesellschaftlichen Strukturen notwendige Verbindungen, die aber nicht auf ein Prinzip (Produktion, Warentausch o. ä.) reduziert werden können; die Relationen der gesellschaftlichen Strukturen werden aber durch eine spezifische Struktur determiniert, so

dass sich der Prozess der ökonomischen Produktion ausschließlich in der Ökonomie abspielt, auch wenn er gerade in den spezifischen Bestimmungen seiner Struktur notwendige Beziehungen zur Natur und anderen Strukturen (juristisch-politischer und ideologischer Art) impliziert, die zusammen die zu einer bestimmten Produktionsweise gehörende Gesamtstruktur einer Gesellschaft bilden. [DKL, Bd. 1, S. 54] 


\section{Geschichte ohne Subjekt: der epistemologische Einschnitt bei Marx}

\begin{abstract}
Die Menschen machen ihre Geschichte, aber sie machen sie nicht aus freien Stücken, nicht unter selbstgewählten, sondern unmittelbar vorgefundenen, gegebenen und überlieferten Umständen. Die Tradition aller toten Geschlechter lastet wie ein Alp auf den Gehirnen der Lebenden.
\end{abstract}

Karl Marx

a) Die bisher dargelegten Ausführungen Althussers, also die Ablehnung einer Philosophie des Ursprungs bei gleichzeitiger Betonung der Rolle objektiver Strukturen innerhalb der Gesellschaftsformation zwingen Althusser dazu, die Rolle des „Subjekts“ innerhalb einer marxistischen Geschichtskonzeption zu überprüfen. Wird die Annahme vertreten, dass einem/dem Subjekt als bewusst handelndes gesellschaftliches Individuum eine privilegierte Rolle innerhalb einer theoretischen Konzeption der Geschichte zukommt - eine Geschichtskonzeption, „die insgeheim, aber völlig, auf die synthetische Aktivität des Subjekts bezogen“" ist [Foucault 1997a, S. 26] - wird diese in der Regel mit einer der drei folgenden Positionen begründet [vgl. Thieme 1982, S. 46 f.]:

1. Das Subjekt ist autonom handelndes Individuum, das die „Geschichte macht".

2. Geschichte wird nicht von Individuen, sondern von Großsubjekten (Volk, Klasse, Rasse) gemacht.

3. Subjekt/Großsubjekte machen die Geschichte, aber nicht autonom, sondern werden auf ein bestimmtes Ziel hin getrieben von einem höheren Willen (Weltgeist/Gott/Stalin).

Wenn versucht wird, eine rationalistische, nicht-philosophische Geschichtskonzeption $\mathrm{zu}$ entwerfen, sind diese Positionen aus mehreren Gründen sehr problematisch [vgl. Thieme 1982, S. 47]:

1. Geschichte wird aus der Perspektive der Sieger betrachtet, die Individuen/gesellschaftlichen Gruppen, die der Durchsetzungsgeschichte des Willens zum Opfer fallen oder die nicht direkt mit dieser Durchsetzungsgeschichte in Kontakt stehen, werden rückblickend zu Fußnoten der Geschichte degradiert. 
2. Kategorien wie „Subjekt“, „Klasse“ etc. werden als ursprüngliche Identitäten eingeführt, obwohl gerade sie Resultate des Geschichtsprozesses sind.

3. Geschichte wird immer teleologisch, als Ausdruck eines subjektiven oder „höheren“ Willens betrachtet.

Althusser formuliert konsequent (vor allem gegen Lukács gerichtet), dass die Geschichte ein Prozess ohne Subjekt sei [FM, 182]. Dieser dem Strukturalismus eigentümliche „Tod des Subjekts“ [vgl. Dosse 1999, Bd. 1, S. 88 ff.] bedeutet keinesfalls, dass das menschliche Handeln aus der Geschichte entfernt wird oder Geschichte schlechthin etwas außer-menschliches wäre [Thieme 1982, S. 47]. Der Kern dieses Ansatzes ist die Annahme, dass die objektiven Strukturen der Gesellschaft wie Ökonomie und Staat natürlich von Menschen geschaffen wurden; diese Strukturen entfalten aber gegenüber dem Individuum eine Objektivität und Gesetzlichkeit, innerhalb derer das konkrete Individuum nicht mehr als Subjekt, sondern als Agent operiert, nicht handelt, sondern von den Gesetzlichkeiten der objektiven Strukturen ,gehandelt wird“ (Bourdieu):

Dass die menschlichen, d. h. sozialen Individuen in der Geschichte aktiv sind - als Agenten der verschiedenen gesellschaftlichen Praxen des historischen Prozesses von Produktion und Reproduktion - das ist Tatsache. Aber betrachtet als Agenten sind die menschlichen Individuen nicht „freie“ und „konstituierende“ Subjekte im philosophischen Sinn dieser Ausdrücke. Sie agieren in und unter der Determinierung der historischen Existenzformen der gesellschaftlichen Verhältnisse von Produktion und Reproduktion (Arbeitsprozess, Teilung und Organisation der Arbeit, Produktions- und Reproduktionsprozess, Klassenkampf etc.) [Althusser 1973d, S. 90]

Die theoretische Einordnung des Subjekts als Agent innerhalb historischer, strukturierter Existenzformen veranlasst Althusser zu dem Schluss, dass innerhalb der Theorie für das Subjekt als bewusst handelndes intentiöses Individuum kein Platz mehr ist. Vielmehr seien die Strukturen und ihre spezifische Wirkungsweise zu untersuchen, Althusser bezeichnet diesen Standpunkt als theoretischen Antihumanismus.

Die Negierung eines bewussten Subjekts, dass die Geschichte „macht“ und die Behauptung, dass dieser Ansatz innerhalb des Werkes von Marx in einem theoretischen „Terrainwechsel“ zum Vorschein komme stellte nicht nur für die Theoretiker der PCF einen der größten Skandale Althussers Theorie- 
bildung dar ${ }^{53}$. Exemplarisch hierfür steht die von Lucien Sève vorgebrachte Kritik $^{54}$, welche vor allem um den „Begriff des Menschen“ kreist: Sève stimmt Althusser insoweit $\mathrm{zu}$, wie dieser sich gegen einen „spekulativen“/ philosophischen Menschenbegriff wendet [Sève 1972, S. 76], indes behauptet er, dass es eine Wissenschaft vom „wirklichen Menschen“/,des Menschen an sich“, also eine Anthropologie im strengen Sinn, gebe [Sève 1972, S. 79] und ein spezifischer anthropologischer Begriff in Marx' Werk existiere. Die von Sève vorgebrachte Kritik an dem postulierten theoretischen Anti-Humanismus ist insoweit nicht von der Hand zu weisen, als Marx auch im seinem Spätwerk einen bestimmten Begriff des Menschen benutzt. Sèves Argumentation, dass eine symptomatische Lesart ${ }^{55}$ eine ,theoretische Kopplung zwischen den gesellschaftlichen Verhältnissen und den wirklichen Menschen ausschließt" und damit der Klassenkampf und letztlich der Marxismus schlechthin unbegreiflich seien [Sève 1972, S. 79], geht aber an der von Althusser vertretenen These vorbei. Der von Althusser behauptete „Terrainwechsel“ Marx' beinhaltet explizit, dass der Gegenstand des Diskurses im Kapital verschieden von dem der Frühwerke ist und der von Marx benutzte „Begriff des Menschen“ im Spätwerk sich sehr genau von dem des Frühwerks unterscheidet; Marx selbst benutzt im Kapital den Begriff der Charaktermaske, ein anthropologischer Begriff (,der Mensch“ im anti-historischen Sinn) ist nicht Gegenstand seines Diskurses $^{56}$, sondern es werden ausschließlich die durch die spezifische Form

53 Vgl. die Kritik von John Lewis [Arentz/Bischoff/Jaeggi 1973, S. 3 ff.]. Allerdings ist nicht nur die parteimarxistische Theorie Gegenstand der Kritik des marxistischen Strukturalismus, sondern alle Formen eines phänomenologischen, existenzialistischen, anthropologischen oder praxisphilosophischen Marxismus [Honneth 1977, S. 408], die mehr oder weniger unter „Historizismus“ subsumiert werden [ebd., S. 412 f.].

54 Diese Kritik stellte wohl den Common Sense der PCF dar, ähnlich bezieht sich Garaudy auf die ,schaffende Rolle“ des Subjekts [Garaudy 1969, S. 172 ff.]. Sève ist aber auch ein geeignetes Beispiel, zu welchen intellektuellen Untiefen dieses subjektzentrierte Denken (wohl idealtypisch für den Marxismus-Leninismus, für den freilich das Subjekt - und Objekt! - nicht das Individuum, sondern die Arbeiterklasse darstellt) führen kann: in einer Replik auf einen Artikel von Baudelot und Establet, die den kapitalistischen Charakter der Schule behaupteten (siehe dazu die Ausführungen Althussers unten), versuchte Sève diese Ausführung mit dem Argument zu entkräften, dass doch viele revolutionäre Arbeiter mit Dankbarkeit an ihre Volksschullehrer zurückdenken würden [Kammler/Plumpe/Schöttler 1978, S. 15].

55 Zur Problematik ,symptomatische Lesart“ - ,authentische Lesart“ (Sève nimmt offenbar an, das es letztere, zumindest in der eingeschränkten Form einer ,authentischeren Lesart“, gibt [Sève 1972, S. 80]) siehe dazu S. 6 ff.

56 Es wird zwar von Terray behauptet, dass eine auf dem Marxismus (in der Althusser'schen Lesart) Anthropologie möglich sei, da er aber gleichzeitig in seiner Lektüre Meillassoux' jeden evolutionistischen Ansatz bestreitet, ist seine Konzeption einer marxistischen Anthropologie nichts anderes eine (marxistische) Soziologie einer linearen und segmen- 
der gesellschaftlichen Produktionsweise determinierten Charaktermasken (also die verschiedenen Formen des Warenbesitzers) polit-ökonomisch, nicht anthropologisch-subjektivistisch untersucht. ${ }^{57}$

Der „Terrainwechsel“ in der Marx'schen Theoriebildung bedeutet also, dass die gesellschaftliche Produktionsstruktur den Individuen ihr Verhalten in dieser Struktur in Abhängigkeit von ihrer Position innerhalb der Struktur aufzwingt $t^{58}$, die Geschichte somit nicht als Manifestation des Willens verschiedener Subjekte, sondern eher als Geschichte von Zwangsverhältnissen zu interpretieren ist, innerhalb derer die Individuen operieren: „Die Menschen machen ihre eigene Geschichte, aber sie machen sie nicht aus freien Stücken“ [MEW, Bd. 8, S. 115]. Wenn Sève weiterhin argumentiert - um die von Althusser vollzogene Gleichsetzung von theoretischem Antihumanismus des Kapitals mit dem historischen Materialismus anzugreifen - dass Marx die Behauptung aufstelle, die Expropriation der Expropiateure sei eine Notwendigkeit, die sich auf die (verelendeten) Klassen stützt [Sève 1972, S. 79; vgl. MEW, Bd. 23, S. 790], wendet sich dieses Zitat gerade gegen einen von Sève vertretene Interpretation. „Die kapitalistische Produktion erzeugt mit der Notwendigkeit eines Naturprozesses ihre eigene Negation“" [MEW, Bd. 23, S. 791]. Die bei Marx prozessierende Struktur „kapitalistische Gesellschaft“ erzeugt in dessen Denken erst die Möglichkeit und den Effekt des eigenen Untergangs (vgl. insbesondere die Theorie über den tendenziellen Fall der Profitrate [MEW, Bd. 25, S. 221 ff.]), die verelendeten Klassen sind lediglich Agenten des Prozesses - im Unterschied zum Marx'schen Frühwerk nicht Klassen, die bewusst ihre Entfremdung aufheben). Althusser geht es aber mit der Formulierung des „theoretischen Antihumanismus“ nicht darum, die gesellschaftlichen Wider-

tären Gesellschaft [Terray 1974].

57 Analog lässt sich argumentieren, dass der Gebrauchswert einer Ware zwar (wie der Tauschwert) eine Eigenschaft derselben ist (und naiv-anthropologisch betrachtet eigentlich Zweck der Produktion ist, oder, idealistisch, sein sollte), in dem Begriff der Ware aber von vollkommen untergeordneter Bedeutung ist: Obwohl der Begriff der Ware ohne ihre Bestimmung als Gebrauchswert undenkbar wäre, wird das Produkt des Arbeitsprozesses erst durch die Eigenschaft als „Träger“ des Werts zur Ware. Gebrauchswert und Tauschwert sind somit Teile verschiedener theoretischer Felder [vgl. Althusser 1983, S. 139].

58 So Marx im Kapital: „Die Gestalten von Kapitalist und Grundeigentümer zeichne ich keineswegs in rosigem Licht. Aber es handelt sich hier um die Personen nur, soweit sie die Personifikation ökonomischer Kategorien sind, Träger von bestimmten Klassenverhältnissen und Interessen. Weniger als jeder andere kann mein Standpunkt, der die Entwicklung der ökonomischen Gesellschaftsformation als einen naturgeschichtlichen Prozess auffasst, den einzelnen verantwortlich machen für Verhältnisse, deren Geschöpf er sozial bleibt, so sehr er sich auch subjektiv über sie erheben mag“" [MEW, Bd. 23, S. 16]. 
sprüche/Klassenkämpfe als Motor der Geschichte zu leugnen, ebenso wenig kritisiert er den Humanismus als solchen oder bestreitet gar, dass Marx Humanist gewesen sei. Allerdings bestreitet er den Humanismus als theoretische wissenschaftliche Kategorie und verweist einen solchen Ansatz in den Bereich der Ideologie ${ }^{59}$, gleichzeitig ist darin aber auch eine grundsätzliche Negation eines überzeitlichen, nicht-gesellschaftsbezogenen Begriff des Menschen (theoretische Anthropologie) enthalten ${ }^{60}$.

Der entscheidende Punkt in diesem „Humanismusstreit“ scheint zu sein, dass die Debatte auf verschiedenen, inkompatiblen Ebenen geführt wurde: ein empirisch existentes Objekt (,Mensch“/,Subjekt“) wird gegen ein theoretisch existentes Objekt („Geschichte“) [Karsz 1976, S. 284] in Stellung gebracht, zugespitzt formuliert wird ein politischer, ideologisch-philosophischer Diskurs einem wissenschaftlichen Diskurs gegenübergestellt. Der (marxistische) Humanismus, der davon ausgeht, dass der Mensch intentiös die Geschichte „macht“", blendet aus, dass das Subjekt nicht bloß das Objekt „Geschichte“ verändert, sondern als Individuum in ein Ensemble ökonomischer, politischer und ideologischer Rahmenbedingungen „eingesetzt“ wird. Für die Theorie/Gesellschaftswissenschaft bedeutet das, den „Menschen“ nicht als übergeordneten, unhintergehbaren Begriff zu akzeptieren, sondern das Individuum als „lokale Inkarnation“ [Karsz 1976, S. 285] innerhalb eines strukturierten Systems zu betrachten ${ }^{61}$. Eine solche Konzeption bedeutet allerdings einen recht dras-

59 Für einige Autoren scheinen die Folgen der Alhusser'schen Analysen für die politische Praxis verheerend, denn mit dem Verzicht eines ,humanistischen“ Marxismus seien Erscheinungen wie der Stalinismus aus marxistischer Sicht nicht kritisierbar, andererseits sei die politisch progressive Rolle des Bürgertums nicht mehr zu begründen [Schoch 1980, S. 234]. Es kann hier nur noch einmal darauf hingewiesen werden, dass diese Vorwürfe immer auf einer politisch-ideologisch-philosophischen Position beruhen, die Althusser gerade aus dem wissenschaftlichen marxistischen Diskurs eliminieren will - nicht um eine Kritik des Stalinismus nicht zuzulassen, sondern um klarzustellen, dass „Menschenrechte“, „Emanzipation“ usw. nicht theoretisch begründet werden können, sondern immer auf einer politisch-philosophischen Position beruhen. So bezeichnet Althusser sich selbst auch nach der Artikulation des „theoretischen Antihumanismus“ weiterhin als Kommunist, die politisch-ideologischen und wissenschaftlich-politischen Implikationen in Kauf nehmend.

60 Genau einen solche ideologische Anthropologie hat Althusser im Auge, wenn er gegen die politische Ökonomie vorbringt, dass ihre theoretische Struktur darin bestehe, ,dass ein homogener Raum gegebener Phänomene in eine unmittelbare und direkte Beziehung gebracht wird zu einer ideologischen Anthropologie, die den ökonomischen Charakter der Phänomene ihres Raumes im Menschen als dem Subjekt der Bedürfnisse (d. h. in der Gegebenheit des homo oeconomicus) begründet" [DKL, Bd. 1, S. 217].

61 Diese Konzeption stützt Althusser auch auf eine Lektüre des Freud'schen Werkes: Freud enthülle, „dass das reale Subjekt, das Individuum in seinem singulärem Wesen nicht die Gestalt eines Ego hat, das auf das 'Ich' (moi), das Bewusstsein oder die 'Existenz' - sei es die Existenz des Für-Sich, der eigenen Leiblichkeit oder des 'Sich-Verhaltens' - zentriert 
tischen Einschnitt für die Sozialwissenschaften ${ }^{62}$, denn dann wird es notwendig, innerhalb der Sozialwissenschaften „,den Begriff vom Menschen radikal zu eliminieren“ [F. Châtelet, vgl. Dosse 1999, Bd. 2, S. 119]. Die Parallele zu Theoretikern wie Foucault ist hier offensichtlich, ,der sozialwissenschaftliche Gegenstandsbereich [...] soll nicht mehr auf die konstituierenden Leistungen eines individuellen, transzendentalen oder Gattungssubjekts zurückgeführt“ [Honneth 1977, S. 407] werden.

Althusser begnügt sich nicht mit einer solchen rein negativen Abgrenzung, also der Ablehnung eines Subjekts als treibende Kraft der Geschichte, sondern versucht innerhalb des „Prozesses ohne Subjekt“ - der Geschichte die Kategorien $\mathrm{zu}$ bestimmen, die für eine marxistische Theoriebildung bezüglich dieses Prozesses von grundlegender Bedeutung sind [vgl. Thieme 1982, S. 48 f.]:

1. Gesellschaftsformation

Die „Subjekte“ der Geschichte sind gegebene menschliche Gesellschaften. Sie stellen sich als Gesamtheiten dar, deren Einheit durch einen bestimmten spezifischen Typ von Komplexität konstituiert wird und dabei Instanzen einsetzt, die man, nach Engels, sehr schematisch auf drei reduzieren kann: die Ökonomie, die Politik und die Ideologie. [FM, S. 182]

2. Produktionsverhältnisse

Die wahren (einen Prozess konstituierenden) „Subjekte“ sind daher weder die Stelleninhaber noch die Funktionäre, also - allem Anschein und jeder „Evidenz" des „Gegebenen“ im Sinne einer naiven Anthropologie zum Trotz - eben nicht die „konkreten Individuen“ und die ,wirklichen Menschen“: die wahren „Subjekte“ sind die Bestimmung und die Verteilung dieser Stellen und Funktionen. Die bestimmenden und verteilenden Faktoren, kurz, die Produktionsverhältnisse (und die politischen und ideologischen Verhältnis einer Gesellschaft) sind die wahren „Subjekte“. Aber da es sich hierbei um „Verhältnisse“" handelt, können sie in der Kategorie des Subjekts nicht gedacht werden. [DKL, Bd. 2, S. 242]

wäre; er entdeckt, dass das menschliche Subjekt dezentriert ist, konstituiert durch eine Struktur, die ebenso wenig ein Zentrum besitzt“ [Althusser/T ort 1976, S. 35].

62 So hat Bourdieu mit seinem ,genetischen Strukturalismus“ einen solchen Einschnitt in der Soziologie zumindest vertieft. Ohne Bourdieu dem strukturalistischen Marxismus zuzurechnen sollte aber an dieser Stelle darauf hingewiesen werden, dass Bourdieu bei der Theoriebildung trotz seines Abgrenzungsgebarens offenbar durchaus durch Althussers Arbeiten beeinflusst wurde. So lassen sich in Bourdieus Hauptwerk Die feinen Unterschiede [Bourdieu 1999] zentrale Althusser'sche Topoi wie „Dominierung“ [ebd., 396], „Determination“ [ebd., S. 354], „Überdetermination“ [ebd., S. 372] sowie die Annahme der relativen Autonomie der gesellschaftlichen Strukturen [ebd., S. 369; 405] finden. 
3. Klassenkampf

Denn nicht die Theoretiker, ob Wissenschaftler oder Philosophen, ja nicht einmal die „Menschen“ machen die Geschichte, sondern die „Massen“, d. h. die im Klassenkampf verbundenen Klassen. [Althusser 1974, S. 44]

Ziel der Argumentation Althussers ist zweifellos, die Kategorie des „Subjekts“ aus dem wissenschaftlichen Diskurs zu entfernen und durch die aufgeführten Begriffe zu ersetzen [Thieme 1982, S. 49], bzw. dem Leser nahe zu legen, dass diese „Auswechslung“ bereits im Marx'schen Diskurs vollzogen wurde (s. u.).

b) Die oben angeführten Kategorien Gesellschaftsformation, Produktionsverhältnisse und Klassenkampf sind allerdings nicht in dem Sinne als „Ersatzsubjekte“ anzusehen, die nun in der Theorie die Stelle eines transzendentalen oder schöpferischen Subjekts einnehmen - insbesondere nimmt der Begriff der Klasse nicht diese Position ein: die gesellschaftliche Klassen sind nicht außerhalb ihrer Beziehungen zu den ökonomisch-politisch-ideologischen Verhältnissen zu begreifen, erst durch diese Beziehungen (und der dadurch ,geregelten“ Beziehungen zu anderen Klassen) ist der Begriff überhaupt konstruierbar, der vor allem durch seine Relationalität gekennzeichnet ist ${ }^{63}$. Konstituierend für eine marxistische Geschichtstheorie ist nicht die Existenz dieser oder jener Klasse, sondern die Ausdifferenzierung einer Gesellschaft in durch den Klassenkampf in Beziehung stehender Klassen. Noch mehr: der Klassenkampf ist selbst ein zielloser Konstitutionsprozess, so dass die Klassen nicht aus den Produktionsverhältnis ,,abgeleitet“ sind oder die Ökonomie die Klassen produziert [Böke 1994, S. 69], sondern dieser Konstitutionsprozess „Klassenkampf" bildet die Klassenverhältnisse als auch die ökonomische Struktur in einer Bewegung ${ }^{64}$. Die Geschichte (genauer: die jeweiligen gesellschaftlichen

63 So schreibt auch Marx: „Die Gesellschaft besteht nicht aus Individuen, sondern drückt die Summe der Beziehungen, Verhältnisse aus, worin diese Individuen zu einander stehn“ [M arx/Engels 1975 ff., II 1.1, S. 188].

64 Das heißt natürlich auch, dass Marx in seiner Kritik der politischen Ökonomie nicht das (personifizierte) Kapital - den Bourgeois - in das Zentrum seiner Kritik rückt, sondern den kapitalistischen gesellschaftlichen Prozess schlechthin als Gegenstand hat. Es kann also keine Rede davon sein, dass im Kapital (wie auch z. B. im 18. Brumaire des Louis Bonaparte) eine „Parteilichkeit in der Theorie“ in dem Sinne vorzufinden ist, dass Marx bestimmte politisch-ideologische Positionen (bewusst) in seine Theoriebildung einbringt; die potenzielle Selbstzerstörung der kapitalistischen Gesellschaft ergibt sich im Kapital allein aus den Strukturzusammenhängen und den ihnen immanenten Widersprüchen. 
Geschichten/partiellen Geschichten ${ }^{65}$ ) sind demnach durch ihre Relationalität gekennzeichnet, diese partiellen Geschichten sind nach Balibar eine Geschichte von Verbindungen von Elementen, eine Geschichte,

deren Subjekt nicht auszumachen ist: das wirkliche Subjekt jeder partiellen Geschichte ist die Verbindung, von der die Elemente und ihre Beziehungen abhängen, also etwas, das gar kein Subjekt ist. [DKL, Bd. 2, S. 336]

Einziges Subjekt einer Gesellschaftstheorie kann nur die Gesellschaft selbst sein, allerdings kann die Gesellschaft nicht in der traditionellen Form des Subjekts gedacht werden. In diesem Zusammenhang ist der Einwand, demzufolge es sich bei den Kategorien „Produktionsverhältnisse“ und „gegebenen menschlichen Gesellschaften“ ebenso wie die Kategorie des „Subjekts“ Resultate wie Triebkräfte der Geschichte seien und deshalb das „Subjekt“ den gleichen theoretischen Status wie der Begriff der „Produktionsverhältnisse“ hat [Thieme 1982, S. 49], strikt zurückzuweisen: dass die Gesellschaftsstruktur Resultat und Triebkraft der Geschichte ist, versucht Althusser ja gerade aufzuzeigen. Allerdings ist das „Subjekt“, gerade in Bezug zu seiner Bedeutung in der Bewusstseinsphilosophie und des hegelianisch geprägten Marxismus ${ }^{66}$, nicht als wissenschaftlich konstruiertes Objekt $\mathrm{zu}$ begreifen, insbesondere, wenn dem strukturalistischen Paradigma gefolgt wird. Im Gegensatz dazu bietet der Begriff des Individuums, verstanden als „leeres Feld“ (Deleuze), auf das die Gesellschaftsstrukturen einwirken, welches als Agent dieser Strukturen operiert, genau diese Eigenschaften, die es in die entwickelten Kategorien einsetzt:

Der Strukturalismus ist keineswegs ein Denken, welches das Subjekt beseitigt, sondern ein Denken, welches es zerbröckelt und es systematisch verteilt, welches die Identität des Subjekts bestreitet, es auflöst und von Platz zu Platz gehen lässt, ein Subjekt, das immer Nomade bleibt, aus Individuationen besteht, aber aus unpersönlichen, oder aus Besonderheiten, aber vorindividuellen. [Deleuze 1992, S. 55; Hervorhebung S.v.B.]

65 Die Dekonstruktion einer homogenen, monolithischen Geschichte zugunsten einer Pluralität von Geschichten, wie sie Althusser und Balibar vorgenommen haben, weist zu Analysen Foucaults, die dieser in der Archäologie des Wissens [Foucault 1997a] später vornahm ebenso wie zur Geschichtsanalyse der Anales-Schule große Parallelen auf.

66 Dies gilt besonders für Georg Lukács: Seine Konzeption der Klasse als Subjekt und Objekt des Geschichtsprozesses bedeutet, dass das Selbstbewusstsein des Proletariats (im Gegensatz zum historisch unbewussten Handeln der Bourgeoisie) notwendig zum Erkennen der Geschichte ist, erst über den Klassenstandpunkt des Proletariats erschließe sich „das Ganze der Gesellschaft“ [Lukács 1970, S. 87]. 
Geschichte als Prozess ist für den (marxistischen) Strukturalismus somit Geschichte von Strukturzusammenhängen und deren Modifikationen, keinesfalls eine Art der Selbstobjektivation einer Klasse, die durch das historische Erkennen seiner selbst diesen Prozess überwindet. Die Entwicklung der Strukturzusammenhänge ist auch keinesfalls eine kontinuierliche, sondern durch Diskontinuitäten geprägt ${ }^{67}$. „Geschichte“ hat somit in dieser Interpretation auch nicht ein Zentrum (sei es ein Subjekt, sei es ein höherer Wille), von dem sie sich aus entwickelt, sondern Geschichte wird als (identisch oder nichtidentisch) reproduzierende Strukturzusammenhänge und damit zusammenhängend von Klassenkämpfen begriffen. Individuen, die innerhalb dieser Strukturverbindungen operieren, werden folglich nicht als Subjekte, sondern als Individuationen dieser Strukturzusammenhänge, gleichsam „Oberfächenerscheinungen“ (Honneth) der gesellschaftlichen strukturalen Totalität begriffen (siehe hierzu vor allem S. 64 ff. $)^{68}$.

c) Althusser ist sich bei seinen Interpretationen bewusst, dass das sogenannte "Frühwerk" von Marx durchaus links-hegelianisch, vor allem durch Ludwig Feuerbach und Moses Hess ${ }^{69}$ geprägt ist und auf einer „materialistisch umgestülpten Dialektik“ basiert. Ein zentrales Thema Althusser ist aber, dass sich in dem Werk Marx' ein epistemologischer Bruch vollziehe, mit dem sich Marx von Hegel (und Feuerbach) trenne und mit/nach diesem Bruch die oben skizzierten Konzeptionen von Geschichte, Gesellschaft und Subjekt entwerfe. Die Abkehr von einer materialistisch umgestülpten hegelianischen Dialektik

67 Honneth stellt treffend fest, dass historische Kontinuität nur eine mögliche Form historischer Zeit ist [Honneth 1997, S. 418]. Die Kritik, die Honneth an der dargestellten Geschichtstheorie übt, ist allerdings nicht unproblematisch: Wenn Geschichte als ein „interaktiv erschlossener Prozesszusammenhang“ gedacht wird, in der Folge „historische Kontinuität [...] materiell in den Lebenszusammenhängen verankert“ sei, ,in denen Geschichte kollektiv angeeignet und tradiert“ würde, schließlich Geschichtstheorie auf „kommunikativ entstandene Geschichtsdeutungen“ Bezug nähme, ,,in denen soziale Gruppen und Klassen vor aller wissenschaftlichen Theoriebildung historische Begebenheiten schon vereinheitlicht haben" [Honneth 1997, S. 419], stellt sich die Frage, ob hier noch der gleiche theoretische Gegenstand bearbeitet wird, oder nicht eine Theorie der Geschichtsschreibung (mit all ihren ideologischen Implikationen) angerissen wird. Ebensolche Geschichtsschreibungen/Interpretationen sind ja Gegenstand der Historizismuskritik Althussers, auch wenn die ontologische Setzung einer historischen Kontinuität hier durch die anthropologische Hintertür eingeführt wird.

68 „Jede Aussage, in der ein Kollektiv Subjekt des Satzes ist - Volk, Klasse, Universität, Schule, Staat -, unterstellt die Frage der Existenz dieses Kollektivsubjekts als bereits gelöst und offenbart damit einmal mehr jene „metaphysische Fälschung“, als die bereits die ontologische Argumentation entlarvt worden ist." [Bourdieu 1995, S. 39 f.]

69 Vgl. Euchner 1983; Euchner 1991, Bd. 1, S.13. 
hin zu einer „marxistischen“ Dialektik lokalisiert Althusser im Marx'schen Werk zwischen dem „materialistischen Hegelianismus“ des Frühwerks [FM, S. 129] und dem Spätwerk, namentlich Das Kapital: insbesondere die Deutsche Ideologie sei davon geprägt, dass sich in diesem Werk zwei Diskurse überlagern, einerseits ein noch Hegel und Feuerbach geschuldeter Diskurs, andererseits ein sich in seinen Anfängen befindender wissenschaftlicher Diskurs, der schließlich mit Das Kapital und den Theorien über den Mehrwert seinen (vorläufigen) Abschluss findet.

Wie Althusser behauptet auch Foucault, dass sich bei Marx ein epistemologischer Bruch vollzieht ${ }^{70}$. Im Gegensatz zu Althusser geht aber Foucault davon aus, dass sich ein epistemologischer Einschnitt in der ökonomischen Theorie Marx' nicht begründen lasse ${ }^{71}$. Foucault ist insoweit zuzustimmen, dass durch die Marx'schen Analysen eine wissenschaftliche Gesellschaftstheorie im eigentlichen Sinn überhaupt erst möglich geworden ist $^{72}$. Problematisch erscheint allerdings einerseits die Unterstellung Foucaults, dass Althusser behauptet hätte, Marx stelle für die politische Ökonomie in dem Sinne einen epistemologischen Einschnitt dar, dass er dieses wissenschaftliche Feld selbst modifiziert hätte, also dass Das Kapital eine „,andere“, von den Klassikern differente politische Ökonomie darstellt ${ }^{73}$. Vielmehr ist anzunehmen, dass durch die Einführung des Begriffs des Mehrwertes mit seiner theoretischen

70 Man kann die Lektüre Althussers in gewissem Maße auch als „Rettungsversuch“ deuten, mit dem er den Marxismus mit dem Strukturalismus ,versöhnt“: die Eliminierung aller humanistischer Ansätze zugunsten einer Objektivierung der gesellschaftlichen Strukturen bei Marx impliziert, dass der im Kapital entwickelte „Marxismus“ Vorläufer des Strukturalismus ist. Zu einer solchen Einschätzung neigen neben Althusser auch Lefebvre [Dosse 1999, Bd. 1, S. 260] und Foucault [Foucault 1997, S. 22].

71 „Er [Althusser] spricht im Hinblick auf Marx von einem erkenntnistheoretischen Einschnitt, während ich umgekehrt behaupte, dass Marx keinen erkenntnistheoretischen Einschnitt darstellt. [...] Was ich über Marx gesagt habe, betrifft exakt den erkenntnistheoretischen Bereich der politischen Ökonomie. Wie bedeutend die Änderungen auch sein mögen, die Marx an den Analysen von Ricardo vorgenommen hat - ich glaube nicht, dass seine ökonomischen Analysen über den erkenntnistheoretischen Raum, den Ricardo geschaffen hat, hinausgehen. Dagegen darf man annehmen, dass Marx in dem historischen und politischen Bewusstsein der Menschen einen radikalen Schnitt herbeigeführt hat und dass mit der marxistischen Gesellschaftstheorie sehr wohl ein gänzlich neuer erkenntnistheoretischer Bereich eröffnet wurde." [Foucault 1973a, S. 159]

72 So auch Bourdieu 1995, S. 41 f.

73 Diese Auffassung wurde zweifellos vom Marxismus-Leninismus geteilt, denn nur so konnte dieser dazu übergehen, im Anschluss an Das Kapital eine positive - ,sozialistische" - Wirtschaftswissenschaft zu entwerfen [vgl. z. B. Autorenkollektiv 1955]. Der Glaube, dass es sich beim Marx'schen Hauptwerk um eine wirtschaftswissenschaftliche Theorie im engen Sinn handeln würde, wird aber auch von anderen Autoren behauptet, z. Schumpeter oder Samuelson. 
Kopplung an die Klassenkämpfe etc. durch Marx die „politische Ökonomie“ als Wissenschaft nicht erweitert, sondern vollkommen beseitigt wird und Marx ein neues Wissenschaftsgebiet betritt $^{74}$. Es liegt somit quasi ein doppelter epistemologischer Bruch vor: einmal innerhalb des Werkes Marx', in dem sich dieser von Hegel und Feuerbach trennt, andererseits ein Bruch, indem sich für Marx durch die Kritik der politischen Ökonomie ein vollkommen anderes wissenschaftliches Feld eröffnet: die Gesellschaftstheorie im engeren Sinn. Die Althusser'sche Konzeption des epistemologischen Bruchs bei Marx beinhaltet dadurch eine mehrfache Verschiebung:

1. In der Kritik der politischen Ökonomie entwickelt Marx den Begriff des Mehrwerts, der das gesamte Feld der klassischen politischen Ökonomie leerräumt und dieser einen ideologischen Status zuweist ${ }^{75}$. Gleichzeitig entwickelt Marx eine politischen Theorie, in der der Klassenkampf eine determinierende Funktion hat, wodurch die „sogenannten ökonomischen Phänomene“ zu begreifen seien [IISA, S. 97]. Diese neue Theorie ist dabei keine überzeitlich geltende, sondern eine für die kapitalistische Gesellschaftsformation spezifische. Hierbei stellt die Form der Aneignung fremder Arbeit durch den Akkumulationsprozess die methodisch entscheidende Kategorie dar. Marx ist wie Galilei oder Newton „Schöpfer“ einer neuen

74 So kann man diesbezüglich Lukács folgen, wenn er behauptet, dass das Kennzeichen orthodoxen Marxismus das Weiterführen der Marx'schen Methode sei [Lukács 1970, S. 59] (wobei natürlich klar sein sollte, dass über das Wesen der Methode relativ verschiedene Meinungen existieren).

75 In der Tat ist es so, dass Althusser (wie seine Mitarbeiter) Marx als Verfasser einer „positive[n] ökonomische[n] bzw. soziologische[n] Theorie gelesen“ hat, die „um die Frage des Klassenkampfs zentriert ist“ [Trenkle 1999] und dass Althusser das „Fetischkapitel“" im Kapital [MEW, Bd. 23, S. 85 ff.] weitgehend ignorierte (oder zumindest empfahl, den ersten Abschnitt des ersten Bandes des Kapitals als letztes zu lesen [Althusser 1969]). Dass aufgrund dieser Tatsache Trenkle Althusser dem „Traditionsmarxismus“/Marxismus-Leninismus zuschlägt, ist bei diesem Autor, der „Krisis“-Gruppe zugehörig, nicht weiter verwunderlich, da diese grundsätzlich mit jeder marxistische „Schule“, die nicht von einem Hegel-Marxismus ausgehend das „Fetischkapitel“ auslegt, so verfährt.

Paradoxerweise greift eben diese Gruppe auf das von Marx entwickelte ,ökonomische Gesetz“ des tendenziellen Falls der Profitrate zurück, um nun seit mehr als zehn Jahren den nahen Untergang des Kapitalismus zu prophezeien. Leider ist es dieser Gruppe bisher nicht gelungen, den tendenziellen Fall der Profitrate aus dem Warenfetisch ,abzuleiten“ und so wenigstens theoretische Konsistenz beanspruchen zu können - der logische Zusammenhang zwischen marxistischer Krisentheorie („Ökonomietheorie“) und Warenfetisch (Ideologiekritik) bleibt immer nur ein behaupteter, siehe z. B. Kurz 1999, S. 37 f. 
Wissenschaft, da durch seine Begriffsentwicklung erst überhaupt eine Geschichtswissenschaft möglich wird: der historische Materialismus ${ }^{76}$.

2. Die Konstitution einer Geschichtswissenschaft ist Marx erst dadurch möglich geworden, dass er sich von ideologischen Geschichtskonzeptionen/ der Geschichtsphilosophie getrennt hat. Geschichte ist nicht mehr Prozess der Verwirklichung der Vernunft (Hegel) sondern eine Geschichte von Klassenkämpfen. Dieser Geschichtsbegriff beinhaltet keineswegs, dass sich innerhalb der Geschichte die Menschheit (oder zumindest größere Teile derselben) zwangsläufig emanzipiert und so zu einem - wie auch immer gearteten - „vernünftigen“ Ende findet; nach Althusser ist die Geschichte potenziell ein Prozess ohne Ende ${ }^{77}$.

d) Wenn Althusser versucht, den epistemologischen Bruch bei Marx genau zu datieren, also den Bruch auf 1845 und die Deutsche Ideologie legt, ist dem zum Teil zuzustimmen, da die Deutsche Ideologie wohl wie kein anderes Hauptwerk von Marx und Engels durch das gegenseitige Überlagern zweier Diskurse gekennzeichnet ist. Allerdings ist zum einen die spätere Einschränkung Althussers zurückzuweisen, nach der das wissenschaftliche Werk Marx nur noch aus Das Kapital und allenfalls den Klassenkämpfen in Frankreich bestehe (hierzu ist m. E. gerade Der achtzehnte Brumaire des Louis Bonaparte insbesondere wegen der darin enthaltenen Bonapartismustheorie $\mathrm{zu}$ rechnen). Zum anderen ist die durch die Datierung erzielte Darstellung des epistemologischen Bruchs als mehr oder weniger „glatter Bruch“ im Denken von Marx fragwürdig ${ }^{78}$ - würden so doch bedeutende Arbeiten Marx' dann nicht mehr zum Marxismus zählen [Schoch 1980, S. 229] und rein ideologischen Charakter haben und somit nur das Spätwerk zur „,reinen Wissen-

76 Die Konzeption des Marxismus als die Wissenschaft von der Geschichte (von Gesellschaftsformationen) bedeutet aber auch, dass der Marxismus für sich keine privilegierte Position gegenüber anderen Wissenschaften beanspruchen kann. Somit kann der Marxismus nicht auf jedes soziale Phänomen angewandt werden; der Anspruch, dass der Marxismus universellen Geltungsanspruch hätte, ist „marxistische Metaphysik“ [Althusser 1983, S. 141].

77 Auch wenn es hier Annäherungen an die Frankfurter Schule gibt, folgt der Geschichtsprozesses bei Althusser keiner ,negativen Dialektik“: als Kommunist hoffte Althusser auch weiterhin auf die Überwindung des Kapitalismus., allerdings beerdigt Althusser das eschatologische Versprechen (dessen Grundzüge aber zweifellos bei Marx zu finden sind) des Marxismus-Leninismus.

78 M. Sprinkler bezeichnet diese Darstellung sehr treffend als zeitliche Inszenierung Althussers [Derrida 1994, S. 118]. 
schaft" zählen. Althusser schreibt dazu selbst relativierend, dass ein epistemologischer Bruch „ein kontinuierlicher Bruch [ist], der in endloser Tätigkeit das von ihm erschlossene theoretische Gebiet ausarbeitet" [Althusser 1974, S. 49]. In diesem Sinne ließe sich das Marx'sche Werk wiederum als Einheit betrachten - nicht als eine von den Ökonomisch-philosophischen Manuskripten aus entwickelte Entfaltung einer dort enthaltenen „Wahrheit“, die im Kapital ihren Abschluss findet, sondern als beständige - wenn auch unbewusste (Selbst-) Korrektur.

\title{
6. Philosophie und Wissenschaft - Althussers Selbstkritik
}

\begin{abstract}
Um Hegel wirklich zu entrinnen, muss man ermessen, was es kostet, sich von ihm loszusagen; muss man wissen, wie weit uns Hegel insgeheim nachgeschlichen ist; und was in unserem Denken gegen Hegel vielleicht noch von Hegel stammt; man muss ermessen, inwieweit auch noch unser Anrennen gegen ihn seine List ist, hinter der er uns auflauert: unbeweglich und anderswo.
\end{abstract}

Michel Foucault

a) Der Dekonstruktionsarbeit, die Althusser indirekt am orthodoxen und dogmatischen Marxismus mit Für Marx und Das Kapital lesen vollzog, folgte umfangreiche Kritik, die vor allem von der 68er-Bewegung, von dem an Einfluß gewinnenden Maoismus $^{79}$ und der tradierten Marx-Interpretation formuliert wurde. Althusser antwortete hierauf mit einer schwerwiegenden Verschiebung innerhalb seines Diskurses, explizit ging er auf die vorgebrachte Kritik in Elemente der Selbstkritik ein ${ }^{80}$. „Selbstkritik“ ist hierbei zu Recht in den Titel aufgenommen, denn das Werk ist weniger eine kritische Überprüfung der eigenen theoretischen Positionen, sondern mehr ein Derrida'scher Akt der Durchstreichung, eine Revision aller bisher erreichten Positionen [vgl. Balibar

79 Vgl. hierzu insb. Rancière 1975. Das Werk dieses Autors - selbst ehemaliger Mitarbeiter Althussers und Co-Autor der ersten Ausgabe von Das Kapital lesen - zeigt vor allem das maoistische Denken der Gauche proletariènne, in dem Althussers Arbeiten dem Revisionismus zugeordnet werden.

80 Wobei sich eine Revision der entwickelten Theorien schon in Philosophie und spontane Philosophie der Wissenschaftler [Althusser 1985] abzeichnet. 
1994, S. 35]. Althusser schätzt in seiner Selbstkritik seine ehemaligen Positionen als „Abweichung“ ein, ein klassischer marxistisch-leninistischer Terminus zur Kennzeichnung seiner „Vergehen“ an der reinen Lehre.

Besonders fraglich ist hierbei die Behauptung Althussers, dass seine vor allem in Für Marx und Das Kapital Lesen entwickelten Positionen lediglich als „Kokettieren“ mit dem Strukturalismus einzuordnen seien [Althusser 1975a, S. 63]. Immerhin waren die verschieden theoretischen Ansätze Althussers in den Augen von Gilles Deleuze so „strukturalistisch“, dass sie zur Illustration seiner Arbeit Woran erkennt man den Strukturalismus? dienten [Deleuze 1992]. Diese - keineswegs als Kritik gemeinte - Einordnung trifft Deleuze unter anderem anhand der folgenden Kategorien, die für ihn kennzeichnend für das strukturalistische Denken sind:

i. Das Symbolische: Charakteristisch für den Strukturalismus sei die bereits angedeutete Akzeptanz der Lacan'schen Trennung von Realem, Imaginären und Symbolischen. Hierbei komme Althusser der Verdienst zu, ein jenseits der realen und imaginären Beziehungen der Menschen angesiedeltes Feld als Bereich der Wissenschaft entdeckt zu haben [Deleuze 1992, S. 10 f.]:

Kein Besserer als Louis Althusser hat den Status der Struktur als identisch mit der „Theorie“ selbst bestimmt - und das Symbolische muss als die Produktion des originalen und spezifischen theoretischen Objekts verstanden werden. [ebd., S. 14]

ii. Die Stellung: symptomatisch ist nach Deleuze weiterhin, dass der strukturalistische Ansatz weniger quantitativ arbeitet, sondern vor allem die Stellung seiner Erkenntnisobjekte zueinander betrachtet, eine Topologie entwirft, innerhalb derer die Begriffe durch ihre relationale Anordnung ihren Sinn erhalten. Althusser entferne in dieser Anordnung die „Subjekte“, indem er „die Plätze in einem topologischen und strukturalen Raum“ untersucht, welcher durch die „Produktionsverhältnisse bestimmt wird“ [ebd., S. 16]. Deleuze folgert daraus, dass der „Sinn“ der Begriffe erst innerhalb des strukturierten Raumes erzeugt wird. Durch die multiplen Relationen der Begriffe innerhalb einer komplexen Topologie gibt es demnach für den Strukturalismus

immer zu viel Sinn, eine Überproduktion, eine Überdetermination des Sinnes, der immer im Übermaß durch die Kombination von Orten in der Struktur hervorgebracht wird [ebd., S. 18]. 
iii.Das Differenzielle: Wenn der topologische Raum in verschiedene Plätze unterteilt ist, stellt dies ein differenzielles Verhältnis dar, das die verschiedenen Plätze umreißt und mit diesen spezifischen Plätzen spezifische Rollen verbindet. Dieses differenzielle Verhältnis stelle innerhalb des strukturalistischen Marxismus die Produktionsverhältnisse dar, die den gesellschaftlichen Agenten ihren Platz in der Struktur und ihre Rolle zuweisen.

Das wahre Subjekt ist die Struktur selbst: das Differenzielle und das Besondere, die differenziellen Verhältnisse und die besonderen Punkte, die gegenseitige Bestimmung und die vollständige Bestimmung. [ebd., S. 26]

iv. Das Differenzierende: Deleuze analysiert die Strukturen als notwendig unbewusst und damit nur in dem Sinn gegenwärtig, indem sie sich verkörpern [ebd., S. 27]. Die verschiedenen gesellschaftlichen Strukturen existieren dabei parallel und relativ autonom, die ,ökonomische Struktur existiert niemals rein, sondern verdeckt von den rechtlichen, politischen, ideologischen Beziehungen, in denen sie sich verkörpert" [ebd., S. 33 $]^{81}$. Diese Verkörperung verlaufe entlang von Differenzierungslinien, an deren sich die Strukturen aktualisieren und „sich im Raum und in der Zeit“ differenzieren [ebd., S. 30].

b) Vor dem Hintergrund der Ausführungen von Deleuze kann die Althusser'sche Theorieentwicklung kaum als bloßer Flirt mit dem Strukturalismus eingeordnet werden, ebenso wenig lässt sich in Das Kapital lesen und Für Marx eine gegen den Strukturalismus gerichtete Ironie oder Parodie entdecken, wie Althusser selbst behauptet [Althusser 1975a, S. 64] ${ }^{82}$. Aber Althusser bleibt bei diesen Einschätzungen in seiner Selbstkritik nicht stehen, sondern versucht den Strukturalismus zu denunzieren (der Terminus des Abschwörens wäre wohl nicht unangemessen) - Strukturalismus sei eine ,philosophische Ideologie von Wissenschaftlern“ [ebd., S. 67], der Strukturalismus sei keine in sich geschlossene Philosophie [ebd.], sondern Formalismus [ebd., S. 68]. Althusser versucht sich darauf zurückzuziehen, dass der Marxismus (jetzt wieder als geschlossene Entität gedacht) im Gegensatz zum Strukturalismus eine

81 Des Weiteren folgt Deleuze Althusser auch in der Ablehnung der Hegel'schen Dialektik [ebd., S. 28], ebenso schließt er einen homogenen Zeit-/Geschichtsbegriff aus [ebd., S. 30].

82 Zur Kritik der Althusser'schen Selbstkritik siehe insb. Böke 1994; Brühmann 1980, 225 ff.; Turchetto 1994. 
revolutionäre Wissenschaft sei, die ,in der theoretischen Anordnung ihrer Begriffe auf revolutionären theoretischen Klassenpositionen steht" [ebd., S. 69].

Althussers Selbstkritik ist zum Teil notwendig, denn er konnte in seiner Epistemologie nicht klären, wie der Erkenntniseffekt beschaffen ist: Wenn angenommen wird, dass ein organisierter wissenschaftlicher Diskurs immer zugleich „wissenschaftlich, beruflich, rechtlich, ökonomisch“ [Althusser/Tort 1976, S. 18] verfasst ist, müssen bestimmte Effekte dieser Verfasstheit auf die Produktion von Erkenntnis Auswirkungen haben. Die Frage ist also, worin der spezifische Modus besteht, der die wissenschaftliche Erkenntnis identifiziert und von der Ideologie trennt, wodurch wissenschaftliche Erkenntnis von wissenschaftlicher Ideologie differenziert wird. Althusser versucht nun hierbei auf die Philosophie zu rekurrieren, die er nicht mehr - wie in seinen früheren Arbeiten - mit der THEORIE/seiner Epistemologie identifiziert [Althusser 1975a, S. 95], sondern der er nun den Status des „Klassenkampfes in der Theorie" zuweist. Das legt nahe, dass der epistemologische Einschnitt einer Wissenschaft nicht mehr in der Epistemologie selbst, sondern in der Politik zu lokalisieren ist, so dass z. B. Marx nur dadurch seinen wissenschaftlichen Durchbruch erzielen könnte, indem er die bürgerliche Ideologie zurückwies [Böke 1994, S. 72]. Mit diesem Ansatz gelingt es zum einen zu klären, warum einerseits der marxistische Diskurs in sich selbst sehr heterogen ist (oder warum es verschiedene marxistische Diskurse gibt), und warum der historische Materialismus in der bürgerlichen Gesellschaft selbst nicht einen „normalen“ wissenschaftlichen Status hat [ebd., S. 71]. Des Weiteren ermöglicht es, im Anschluss an Foucault eine Beziehung zwischen Wahrheit/Wissenschaft und Macht herzustellen: wenn der Klassenkampf ständig in der Theorie anwesend ist, wird diese selbst durch den Kampf modifiziert, die „Wahrheit“, die der wissenschaftliche Diskurs produziert, steht nun mit den gesellschaftlichen Machtbeziehungen in Verbindung. Hiermit öffnet sich die Althusser'sche Epistemologie tendenziell der Genealogie Foucaults, der explizit die Frage nach dem Zusammenhang von Wahrheits-Wirkung und Macht-Wirkung stellt [ebd., S. 73] $]^{83}$.

83 Notabene: die Kritik, die sich am Strukturalismus, auch an der Althusser'schen und Foucault'schen „Schule“, nach '68 entwickelte und der (zum Teil) in der Theorie ein Rollback hin zum Historizismus und Subjektzentrismus folgte, ist beredtes Beispiel für die Eingriffe der Macht in die „Wahrheitsproduktion“. Dass die politischen Manöver im nach- 
Althusser weist nun der Philosophie die Rolle zu, die Demarkationslinie zwischen dem Ideologischen und dem Wissenschaftlichen zu ziehen [Althusser 1985, S. 68]. Die Aufnahme einer auf den ersten Blick externen, also außerhalb des wissenschaftlichen Diskurses angesiedelten Analyse der Produktion von „Wahrheit“" scheint ein notwendiger Schritt Althussers, problematisch ist aber zum einen seine Annäherung an den Marxismus-Leninismus (nun wieder als „revolutionäre Wissenschaft“" gedacht), denn dies beinhaltet das Zurückgreifen auf eine genau spezifizierbare Philosophie: nur eine „revolutionäre“ Philosophie kann in dieser Konstellation den wissenschaftlichen und revolutionären Charakter des historischen Materialismus bestätigen. Die Akzeptanz einer revolutionären (für Althusser also marxistischen) Philosophie ist aber problematisch, zumal wenn zugleich die wesentlichen Positionen von Für Marx und Das Kapital lesen aufrecht erhalten werden sollen ${ }^{84}$.

Allerdings ist weiterhin $\mathrm{zu}$ fragen, warum ausgerechnet die - marxistische oder nicht-marxistische - Philosophie (als Ideologie unter Ideologien) die privilegierte Rolle ${ }^{85}$ wahrnehmen kann und soll, wissenschaftliches von ideologischem zu differenzieren ${ }^{86}$. Diese „Parteilichkeit in der Theorie“ würde letztendlich dem „Lyssenkoismus“ ${ }^{\text {“87 }}$ Vorschub leisten. Sicher kann angenommen werden, dass der Bruch Marx' mit der bürgerlichen Ideologie (und der Bruch mit Hegel) eine Voraussetzungen für den wissenschaftlichen Durchbruch Marx' war, dies verweist natürlich auf die Beziehung von Ideologie, Wissenschaft und Macht. Allerdings ist fraglich, ob die Beurteilung der

strukturalistischen antimarxistischen Diskurs - die vor allem von den „,neuen Philosophen“ (ausgerechnet ehemalige Maoisten, vgl. Dosse 1999, Bd. 2, S. 333 ff.]) vorgetragen wurde - bis hin zur Selbstzerstörung führen können, zeigen die zahlreichen Selbstmorde (nicht nur) im Umfeld der Althusser-Schule, so z. B. Poulantzas und Pêcheux. Macherey (selbst Mitarbeiter Althussers) stellt dazu lapidar fest: „Erstaunlich ist eher, dass es nicht noch mehr Tote gegeben hat“" [Dosse 1999, Bd. 2, S. 472].

Diese politischen Prozesse sind natürlich nicht nur im Pariser Intellektuellenmilieu, sondern ebenso im Wissenschaftsbetrieb der BRD präsent: wurde ab '68 Adorno als geistiger Vater der Studentenrevolte angegriffen (woraufhin er an einem Herzinfarkt starb), geht man heute dazu über, die Frankfurter Schule als „geistige Geburtshelferin“ der BRD abzufeiern.

84 Dies versucht Althusser allerdings nicht, sondern geht den von ihm eingeschlagenen Weg konsequent zu Ende, er behauptet schließlich, dass der Marxismus - wie die Psychoanalyse - keine (positive) Wissenschaft, sondern „Kritik“ sei [Böke 1994, S. 77 ff.], zum Verhältnis von „Kritik“ und Wissenschaft bei Marx vgl. Heinrich 1991, S. 244.

85 Mit dieser Annahme ist Althusser plötzlich in einer ähnlichen Position wie Heidegger, der versucht, die Philosophie (wieder) über die Wissenschaft zu stellen, vgl. Habermas 1996, S. 158.

86 Denn eigentlich hat die Philosophie nur einen Erkenntnisbereich: sich selbst.

87 Vgl. Lecourt 1976. 
Legitimität einer Theorie, überhaupt die Identifikation eines epistemologischen Einschnitts allein von der subjektiven Annahme eines neuen politisch-ideologischen Standpunktes abhängig gemacht werden kann, oder ob hier nicht auf den „geregelten Diskurs wissenschaftlicher Demonstration“ [DKL, Bd. 1, S. 91] rekurriert werden muss, der selbst den epistemologischen Bruch in seinem Diskurs - wenn auch erst nachträglich - identifiziert.

c) Es stellt sich in diesem Zusammenhang aber grundsätzlich die Frage bezüglich des Verhältnisses von dialektischem und historischem Materialismus. Wenn der historische Materialismus den „harten Kern“ des Marxismus darstellt, also die von Marx begründete neue Wissenschaft „Geschichte“ ist, welchen Status hat dann der dialektische Materialismus? Ist er die „Philosophie des Marxismus“, gibt es überhaupt eine marxistische Philosophie oder ist dies nicht schon ein Widerspruch; ist historischer Materialismus überhaupt mit einer - wie auch immer gearteten - Philosophie vereinbar? M. E. ist hier Labica vollkommen zuzustimmen, wenn er hierzu in seiner ,Thèse“ schreibt:

Der Marxismus ist keine Philosophie sondern die sciencia nova [...] der Geschichte.

Folglich kann es keine marxistische Philosophie geben, es sei denn, man missbraucht die Worte. [... $]^{88}$

Der Materialismus ist keine Philosophie, oder: es gibt keine materialistische Philosophie [Labica 1976, S. 194].

Dialektischer Materialismus kann folglich nicht mehr sein als Epistemologie. Wenn der historische Materialismus die (neue) Wissenschaft ist und der dialektische Materialismus dessen Wissenschaftlichkeit garantiert, kann es aber auch keine dem Marxismus eigene Epistemologie geben, es kann zwischen dem dialektischen Materialismus und der Epistemologie nicht nur Schnittpunkte geben, sondern dialektischer Materialismus/Epistemologie ist Wissenschaft im allgemeinen [Descombes 1981, S. 147]. Diese Epistemologie, die selbst mit den Klassenkämpfen in Beziehung steht (siehe dazu S. 123 ff.), muss das Verhältnis von Macht und Wissen natürlich selbst reflektieren - sicher selbst wiederum eine ,philosophische“ Aufgabe, eine innerhalb des wissenschaftli-

88 Ähnlich auch Balibar: „En réalité, il n'existe pas de philosophie marxiste, ni comme conception du monde d'un mouvement social, ni comme doctrine ou système d'un auteur nommé Marx“ [Balibar 1993a, S. 5], daran (zumindest partiell) anschließend Derrida [Derrida 1996, S. 115]. 
chen Diskurses angeordnete „Philosophie des Neins“ (Bachelard) gegenüber den Eingriffen der Ideologie (Philosophie, Politik usw. ${ }^{89}$.

89 So schreibt Marx: „Einen Menschen aber, der die Wissenschaft einem nicht aus ihr selbst (wie irrthümlich sie immer sein mag), sondern von aussen, ihr fremden, äusserlichen Interesse entlehnten Standpunkt zu accomodieren sucht, nenne ich 'gemein'“ [MEW, Bd. 26.2, S. 112]. Heinrich zieht aus diesem Zitat den folgerichtigen Schluss, dass zwar ein wissenschaftlicher Sozialismus, nicht aber eine sozialistische Wissenschaft möglich ist [Heinrich 1991, S. 248]. 


\section{Kapitel 2: Zur Staats- und Ideologietheorie}

Die Staatstheorie stellt innerhalb des marxistischen Diskurses zwar keinen „blinden Fleck“ dar, ist aber im Vergleich zur polit-ökonomischen Theorie deutlich unterentwickelt, so dass verschiedene Autoren zwar die staatstheoretischen Arbeiten von Lenin und Gramsci würdigen, dabei aber vor allem auf die theoretischen Unzulänglichkeiten - auch der diesbezüglichen Arbeiten von Marx und Engels - hinweisen [Hirsch 1983, S. 158] oder gar die „Krise des Marxismus ${ }^{690}$ mit dem Fehlen einer adäquaten Staatstheorie in Verbindung bringen [Althusser 1978, S. 11]. Die Notwendigkeit der Entwicklung einer marxistischen Staatstheorie, die vor allem die spezifische Form der bürgerlichen politischen Herrschaft ausarbeitet, hatte schon Eugen Paschukanis ${ }^{91}$ in der Sowjetunion der 20er Jahre formuliert, der genau die Differenz zwischen dem bürgerlichen Staat und den historisch vorgelagerten Herrschaftsformen erkannte:

Warum bleibt die Klassenherrschaft nicht das, was sie ist, d. h. die faktische Unterwerfung eines Teils der Bevölkerung unter die andere? Warum nimmt sie die Form einer offiziellen staatlichen Herrschaft an oder - was dasselbe ist - wird der Apparat des staatlichen Zwangs nicht als privater Apparat der herrschenden Klasse geschaffen, warum spaltet er sich von der letzteren ab und nimmt die Form eines unpersönlichen, von der Gesellschaft losgelösten Apparats der öffentlichen Macht an? [Paschukanis 1991, S. 145]

In dem als ein Spezifikum des bürgerlichen Staates, nämlich die Form, innerhalb der gesellschaftliche Macht ausgeübt wird, erkannt wird [Hirsch 1974, S. 15], wird einerseits darauf bestanden, dass gesellschaftliche Macht nicht in der staatlichen Instanz selbst begründet ist, der Staat aber ein gesellschaftlicher Ort ist, in dem diese Macht zu Geltung kommt. Aber auch in der Problemstellung Paschukanis' wird selbst ein Begriff des Staates umrissen, der für den Marxismus-Leninismus symptomatisch und selbst problematisch ist. Althusser merkt in diesem Zusammenhang zurecht an, dass seit dem Manifest der kommunistischen Partei und dem 18. Brumaire des Louis Bonaparte der klassische Marxismus den Staat immer $^{92}$ als rein repressiven Apparat, als Werkzeug einer Klasse definiert [IISA, S. 115]. Im marxistischen Ökonomis-

90 Wohlgemerkt die Krise des Marxismus in den 70er Jahren.

91 Zur Theorieentwicklung und -rezeption Paschukanis' vgl. Harms 2000.

92 Als Ausnahme können hier nur Gramsci und Bauer aufgeführt werden. 
mus wird dann der Staat nur noch als „Überbau“ der ökonomischen „Basis“ eingeordnet und folgt in seiner historischen Entwicklung - der marxistischleninistischen „Dialektik“ entsprechend - der jeweiligen Bewegung der Basis.

Dem Basis-Überbau Schema gesteht Althusser zwar zu, dass es als Metapher geeignet sei, die Theorie zu veranschaulichen, habe aber dadurch den Nachteil, dass es keine Theorie im strengen Sinn sei, da es nur beschreibenden Charakter habe. Das Schema könne die Determinierung in letzter Instanz als räumliche und pädagogische Metapher darstellen, es müsse aber über diese Metapher hinausgegangen werden, sollen die spezifischen Determinierungen und Rückwirkungen der verschiedenen gesellschaftlichen Instanzen erfasst werden [IISA, S. 114]. Ebenso sei die bisherige marxistische Staatstheorie, die den Staat vor allem als Repressionsapparat begriffen habe, zwar geeignet, die verschiedenen Formen der Repression zu erfassen (von der einfachen Zensur bis zur offenen Diktatur), allerdings ,stellt die beschreibende Staatstheorie eine Phase der Konstituierung der Theorie dar, die ihrerseits ihre Aufhebung fordert“" [IISA, S. 117].

Als zentraler Aspekt, der Althusser dazu veranlasst, die marxistische Staatstheorie neu zu überdenken, kann sein Begriff der Überdetermination gelten. Die Widersprüche innerhalb einer entwickelten Gesellschaft sind, wie oben bereits dargelegt, nicht auf einen Hauptwiderspruch reduzierbar, sondern es existieren vielmehr neben dem in letzter Instanz determinierenden Widerspruch von diesem unabhängige Widersprüche als auch diesen konstituierende Widersprüche. Beispielsweise existieren neben dem Widerspruch zwischen Kapital und Arbeit Widersprüche innerhalb der Klassen selbst (Finanz- vs. Industriekapital, exportorientiertes Kapital vs. binnenmarktorientiertes Kapital usw., ebenso existieren innerhalb der lohnabhängigen Klasse zwischen den verschiedenen Schichtungen spezifische und widersprüchliche Interessen).

Zentrale Fragestellung für eine marxistische Staatstheorie ist somit, wie eine Gesellschaft, die so mit Widersprüchen durchzogen und überdeterminiert ist, selbst nicht einfach auseinander fällt, sondern sich selbst und das herrschende Akkumulationsregime (und die dafür spezifische Form der Trennung in Klassen) reproduzieren kann, sich also als Gesellschaftsformation reproduziert. Diese Fragestellung bedeutet, dass eine Theorie des Staates nicht aus dem Kapitalverhältnis direkt abgeleitet werden kann, sondern, da die ökonomische 
Struktur in letzter und nicht in absoluter Instanz determinierend ist, die relative Autonomie der staatlichen wie nicht-staatlichen ideologischen Strukturen in Bezug auf die ökonomische Basis zu untersuchen ist und - die Arbeiten von Gramsci aufnehmend - Fragen der politischen Hegemonie und Ideologie vor dem Hintergrund des Verhältnisses von ökonomischer und staatlicher Struktur wieder neu zu überdenken. Es geht also darum, die einzelnen Sektoren des Staates auch in Verbindung zur Ideologie zu bringen.

\section{Das automatische Subjekt}

\subsection{Ideologie und Praxis}

Knie nieder, bewege die Lippen zum Gebet, und Du wirst glauben.

Louis Althusser ${ }^{93}$

Althussers Ideologietheorie wird von einigen Autoren als „point of no return“ in der marxistischen Ideologieforschung bezeichnet [Kammler/Plumpe/ Schöttler 1978]. Sie stellt dabei selbst einen Einschnitt in den Diskurs Althussers dar: Wenn in den bisherigen Ausführungen in der epistemologischen Konzeption Althussers von Ideologie die Rede war, erfolgte die Abgrenzung immer rein negativ bezüglich der Wissenschaft, als nicht näher spezifizierte gesellschaftliche Form von „Erkennen“.

Althusser hat bereits in Das Kapital lesen eine Kategorie benannt, mit der der Ideologiebegriff schärfer zu umreißen ist: die Praxis - wie der Wissenschaft sei der Ideologie eine spezifische materielle Praxis eigen. Hierauf aufbauend entwickelt Althusser in Ideologie und ideologische Staatsapparate ${ }^{94}$ eine Ideologiekonzeption, die sich dabei sowohl von der „Theorie“ abgrenzt, die Ideologie als aufgedrängtes falsches Weltbild („Priestertrug“) definiert, als auch die

93 Althusser schreibt dieses Zitat fälschlicherweise Pascal zu [Berthold 1992, S. 93, Fn. 178].

94 Der Text war von Althusser ursprünglich nicht zur Veröffentlichung bestimmt und hat deshalb einen recht fragmentarischen Charakter, auch durch seine Zusätze $P$. S. und Anmerkungen über die ideologischen Staatsapparate. Zur Struktur dieses Textes siehe Berthold 1992, S. 48 ff. 
im Marx'schen Frühwerk entwickelte (und später vor allem von Lukács aufgenommene [Lukács 1970]) Konzeption des „falschen Bewusstseins“ ablehnt, in der für die Individuen Ideologien „entfremdete (=imaginäre) Vorstellung ihrer Existenzbedingungen bilden, weil diese Existenzbedingungen selbst entfremdet sind“ [IISA, S. 135; Hervorhebung S.v.B.]. Eine solche Konzeption von „richtigem“ und „falschem“ Bewusstsein (wobei behauptet werden könnte, dass das falsche Bewusstsein des Proletariats aufgrund der fetischistischen Formen des Kapitalismus notwendig falsch ist und die These, dass eine Lösung der Krise des Kapitalismus nur über das „richtige“ Bewusstsein des Proletariats erfolgen könne [Lukács 1970, S. 163], lediglich frommer Wunsch bleiben muss) kann aufgrund der oben dargelegten wissenschaftlichen Paradigmen nicht gehalten werden: in der strukturalistischen Theoriebildung ist das „Subjekt“ mit dazugehörigen elementaren Interessen und davon abgeleiteten Motivationen als ursprüngliche Kategorie nicht zu fundieren ${ }^{95}$. Das Subjekt/ Individuum als solches wird erst innerhalb der objektiven gesellschaftlichen Strukturen konstituiert [Arentz/Bischoff/ Jaeggi 1973, 90 S. ff.], es muss also auch in der Theoriebildung bezüglich der Ideologie ein anthropologischer Begriff des Menschen zurückgewiesen werden und allein auf die „Kultur“ rekurriert werden (Althusser nannte diese Konzeption bereits in seiner Lektüre Lacans „Kulturgebot“ ${ }^{\star 96}$ [Althusser/Tort 1976, S. 25]).

Althusser konstatiert in seinen Ausführungen, dass im Marx'schen Werk, insbesondere in der Deutschen Ideologie, zwar eine Konzeption der Ideologie enthalten sei, allerdings sei diese nicht marxistisch [IISA, S. 130]; er versucht demgegenüber eine Theorie zu entwerfen, die diesem Anspruch genügt und legt dar, dass es ihm grundsätzlich möglich scheint, eine ,Theorie der Ideologie im Allgemeinen“ zu formulieren. Analog sei eine Theorie der „besonderen Ideologien“ zu erarbeiten, welche in religiöser, moralischer etc. Form Klassenpositionen darstellen würden [IISA, S. 131]. Althusser stellt diesbezüglich zwei zentrale Thesen auf:

95 Erst recht sind somit philosophisch-ideologische Kategorien wie der der „Entfremdung“ zurückzuweisen.

96 Auch hierin überschneidet sich die Auffassung Althussers entscheidend mit der Foucaults: „Die fundamentalen Codes einer Kultur, die ihre Sprache, ihre Wahrnehmungsschemata, ihren Austausch, ihre Techniken, ihre Werte, die Hierarchie ihrer Praktiken beherrschen, fixieren gleich zu Anfang für jeden Menschen die empirischen Ordnungen, mit denen er zu tun haben und in denen er sich wiederfinden wird" [Foucault 1997b, S. 22]. 
1. Ideologie hat keine Geschichte.

2. Ideologie ist eine „Vorstellung“ des imaginären Verhältnisses der Individuen zu ihren realen Existenzbedingungen.

Das die Ideologie keine Geschichte habe, sei bereits von Marx in der Deutschen Ideologie ausgeführt, Althusser kritisiert aber an der Marx'schen Konzeption, dass Ideologie als leerer Traum, als imaginäre Konstruktion erscheine, folglich könne eine so begriffene Ideologie keine eigene Geschichte haben. Althusser behauptet demgegenüber, dass die Ideologie im allgemeinen zwar keine Geschichte hat, die verschiedenen Ideologien aber sehr wohl eine spezifische, eigene Geschichte hätten [IISA, S. 132]. Dies begründet Althusser damit, dass Ideologie - eben nicht als „Traum“ oder „Reflex“ einer Wirklichkeit gedacht - eine eigene Struktur mit einer spezifischen Funktionsweise besitze, die sie zu einer ,nicht-historischen, d. h. omnihistorischen Realität machen“ [ebd.] würde, die in der Geschichte der Klassenkämpfe präsent sei. Ideologie sei - wie das Freud'sche Unterbewusste - in dem Sinne „ewig“, dass sie sich „,der Form nach unveränderlich über die gesamte Geschichte“ [IISA, S. 133] erstrecke und eine Beziehung zur Ewigkeit des Unterbewussten habe.

Dass Ideologie eine „Vorstellung“ des imaginären Verhältnisses der Individuen zu ihren realen Existenzbedingungen sei, versucht Althusser mit zwei weiteren Thesen zu stützen:

1. Ideologie repräsentiert das imaginäre Verhältnis der Individuen zu ihren realen Existenzbedingungen.

2. Ideologie hat eine materielle Existenz.

Wenn gemeinhin angenommen werde, dass Ideologie - sei es als religiöse, moralische etc. Ideologie oder als Weltanschauung - nicht mit der „Wirklichkeit“ übereinstimme, sondern „Illusion“ sei, gehe man doch davon aus, dass die Ideologie „eine Allusion (Anspielung) auf die Wirklichkeit“ darstelle „und dass man sie nur zu 'interpretieren' brauche, um hinter ihrer imaginären Vorstellung der Welt die Wirklichkeit“" [IISA, S. 134] wiederzufinden. Diese Konzeption lasse leider die Frage offen, warum es überhaupt bei den Individuen eine „imaginäre Transposition ihrer realen Existenzbedingungen“ [ebd.] gebe. Die Antworten seien hinreichend bekannt, entweder werde auf den Priestertrug zurückgegriffen, der durch ein „gefälschtes Weltbild“ die Menschen gefügig 
mache, oder, wie bei Feuerbach und dem frühen Marx, auf die „Entfremdung“ zurückgegriffen [IISA, S. 134 f.].

Althusser besteht demgegenüber auf einer Position, die er bereits in Für Marx entwickelt hat. Für Althusser ist die Ideologie „eine für das historische Leben der Gesellschaft wesentliche Struktur" [FM, S. 183], Ideologie ist nicht auf das Bewusstsein zu reduzieren, sondern ist vor allem eine Struktur,

ein System von Vorstellungen, [...] sie sind meistens Bilder, bisweilen Begriffe, aber die Mehrzahl der Menschen drängen sie sich vor allem als Strukturen auf, ohne durch ihr „Bewusstsein“ hindurchzugehen. Sie sind wahrgenommene-angenommene-ertragene kulturelle Objekte und wirken funktional auf die Menschen ein durch einen Vorgang, der ihnen entgeht. [FM, S. 183]

Als solche, vor allem unbewusste Form der „Erkenntnis“ ist die Ideologie ein Bestandteil jeder gesellschaftlichen Gesamtheit, sie ist nicht auf bestimmte Formen der Klassengesellschaft beschränkt, sondern nach Meinung Althussers (und dies stellt wohl in den Augen der marxistischen Dogmatiker eine seiner größten Ketzereien dar) ebenso in der klassenlosen Gesellschaft aufzufinden sei [FM, S. 182]. Die Ideologie ist demzufolge ein lebensnotwendiger Mechanismus, da die Menschen

in der Ideologie, über und durch die Ideologie leben; kurz, dass das „gelebte“ Verhältnis der Menschen zur Welt, einschließlich das zur Geschichte [...], über die Ideologie geht, besser noch, die Ideologie selbst ist [FM, S. 184].

Die Ideologie stellt somit eine unbewusste, aber für das Individuum materielle Struktur dar, für Althusser steht die Vorstellung des individuellen Verhältnis zu den Existenzbedingungen, nicht die Existenzbedingungen selbst, im Zentrum der Ideologie:

Wenn es wahr ist, dass die Vorstellung von den realen Existenzbedingungen der Individuen, die als Agenten der Produktion, der Ausbeutung, der Repression, der Ideologisierung und der wissenschaftlichen Praxis fungieren, in letzter Instanz von den den Produktionsverhältnissen und den daraus abgeleiteten Verhältnissen abhängt, so können wir folgendes sagen: Jede Ideologie repräsentiert in ihrer notwendig imaginären Verzerrung nicht die bestehenden Produktionsverhältnisse (und die anderen daraus abgeleiteten Verhältnisse), sondern vor allem das (imaginäre) Verhältnis der Individuen zu den Produktionsverhältnissen und den daraus abgeleiteten Verhältnissen. [IISA, S. 135]

Für Althusser verschiebt sich durch diese Annahme die Fragestellung, was Ursache der Ideologie sei, hin zu der Problemstellung, warum Ideologie grund- 
sätzlich imaginär ist und worin der Charakter des Imaginären liegt [IISA, S. $136]^{97}$.

Wie bereits angedeutet ist Ideologie in der Konzeption Althusser eine gesellschaftliche Struktur, nicht eine ideelle oder geistige Existenz von Ideen dar (dieses wäre selbst wieder ideologisch), sondern Ideologie existiert materiell in spezifischen gesellschaftlichen Praxisformen [IISA, S. 137]. Althusser demonstriert diesen Zusammenhang anhand eines mit „Bewusstsein“ ausgestattetem Individuum, eines „Subjekts“, „dessen Bewusstsein die Ideen seines Glauben enthält“. Wenn dieses Subjekt einer spezifischen Ideologie folgt, ,ergibt sich völlig natürlich das (materielle) Verhalten des besagten Subjekts“, es nehme an bestimmten Praxen teil, indem es die Ideologie ,verwirklichen“ könne. Folge es beispielsweise dem Glauben an Gott, nehme es an einem Gottesdienst teil etc. Diese „,ideologischen Praxen“wie Salutieren, Beten, Demonstrieren, sportlicher Wettkampf usw. stellen für Althusser Rituale dar, die innerhalb der materiellen Existenz eines ideologischen Apparats (s.u.) geregelt werden $^{98}$ [IISA, S. 138]; die Existenz der Ideen des Glaubens eines Subjekts seien materiell,

insofern seine Ideen seine materielle Handlung sind, die in materielle Praxen eingegliedert und durch materielle Rituale geregelt sind, die ihrerseits durch den materiellen ideologischen Apparat definiert werden, dem die Ideen dieses Subjekts entstammen. [IISA, S. 139]

Das „Bewusstsein“ eines Individuums entspringt folglich nicht direkt aus seiner Stellung im Produktionsprozess, sondern ist formiert durch ideologische, materielle Praxisformen, die von materiellen ideologischen Apparaten definiert werden. Das Bewusstsein ist mit der Ideologie, die innerhalb eines materiellen ideologischen Apparats existiert, in dem Sinne identisch, dass die Praxis des Individuums seiner Ideologie entspricht: der Ideologie, die durch den ideologischen Apparat vorgeschrieben wird [IISA, S. 139 ${ }^{99}$.

In der Anordnung Ideologie - Subjekt sind nun diese Kategorien für Althusser gegenseitig konstituierend: Ideologie existiert nur für und durch Sub-

97 Hierauf kann Althusser allerdings auch keine Antwort geben.

98 Dementsprechend ist die Geschichte einer Ideologie nie eine Geschichte von „Ideen“, sondern eine Geschichte einer spezifischen Praxis und eines spezifischen Apparates.

99 Nimmt man an, dass mehr als nur ein ideologischen Apparat existiert, heißt dass natürlich auch, dass das Individuum nicht nur eine Praxis ausübt, eine Identität besitzt, sondern quasi mehrere Identitäten ausübt, abhängig von den ideologischen Apparaten, denen es jeweils unterworfen ist. 
jekte, hat aber die sie selbst definierende Funktion, „konkrete Individuen zu Subjekten zu 'konstituieren'“ [IISA, S. 140]. Hieraus zieht Althusser die Schlüsse:

1. Es gibt Praxis nur durch und unter einer Ideologie

2. Es gibt Ideologie nur durch das Subjekt und für Subjekte [IISA, S. 139], folglich wird erst in der Ideologie (der ideologischen Praxis) das Individuum zum Subjekt. Althusser entwickelt daraus seine These, mit der er die „Subjektwerdung“ des Individuums erklärt: „Die Ideologie ruft die Individuen als Subjekte an“ [IISA, S. 140].

Entgegen einer subjektzentrierten Konzeption wird so das Individuum nicht als freies oder intentionales Subjekt begriffen, sondern das individuelle Handeln und Bewusstsein vollzieht sich als Effekt materieller ideologischer Mechanismen, wobei die Subjekte ihr eigenes, determiniertes Handeln als freies Handeln wahrnehmen können [Kammler/Plumpe/Schöttler 1978, S. $10]^{100}$. Mit der Anrufung der Subjekte und der Wiedererkennung/Anerkennung durch die Subjekte vollzieht sich dieser Mechanismus, „die Individuen sind immer-schon Subjekte“ [IISA, S. 144], da sie als solche ,ununterbrochen ideologische Wiedererkennungsrituale“ praktizieren [ebd.] bzw. immer schon in Praxen eingesetzt werden, die spezifische ideologische Handlungen von ihnen erwarten. Sie werden selbst als „konkrete, unverwechselbare und (natürlich!) unersetzliche Subjekte“ bestätigt [IISA, S. 141 f.], durch die Anrufung als individuelle „Ansprache“ werden konkrete Individuen in konkrete Subjekte „transformiert“ bzw. konkrete Subjekte ,rekrutiert“ [IISA, S. 142].

Die Anrufung der Individuen erfolgt nach Althusser im ideologischen Mechanismus immer durch eine äußere Referenz, das „,rufende“ SUBJEKT, ein einziges, anderes, zentrales ideologisches SUBJEKT ${ }^{101}$, was je nach konkreter Ideologie z. B. Gott oder der Staat sein kann. Erst im Bezug auf dieses SUBJEKT konstituiert sich das Individuum zum Subjekt und unterwirft sich diesem [IISA, S. 146], das Individuum wird in der ideologischen Konstruktion durch seine ideologische Unterwerfung selbst als Subjekt durch das SUBJEKT

100 Pêcheux nennt diese Haltung „Münchhauseneffekt“.

101 Durch die Großschreibung (SUBJEKT) versucht Althusser aus Ermangelung eines besseren Begriffs die Differenz von Subjekt als anrufendes Subjekt und Subjekt als angerufenem zu verdeutlichen. 
anerkannt. Althusser zieht daraus den Schluss, dass die Struktur der Ideologie somit eine doppelte Spiegelstruktur bildet,

diese spiegelhafte Verdoppelung ist konstitutiv für die Ideologie und gewährleistet zugleich ihre Funktionsweise, das bedeutet, dass jede Ideologie zentriert ist, dass das Absolute SUBJEKT den einzigen Platz des Zentrums einnimmt und um sich herum die unendliche Zahl der Individuen als Subjekte anruft, und zwar in einem doppelt spiegelhaften Verhältnis, indem es die Subjekte dem SUBJEKT unterwirft, während es ihnen im SUBJEKT [...] die Garantie bietet, dass es sich wirklich um sie und Es handelt. [IISA, S. 147]

Das heißt, die - gegenüber dem SUBJEKT dezentrierten - Subjekte werden in einer Bewegung (der Anrufung) dem SUBJEKT unterworfen, erhalten dadurch aber auch ihre Identität (Bestätigung) als Subjekt, nur durch die Existenz des differenten und zentralen SUBJEKTS ist die Existenz des Subjekts möglich [IISA, S. 146].

Die doppelte Spiegelstruktur der Ideologie gewährleistet gleichzeitig: 1) die Anrufung der „Individuen“ als Subjekt, 2.) ihre Unterwerfung unter das SUBJEKT, 3.) die wechselseitige Wiedererkennung zwischen den Subjekten und dem SUBJEKT sowie der Subjekte untereinander und schließlich die Wiedererkennung des Subjekts durch sich selbst, 4.) die absolute Garantie, dass alles in Ordnung ist und das alles gut gehen wird, solange die Subjekte nur wiedererkennen, was sie sind, und sich dementsprechend verhalten. [IISA, S. 147 f.] ${ }^{102}$

In diesem „vierfachen System der Anrufung der Subjekte“ [ebd.] funktionieren nach Althusser die Subjekte ,ganz von alleine“ und nur wenige „schlechte Subjekte" fallen aus der Rolle, welche letztendlich daraus besteht, als freies Individuum als Subjekt angerufen zu werden, um sich freiwillig den Anordnungen des SUBJEKTS zu unterwerfen und in seinen Praxen die Rituale und Handlungen seiner Unterwerfung zu vollziehen, „es gibt Subjekte nur durch und für ihre Unterwerfung“ [IISA, S. 148]. Das Verhältnis von Ideologie und Unterwerfung wird für die Theorie des Staates von maßgeblicher Bedeutung sein.

102 Zur Spiegelstruktur siehe Lacan 1980, Bd. 1, S. 99 ff. 


\subsection{Ideologie als Staatsapparat}

Die oben skizzierte Ideologiekonzeption legt Althusser seiner Staatstheorie zugrunde: er unterscheidet in der Analyse des bürgerlichen Staates zwischen repressiven und ideologischen Apparaten des Staates. Hierbei ist es (wie bei Gramscis Zivilgesellschaft) unerheblich, ob diese Apparate ,privaten“ oder „öffentlichen“ Charakter haben denn die Trennung zwischen „öffentlich“ und „privat“ wird selbst juridisch durch den Staat gesetzt, entscheidend ist allein die Funktionsweise der Apparate [IISA, S. 120].

Der repressive Staatsapparat (RSA) ist in der Konzeption Althussers wie auch im orthodoxen Marxismus üblich - ein zentralisierter Apparat, der die verschieden Organe der Repression wie Armee, Polizei und Verwaltung vereinheitlicht. Der Name „repressiver Staatsapparat“ zeige bereits an, dass dieser in erster Linie aufgrund von (physischer oder nicht-physischer) Gewalt funktioniere [IISA, S. 119]. Demgegenüber bestehen eine Anzahl ideologischer Staatsapparate (ISA), u. a. sind dies

1. der religiöse ISA,

2. der schulische ISA,

3. der familiäre ISA,

4. der juristische ISA,

5. der politische ISA,

6. der gewerkschaftliche ISA,

7. der ISA der Information (Presse, Radio, Fernsehen),

8. der kulturelle ISA [IISA, S. 119 f.].

Diese (provisorische!) Liste führt laut Althusser die Staatsapparate auf, die in erster Linie eine ideologische Funktionsweise aufweisen ${ }^{103}$. Die zentrale Aufgabe der ISA stellt für Althusser die Sicherung der Hegemonie dar:

Unseres Wissens kann keine herrschende Klasse dauerhaft die Staatsmacht innehaben, ohne gleichzeitig ihr Hegemonie über und in den Ideologischen Staatsapparaten auszuüben. [IISA, S. 122]

Sowohl die Betonung des Kampfs um Hegemonie in Bezug auf die politische Herrschaft einer Klasse wie die Unterscheidung zwischen repressiven und

103 Ideologischer und repressiver Staatsapparat handeln beide immer ideologisch und repressiv, aber, wie Poulantzas formuliert, Repression bzw. Ideologie stellen den „Hauptaspekt“ der Funktionsweise des jeweiligen staatlichen Apparates dar [Poulantzas 1973d, S. 324]. 
ideologischen Staatsapparaten hat den theoretischen Arbeiten Gramscis viel zu verdanken.

\subsubsection{Gramsci-Exkurs I: Hegemonie und hegemoniale Apparate}

Gramsci erkannte bereits in seinen Gefängnisheften, dass Ideologie nicht lediglich ein Verblendungszusammenhang oder falsches Bewusstsein darstellt, sondern eine spezifische Materialität besitzt; diese Materialität habe im politischen Kampf eine außerordentliche Bedeutung, in der Theorie müsse folglich berücksichtigt werden,

wie die ideologische Struktur einer herrschenden Klasse tatsächlich organisiert ist: dass heißt die materielle Organisation, die darauf gerichtet ist, die theoretische oder ideologische „Front“ zu bewahren, zu verteidigen und zu entfalten. [Gh, Bd. 2, S. 373]

Indem die Kultur (,ideologische Struktur“) als Organisationsfeld der „ideologischen Front" ausgemacht wird, ergibt sich für Gramsci ein weites Untersuchungsgebiet, denn

all das, was die öffentliche Meinung direkt oder indirekt beeinflusst oder beeinflussen kann [...], die Bibliotheken, die Schulen, die Zirkel und Clubs unterschiedlicher Art, bis hin zur Architektur, zur Anlage der Straßen und zu den Namen derselben [Gh, Bd. 2, S. 374]

müsse dabei in die Theoriebildung einbezogen werden. Hier ist schon ein zentraler Ort der Bildung des Konsens genannt: die „öffentliche Meinung“ als Schnittstelle zwischen ,privatem“ und juristisch-administrativen Überbau [Gh, Bd. 4, S. 916 f.].

\subsubsection{Der Hegemoniebegriff bei Gramsci}

Der Begriff der Hegemonie stellt keine originäre Entdeckung Gramscis dar, wie in der Literatur z. T. angenommen wird, sondern war seit dem Ausgang des 19. Jahrhunderts fester Bestandteil der Programmatik der russischen Sozialdemokratie. Die Konzeption der „Hegemonie“ geht auf Schriften Plechanows aus den Jahren 1883 und 1884 zurück, über die konkrete Aufgabenstellung, die sich hieraus ergaben, entbrannten zwischen Bolschewiki und Menschewiki heftige Polemiken [Anderson 1979, S. 20]. Während der Revolution von 1905 artikulierte Lenin die Notwendigkeit, ein Bündnis des Proletariats sowohl mit der Kleinbourgeoisie [LW, Bd. 9, S. 33] als auch mit den Bauern unter Führung 
der Sozialdemokratie herzustellen, um eine bürgerlich-demokratische Staatsform zu erreichen [LW, Bd. 9, S. 119]. Nach dem Scheitern der Revolution polemisierte Lenin gegen den „Reformismus“ in der russischen Sozialdemokratie und beschuldigte die Menschewiki, den Gedanken der Hegemonie nicht begriffen, bzw. nicht angewandt zu haben:

Als die einzige konsequent revolutionäre Klasse der modernen Gesellschaft muss das Proletariat der Führer sein, der Hegemon im Kampf des ganzen Volkes für die vollständige demokratische Umwälzung, im Kampf aller Werktätigen und Ausgebeuteten gegen die Unterdrücker und Ausbeuter. Das Proletariat ist nur insofern revolutionär, als es sich dieser Idee der Hegemonie bewusst ist und in die Tat umsetzt. Der Proletarier, der sich der Idee der Hegemonie nicht bewusst geworden ist oder diese Idee verleugnet, ist ein Sklave der seinen Sklavenzustand nicht begreift. [...] Aber der Verzicht auf die Idee der Hegemonie ist die gröbste Art von Reformismus in der russischen Sozialdemokratie... [LW, Bd. 17, S. 219 f.]

Im Vergleich zu seinen früheren Ausführungen unterstrich hier Lenin die ökonomische Basis des Klassenbündnisses. Im gleichen Sinn, aber unter größerer Berücksichtigung der Gefahren einer bürgerlichen Trennung von Ökonomie und Politik, die eine korporatistische Politik der Arbeiterbewegung zu Folge haben könnte, formulierte dann in den zwanziger Jahren der Vierte Kongress der Kommunistischen Internationale:

Das Proletariat wird nur dann zur revolutionären Klasse, wenn es sich nicht auf den Rahmen eines engstirnigen Zunftgeistes beschränkt und in jeder Äußerung und in jedem Bereich des gesellschaftlichen Lebens als Führer der gesamten arbeitenden und ausgebeuteten Bevölkerung handelt [...] Das industrielle Proletariat kann seine weltgeschichtliche Mission nicht vollenden, [...] wenn es sich auf seine eigenen korporativen Sonderinteressen und auf Versuche zur Verbesserung seiner - bisweilen recht zufriedenstellenden - Lage innerhalb der bürgerlichen Gesellschaft beschränkt. [Zit. nach: Anderson 1979, S. 25]

Gramsci war als Teilnehmer des Vierten Kongresses der Kommunistischen Internationale mit dem von Lenin entwickelten Hegemonie-Begriff vertraut. Er benutzt diesen in gleicher Weise, wenn er rückblickend über die Strategie der Turiner Rätebewegung gegenüber dem Süden Italiens schreibt:

Die Turiner Kommunisten hatten sich konkret die Frage der „Hegemonie des Proletariats“ gestellt, das heißt die Frage der sozialen Basis der proletarischen Diktatur und des Arbeiterstaates. Das Proletariat kann in dem Maße zur führenden und herrschenden Klasse werden, wie es ihm gelingt, ein System von Klassenbündnissen zu schaffen, das ihm gestattet, die Mehrheit der Bevölkerung gegen den Kapitalismus und den bürgerlichen Staat zu mobilisieren; und das bedeutet in Italien, unter den 
real bestehenden Klassenverhältnissen, in dem Maß, wie es ihm gelingt, die Zustimmung der breiten, bäuerlichen Massen zu erlangen. [Gramsci 1986, Bd. 1, S. 191]

Wie in der Definition Lenins basiert das Klassenbündnis auf den gegebenen sozioökonomischen Verhältnissen, hier wird aber ein Begriffspaar eingeführt, das von Gramsci später auch in den Gefängnisheften aufgenommen wird: herrschende Klasse - führende Klasse ${ }^{104}$. Die Differenzierung „herrschendführend" wird in Gramscis Gefängnisheften aber nicht mehr explizit auf die Strategie der Arbeiterbewegung und ,ihren“ Weg zur Revolution angewendet, sondern ebenso auf die Kapitalherrschaft bezogen [Anderson 1979, S. 29] und zur Grundlage der Analyse jeglicher Klassenherrschaft gemacht .

Die Vormachtstellung einer sozialen Gruppe offenbart sich auf zweierlei Weise, als „Herrschaft“ und als ,geistige und moralische Führung“. Eine soziale Gruppe ist herrschend gegenüber den gegnerischen Gruppen, die sie zu „liquidieren“ oder selbst mit Waffengewalt zu unterwerfen sucht. Sie ist führend gegenüber den ihr verwandten und verbündeten Gruppen.[Gh, Bd. 2, S. 277]

Gramsci unterstreicht so, dass die Herrschaft einer Klasse zum einen darauf angewiesen ist, gegnerische Klassen („Gruppen“) ${ }^{106}$ notfalls gewaltsam zu unterdrücken, andererseits jedoch ihre Herrschaft auf einem Klassenbündnis beruht, in dem sie selbst führend ist. Weiterhin wird die Hegemonie einer Klasse im Lenin'schen Sinn auf die ökonomische Konstitution derselben zurückgeführt:

Die Tatsache der Hegemonie setzt zweifellos voraus, dass den Interessen und Tendenzen der Gruppierungen, über welche die Hegemonie ausgeübt werden soll, Rechnung getragen wird, dass sich ein gewisses Gleichgewicht des Kompromisses herausbildet, dass also die führende Gruppe Opfer korporativ-ökonomischer Art bringt, aber es besteht auch kein Zweifel, dass solche Opfer und ein solcher Kompromiss nicht das Wesentliche betreffen können, denn wenn die Hegemonie politischethisch ist, dann kann sie nicht umhin, auch ökonomisch zu sein, kann nicht umhin, ihre materielle Grundlage in der entscheidenden Funktion zu haben, welche die führende Gruppe im entscheidenden Kernbereich der ökonomischen Aktivität ausübt. [Gh, Bd. 7, S. 1567]

104 Dieses Begriffspaar geht allerdings auf die Urheberschaft Bucharins zurück, der den Unterschied zwischen „Führend“ und „Herrschend“ in Bezug auf die „Neue Ökonomische Politik“ (NEP) der UdSSR dahingehend formulierte, dass das Proletariat die Bourgeoisie beherrscht, ,aber es führt die Bauern“ [Zit. nach: Buci-Glucksmann 1981, S. 259].

106 Gramsci hat seine fragmentarischen Gefängnishefte während seiner Inhaftierung im faschistischen Italien geschrieben. Hierdurch wurde er genötigt, zentrale marxistische Begriffe zu ,codieren“ (Gruppe = Klasse, Philosophie der Praxis = Marxismus etc.) 
Die Hegemonie einer Klasse, basierend auf einem Bündnis mit einer anderen Klasse, kann somit nur zustande kommen, wenn die zwischen den beteiligten Klassen bestehenden Widersprüche in Bezug auf das gemeinsame Ziel nichtantagonistischer Art sind,

das Bürgertum hat die Macht ergriffen, indem es gegen bestimmte gesellschaftliche Kräfte kämpfte, unterstützt von bestimmten anderen Kräften; um sich im Staat zu vereinigen, musste es die einen ausschalten und den aktiven oder passiven Konsens der anderen haben. [Gh, Bd. 2, S. 410]

Diese eindeutige Definitionen des Begriffs „Hegemonie“ wird allerdings in Gramscis Schriften nicht kontinuierlich verwendet, sondern durch einen, sein Werk prägenden, erweiterten Begriff ersetzt:

Diese Studie [über die Intellektuellen] führt auch zu gewissen Feststellungen über die Konzeption des Staates, der gewöhnlich als politische Gesellschaft verstanden wird [...] und nicht als ein Gleichgewicht zwischen der politischen Gesellschaft und der kulturellen Gesellschaft (oder als Hegemonie einer sozialen Gruppe über die gesamte nationale Gesellschaft, ausgeübt durch die sogenannten Privatorganisationen, wie Kirche, Syndikate, Schulen usw.). [Gramsci o. J., S. 224]

Hegemonie wird so nicht mehr im Sinne der Führung eines Klassenbündnisses nicht-antagonistischer Art gebraucht, sondern als eine über kulturelle Institutionen vermittelte Herrschaft einer einzelnen Klasse über alle anderen, auch antagonistischen, Klassen begriffen. Hierin liegt ein entscheidender Unterschied zu der Lenin'schen Definition der Hegemonie: Verstand auch Gramsci ursprünglich Hegemonie als die Führung nicht-antagonistischer Klassen im Gegensatz zur gewaltsamen Unterdrückung gegnerischer Klassen, wird nun Hegemonie über alle Klassen ausgeübt, indem auch (und vor allem) der Konsens der gegnerischen Klassen organisiert wird, also zum einen die Unterstützung des „Aktivbürgers“, zum anderen die Duldung/passive Zustimmung antagonistischer Klassen erzielt wird.

Dieser Hegemoniebegriff ist zweifellos auf die modernen Gesellschaften zugeschnitten, in dem sich das Bürgertum ökonomisch, politisch und kulturell zur führenden und herrschenden Klasse aufgeschwungen hat [Anderson 1979, S. 30]. Diese Begriffsverschiebung, im Gegensatz zum eher strategisch ausgerichteten Begriff Lenins, hin zu einer analytischen Kategorie [Poulantzas 1980, S. 135 f.] stellt Gramsci vor die Frage, wie die Bourgeoisie den Konsens der von ihr unterdrückten Klassen erlangt. Diese Fragestellung konstituiert die 
weitere Begriffsbildung Gramscis, vor allem in Bezug auf die staatlichen und kulturellen Überbauten (im folgenden wird aber immer zu berücksichtigen sein, dass Gramsci z.T. auch die Lenin'sche Definitionen der Hegemonie verwendet).

\subsubsection{Staat und Zivilgesellschaft}

Wie sehr die Frage des Konsens in Bezug auf die Analyse des Staates im Mittelpunkt des Denkens Gramscis steht, kann durch seine Interpretation der Hegel'schen Staatskonzeption angedeutet werden:

Regierung mit dem Konsens der Regierten, aber mit dem organisierten Konsens, nicht mit einen allgemeinen und vagen, wie er sich zum Zeitpunkt der Wahlen äußert: der Staat hat und verlangt den Konsens, aber er „erzieht“ auch zu diesem Konsens mittels der politischen und gewerkschaftlichen Vereinigungen, die jedoch private, der Privatinitiative der führenden Klasse überlassene Organismen sind. [Gh, Bd. 1, S. 117 f.]

Hier sind die grundlegenden Kategorien Gramscis Begriffs des Staates enthalten: auf der einen Seite der Staat im engeren Sinn als „Regierung“/administrativen Apparat, auf der anderen Seite die „Organismen“, die er später „Zivilgesellschaft“" nennen wird (wie noch zu zeigen sein wird, sieht Gramsci diese „Überbauten“ immer in Bezug auf die jeweilige ökonomische Basis). „Zivilgesellschaft“ ist dabei nicht mit „bürgerlicher Gesellschaft“ zu verwechseln $^{107}$, die Marx so skizzierte:

Die bürgerliche Gesellschaft umfaßt den gesamten materiellen Verkehr der Individuen innerhalb einer bestimmten Entwicklungsstufe der Produktivkräfte. Sie umfaßt das gesamte kommerzielle und industrielle Leben einer Stufe und geht insofern über den Staat und die Nation hinaus, obwohl sie andrerseits wieder nach Außen hin als Nationalität sich geltend machen, nach Innen als Staat sich gliedern muss. [...] Die bürgerliche Gesellschaft als solche entwickelt sich erst mit der Bourgeoisie; die unmittelbar aus der Produktion und dem Verkehr sich entwickelnde gesellschaftliche Organisation, die zu allen Zeiten die Basis des Staates und der sonstigen idealistischen Superstruktur bildet, ist indes fortwährend mit demselben Namen bezeichnet worden. [MEW, Bd. 3, S. 36]

An anderer Stelle heißt es:

Die Gesamtheit dieser Produktionsverhältnisse bildet die ökonomische Struktur der Gesellschaft, die reale Basis, worauf sich ein juristischer und

107 Kaminski et al. scheint es, offenbar nicht nur durch einen Übersetzungsfehler bedingt, entgangen zu sein, dass Gramsci eben nicht über die „,bürgerlichen Gesellschaft“ (società borghese), sondern über die „Zivilgesellschaft“ (società civile) theoretisiert [Kaminski/ Karuscheit/Winter 1982, S. 180 ff.] 
politischer Überbau erhebt und welcher bestimmte gesellschaftliche Bewußtseinsformen entsprechen. [MEW, Bd. 13, S. 8]

Im Gegensatz zur Marx'schen Begrifflichkeit der „bürgerlichen Gesellschaft“, die die Gesamtheit der Produktions- und materiellen Verkehrsformen bezeichnet, über der sich der Staat erhebt, ist der Begriff der Zivilgesellschaft dahingehend inhaltlich eingeschränkt, dass er die vor allem kulturell-ideologischen gesellschaftlichen Überbauten erfassen soll [Kebir 1991 b, S. 52 f.].

Die Herausbildung der Begriffe Staat und Zivilgesellschaft unterlag bei Gramsci mehrfachen Verschiebungen, die im folgenden dargestellt werden sollen. Hierbei wird im Anschluss an Anderson zwischen drei verschiedenen Strängen der Begriffsentwicklung unterschieden [Anderson 1979, S. 34 ff.], anzumerken ist jedoch, dass diese verschiedenen Stränge keine zeitlich aufeinander folgende Entwicklung sind [Priester 1981, S. 61], sondern Gramsci die Begriffe mehrfach neu formulierte, wobei auch Modulationen zwischen den einzelnen „Stufen“ aufzufinden sind. Die dargestellten Phasen sind somit nur als idealtypische „Kristallisationspunkte“ in der Begriffsentwicklung Gramscis zu begreifen.

a) „Staat versus Zivilgesellschaft“: In einem ersten Schritt zur Definition des Verhältnisses von Staat und Zivilgesellschaft versucht Gramsci dieses durch eine strikte Funktionszuweisung zu bestimmen:

Was „öffentliche Meinung“ genannt wird, ist aufs engste mit der politischen Hegemonie verknüpft, es ist nämlich der Berührungspunkt zwischen der „Zivilgesellschaft" und der „politischen Gesellschaft“, zwischen dem Konsens und der Gewalt. Der Staat schafft, wenn er eine wenig populäre Aktion starten will, vorbeugend die angemessene öffentliche Meinung, das heißt, er organisiert und zentralisiert bestimmte Elemente der Zivilgesellschaft. [Gh, Bd. 4, S. 916 f.]

Somit werden die Funktionen „Gewalt“ an den Staat und „Hegemonie/ Konsens“ an die Zivilgesellschaft gebunden gesehen. Anhand dieser Funktionszuweisung versucht Gramsci, den Unterschied zwischen dem „Osten“ (Russland) und dem „Westen“ zu analysieren:

Im Osten war der Staat alles, die Zivilgesellschaft war in ihren Anfängen und gallertenhaft; im Westen bestand zwischen Staat und Zivilgesellschaft ein richtiges Verhältnis, und beim Wanken des Staates gewahrte man sogleich eine robuste Struktur der Zivilgesellschaft. Der Staat war nur ein vorgeschobener Schützengraben, hinter welchem sich eine robuste Kette von Festungen und Kasematten befand. [ebd., S. 874] 
Hieraus lassen sich zum einen einige Gegensätze ermitteln, die die Differenzen der Herrschaftsmethoden zwischen „Ost“ (dem zaristischen Russland) und „West“ (den bürgerlich-demokratischen Staaten) beschreiben, zum anderen eine von der geographischen Lage abhängige „Übermacht“ des Staates bzw. der Zivilgesellschaft ableiten [in Anlehnung an Anderson 1979, S. 34]:

\begin{tabular}{|l|l|l|}
\hline & Osten & Westen \\
\hline Dominant & Staat & Zivilgesellschaft \\
\hline Nicht-dominant & Zivilgesellschaft & Staat \\
\hline $\begin{array}{l}\text { Politische Herrschaft } \\
\text { durch }\end{array}$ & Zwang & Konsens - Hegemonie \\
\hline
\end{tabular}

Der fundamentale Unterschied zwischen „Ost“ und „West“ ist somit nach Gramsci in der Form der Herrschaftsausübung zu suchen, was vor Gramsci bereits von Lenin (eher beiläufig) bemerkt wurde [Anderson 1979, S. 35]:

Die Erfahrungen der bürgerlichen und gutsherrlichen Regierungen der ganzen Welt haben zwei Methoden der Niederhaltung des Volks gezeitigt. Die erste ist die der Gewalt. [...] Aber es gibt noch eine andere Methode, eine Methode, die die durch eine Reihe großer Revolutionen und revolutionärer Massenbewegungen „klug gewordene“ englische und französische Bourgeoisie zur höchsten Vollkommenheit gebracht hat. Es ist das die Methode des Betrugs, der Schmeichelei, der Phrase, der millionenfachen Versprechungen, der lumpigen Bettelgaben, der Zugeständnisse im Unwichtigen, der Erhaltung des Wichtigen. [LW, Bd. 24, S. 48]

Die von ihm erkannten Differenzen zwischen den westeuropäischen Staaten und Russland führten Gramsci zum einen zu der Annahme, dass eine einfache Adaption der bolschewistischen Taktik zwangsläufig eine Niederlage zur Folge hat, angesichts dieser Differenzen vielmehr eine neue Strategie erarbeitet werden müsse, zum anderen rückt das Verhältnis Staat - Zivilgesellschaft bezüglich der Frage der Hegemonie in das Zentrum des Blickfeldes Gramscis.

Bei seinem Vergleich zwischen „Ost“ und „West“ hat Gramsci aber nie die „historische Ungleichzeitigkeit“ der Entwicklung dieser Gesellschaftssysteme, also einerseits Feudalismus, andererseits auf kapitalistischer Produktionsweise basierender Parlamentarismus, erkannt und konnte dadurch die wesentlichen Differenzen der Staatstypen nicht erfassen [Anderson 1979, 71 S. ff.]. Amadeo Bordiga, Vertreter der Linken der Kommunistischen Partei Italiens und politischer Gegenspieler Gramscis, würdigte diesen elementaren Unterschied dagegen schon sehr früh [ebd., S. 75]. 
b) „Der integrale Staat“: Offensichtlich bemerkte Gramsci, dass die Funktionszuweisung Staat - Gewalt und Zivilgesellschaft - Hegemonie so nicht aufrecht zu erhalten ist, da der Staat eine Konsens- und Zwangsfunktion hat [Anderson 1979, S. 44]. Dies veranlasste Gramsci zu einer neuen Definition des Staates:

Wir sind noch auf dem Boden der Gleichsetzung von Staat und Regierung, einer Gleichsetzung, die gerade ein Wiederauftauchen der korporativ-ökonomischen Form ist, das heißt der Verwechslung von Zivilgesellschaft und politischer Gesellschaft, denn es ist festzuhalten, dass in den allgemeinen Staatsbegriffen Elemente eingehen, die dem Begriff der Zivilgesellschaft zuzuschreiben sind (in dem Sinne, könnte man sagen, dass Staat = politische Gesellschaft + Zivilgesellschaft, das heißt Hegemonie, gepanzert mit Zwang. [Gh, Bd. 4, S. 783]

Hierdurch entsteht eine „methodologische Verdoppelung“ (Buci-Glucksmann) des Staatsbegriffs: der Staat besteht im weiteren Sinn aus (Zivil-) Gesellschaft und Staat im „engeren Sinn“ (Verwaltung, Polizei, Regierung), Zivilgesellschaft und administrativer Apparat bilden den „,integralen“ Staat, der Staat ist „in integraler Bedeutung: Diktatur + Hegemonie“ [ebd., S. 824]. Hierdurch ergibt sich eine Abgrenzung zu einer Staatstheorie, die im Staat nur den Verwaltungs-/Repressionsapparat sieht und diesen als Instrument der herrschenden Klasse interpretiert. Die organisierte Hegemonie wird als wesentlicher Bestandteil der „westlichen“ Staaten in die Staatstheorie aufgenommen. Nach Gramsci erfüllt der Staat die Funktion der Konsensbildung u.a. dadurch, dass er die kulturell notwendigen Rahmenbedingungen der jeweiligen Produktionsweise herstellt:

Erziehungs- und Bildungsfunktion des Staates, der immer das Ziel hat, neue und höhere Zivilisationstypen zu schaffen, die „Zivilisation“ und die Moral der breitesten Volksmassen den Erfordernissen der ständigen Entwicklung des ökonomischen Produktionsapparates anzupassen, folglich auch physisch neue Menschheitstypen herauszuarbeiten. [Gh, Bd. 7, S. 1544]

Diese „erzieherische“ Funktion wird dabei nicht nur von den Erziehungs- und Bildungsapparaten wahrgenommen, sondern vor allem durch das Recht gesteuert, dass darauf abziele, „einen bestimmten Typus von Zivilisation und von Staatsbürgern“ hervorzubringen, indem es versucht, „bestimmte Gewohnheiten und Verhaltensweisen zum Verschwinden zu bringen und andere zu verbreiten“ [ebd., S. 1548]. Vor dem Hintergrund der sich neu entwickelnden Produktionsorganisation des Fordismus/Taylorismus sieht Gramsci aber auch eine direkte ökonomische Funktion des Staates: 
Aufgrund der Tatsache, dass im wesentlichen auf die ökonomischen Kräfte eingewirkt wird, dass der Apparat der ökonomischen Produktion reorganisiert und entwickelt wird, dass die Struktur erneuert wird, darf nicht der Schluss gezogen werden, die Fakten der Superstruktur müssten sich selbst, ihrer spontanen Entwicklung, einem zufälligen und sporadischen Aufkeimen überlassen werden. Der Staat ist auch auf diesem Gebiet ein Instrument der „Rationalisierung“, der Beschleunigung und der Taylorisierung, er wirkt nach einem Plan, drängt, fördert, und „straft", denn wenn einmal die Bedingungen geschaffen sind, unter denen eine bestimmte Lebensweise „möglich“ ist, muss das „kriminelle Tun und Lassen" eine Strafsanktion von moralischer Tragweite haben, und nicht nur ein Urteil hinsichtlich einer allgemeinen Gefährlichkeit. Das Recht ist der repressive, negative Aspekt der gesamten positiven Enkulturation des Staates. In die Rechtsauffassung müssen auch die Aktivitäten der „Belohnung“ von Individuen, Gruppen usw. einbezogen werden; man belohnt die lobenswerte, verdienstvolle Aktivität, wie man die kriminelle Aktivität bestraft (und auf originelle Weisen bestraft, indem man die „öffentliche Meinung“ als sanktionierendes Element auftreten lässt). [ebd., S. 1549]

Diese Passage ist in mehrfacher Hinsicht interessant. Zum einen belegt sie, dass Gramsci nicht in den ökonomistischen Mechanismus verfallen ist, nach dem der Staat (bzw. alle Überbauten) Ableitungen der ökonomischen Basis sind und sich sein eigenes Wesen automatisch den Entwicklungen der ökonomischen Basis anpasst, sondern vielmehr die Wechselwirkung respektive „Verschränkung“ (Sabine Kebir) der Basis und der (staatlich-juristischen) Überbauten betont wird, also die Möglichkeit herausgearbeitet wird, mittels des Überbaus auf die ökonomische Basis entsprechend den Erfordernissen einzuwirken. [Kebir 1991b, S. 62]

Ein weiterer Aspekt ist die Weiterentwicklung des marxistischen Rechtsbegriffs, der - insbesondere innerhalb der vulgärmarxistischen Darstellungen - auf die Funktion der Eigentums- und Herrschaftssicherung beschränkt wurde. Gramsci versucht hier, die Frage des Rechts nicht nur in Bezug auf die Produktionsverhältnisse, sondern ebenso auf die Produktionsweise im engeren Sinn anzuwenden: das Recht erscheint so nicht nur als Faktor, um die Gesellschaft auf ein den Erfordernissen der Produktion entsprechendes Kulturniveau $\mathrm{zu}$ heben, sondern ebenso als direktes Mittel, die Aufrechterhaltung und Intensivierung des Produktionsprozesses zu betreiben. Dies bedürfe allerdings einer $\mathrm{zu}$ erzeugenden moralischen Komponente, um $\mathrm{zu}$ funktionieren. Die „erzieherischen“ und „repressiven“ Funktionen werden allerdings nicht nur 
durch den Staat im engeren Sinn, sondern ebenso von den ,privaten“ Organen der Zivilgesellschaft getragen [Gh, Bd. 5, S. 1043].

Zwischen der ökonomischen Struktur und dem Staat mit seiner Gesetzgebung und seinem Zwang steht die Zivilgesellschaft, und diese muss radikal umgestaltet werden [...]; der Staat ist das Instrument zur Anpassung der Zivilgesellschaft an die ökonomische Struktur, aber es ist nötig, dass der Staat dies tun „will“, dass also die Führung des Staates bei den Vertretern der in der ökonomischen Struktur eingetretenen Veränderung liegt. [Gh, Bd. 6, S. 1267]

Im Zusammenhang mit der ökonomischen Basis ergibt sich so ein weiteres Verhältnis zwischen Staat und Zivilgesellschaft: die Zivilgesellschaft erscheint zum einen als Vermittlungsinstanz zwischen Basis und staatlichem Überbau, in welcher die, für die (Um-) Gestaltung der gesellschaftlichen Verhältnisse notwendigen, Kämpfe ausgetragen werden; zum anderen ist die Zivilgesellschaft selbst anvisierter Gegenstand des „Umbaus“.

Die oben genannte Formel ,Staat $=$ politische Gesellschaft + Zivilgesellschaft, das heißt Hegemonie, gepanzert mit Zwang“ benutzt Gramsci allerdings nicht durchweg, sondern diese wird teilweise durch eine Neudefinition der Hegemonie überlagert, nach der Hegemonie nun nicht mehr allein aus der Organisierung des Konsens, sondern ebenso in der Ausübung des Zwangs besteht [Anderson 1979, S. 43 f.]. Dies ist offensichtlich dem Umstand geschuldet, dass zwischen den Begriffen „Staat“ und „Zivilgesellschaft“ eine strukturelle Asymmetrie besteht:

Staat und zivile Gesellschaft teilen sich die Ausübung ideologischer Herrschaft; die Gewalt fällt nur dem Staat zu. Oder anders: In jede Gleichung von Konsens und Gewalt geht der Staat gleich doppelt ein. [Anderson 1979, S. 44]

„Diktatur + Hegemonie“ respektive „Hegemonie, gepanzert mit Zwang“ bedeutet auf staatlicher Ebene somit nicht, dass die „Gewalt-, Militär- und Polizeiapparate nicht ohne ein Element des Konsenses funktionieren“ [Albers 1983, S. 41], sondern im Gegenteil, dass diese Apparate zum Einsatz kommen, sobald der Konsens auch nur in geringer Weise gestört wird, um diesen wieder herzustellen. Oder, wie Sabine Kebir formuliert: „Konsensbildend ist nicht nur die Diskussion, sondern auch ein gelegentlicher Demonstrationstoter“ [Kebir 1991 b, S. 72]. 
c) „Zivilgesellschaft = Staat“: Die Mängel der bisherigen Begriffsdefinitionen scheinen Gramsci durchaus bewusst gewesen zu sein, denn er lässt diesen eine weitere, fast entgegengesetzte Definition folgen, in der er behauptet, dass ,in der Wirklichkeit der Tatsachen Zivilgesellschaft und Staat ein und dasselbe sind“" [Gh, Bd. 7, S. 1566]. Durch diese behauptete Einheit von Staat und Zivilgesellschaft kommt Gramsci zwar der oben gezeigten strukturellen „Übermacht" des Staates gegenüber der Zivilgesellschaft entgegen, allerdings um den Preis, dass „Zivilgesellschaft“ als eigenständige Kategorie aufgelöst wird. Alle vormals in der „Zivilgesellschaft“" verorteten privaten Organe zur Herstellung und Aufrechterhaltung der Hegemonie werden nun als staatliche Organe begriffen und eine Unterscheidung zwischen ziviler Gesellschaft und Staat wird aufgegeben [Anderson 1979, S. 46], der Staat vielmehr der

gesamte Komplex praktischer und theoretischer Aktivitäten ist, womit die führende Klasse ihre Herrschaft nicht nur rechtfertigt und aufrechterhält, sondern es ihr auch gelingt, den aktiven Konsens der Regierten zu erlangen. [Gh, Bd. 7, S. 1725]

Bei der Identifizierung privater Institutionen mit staatlichen Apparaten bleibt Gramsci allerdings nicht stehen, selbst außerhalb des eigentlichen Staates stehende Gruppen und Individuen werden jetzt als Elemente des Staates begriffen:

In Wirklichkeit ist jedes homogene gesellschaftliche Element „Staat“, repräsentiert den Staat, insofern es seinem Programm anhängt: sonst verwechselt man den Staat mit der staatlichen Bürokratie. Jeder Mitbürger ist „Beamter“, wenn er im gesellschaftlichen Leben in der vom Staat - Regierung vorgezeichneten Führung aktiv ist, und er ist desto mehr „Beamter“, je mehr er dem staatlichen Programm anhängt und es intelligent bearbeitet. [Gh, Bd. 2, S. 380]

An anderer Stelle:

Was ist die Polizei? Sicherlich ist sie nicht nur jene gewisse offizielle Organisation, die juristisch anerkannt und mit der öffentlichen Aufgabe der öffentlichen Sicherheit betraut ist, die man für gewöhnlich meint. Dieser Organismus ist der zentrale und formal verantwortliche Kern der „Polizei“, die eine sehr viel umfangreichere Organisation ist, an der, direkt oder indirekt, mit mehr oder weniger präzisen und bestimmten, dauerhaften oder zufälligen usw. Bindungen ein großer Teil der Bevölkerung eines Staates teilhat. Die Analyse dieser Verhältnisse dient dem Begreifen dessen, was der „Staat“ ist, viel mehr als viele philosophisch-juristische Abhandlungen. [ebd., S. 325] 


\subsubsection{Ideologie und Reproduktion der Produktionsverhältnisse}

Der Sinn der begrifflichen Ausweitung des Staates und der Rückgriff auf Gramsci wird bei Althusser deutlich, wenn er die zentrale Aufgabe des Staates (als Summe von ISA und RSA) benennt: der Staat sei erforderlich zur Reproduktion der Produktionsverhältnisse. Die Produktionsverhältnisse müssen nach Althusser in ihrer Gesamtheit (also alle ökonomischen, ideologischen, politischen Strukturen) reproduziert werden. Die Reproduktion erfolgt nach Althusser vor allem in den politisch-juristischen und ideologischen Formen [IISA, S. 123] ${ }^{109}$, denn diese Reproduktion ist - als Reproduktion des Klassengegensatzes - vor allem eine Reproduktion der politischen Herrschaft, folglich müsse die Hegemonie einer Klasse reproduziert werden. Bei der Reproduktion der Produktionsverhältnisse falle den RSA die Aufgabe zu, „mit (physischer oder nicht-physischer) Gewalt die politischen Bedingungen der Reproduktion der Produktionsverhältnisse zu sichern“ [IISA, S. 124], sich nicht nur selbst zu reproduzieren, sondern die politischen Rahmenbedingungen der ISA zu schaffen. Im Gegensatz zu den RSA, die ein unter einer zentralisierenden Klassenkampfpolitik organisiertes Ganzes darstellen würden, seien die ISA

„relativ autonom“ und in der Lage, ein objektives Feld für Widersprüche $\mathrm{zu}$ liefern, in denen sich in mal begrenzten, mal extremen Formen die Auswirkungen der Zusammenstöße zwischen dem kapitalistischen Klassenkampf und dem proletarischen Klassenkampf sowie ihrer untergeordneten Formen ausdrücken. [IISA, S. 123]

Die ISA sind demnach sowohl Einsatz wie auch Ort des Klassenkampfes [IISA, S. 122]. Während die Einheit der RSA durch die eigene Struktur und Organisation garantiert werde, sei die Einheit der ISA durch die (widersprüchlichen) Formen der herrschenden Ideologie gesichert (welche wiederum die Ideologie der herrschenden Klasse ist).

Somit findet in den ISA die eigentliche Reproduktion der Produktionsverhältnisse statt: die Individuen werden in dem Sinne mit der herrschenden Ideologie ,ausgestattet“, in dem die ISA die materiellen Apparate darstellen, die die ideologischen Praxisformen definieren, in denen die Individuen als Subjekte konstituiert werden. Somit trügen alle ISA zu dem Ergebnis bei, die Produktionsverhältnisse zu reproduzieren,

109 Wobei sich diese Strukturen niemals identisch reproduzieren, die Konzeption ist also keineswegs anti-historisch ausgerichtet, vgl. Balibar 1994b, S. 37. 
jeder von ihnen trägt zu diesem einzigen Ergebnis bei auf eine Art und Weise, die ihm eigen ist. Der politische Apparat, indem er die Individuen der politischen Staatsideologie unterwirft: der „,demokratischen“, der ,indirekten“ (parlamentarischen) oder der „direkten“ (plebiszitären oder faschistischen) Ideologie. Der Informationsapparat indem er alle „Bürger“ durch Presse, Rundfunk und Fernsehen mit einer täglichen Ration Nationalismus, Chauvinismus, Liberalismus, Moralismus usw. vollstopft. Ebenso der kulturelle Apparat (die Rolle des Sports im Chauvinismus ist von großer Bedeutung). [IISA, S. 127]

Im Gegensatz zum Feudalismus, in dem die Kirche der dominierende ideologische Staatsapparat gewesen sei, komme im entwickelten kapitalistischen System dem schulischen ISA die dominierende Rolle zu [IISA, S. 125 ff.] ${ }^{110}$, da dort (neben dem familiären ISA) die grundlegende ideologische „Zurichtung“ der Individuen stattfindet, der schulische ISA (vom Kindergarten bis zur Eliteuniversität) versieht die verschiedenen gesellschaftlichen Agenten der Klassengesellschaft mit der ihnen adäquaten Ideologie. Jede gesellschaftliche Gruppe, die aus dem schulischen ISA ausscheidet,

ist praktisch mit der Ideologie versehen, die ihrer Rolle in der Klassengesellschaft entspricht: der Rolle des Ausgebeuteten (mit stark „,entwickeltem“, ,professionellen“, „moralischen“, „staatsbürgerlichen“, „nationalen“ und unpolitischen Bewusstsein); der Rolle des Agenten der Ausbeutung [...], der Rolle der Agenten der Unterdrückung (Fähigkeit zu befehlen [...] oder mit der Demagogie der Rhetorik von politischen Führern vorzugehen) oder der Berufsideologen. [IISA, S. 128]

Durch das Erlernen von (vermeintlich) „neutralen“ Fähigkeiten werden „zu einem Großteil die Produktionsverhältnisse einer kapitalistischen Gesellschaftsformation“ [IISA, S. 129], die gesellschaftlichen Verhältnisse von „Ausgebeuteten zu Ausbeutern und Ausbeutern zu Ausgebeuteten“ [ebd.] reproduziert.

Von Bedeutung wird die ,ideologische Ausstattung“ der Agenten auch bezüglich der Unterscheidung von Staatsmacht und Staatsapparat: die Frage, wie die den Produktionsverhältnissen ,entspringende“ Macht der herrschenden Klasse sich in den Staatsapparat als Staatsmacht transformiert, kann provisorisch dahingehend beantwortet werden, dass es auf eine personelle „Verstrickung“ zwischen herrschender Klasse und den „Politikern an der Macht“ nicht

110 Aufgrund dieser Konzeption der Schule als dominierenden ISA wurde die Schule Gegenstand von empirisch-soziologischen und linguistisch-genealogischen Untersuchungen, die diese Konzeption stützen [Dosse 1999, Bd. 2, S. 208 f.]. 
ankommt ${ }^{111}$. Die Inhaber der politischen „Schlüsselstellen“ in den RSA und ISA handeln als Agenten eines (ihnen bewussten oder unbewussten) gesellschaftlichen Prozesses, der die Reproduktion der Produktionsverhältnisse zum Ziel hat, sie handeln in einem individuell und gesellschaftlich immer-schongegebenen ideologischen Kontext, der auf dieses Ziel gerichtet ist.

111 Milliband hat die (insbesondere im Marxismus-Leninismus) vertretene Vorstellung, dass die Bourgeoisie dadurch herrschende Klasse sei, dass sie persönlich die staatlichen Apparate „bediene“ (wie auch die umgekehrte Argumentation der bürgerlichen) empirisch in Frage gestellt [Milliband 1972]. 


\subsection{Zur Ideologie- und Diskurstheorie}

a) Mit der oben skizzierten Ideologiekonzeption, also einer innerhalb von gesellschaftlichen Praxen definierten Ideologie ${ }^{112}$, die aus den Individuen beherrschte Subjekte macht, entwickelt sich die Theoriebildung Althussers partiell zu der Foucaults parallel: In dessen Konzeption des Diskurses wird das Subjekt selbst innerhalb von - von Machtverhältnissen durchzogenen diskursiven Praktiken konstituiert [Poster 1984, S. 38 f.]. Ähnlich verhält es sich in der Ideologietheorie Althussers, in der Individuen durch den Akt der Anrufung zu Subjekten werden, in dieser Konzeption stellt sich dabei weniger die Frage nach den Subjekten selbst, sondern die Mechanismen der Subjektivierung und damit die ideologische Vergesellschaftung ${ }^{113}$ der Individuen stehen im Zentrum.

112 Wird die Konzeption der Ideologie als Praxisform auf die Stellen des Kapitals angewandt, die sich dem Warenfetischismus widmen, können diese ebenso in die Theorie integriert werden: Wenn Ideologie, streng materialistisch, aus einer bestimmten Praxis entspringt, ist natürlich der Warentausch ursächlich für den Warenfetisch, in der Warenform erscheint das gesellschaftliche Verhältnis der einzelnen Produzenten plötzlich als Verhältnis von Dingen, dabei hat aber „die Warenform und das Wertverhältnis der Arbeitsprodukte, worin sie sich darstellt, mit ihrer physischen Natur und den daraus entspringenden dinglichen Beziehungen absolut nichts zu schaffen" [MEW, Bd. 23, S. 86]. Das heißt allerdings nach den Analysen Marx' auch, dass der Warentausch selbst eine „ideologische Praxis“ ist: „Indem sie [die Menschen] ihre verschiedenartige Produkte einander im Austausch als Werte gleichsetzen, setzen sie ihre verschiednen Arbeiten einander als menschliche Arbeit gleich“ [MEW, Bd. 23, S. 88]. Diese, sich sowohl in die alltäglichen als auch in die wissenschaftlichen Ideologien einschreibende ideologische Praxis setzt sich dann in den wissenschaftlichen Kategorien der politischen Ökonomie fort, beispielsweise erscheint der Zins dann als „Resultat des gesamten Reproduktionsprozesses [...] als eine, einem Ding von selbst zukommende Eigenschaft. [....] Im zinstragenden Kapital ist daher dieser automatische Fetisch rein herausgearbeitet, der sich selbst verwertende Wert, Geld heckendes Geld [...]. Das gesellschaftliche Verhältnis ist vollendet als Verhältnis eines Dings, des Geldes, zu sich selbst. [...] Während der Zins nur ein Teil des Profits ist, d. h. des Mehrwerts, den der fungierende Kapitalist dem Arbeiter auspreßt, erscheint jetzt umgekehrt der Zins als die eigentliche Frucht des Kapitals“ [MEW, Bd. 25, S. 405].

Streng genommen (und gegen Marx verwandt) ist dies keine Theorie des Fetischs, sondern eine Ideologietheorie, die also nicht auf den philosophischen Fundamenten einer Theorie des Fetischs beruht. Balibar hat in aller Deutlichkeit diese philosophische Fundierung des Warenfetischs herausgearbeitet, die vollkommen auf der Annahme eines sich entfremdenden Subjekts beruht [Balibar 1977c, S. 312].

Notabene: Eine Kritik des Warenfetischismus stellt sicherlich eine Fundamentalkritik der bürgerlichen Gesellschaft dar, wenn aber auf den Warenfetisch zurückgegriffen wird, um monistisch alle „Erscheinungsformen“ der bürgerlichen Gesellschaft zu erklären, muss eine solche Konzeption selbst Gegenstand der Kritik werden - erst recht, wenn sie an einem essenzialistischen Wertbegriff festhält.

113 Vergesellschaftung wird hier nicht wie bei Weber als von Vergemeinschaftung differenziert verstanden [Weber 1984, S. 69 ff.] sondern beinhaltet explizit auch die affektuellen, traditionellen und emotionalen Mechanismen [ebd.] zur „Herstellung“ von Gesellschaft. 
Althussers Theorieansatz scheint hierbei einigen Autoren insoweit wegweisend, indem daran eine diskursorientierte Theorie zur Problematik der Subjektkonstitution angeschlossen werden kann; diese soll klären, wie der herrschenden Ideologie entgegengesetzte Ideologien entstehen können. Die Anrufung der Subjekte durch die herrschende Ideologie verlaufe nach dieser Konzeption niemals ,glatt“, sondern mit Brüchen,

in den Bruchstellen, den Widersprüchen, den Fehlleistungen etc. der herrschenden Anrufungen - und nicht etwa jenseits der Ideologie! entsteht die Gegenanrufung. [...] Es gibt weder die einheitliche Welt der herrschenden Ideologie noch zwei einander diametral entgegengesetzte Welten. Vielmehr teilt sich auf der Grundlage der herrschenden Ideologie und durch deren Widersprüche das Eine in Zwei (oder mehr Welten). [Müller et. al. 1994, S. 144]

Aus diesen (kognitiven) Fehlleistungen ließe sich somit die Existenz neuer „regionaler Ideologien“ erklären, die sich den herrschenden Ideologien entgegenstellen und in den Kampf um Hegemonie eingebracht werden [Müller et. al. 1994, S. 145 f.]. Der vorgestellte Ansatz lässt sich noch radikalisieren, so setzt eine an Althusser und Foucault angelehnte Analyse von Laclau/Mouffe vollkommen auf den Begriff des Diskurses. Laclau definiert innerhalb seiner Analyse Populistischer Bruch und Diskurs dabei das Diskursive als das „Ensemble der Phänomene gesellschaftlicher Sinnproduktion“ [Laclau 1981, S. 176]. Diskurse sind demnach nicht „Überbauten“, sondern alle sozialen, gesellschaftlichen Verhältnisse sind Diskurse, ,in dieser Perspektive muss die ökonomische Praxis selbst als Diskurs aufgefasst werden“" [ebd.]. Dementsprechend vollzieht sich die Subjektkonstitution nur innerhalb und durch Diskurse, das Subjekt wird „selbst als Differenz im Inneren des jeweiligen Diskurses“ konstituiert [ebd.]. Der Klassenwiderspruch zwischen Arbeiterklasse und Bourgeoisie entspringt in dieser Konzeption nicht einer Produktionsweise, also der jeweiligen Stellung zu den Produktionsmitteln, sondern die Klassen konstituieren sich erst innerhalb von Diskursen,

class antagonism is not inscribed in the relations of production considered as an extra-discursive structure but derives instead from the particular discursive identification (or ,interpellation“) of class subjects. [Jessop 1982, S. 196].

Demirović merkt zu der Konzeption von Laclau/Mouffe zurecht an, dass das Diskursive hier zu einem Spiel der Signifikanten wird, zu Identitätselementen, die in einem Diskurs beständig neu kombiniert werden können und eine neue 
Identität schaffen, „die einzelnen diskursiven Elemente haben jedenfalls, außerhalb des jeweils konkreten Diskurses, keine eigene gleichsam natürliche und ontologische Bedeutung“ [Demirović 1994, S. 97]. Diese Konzeption sei insoweit ahistorisch, da die Signifikanten keine Geschichte haben, so ,als würden sich die Signifikanten niemals anreichern, zur Konvention werden und geschichtlich werden“ [ebd., S. 98]. Die Stärke des Ansatzes ist aber, dass er verdeutlicht, dass die Gesellschaft nicht per se existiert, sondern von den sozialen Akteuren beständig neu produziert wird [ebd., S. 97] ${ }^{115}$.

Diese Kritik an Laclau/Mouffe sollte allerdings keineswegs nahe legen, den Begriff des Diskurses wieder aufzugeben, denn wenn der (strukturalistische) Marxismus behauptet, dass die ökonomische Struktur determinierend gegenüber den anderen gesellschaftlichen Strukturen (Ideologie, Politik) ist, bezeichnet er mit dem „Ökonomischen“ schon eine Struktur, in der Ideologie und Politik konstitutiv anwesend sind - es gibt keine „reine“ Ökonomie. Wenn also der Marxismus eine Logik ökonomischer Handlungen entwickelt, ist dies keine innere, ahistorische Logik der „Produktion an sich“, sondern eine Logik von Produktionsverhältnissen, welche selbst aus politischen und ideologischen Prozessen hervorgegangen sind und mit diesen in engstem Verhältnis steht. Das Problem der relativen Trennung und der Determination der gesellschaftlichen Strukturen ist also, dass Politik, Ideologie und Ökonomie der gesellschaftlichen Form nach getrennt und doch gleichzeitig beständig in den jeweils anderen Strukturen anwesend sind und sich ineinander einschreiben. Die Differenzierungslinien der verschiedenen gesellschaftlichen Strukturebenen werden dabei von den gesellschaftlichen Praxen gezogen: in der gegenseitigen Konstitution der gesellschaftlichen Strukturen kann nicht mehr alles auf die Praxis der Produktion oder des Warentausches reduziert werden, sondern es muss anerkannt werden, dass ebenso diskursive Formationen vorliegen, mit denen die verschiedenen gesellschaftlichen Bereiche ineinander „eindringen“. Umgekehrt kann argumentiert werden, dass aber auch die relative Trennung der verschiedenen gesellschaftlichen Bereiche, ihre relative Autonomie und ihre Determinationsweisen - also vor allem die determinierende Stellung der Ökonomie und ihre spezifische Autonomie - selbst Produkt von zum „objektiven Geist“ Adornos und Hegels ist [Demirović 1994, S. 97]. 
diskursiven Praxen sind. Es kann Marx durchaus gefolgt werden, wenn er annimmt, dass die Trennung in Klassen durch den Prozess der ursprünglichen Akkumulation eingeleitet wurde, aber die Legitimation dieses Prozesses, die Reproduktion der gesellschaftlichen Klassen und die gleichzeitige im bürgerlichen System manifeste Ausgrenzung des „harten Kerns“ der Ökonomie (die Eigentums- und Aneignungsverhältnisse) aus dem Bereich des Politischen (vor allem durch das positive Recht) muss im Zusammenhang mit diskursiven Praktiken gedacht werden.

Der Begriff des Diskurses ist aber auch ein entscheidender Punkt, an dem sich die Arbeiten von Althusser und Foucault in einem anderen Aspekt treffen: während der Begriff des Diskurses die gesellschaftliche Praxis bezeichnet, innerhalb derer der ideologische, wissenschaftliche, kulturelle etc. Zusammenhalt einer Gesellschaft organisiert wird, bezeichnet Althusser mit dem Begriff der ideologischen Staatsapparate die jeweiligen gesellschaftlichen Institutionen oder Orte, innerhalb derer eben diese Diskurse produziert, deren Regeln definiert und kontrolliert werden; in der modernen bürgerlichen Gesellschaft sind die gesellschaftlichen Praxen des (wissenschaftlichen wie nichtwissenschaftlichen) Diskurses mit spezifischen Orten und Institutionen gekoppelt, für die der Staat eine integrative und organisierende Funktion hat:

Niemand wird es entgehen, dass die drei Orte, Formen und Mächte der Kultur [...] (der explizit politische Diskurs der ,politischen Klasse“, der mediale Diskurs und der intellektuelle, gelehrte oder akademische Diskurs), mehr denn je durch dieselben Apparate oder durch nicht voneinander trennbare Apparate verschweißt sind. Diese Apparate sind zweifellos komplex, differenziell, konfliktuell, überdeterminiert. [Derrida 1996, S. 91] ${ }^{116}$

Die Diskurse haben dadurch funktionalen Charakter für die ökonomische, ideologische und politische Reproduktion der Gesellschaft und ihrer Produktionsweise. Die gesellschaftlichen Orte, in denen diese Diskurse organisiert werden, sind dabei in dem Sinn repressiv, in dem von diesen (staatlichen) Institutionen die Faucault'schen Ausschliessungsprinzipien des Diskurses

116 Das bedeutet natürlich auch, dass innerhalb der Diskursordnung eine Klasse strukturell übervorteilt ist, denn die materielle Organisation der Diskurse in den verschiedenen Apparaten vollzieht sich schon selbst als (staatliche) Struktur: privatwirtschaftlich oder staatlich organisierte Massenmedien (die diskursive Formation der modernen Gesellschaft schlechthin), staatlich ausgebildete Journalisten, Lehrer und Wissenschaftler als Teilnehmer oder Moderatoren der Diskurse (Gramscis Intellektuelle) usw. 
durchgesetzt werden [vgl. Foucault 1997d, S. 16 ff.] ${ }^{117}$. Durch diese Ausschliessungsprinzipien haben Diskurse natürlich auch (und nicht nur wegen ihrer engen Verbindung mit der staatlichen Struktur) immer einen politischen Charakter. Dieser Charakter scheint aber auch dadurch gegeben, dass in diesen Diskursen sowohl die herrschende Ideologie „kommuniziert“ wird; ebenso ist aber auch die Aneignungsweise und -möglichkeit des Diskurses selbst schon Gegenstand politischer Techniken:

Die Erziehung mag de jure ein Instrument sein, das in einer Gesellschaft wie der unsrigen jedem Individuum den Zugang zu jeder Art von Diskurs ermöglicht - man weiß jedoch, dass sie in ihrer Verteilung, indem, was sie erlaubt, und in dem, was sie verhindert, den Linien folgt, die von den gesellschaftlichen Unterschieden, Gegensätzen und Kämpfen gezogen sind. Jedes Erziehungssystem ist eine politische Methode, die Aneignung der Diskurse mitsamt ihrem Wissen und ihrer Macht aufrechtzuerhalten oder zu verändern. [Foucault 1997d, S. 29 f.]

Die bisherigen Ausführungen sollen natürlich nicht nahe legen, dass die Diskurse, in denen die herrschende Ideologie ausgearbeitet und verbreitet wird, ohne gesellschaftlichen Widerspruch bleiben, allerdings ist zu konstatieren, dass die „Gegendiskurse“ und „regionalen Ideologien“ sich zwangsläufig auf den herrschenden Diskurs beziehen müssen, der „Kampf der Ideologien“ vollzieht sich innerhalb von Orten, die selbst wiederum Teil der staatlichen Struktur sind, oder, um es mit Gramsci zu formulieren: die gesellschaftlichen Orte der Diskurse sind zivilgesellschaftliche Apparate, in denen der Kampf um Hegemonie ausgetragen wird. Das beinhaltet natürlich auch, das sich die „Nichtübereinstimmenden“ (Gramsci) genau dort zu artikulieren versuchen.

Die Kopplung der verschiedenen Diskurse mit verschiedenen Institutionen der Zivilgesellschaft legt nahe, dass Diskurse nicht „beliebig“ existieren können, sondern Diskurse werden in der kapitalistischen Gesellschaftsformation in dem Sinn ,zentriert“ (durch einen gemeinsamen Bezugspunkt: dem Staat), dass sie zur Reproduktion der Produktionsverhältnisse beitragen. Diskursive Praxen außerhalb dieses Verhältnisses können insoweit nicht existieren, da auch „negative“ Diskurse sich immer auf den herrschenden Diskurs

117 Vor dem bisher gesagten sollte offensichtlich sein, dass, versteht man unter Marxismus ein anderes theoretisches Feld als den unsäglichen „Marxismus-Leninismus“, sich zahlreiche Arbeiten Foucaults, insbesondere Überwachen und Strafen sowie Der Wille zum WissenSexualität und Wahrheit I als materialistische Studien der Macht als wertvolle Beiträge auch zum marxistischen wissenschaftlichen Diskurs begreifen lassen - Beiträge, die dazu geeignet sind, gewisse ,ideologische Theorien“ zu überwinden (vgl. Lecourt 1975a). 
beziehen und von diesem auf- und umgearbeitet werden. Innerhalb einer kapitalistischen Gesellschaft gibt es demnach keine „herrschaftsfreien“ Diskurse $^{118}$, der entwickelte herrschende Diskurs bildet das „historische Apriori“ (Foucault) jedes - auch antagonistischen - politischen Diskurses.

b) Wenn Althussers Ideologie- und Subjektkonzeption ${ }^{119}$ in Verbindung mit den ideologischen Staatsapparaten bedeutet, dass das Subjekt in einer kapitalistischen Gesellschaftsformation über und durch den Staat konstituiert wird und die Totalität der kapitalistischen Gesellschaft dann u. a. darin besteht, dass es keinen gesellschaftlichen Bereich mehr gibt, der nicht „Staat“ ist, entstünde aber nun bezüglich des Verhältnisses zwischen ISA und RSA das Problem, wozu jetzt noch der repressive Staatsapparat dienen sollte: Angesicht der Monstrosität der ideologischen Staatsapparate, die die Subjekte vollkommen umgeben und beherrschen, bliebe eigentlich kein Raum, in denen Althussers „schlechte Subjekte“ entstehen könnten, gegen die sich dann der repressive Staatsapparat richtet. Dieser Interpretation ließe sich aber entgegensetzen, dass im Moment der „Installation“ eines ideologischen Staatsapparats der Klassenkampf (und damit bestimmte Formen des Widerstands) in diesem immer schon gegeben ist [IISA, S. 156].

Allerdings stellt sich wiederum die Frage, wie dem herrschenden Diskurs entgegengesetzte Ideologien entstehen und in welchem Zusammenhang diese mit der gesellschaftlichen Praxis stehen. Die bereits angesprochene Konzeption, die das Entstehen von „regionalen“/antagonistischen Ideologien auf das „Versagen“ von ideologischen Apparaten zurückführt, scheint diesbezüglich nicht überzeugend, polemisch ausgedrückt hieße das, dass die „Subjektivität“ eines revolutionären Gewerkschafters, einer radikalen Feministin oder eines

118 Wenn G. Hauck in bester Habermas'scher Tradition Regeln für einen herrschaftsfreien Diskurs definiert und sich gleichzeitig Althussers Totalitätskonzeption der Gesellschaft anschließt und den Diskurs als soziale Praxis interpretiert [Hauck 1992, S. 120 f.], erkennt er zwar die Problematik an, die Schlussfolgerung steht aber in keinem Verhältnis zum theoretisierten Gegenstand.

119 Die „Ideologietheorie“ Althussers ist - wie seine Theorie der ideologischen Staatsapparate - keineswegs ,,abgeschlossen“ (einige Autoren nehmen an, dass eine solche wissenschaftliche „Theorie der Ideologie im allgemeinen“ schlicht unmöglich ist [Kammler/Plumpe/ Schöttler 1978, S. 14]), sie lässt immerhin zu, dass verschiedene „Erscheinungen“ wie Sprache und Ästhetik - Sinnproduktion schlechthin - materialistisch untersucht werden können. 
Mitglieds der „Black Panther“ darauf zurückzuführen ist, dass sie den herrschenden Diskurs/die Anrufung „nicht richtig verstanden“ hat.

Wenn im Gegensatz dazu die Materialität (verstanden als „Institutionen“) der ideologischen/diskursiven Praktiken, die das Subjekt formen, in den Staatsapparaten lokalisiert werden und damit auch Gegenstand des Klassenkampfs sind, bedeutet das zum einen, dass sie für das Individuum auf den ersten Blick nicht „hintergehbar“ sind. Zum anderen heißt das, im Gegensatz zur Konzeption von Laclau/Mouffe, dass sich die Signifikanten dort aber historisch ,aufladen“ und gleichzeitig - nun eben nicht mehr beliebig in Diskursen kombinierbar - bestimmten Determinations- und Dominierungsmechanismen unterliegen, die selbst wiederum mit dem Klassenkampf in Verbindung stehen. Die Gesamtheit der ideologischen Praxen der verschiedenen Staatsapparate bildet so (frei nach Foucault) das ideologische Archiv einer Gesellschaftsformation. Hierbei deutet die Vielzahl Althussers ISAs bereits an, dass die „Subjekte“ eine große Anzahl sehr verschiedener ideologischer Praktiken ausüben, wie Religion, Sport usw. Diese Praxen, die innerhalb der ISA ausgeübt werden, sind in der Konzeption Althussers offensichtlich in ihrer Gesamtheit notwendig, um die politischen und ökonomischen Verhältnisse aufrecht $\mathrm{zu}$ erhalten und die Reproduktion der Gesellschaftsformation zu gewährleisten Diese Vielzahl bedeutet auch, dass jedes Individuum eine individuelle Konfiguration von ideologischen Staatsapparaten vorfindet (besser: in diese Konfiguration eingesetzt wird), die sich von der Familie über die Schule bis hin zum Sportverein erstreckt. In diesen Apparaten wird es beständig als „Subjekt“ (als Kind, Arbeiter, Staatsbürger, Soldat, Demokrat, Warenbesitzer/-nichtbesitzer usw.) angerufen, wobei diese Identitäten verschiedenste Unterordnungs- und Gleichstellungsregularien beinhalten.

Dabei ist anzunehmen, dass die verschiedenen Anrufungen - wie die herrschende(n) Ideologie(n) selbst - widersprüchlich sind und so widersprüchliche Handlungen vom „Subjekt“ fordern (so wie die Anrufung des Arbeiters als formell Gleicher im Prozess des Warentausches schon seine reale Unterordnung unter das Kapital, die Anrufung als formell gleicher Staatsbürger dessen Unterwerfung unter den Staat und die bürgerliche Herrschaft impliziert). Diese Anrufungen, schon jeweils widersprüchlich, kulminieren folglich in einem überdeterminierten und tendenziell ,dezentrierten“ Subjekt. 
c) Eine so im Kontext der Marx'schen Kritik der politischen Ökonomie verstandene Kopplung von Diskurs- und Ideologietheorie würde tendenziell ermöglichen, eine Kopplung von Mikro- und Makrotheorie herzustellen, ohne auf einem Dualismus von System und Lebenswelt, wie er beispielsweise bei Habermas zu finden ist [Habermas 1981], zu rekurrieren. In diesem Kontext wäre folglich die Dezentrierung des Subjekts dahingehend mit Einschränkungen zu verstehen, dass die Trennung in gesellschaftliche Klassen bedingt, dass bestimmte Anrufungen immer gelingen (bzw. gelingen müssen) und diese tendenzielle Dezentrierung der Subjekte beherrscht, um die Strukturierung der Gesellschaft in Klassen zu reproduzieren. Aus marxistischer Sicht ist somit eine wie beispielsweise bei Poster vollzogene Trennung von Produktionsverhältnissen („Mode of Production”) und „,diskursiven Verhältnissen“ („Mode of Information“) [vgl. Poster 1984, 44 S. ff.] nicht aufrechtzuerhalten ist, letztere sind ohne die gesellschaftlichen (Re-) Produktionsverhältnisse und die davon determinierten Apparate nicht zu denken. ${ }^{120}$

D. h. aber auch, dass bezüglich des Modus der Subjektkonstitution und der Vergesellschaftung nicht allein auf den „Diskurs“ (wie bei Laclau/Mouffe) oder auf „Kommunikation“ (Luhmann, Habermas ${ }^{121}$ ) zurückgegriffen werden kann. Aus (traditions-) marxistischer Sicht könnte diesen Konzeptionen als Modus der Vergesellschaftung die ökonomische Praxis entgegengesetzt werden und zu einem gewissen Teil haben dies auch Althusser und Poulantzas getan; allerdings nicht um eine bestimmte gesellschaftliche Praxis zu verabsolutieren und so wieder das alles erklärende Grundprinzip ${ }^{122}$ einzuführen oder dem Ökonomismus zu huldigen. Aus der oben beschriebenen Perspektive ist sicherlich die ökonomische Praxis die determinierende Praxis, die aber m. E. wie

120 In diese Zusammenhang zeigt sich aber auch bezüglich des Begriffs der ,diskursiven Praxis“ eine Verschiebung in der Analyse Foucaults an: der Schwerpunkt verlagert sich weg von dem Diskurs an sich hin zu einer gesellschaftlichen Praxis des Diskurses.

121 Zur Abgrenzung Habermas' gegenüber Luhmanns Systemtheorie vgl. Habermas 1996, S. $426 \mathrm{ff}$.

122 Demirović weist zurecht darauf hin, dass diese Haltung auch bei Habermas vorliegt, der durch seine Konzeption der Theorie des kommunikativen Handelns [Habermas 1981] Macht und Herrschaft als sprachextern betrachtet, „Prozesse der kommunikativen Vergesellschaftung stehen in keiner Beziehung zu Formen der ökonomischen und politischen Vergesellschaftung“ mehr [Demirović 1994, S. 96]. Wenn so die sprachinternen Machtbeziehungen (siehe hierzu z. B. die Ausführungen Poulantzas zur Nationalsprache) ausgeklammert werden, verliert die „Theorie des kommunikativen Handelns“ auch jedes wissenschaftliche Potenzial und hat rein normativen Charakter. 
beschrieben den ergänzenden Begriff des Diskurses benötigt ${ }^{123}$, um den Mechanismus zu begreifen, in dem sich diese Determination durchsetzt, also wie die ökonomischen Praxis im engeren Sinn mit den nicht-ökonomischen produktiven Praxen (Produktion von Wissenschaft, Produktion von Ideologie, Produktion von Sinn usw.) gekoppelt ist und die differenten Praxen auch aus einer individuellen Perspektive beherrscht (das impliziert auch, dass diese Differenzierung selbst durch die ökonomische Praxis begrenzt ist).

Wird also angenommen, dass die ideologische Konstitution des Subjekts vor allem innerhalb von ideologischen Staatsapparaten vollzogen wird, sich die Praktiken innerhalb dieser Apparate in das Individuum einschreiben und dieses zu einer - wenn auch mehr oder weniger widerspruchsvollen - Einheit, einer Identität, einem „Subjekt“ formen, können die in diesen Apparaten ausgeübten Praktiken auch als eine Form von Identitätspolitik bezeichnet werden. Diese Identitätspolitik, die über Hoch- und Populärkultur, Warenproduktion und -tausch, wissenschaftliche Praxis usw. funktioniert, wäre dann als Technik und Technologie zur Konstitution und Beherrschung der „Subjekte“ zu verstehen, die individualisiert und homogenisiert, so aber auch beherrschbare kollektive Identitäten und Kollektivsubjekte erzeugen,

mit zunehmender Differenzierung der sozialen Welt und der Konstituierung relativ autonomer Felder vollzieht sich Produktion wie Durchsetzung von Sinn in den und vermittels der Auseinandersetzungen auf dem Feld der Kulturproduktion (insbesondere auf dem Teilfeld des Politischen). Sinn-Produktion und Sinn-Durchsetzung werden jetzt zum eigentlichen Geschäft, zum spezifischen Interesse berufsmäßiger Produzenten von objektivierten Repräsentationen der sozialen Welt, oder besser: von Objektivierungsmethoden. [Bourdieu 1995, S. 19 f.]

123 Dies ist schon deshalb notwendig, wenn politische Erscheinungen wie patriachale Machtstrukturen nicht durch eine bestimmte Definition des Politischen ausgegrenzt/ eliminiert oder von dem Klassenkampf ,abgeleitet“ werden sollen. Poulantzas ist dabei zuzustimmen, wenn er diese politischen Felder und Diskurse als von dem Klassenkampf determiniert (und gegebenenfalls dominiert) denkt und diese so innerhalb des Staates zu einer spezifischen Konfiguration zusammengesetzt werden. Diese spezifischen politischen Konfrontationslinien, die also im Einzelfall auch durchaus „quer“ zu dem Klassenkampf verlaufen können, müssten demnach in ihrem Verhältnis zum Klassenkampf/ihrer spezifischen Autonomie von diesem identifiziert und theoretisch konstruiert werden. 


\section{Der Staat - materielle Verdichtung eines Kräfteverhältnisses}

Der Staat ist kein monolithischer Block sondern ein strategisches Feld.

Nicos Poulantzas

\subsection{Zur theoretischen Konstitution des Politischen}

Eine Annäherung an das theoretische Objekt „Staat“ versucht Poulantzas, indem er dieses Objekt zu den marxistischen Begriffen der Produktionsweise und der Gesellschaftsformation in Beziehung setzt und unter Rückgriff auf die Epistemologie Althussers den Begriff des Politischen eingrenzt. Für Poulantzas sind dabei die Begriffe Produktionsweise und Gesellschaftsformation nicht identisch zu setzen ${ }^{124}$ :

a) Die Produktionsweise ist der Modus, in welcher eine bestimmte Verbindung von ökonomischen, politischen, ideologischen und theoretischen Strukturen und darin eingebettete Praxisformen hergestellt wird und diese zu einer Einheit formiert werden, die Strukturen und Praxisformen sind selbst durch ihre spezifische Verbindung Teilbereichsstrukturen einer spezifischen Produktionsweise. Das Spezifikum einer Produktionsweise lässt sich somit über die Art ermitteln, wie die Einheit der Produktionsweise, also die Einheit relativ autonomer gesellschaftlicher Strukturen erzeugt wird. Hierbei kommt der ökonomischen Struktur die Rolle der determinierenden Struktur zu, indem sie einer anderen gesellschaftlichen Struktur die dominante Rolle zuweisen als auch diese Rolle selbst wahrnehmen kann ${ }^{125}$ :

Wenn die Einheit, die die Struktur mit Dominante darstellt, impliziert, dass zu jeder Produktionsweise eine dominante Ebene oder Instanz gehört, dann ist das Ökonomische tatsächlich nur insofern determinierend, als es dieser oder jener Instanz die beherrschende Rolle

124 Bei der theoretischen Konstruktion der Produktionsweise/Produktionsverhältnisse greift Poulantzas offensichtlich auf die Arbeiten Balibars zurück, vgl. DKL, Bd. 2, S. 279 ff.

125 So findet sich auch bei Marx die Ansicht, dass die Ökonomie nicht in jeder Gesellschaftsformation die dominante, aber immer die determinierende Struktur ist: „Soviel ist klar, daß das Mittelalter nicht vom Katholizismus und die antike Welt nicht von der Politik leben konnte. Die Art und Weise, wie sie ihr Leben gewannen, erklärt umgekehrt, warum dort die Politik, hier der Katholizismus die Hauptrolle spielte“ [MEW, Bd. 23, S. 96, Fn. 33]. 
zuschreibt; das heißt also, nur insofern, als es die Verschiebung der Dominanz regelt, die sich aus der Dezentrierung der Instanzen ergibt. [Poulantzas 1980, S. 12]

Diese Dezentrierung der Strukturen und die daraus resultierende spezifische Anordnung bilden die Grundstruktur der Produktionsweise. Die spezifische Determination durch das Ökonomische in dieser Grundstruktur ist „Indiz der Dominiertheit und Überdeterminiertheit der Produktionsweise“ [ebd.]. Eine spezifische Produktionsweise als abstrakt-formales Objekt (Erkenntnisobjekt) existiert in einer historisch determinierten Gesellschaftsformation aber nicht in dem Sinn, dass sie die alleinige innerhalb dieser Gesellschaftsformation ausgeübte Produktionsweise wäre und demzufolge das abstrakt-formale Objekt (Erkenntnisobjekt) mit dem historisch-konkreten Objekt (Realobjekt) zusammenfallen würde.

b) Nach Poulantzas werden in einer konkreten Gesellschaftsformation mehrere „reine“ Produktionsweisen (feudalistische, kapitalistische, patriarchale usw.) gleichzeitig ausgeübt ${ }^{126}$, hierbei werden dieses Produktionsweisen miteinander verknüpft; die spezifische Verbindung der Produktionsweisen untereinander ist Kennzeichen für die konkreten historische gesellschaftliche Produktionsweise [ebd., S. 13]. Die Untersuchung einer solchen „Pluralität von Produktionsweisen“ [Lipietz 1992, S. 9] oder „Konfiguration von Konfigurationen“ [ebd.] ermöglicht es zum einen, die Differenz zwischen sich ähnlichen Gesellschaftsformationen zu erschließen; zum zweiten ist es möglich, theoretisch den Übergang von einer Produktionsweise in eine andere zu erschließen, ohne dabei anzunehmen, dass die eine Produktionsweise aus der historisch vorgelagerten heraus entstanden wäre.

Eine Gesellschaftsformation ist also dadurch gekennzeichnet, dass in ihr eine bestimmte Produktionsweise eine dominierende Rolle inne hat und diese die anderen neben dieser ausgeübten Produktionsweisen beherrscht. Die Dominanz einer Produktionsweise über die anderen bewirkt, dass die sich Grundstruktur der beherrschenden Produktionsweise in die Gesellschaftsformation einschreibt, quasi „der gesamten Gesellschaftsformation ihren Stempel aufdrückt“ [ebd.]. Diese Beherrschung einer Gesellschaftsformation durch eine 
dominante Produktionsweise bestimmt die spezifische Anordnung und Verknüpfung der anderen gesellschaftlichen Instanzen. Dies bedeutet für Poulantzas natürlich auch, dass die Ebene des Politischen in einem spezifischen Verhältnis zu der beherrschenden Produktionsweise steht und dementsprechend die theoretische Konstitution des Politischen als Teilbereichsebene der Produktionsweise erfolgen muss [ebd., S. 14] und sich in die Synchronie des Begriffs der Produktionsweise [DKL, Bd. 2, S. 317] einfügen muss, die Dezentrierung der Struktur in der theoretischen Konstitution also reflektiert wird. Eine Teilbereichsinstanz wie das Politische könne somit

insoweit Gegenstand einer Teilbereichstheorie sein, als sie innerhalb einer gegebenen Produktionsweise gesondert dasteht. Ihre Erhebung zum Objekt der Wissenschaft, d. h. die Aufstellung ihres eigenen Begriffs, hängt nicht von ihrer Natur ab, sondern von ihrer Stellung und Funktion innerhalb der besonderen Verbindung, die diese Produktionsweise kennzeichnet. [Poulantzas 1980, S. 14]

Eine Teilbereichstheorie des Politischen setzt laut Poulantzas eine Einzeltheorie der Produktionsweise voraus [ebd., S. 15]; bevor die Teilbereichstheorie des Politischen entworfen werden kann, ist also zu rekapitulieren, wodurch eine Produktionsweise innerhalb des historischen Materialismus gekennzeichnet ist.

Die Grundstruktur einer Produktionsweise ist nach Poulantzas eine Verbindung spezifischer, dieser Grundstruktur zugehöriger Elemente ${ }^{127}$ :

1. die unmittelbaren Produzenten/ArbeiterInnen,

2. der Produktionsmittel,

3. der Nicht-Arbeitenden, die sich das Mehrprodukt aneignen [ebd., S. 24].

Die jeweilige Verbindung dieser Elemente sei spezifisch für jede Produktionsweise und werde durch eine doppelte Beziehung hergestellt:

1. das Aneignungsverhältnis,

2. das Eigentumsverhältnis [ebd.].

Das Aneignungsverhältnis betreffe das Verhältnis der Arbeitenden zu den Produktionsmitteln innerhalb des Arbeitsprozesses, mithin die Produktivkräfte. Davon zu unterscheiden sei das Eigentumsverhältnis, das den Eigentümer als Eigentümer sowohl an den Produktionsmitteln, der Arbeitskraft und dem

127 Hier schließt sich Poulantzas unmittelbar an Balibars Ausführungen in Das Kapital lesen an, vgl. DKL, Bd. 2, S. 287]. 
Arbeitsprodukt zwischen das Aneignungsverhältnis treten lässt, das Eigentumsverhältnis „,definiert die Produktionsverhältnisse im eigentlichen Sinne“ [ebd.].

c) Das Verhältnis von Aneignung und Eigentum lässt sich weiter differenzieren: Das Eigentumsverhältnis gehört für Poulantzas vollkommen der ökonomischen Struktur an und ist von den juristischen Formen, die es annimmt, zu trennen ${ }^{128}$. Die Trennung des Arbeiters von den Produktionsmitteln und die Aneignung des Mehrwerts durch den Eigentümer der Produktionsmitteln sei kennzeichnend für jede Klassengesellschaft. Demgegenüber sei das Aneignungsverhältnis innerhalb von Klassengesellschaften variabel: während der vorkapitalistischen Produktionsweisen konnte laut Poulantzas dieses Verhältnis eine Einheit der Arbeitenden mit den Produktionsmitteln darstellen, ist demgegenüber in der kapitalistischen Produktionsweise dieses Verhältnis durch die Trennung der Arbeitenden von den Produktionsmitteln geprägt. Die Eigentums- und Aneignungsverhältnisse bilden somit eine historisch variable Verbindung, die den eigentlichen Bereich der Ökonomie innerhalb einer Produktionsweise darstellt, ,die Verbindung des Systems der Produktivkräfte mit dem System der Produktionsverhältnisse“ [ebd.].

Symptomatisch für die kapitalistischen Produktionsweise sei, dass das Aneignungs- und das Eigentumsverhältnis eine Homologie bilden würden, also die Trennung der Eigentumsverhältnisse mit der Trennung innerhalb des Verhältnisses der realen Aneignung zusammenfalle. Hingegen seien die vorkapitalistischen Produktionsweisen durch die Nicht-Homologie dieser beiden Verhältnisse gekennzeichnet. Dabei seien die Relationen von Aneignungs- und Eigentumsverhältnis bestimmend für „die Determiniertheit einer Produktionsweise in letzter Instanz durch das Ökonomische, und die der Verknüpfung und des Indizes der Dominanz in ihren Instanzen“ [ebd., S. 25].

Ausgehend von der relativen und spezifischen Autonomie der Instanzen einer Produktionsweise, also der ideologischen, politischen und ökonomischen Ebenen und deren spezifische Determiniertheit lasse sich theoretisch eine Teil-

128 So führt auch Offe aus, dass sich das Eigentumsverhältnis zwar historisch über die juristische Form des Eigentums herausgebildet habe, dies sei im entwickelten Kapitalismus aber kein geeignetes Unterscheidungskriterium, da selbst öffentlich-rechtliche Institutionen „Träger des unverändert kapitalistischen Verwertungsprozesses“ sein könnten [Offe 1975, S. 9]. 
bereichstheorie dieser Ebenen konstruieren, soweit sie die Einordnung der jeweiligen Ebenen innerhalb einer spezifischen Produktionsweise berücksichtige. Dies trifft nach Poulantzas auch auf die politische Instanz zu, so dass vor dem Hintergrund der Produktionsweise die Frage nach dem Begriff der Politik aufgeworfen werden kann.

In einer ersten Annäherung bestimmt Poulantzas den rechtlich-politischen „Überbau“ Staat als das Politische, demgegenüber die verschiedenen Momente des Klassenkampfes als die Politik [ebd., S. 35]. Die Bestimmung des Klassenkampf als die Politik führt Poulantzas auf die Aussagen von Marx und Engels zurück, dass jeder Klassenkampf ein politischer Kampf und dieser Klassenkampf der Motor der Geschichte sei. Hierbei seien diese Aussagen antihistorizistisch zu interpretieren, das Politische müsse

in die Struktur einer Gesellschaftsformation eingeordnet werden, nicht nur als spezifische Ebene, sondern auch als kritische Ebene, wo sich die Widersprüche einer Gesellschaftsformation widerspiegeln und verdichten. [ebd., S. 38]

Die Struktur, innerhalb derer diese Widersprüche zu einer politischen Praxis führen und die gleichzeitig selbst Angriffsziel dieser politischen Praxis bildet, ist für Poulantzas der Staat: „Die politischen Strukturen [...] einer Produktionsweise und einer Gesellschaftsformation bestehen in der institutionalisierten Staatsmacht“ [ebd., S. 40 f.]. 


\title{
2.2. Produktionsverhältnisse, Klassen und Klassenkampf
}

\begin{abstract}
Jede Analyse einer Gesellschaftsformation muss gleichzeitig unmittelbar die Verhältnisse des Klassenkampfs, die Machtverhältnisse und die Staatsapparate, die diese Verhältnisse verkörpern, bündeln und wiederspiegeln, in Betracht ziehen.
\end{abstract}

Nicos Poulantzas

Die grundsätzliche Bestimmung der gesellschaftlichen Klassen basiert bei Poulantzas auf einer strukturellen Bestimmung (vgl. S. 49), der Begriff der gesellschaftlichen Klasse ist demnach strukturell definiert als eine Gesamtheit von gesellschaftlichen Agenten (Individuen), die selbst in erster Linie durch ihre Stellung im Produktionsprozess bestimmt werden. Innerhalb der Produktionsverhältnisse bestehen diese Klassen nicht a priori, sondern nur innerhalb des Klassenkampfs (Klassenpraktiken). Diese Praktiken der jeweiligen Klassen würden auf den objektiven Stellungen beruhen, die die Klassen innerhalb der Struktur der gesellschaftlichen Arbeitsteilung einnehmen [Poulantzas 1975, S. 14]. Dies stellt insoweit eine strukturelle Bestimmung der Klassen dar, da der Begriff der Klasse allein in Bezug zu den bisher gewonnen Begriffen konstituiert wird, der Klassenbegriff unabhängig von den einzelnen gesellschaftlichen Agenten (und vor allem unabhängig von deren Bewusstsein) ,funktioniert“.

Von der strukturellen Bestimmung der Klassen und ihren Klassenpraktiken seien die konjunkturellen Klassenpositionen zu unterscheiden, wie sie sich in einer konkreten Situation des Klassenkampfes äußern ${ }^{129}$. Diese Unterscheidung wird dann sichtbar, wenn sich eine Differenz zwischen struktureller Klassenbestimmung und konkreter (politischer) Klassenposition abzeichnet, d.

129 Diese Trennung von logischem und (hier) soziologisch-empirischem Widerspruch bietet nach Offe drei analytische Vorteile: erstens sei es so möglich, „das Abbildungsverhältnis zwischen Widerspruch und manifestem Klassenkampf selbst als ein historisch variables zu untersuchen“; zweitens biete allein diese Konzeption die Möglichkeit, „die irreversible Verschärfung des Verhältnisses 'funktioneller Unvereinbarkeit' zwischen faktischer Vergesellschaftung der Produktivkräfte und institutionalisierter 'Privatheit' der Produktionsverhältnisse als objektivem Prozess zu erklären“; drittens könne so die „objektive Verlangsamung und Stockung der Widerspruchsentwicklung eingesehen werden, die aus adaptiven Strukturbildungen resultiert und die Lücke zwischen Vergesellschaftung und festgehaltenen Produktionsverhältnissen durchaus temporär $\mathrm{zu}$ entproblematisieren vermag“" [Offe 1975, S. 13 f.]. 
h. dass sich zwischen den sich aus der strukturellen Bestimmung ergebenden ideologischen und politischen Dispositionen und den konkreten Positionen eine Differenz ergeben kann. Die Bestimmung einer Klasse ist folglich nicht auf die Klassenposition $\mathrm{zu}$ reduzieren: Innerhalb jeder Klasse existieren nach Poulantzas Fraktionen und Schichten, die durch ihre Stellung innerhalb der gesellschaftlichen Arbeitsteilung grundsätzlich einer spezifischen Klasse angehören, dabei aber auch durch ihre Stellung im Produktionsprozess ideologisch und politisch von den anderen Fraktionen und Schichten der Klasse getrennt werden, so z. B. die sogenannte Arbeiteraristokratie oder das Kleinbürgertum. Jede dieser Gruppen gehöre zu einer bestimmten Klasse, kann aber im politischen „Tagesgeschäft“ durchaus Positionen einer anderen Klasse einnehmen, eine solche Positionierung habe jedoch keinen Einfluss auf die objektive Klassenbestimmung [Poulantzas 1975, S. 14 ff.] ${ }^{130}$.

Die Differenz zwischen Klassenposition und struktureller Klassenbestimmung bedeute aber nicht, dass diese gleichzusetzen wäre mit der Konzeption von „Klasse an sich“ und der „Klasse für sich“: die Klassenstellung innerhalb des Produktionsprozesses beinhalte spezifische Wirkungen, die die jeweilige Klassenstellung impliziert und sich innerhalb der „ökonomische Existenz in spezifischen materiellen politisch-ideologischen Praktiken “ niederschlägt ${ }^{131}$. Das heißt aber auch, dass für die volle Entfaltung des Klassenkampfs ein Klassenbewusstsein, auch „materialisiert“ in Form einer ,autonomen“ politischen Organisation, überhaupt nicht erforderlich ist, die politischen Organisationen sind vielmehr eine Frage der Klassenpositionen innerhalb der politischen Konjunktur und den konkreten gesellschaftlichen Kräfteverhältnissen [Poulantzas 1975, S. 16 f.].

130 Ähnlich argumentiert Offe, dass der (logische) Klassenbegriff der klassensoziologischen Begriffsbildung vorgelagert sei, der Klassenantagonismus bestehe grundsätzlich „dort, wo aufgrund der Logik privater Akkumulation gesellschaftliche Konflikte erzeugt werden, die die Fortsetzung dieser Akkumulation und den Fortbestand ihrer politischen und institutionellen Voraussetzungen in Frage stellen" [Offe 1975, S. 19].

131 Insoweit ist Poulantzas noch dem Problem des traditionellen Klassenbegriffs - Klasse als Sein und Sollen (Bourdieu) - noch verpflichtet. Allerdings ist eine solche strukturelle Klassendefinition im Kontext der Produktionsverhältnisse vollkommen legitim, insoweit sie nicht alle sozialen Verhältnisse auf die Ökonomie reduziert und jedes soziale Handeln als Reflex der (strukturellen) Klassenbestimmung begreift und vor allem nicht den theoretisch gewonnen Begriff der Klasse mit „realen“ Gruppierungen in Eins setzt. Zur Kritik des traditionalistischen marxistischen Klassenbegriffs siehe Bourdieu 1995. 
Unter dem Begriff der Klasse kann laut Poulantzas aber auch nicht eine einfache Zusammensetzung als Gruppe von Individuen verstanden werden ${ }^{132}$. Es sei also nicht zu bestimmen, zu welcher Klasse ein bestimmtes Individuum gerechnet werden muss, noch sei auf die Frage der sozialen Ungleichheit $\mathrm{zu}$ rekurrieren, „diese sozialen Ungleichheiten sind nur die Auswirkungen der gesellschaftlichen Klassen auf die Agenten, d. h. der objektiven Stellungen, die sie einnehmen“ [ebd., S. 17], der Klassencharakter einer Gesellschaftsformation ist keinesfalls auf eine Ungleichheit der Chancenverhältnisse der Individuen $\mathrm{zu}$ reduzieren. Trotzdem bleibe die Frage der Stellung der Klassen innerhalb der ökonomischen Instanz für ihre Bestimmung von entscheidender Bedeutung und müsse mit dem Arbeitsprozess in Verbindung gebracht werden. Hierbei seien die bereits oben genannten „Beziehungen der Agenten der Produktion zum Gegenstand und $\mathrm{zu}$ den Mitteln der Arbeit (den Produktivkräften)“ [ebd., S. 18] von maßgeblicher Bedeutung. Unter Agenten der Produktion fasst Poulantzas sowohl den Nicht-Arbeiter (Eigentümer) als auch den unmittelbaren Produzenten (Arbeiter) so dass diese Beziehungen zwei Aspekte aufweisen: zum einen bildet sich eine Beziehung über das ökonomische Eigentum an den Produktionsmitteln, also die Fähigkeit, die Produktionsmittel speziellen Verwendungszwecken zuzuweisen und über die Produkte zu verfügen, anderseits über den Besitz, verstanden als Beherrschung des Produktionsprozesses; das ökonomische Eigentum an den Produktionsmitteln ist für Poulantzas charakteristisch für die Klassengesellschaft im allgemeinen ${ }^{133}$. Im Gegensatz dazu weist das Verhältnis der unmittelbar Produzierenden zu den Mitteln und Gegenständen der Arbeit auf die spezifische Form der Klassengesellschaft hin: Kennzeichnend für die vorkapitalistische Produktionsweise sei demzufolge, dass die Arbeiter nicht vollständig von den Produktionsgegenständen und Produkten ihrer Arbeit getrennt gewesen seien, sondern, obgleich weder juristische noch ökonomische Eigentümer, Verfügungsgewalt über diese gehabt hätten und den Produktionsprozess selbst steuern konnten. Die ökonomische Ausbeutung der unterdrückten Klassen habe sich hierbei vor allem

132 Vgl. Balibars Ausführungen in DKL, Bd. 2, S. 360.

133 Der ökonomische Besitz muss nach Poulantzas nicht immer identisch mit dem juristischen Besitz sein [Poulantzas 1975, S. 18], so z. B. im sog. real existierenden Sozialismus: während die Produktionsmittel juristisch im Besitz der Staatsbevölkerung war, verfügte nur eine Klasse derselben - die Bürokratie - sowohl über die Produktionsmittel als auch über die Produkte des Arbeitsprozesses. 
durch die „unmittelbare Abschöpfung der Mehrarbeit“ in der Form von Fronarbeit und Naturalsteuer vollzogen [ebd., S. 19].

Die Durchsetzung der kapitalistischen Produktionsweise ist nach Poulantzas auf die Aufhebung der Verfügungsgewalt über Produktionsmittel und Produktionsprozess durch die ursprüngliche Akkumulation des Kapitals zurückzuführen: nach der ursprünglichen Akkumulation ist der Arbeiter doppelt frei (Marx) und somit allein auf den Verkauf seiner Arbeitskraft angewiesen, die dadurch selbst eine Ware wird. Die Trennung des Arbeiters von den Produktionsmitteln, der somit nicht länger den Produktionsprozesses selbst steuern konnte,

bestimmt die Verallgemeinerung der Warenform und nicht umgekehrt: die Arbeit als Ware ist nicht die Auswirkung der ersten Verallgemeinerung der berühmten „Warenverhältnisse“, sondern auf dem Umweg über die der Ware einverleibten Arbeit, d. h. durch die Schaffung und das Ansichreißen des Mehrwerts [ebd., S. 19],

der kapitalistische Arbeitsprozess (und die kapitalistische Arbeitsform) ist also konstitutiv für das Warenverhältnis. Die Produktionsverhältnisse werden konstituiert durch die miteinander verwobenen Beziehungen zu den Produktionsmitteln und dem Produktionsprozess, und genau durch diese Beziehungen ist innerhalb einer auf Klassen basierender Produktionsweise das herrschende Ausbeutungsverhältnis spezifizierbar, das ökonomische/juristische Eigentumsverhältnis somit nicht alleiniges Kriterium ${ }^{134}$. Ebenso wenig lasse sich eine Produktionsweise auf die verwendete Technologie zurückführen, welche den modus operandi des Arbeitsprozess bestimmen würden:

Die Arbeitsprozesse und die Produktivkräfte, einschließlich der „Technologie“, existieren nicht an sich, sondern immer in ihrer konstitutiven Beziehung zu den Produktionsverhältnissen. Man kann somit in Klassengesellschaften nicht von neutraler ,produktiver“ Arbeit oder „,produktiver“ Arbeit an sich sprechen. In jeder in Klassen gespaltenen Produktionsweise ist produktive Arbeit die Arbeit, die den Produktionsverhältnissen dieser Produktionsweise entspricht, d. h. die, die die spezifische und herrschende Form der Ausbeutung hervorruft. Produktion in diesen Gesellschaften heißt gleichzeitig und in ein und derselben Bewegung Aufspaltung in Klassen, Ausbeutung und Klassenkampf. [ebd., S. 20]

134 Auch anhand dieser Kriterien ließe sich unschwer der Klassencharakter des sogenannten Staatssozialismus nachweisen (dabei wird man sicherlich nicht zu dem Schluss kommen, dass es sich hierbei um Staaten unter der Führung der Arbeiter und Bauern handelte). 
Der Produktionsprozess, gebildet durch die Einheit von Arbeitsprozess und der Produktionsverhältnisse, werde dabei durch die Produktionsverhältnisse dominiert, d. h. diese bestimmen die eingesetzte Technologie, die Produktivkräfte und die konkrete Arbeitsorganisation ,indem sie ihnen ihren Grundriss (tracé) und ihre Gangart (allure) aufprägen“ [ebd., S. 21]; die Dominanz der Produktionsverhältnisse bedingt „,die konstitutive Rolle der politischen und ideologischen Verhältnisse in der strukturellen Bestimmung der gesellschaftlichen Klassen“ [ebd.]. Die die Produktionsverhältnisse konstituierenden Beziehungen sind selbst nicht innerhalb der ökonomischen Sphäre isoliert, sondern korrespondieren mit den ideologischen und politischen Verhältnissen, die die Produktionsverhältnisse legitimieren und aufrechterhalten, diese seien in den Produktionsverhältnissen „,präsent“ und indem der Produktionsprozess aufrecht erhalten wird, werden diese politischen und ideologischen Herrschaftsverhältnisse reproduziert [ebd.].

Eine erste Bestimmung des Staates vor dem Hintergrund der beschriebenen strukturellen Klassendefinition erfolgt bei Poulantzas eng an den oben dargelegten Ausführungen Althussers (vgl. S. 83). Die hauptsächliche Funktion der Staatsapparate ist es demnach,

die Einheit und den Zusammenhalt einer Gesellschaftsformation aufrecht $\mathrm{zu}$ erhalten, indem sie die Klassenherrschaft zusammenfassen und bestätigen, um so die gesellschaftlichen Verhältnisse, d. h. die Klassenverhältnisse $\mathrm{zu}$ reproduzieren. Die politischen und ideologischen Verhältnisse materialisieren und verkörpern sich als materielle Praktiken in den Apparaten des Staates. [ebd., S. 25]

Der Reproduktionsprozess der Produktionsweise ist also vor allem von der ideologisch-politischen Reproduktion gekennzeichnet ${ }^{135}$ :

Weil die politisch-ideologischen Beziehungen von Anfang an in der Konstitution der Produktionsverhältnisse präsent sind, spielen sie bei der Reproduktion eine wesentliche Rolle, ist der Produktions- und Ausbeutungsprozess zugleich Reproduktionsprozess der politischen und ideologischen Herrschafts- und Unterwerfungsbeziehungen. [St, S. 24 f.]

Die Produktionsverhältnisse und deren Reproduktion finden somit nicht (nur) innerhalb der Ökonomie, sondern ebenso in der staatlichen Struktur statt, diese

135 Hier bleibt z. B. Offe zurück, wenn er behauptet, die Mechanismen der Institutionalisierung zur Bekämpfung der selbstnegatorischen Tendenzen des Kapitalismus seien auf der politischen Ebene die der ,politischen Gewalt“ [Offe 1975, S. 21] bzw. wenn er diese Ebene allein auf verschiedene Sozialtechniken reduziert [ebd., S. 22] oder die Ideologie auf ein Normensystem reduziert [ebd., S. 80]. 
Strukturen reproduzieren sich gegenseitig auf erweiterter Stufenleiter in ständig modifizierter Form [Demirović 1987, S. 54]. Hierbei differenziert Poulantzas wie Althusser ${ }^{136}$ zwischen dem repressiven und dem ideologischen Apparat, die von der (nicht zu dem Staat gehörenden) ökonomischen Struktur im engeren Sinn $\mathrm{zu}$ unterscheiden sind. Letzterer materialisiert und verkörpert als „Zentrum der Aneignung der Natur die ökonomischen Verhältnisse in ihrer Verbindung mit den politisch-ideologischen Verhältnissen“ [Poulantzas 1975, S. 25]. Die politischen Verhältnisse existieren für Poulantzas nur als innerhalb der staatlichen Apparate verkörperte, ebenso existieren die gesellschaftlichen Klassen und ihre Reproduktion

nur durch die Beziehung gesellschaftliche Klassen/Staatsapparate und ökonomische Apparate: diese Apparate sind dem Klassenkampf nicht einfach wie überflüssige Wurmfortsätze ,angefügt“, sondern sie spielen in ihm eine konstitutive Rolle [ebd.].

D. h. allerdings nicht, dass die Staatsapparate dem Klassenkampf selber zu Grunde liegen, oder, wie Poulantzas Max Weber unterstellt, die Macht/Machtverhältnisse erst innerhalb von Institutionen zu Klassenverhältnissen werden, sondern dass die Staatsapparate materieller Niederschlag des Klassenkampfes sind, somit selbst untrennbar mit dem Klassenkampf verbunden sind. Wenn die staatlichen Apparate selbst nur Materialisierung von Stellungen innerhalb des Klassenkampfs sind, besitzen diese auch keine Macht im eigentlichen Sinn, sie bündeln vielmehr „Klassenverhältnisse, Verhältnisse, die gerade der Begriff der 'Macht' umfasst. Der Staat ist keine 'Entität' [...] sondern ist selbst ein Verhältnis" [ebd., S. 26]; in der Folge sind Staatsmacht und Staatsapparat begrifflich $\mathrm{zu}$ trennen. Indem die staatlichen Apparate erst durch den Klassenkampf selbst entstehen, seien sie auch nicht neutrale Apparate; die Funktionen des Staates

sind von der Macht im Staate abhängig, die in die Struktur ihrer Apparate selbst eingegossen ist, nämlich von Klassen und Klassenfraktionen, die das Terrain der politischen Herrschaft besetzt halten [ebd.];

eben diese politische Herrschaft ist Bedingung für das Existieren und das Funktionieren des Staatsapparats. Die Staatsapparate könnten somit nicht je nach der politischen Situation beliebig von einer der am Kampf teilnehmenden 
Klassen eingenommenen werden, um dadurch einen Wechsel der Staatsmacht herbeizuführen ${ }^{137}$.

Die Trennung von Staatsmacht und Staatsapparate bedeutet, dass die staatlichen Apparate sich nicht auf die Staatsmacht beschränken lassen, die Funktionen des Staatsapparats sich auch nicht aus dem Wesen des Staates selbst ableiten lassen, sondern in spezifischer Weise von der Staatsmacht abhängen. Staatsmacht ist hierbei die hegemoniale Klasse, Fraktion, aber auch ein Bündnis von Fraktionen/Klassen, führenden Klassen und Klassenstützen (wobei die führende Klasse nicht identisch mit der herrschenden Klasse sein muss), Poulantzas benutzt hierfür den Begriff des Blocks an der Macht. Die Abhängigkeit der Staatsapparate von der Staatsmacht/ dem Block an der Macht bedeute, dass die Konstitution einer Staatstheorie vor allem vor dem Hintergrund des Klassenkampfs erfolgen müsse:

Jede Analyse einer Gesellschaftsformation muss gleichzeitig unmittelbar die Verhältnisse des Klassenkampfes, die Machtverhältnisse und die Staatsapparate, die diese Verhältnisse verkörpern, bündeln und widerspiegeln, in Betracht ziehen. [ebd., S. 27] ${ }^{138}$

Somit sind bei der Bestimmung der staatlichen Struktur vor allem die politischen Verhältnisse der Gesellschaftsformation, nicht die ökonomischen Anforderungen der jeweiligen Produktionsweise von ausschlaggebender Bedeutung. Letztere erscheinen natürlich mittelbar wieder innerhalb des Klassenkampfs, die Durchsetzbarkeit der „objektiven“ ökonomischen Notwendigkeiten ist dabei vor allem von den politischen Verhältnissen abhängig $^{139}$.

137 Dies ist durchaus als Kritik an Gramsci zu verstehen, den dessen Bild von „Stellungskrieg“ bzw. „Bewegungskrieg“ impliziert ein Kampf um ein spezifisches „Ziel“: der Staat.

138 Hirsch konstatiert ähnlich, dass der Staatsapparat grundsätzlich mit den Klassenkämpfen in Verbindung steht, dies sei schon deshalb notwendig, ,um den ökonomischen Reproduktionsprozess in Gang und den Klassenkonflikt latent" zu halten [Hirsch 1974, S. 52].

139 Mit dieser Bestimmung steht Poulantzas zu der, vor allem in Deutschland in den 70er Jahren aktuellen, „Ableitungsdebatte“ in Opposition, die alle Formen staatlicher und ideologischer Erscheinungen, die jeweilige Konjunktur des Klassenkampf selbst direkt aus der Kapitalbewegung herleitet. 


\subsection{Der Staat als soziales Verhältnis}

a) Wie dargelegt, folgt Poulantzas der Annahme, dass der Staat wie die ökonomische Struktur ein gesellschaftliches Verhältnis ist und eng mit den Klassenkämpfen verbunden ist. Dabei basiert die von Poulantzas entwickelte Staatstheorie auf der Althusser'schen Konzeption der Gesellschaft als „determinierte Struktur mit Dominante“, also der Annahme, dass Staat und Ökonomie miteinander korrelierende (Teil-) Strukturen der Gesamtstruktur (bürgerliche) Gesellschaft sind. Hierbei stelle die ökonomische Basis die determinierende Struktur dar, sie sei die Struktur, die einer anderen Struktur die dominierende Rolle zuweise (oder selbst wahrnehme). Nach Poulantzas ist eine Staatstheorie somit grundsätzlich mit den Produktionsverhältnissen und der gesellschaftlichen Arbeitsteilung in Beziehung zu setzen. Dies sei notwendig, aber keineswegs hinreichend, um eine angemessene Theorie zu entwickeln, denn ebenso seien in der theoretischen Erfassung des Staates die gesellschaftlichen Klassen und die Klassenkämpfe zu berücksichtigen. Dies sei schon deshalb nötig, um die verschiedenen historischen Formen des Staates theoreisch einzuordnen, wird der Staat allein in Bezug zu den Produktionsverhältnissen gesehen, könnten die „Ausnahmeformen“ der bürgerlichen Herrschaft nicht theoretisch begründet werden $^{140}$. Eine Theorie des Staates kann nach Poulantzas aber auch nicht ein bloßes Aufzeichnen der Genealogie des Staates sein, sondern müsse die Reproduktion der staatlichen Struktur selbst erfassen; es gehe also auch um die Historizität des Staates: „Eine Theorie des kapitalistischen Staates muss die Metamorphosen ihres Gegenstandes kennen“ $[\text { St, S. 114 }]^{141}$.

Diese Metamorphosen des Staates würden zweifellos mit den Veränderungen der Produktionsverhältnisse und der gesellschaftlichen Arbeitsteilung in Verbindung stehen, so dass auch die staatliche Struktur mit den veränderten ökonomischen Verhältnissen in Verbindung zu bringen sei. Es dürfe dabei aber nicht in einen Reduktionismus verfallen werden, der dahingehend argumentiere, dass, wenn sich auch die ökonomischen Verhältnisse modifizieren, der Staat grundsätzlich ein kapitalistischer bleibe und somit immer eine Diktatur der herrschenden Klasse darstelle (diese Polemik richtet Poulantzas vor allem

140 Es sei denn, man geht beispielsweise dazu über, den Nationalsozialismus aus dem Warenfetischismus ,,abzuleiten“.

141 So auch Hirsch 1974, S. 51. 
gegen Balibar und andere Vertreter der PCF [St, S. 115] ${ }^{142}$ ). Es geht Poulantzas also darum, dass mit den verschiedenen Stadien des Kapitalismus verschiedene Formen der politischen Herrschaft auftreten, die immer sowohl auf die Produktionsverhältnisse als auch auf die konkreten Klassenverhältnisse der jeweiligen Gesellschaft verweisen, denn gleiche historische Produktionsverhältnisse vorzufinden bedeute nicht, dass automatisch gleiche politische Formen der (bürgerlichen) Herrschaft aufzufinden seien ${ }^{143}$. Ein „formalistischer Theoretizismus“, der den Staat allein in Bezug zu den Produktionsverhältnissen setze und die Klassenkämpfe nachträglich in diese Theorie einbaue, könne nicht die spezifischen Formen des Staates erklären [ebd.] ${ }^{144}$. Die Formen des bürgerlichen Staates seien demgegenüber darauf zu untersuchen, in welchem Maße der „Klassenkampf, spezieller der politische Kampf und die politische Herrschaft, im institutionellen Gerüst des Staates eingeschrieben sind [...], und zwar so, dass die unterschiedlichen Formen und historischen Transformationen“ [St, S. 116] erklärt werden können. D. h. die Materialität des Staates in seinen Apparaten müsse als Materialisierung des Klassenkampfs erfasst werden ${ }^{145}$, dabei komme dem Klassenkampf zwar das Primat gegenüber den Institutionen zu, allerdings definiere der Staat schon den Ort des Klassenkampfes, er „steckt von Anfang an das Kampffeld ab“ [St., S. 36]. Ebenso habe der Staat aber auch schon eine organische Rolle im Klassenkampf inne: „Der kapitalistische Staat konstituiert die Bourgeoisie als politisch herrschende Klasse“ [St, S. 117].

Diese organische Funktion sei zum einen bezüglich der Bourgeoisie selbst erforderlich: die Bourgeoisie müsse als herrschende Klasse, als politische Einheit durch den Staat konstituiert werden, da die Bourgeoisie durch ihre ökonomische Heterogenität „,konstitutiv in Klassenfraktionen gespalten“ [St, S. 118] sei, sie ist keine Entität ${ }^{146}$. Die Organisation der Einheit dieser Klasse

142 Vgl. dazu Balibar 1977.

143 Poulantzas zieht daraus auch den Schluss, dass es eine generelle marxistische Theorie des Staates nicht geben kann, folglich ist der theoretische Ansatz historisch auf die kapitalistische Gesellschaftsformation begrenzt.

144 Vgl. Offe 1973, S. 68.

145 Durch diese Konzeption erscheint der Ansatz Poulantzas' für Hirsch mit der Regulationstheorie kompatibel [Hirsch 1993, S. 196, ebenso Lipietz 1992a, S. 10 f.], zur Abgrenzung des strukturalistischen Marxismus von der Regulationstheorie und der Systemtheorie s. u.

146 Ähnlich zieht Offe aus dem Marx'schen Diktum, dass der Staat geschäftsführender Ausschuss der herrschenden Klasse sei, den Schluss, dass diese Klasse - aufgrund ihrer kurzfristigen und widersprüchlichen Interessen - unfähig sei, ihre Geschäfte selbst zu führen und daher dieses Ausschusses bedürfe. Der Staat sei somit die einzige Instanz, die das allgemeine Interesse dieser Klasse (auch gegen einzelne Fraktionen des Kapitals) 
gegen die divergierenden Partikularinteressen ihrer Fraktionen durch den Staat gelänge diesem, indem er zum einen relativ autonom gegenüber den verschiedenen Fraktionen sei $^{147}$, diese Fraktionen aber in einem Block an der Macht unter der Führung einer hegemonialen Fraktion zusammenfasse [St, S. 117 f.]. Aus dieser Konzeption zieht Poulantzas die Schlussfolgerung, dass zum einen die Bourgeoisie immer gespalten ist, also verschieden Kapitalfraktionen existieren würden, dabei nehme die Spaltung in Fraktionen unter dem Druck der Internationalisierung des Arbeitsprozesses beständig zu. Zum anderen würden immer alle bürgerlichen Fraktionen zum Block an der Macht gehören, es seien immer alle Fraktionen der Bourgeoisie auf dem Feld der Politik anwesend, dieses ist also nicht ausschließlich von einer bestimmten Fraktion (z. B. dem Monopolkapital) besetzt. Des Weiteren besitze der Staat gegenüber den Fraktionen des Blocks an der Macht relative Autonomie und könne so die Einheit der Klasse unter der Hegemonie einer Fraktion organisieren [St, S. 118]. Um zu verstehen, in welcher Beziehung sich Staat und herrschende Klasse zueinander stehen, also wie sich die Politik des Staates zugunsten des Blocks an der Macht formiert, muss nach Poulantzas der Staat begriffen werden ,als ein Verhältnis, genauer als die materielle Verdichtung eines Kräfteverhältnisses zwischen Klassen und Klassenfraktionen, das sich im Staat immer in spezifischer Form ausdrückt“ [St, S. 119].

b) Der Staat ist folglich - wie das Kapital - ein gesellschaftliches Verhältnis, der Staat besitzt dabei - wie das Kapital - eine spezifische Materialität, aber der Begriff des Staates ist - wie der des Kapitals - nicht auf eine spezifische Materialität, also seine Apparate, zu reduzieren. Hierdurch grenzt sich Poulantzas zum einen von deutlich von solchen Theoretikern ab, die den Staat als Werkzeug einer Klasse analysieren (so z. B. die Theorie des „staatsmonopolistischen Kapitalismus“/,Stamokap“, vor allem in der PCF vertreten). Ebenso grenzt sich Poulantzas von der Auffassung des Staates als Subjekt ab, welche sich, vor allem von Hegel geprägt, über Weber hin zum modernen Funktionalismus entwickelt habe [ebd.]. Des Weiteren richtet sich

artikulieren könne [Offe 1973, S. 76 f.].

147 Diese relative Autonomie gegenüber den verschiedenen Klassenfraktionen weist nach Poulantzas darauf hin, dass der Staat auch relativ autonom gegenüber den Produktionsverhältnissen ist [St, S. 118]. 
diese Konzeption gegen die Auffassung des Staates als Schiedsrichters, der zwischen den Klassen ausgleiche, diese Auffassung sei vor allem in der Sozialdemokratie vorzufinden. Die Konzeption des Staates als Verhältnis hat demgegenüber viel Gramsci zu verdanken, der im marxistischen Diskurs des Staates einen wesentlichen Einschnitt vornahm, indem er wie gezeigt den Staat nicht mehr als rein repressiven Apparat, als Werkzeug einer herrschenden Klasse, sondern ebenso als einen Apparat zur Organisation von Hegemonie und Zustimmung der beherrschten Massen analysierte, in dessen Denken die politische/hegemoniale Herrschaft aber fast durchweg materiell in den zivilgesellschaftlich-hegemonialen wie repressiven - Staatsapparaten erscheint, diese zivilgesellschaftlichen Apparate Feld des Klassenkampfs sind. Poulantzas kann sich hier insoweit anschließen, da er dem Staat seine Materialität nicht abspricht, diese Materialität aber generell in Bezug zu den Klassenkämpfen setzt:

Der Staat ist nicht bloß einfach ein Verhältnis oder die Verdichtung eines Verhältnisses: Er ist die materielle und spezifische Verdichtung eines Kräfteverhältnisses zwischen den Klassen und Klassenfraktionen. [ebd.]

Der Staat ist in Poulantzas Analysen folglich kein „instrumentelles Ganzes, kein Ding “ [Poulantzas 1975, S. 86], sondern ein soziales Verhältnis, dementsprechend ist der Staat auch kein statischer Komplex, sondern, der Konjunktur der Klassenkämpfe entsprechend, einer ständigen Transformation unterworfen. Gleichzeitig ist der Staat durch die relative Trennung von Politik und Ökonomie in der bürgerlichen Gesellschaft eine relativ autonome Struktur, dabei schreiben sich die Klassenkämpfe und gesellschaftlichen Machtverhältnisse aber nicht direkt in die Materialität des Staates ein, sondern der Staat besitzt eine ,eigene Dichte und Widerstandskraft und reduziert sich nicht auf ein Kräfteverhältnis“, die veränderten Klassenpositionen innerhalb des Klassenkampfs materialisieren „sich im Staat nur in gebrochener und differenzierter, den Apparaten entsprechender Form“ [St, S. 121].

Die bereits angedeutete Kritik Poulantzas' an der Auffassung des Staates als Subjekt oder als Werkzeug ist schon deshalb notwendig, da nach Poulantzas diese Konzeptionen ein Phänomen überhaupt nicht erfassen können: Die internen Widersprüche des Staates. Jede dieser Konzeptionen müsse den Staat als monolithische Einheit denken, in der Widersprüche allenfalls als „,dysfunktionale Unfälle“ auftreten, ein widersprüchliches Handeln des Staates wäre nur trotz seiner Einheit denkbar. Demgegenüber geht Poulantzas davon aus, dass 
die staatliche Struktur selbst in engem Zusammenhang mit den Klassenverhältnissen und den diesen immanenten Widersprüchen steht:

Die Etablierung der staatlichen Politik muss als Resultante der in die Struktur des Staates (der Staat als Verhältnis) selbst eingeschriebenen Klassenwidersprüche verstanden werden. [St, S. 122]

Hieraus zieht Poulantzas den Schluss, das die Klassenwidersprüche im inneren des Staates ebenfalls vorzufinden sind und somit der Staat selbst, seine Materialität wie seine Politik, diese Widersprüche reproduzieren. Noch mehr, die Klassenwidersprüche selbst durchziehen nicht nur den Staat, sondern sind für diesen und seine Politik konstituierend, „die Politik des Staates ist die Auswirkung ihrer Funktionsweise im Innern des Staates“ [St, S. 123]. Die Widersprüche innerhalb des Staates ergeben sich demnach in Bezug auf zwei Klassenverhältnisse: einmal aufgrund der Widersprüche zwischen der herrschenden und den beherrschten Klassen, zum zweiten aufgrund der Widersprüche innerhalb des Blocks an der Macht. Da letztere die Widersprüche zwischen den Fraktionen der herrschenden Klasse darstellen, schreiben sich diese in die Apparate des Staates ein, so dass die Widersprüche in dieser Materialität, sowohl „in vertikaler wie in horizontaler Richtung“" [ebd.] erscheinen. Dies deshalb, weil die verschiedenen Fraktionen innerhalb der staatlichen Struktur anwesend sind, sie können nur in soweit an der politische Herrschaft partizipieren, „wie sie innerhalb des Staates präsent sind" [ebd.]. Die verschiedenen Apparate des Staates sind nach Poulantzas demnach Sitz von verschiedenen Fraktionen oder konfliktueller Bündnisse von Fraktionen des Blocks an der Macht,

sie konzentrieren oder kristallisieren also in sich dieses oder jenes Interesse oder den Zusammenschluss von Sonderinteressen. Exekutive und Parlament, Armee und Justizbehörden, verschiedene Ministerien, kommunale Apparate, der zentrale Apparat, sowie die ideologischen Apparate, die alle selbst in bestimmte Kreise, Netze und Bahnen eingeteilt sind, repräsentieren zumeist - je nach Formationen - par excellence die divergierenden Interessen aller oder einzelner Teile des Blocks an der Macht. [ebd.]

c) Wenn der Staat in sich die inneren Widersprüche des Blocks an der Macht aufnehme, stellt sich für Poulantzas die Frage, wie die politische Einheit dieses Blocks organisiert wird. Diese Organisation ergebe sich dadurch, dass er selbst in seinen Apparaten diese Widersprüche aufnehme und damit der Staat ein objektives Feld darstelle, in dem sich eine hegemoniale Fraktion des Blocks an 
der Macht sich durchsetzen und in diesem ein relatives Kräftegleichgewicht herstellen könne. Das heißt für Poulantzas auch, dass dieses Kräftegleichgewicht beständig neu organisiert werden muss, da Materialität und Politik des Staates konfliktuell und widersprüchlich seien - das Kompromissgleichgewicht werde entsprechend den sich ändernden Kräfteverhältnissen austariert und schreibe sich wiederum in die staatliche Struktur ein ${ }^{148}$. Folglich könne keine Rede davon sein, dass der Staat „ein von oben nach unten einheitlich organisiertes Dispositiv darstellt und auf einer hierarchischen und homogenen Aufteilung der Machtzentren begründet“ [St, S. 124] werden könne. Dementsprechend stelle sich die staatliche Struktur auch als relativ autonom gegenüber dem Monopolkapital (der hegemonialen Klasse im Block an der Macht) dar, die Politik innerhalb des Staates des monopolistischen Kapitalismus ,ist die Resultante der innerstaatlichen Widersprüche zwischen den staatlichen Zweigen und Apparaten, aber auch der Widersprüche innerhalb dieser Zweige und Apparate selbst“" [ebd.].

Indem der Staat die langfristigen Interessen des Blocks an der Macht unter der Hegemonie einer bestimmten Fraktion als staatliche Politik organisiere, werde erreicht, dass das staatliche Handeln, auf der Mikroebene des Staates „,öllig chaotisch und inkohärent“ wirkend, auf der Makroebene durch die organische Funktion des Staates an Kohärenz gewinne. Dieser organisierenden Rolle des Staates seien aber strukturelle Grenzen gesteckt, so dass nicht davon auszugehen sei, dass sich der Kapitalismus zu einem „organisierten Kapitalismus" gewandelt hätte und dadurch seine eigene Widersprüchlichkeit überwunden hätte. Die organisierende Funktion des Staates ergibt sich selbst aus den Widersprüchen des Kapitalismus, und eben diese Widersprüche bilden die fundamentalen Grenzen des staatlichen Handelns. Gleichwohl gewinne der Staat durch die Widersprüche - lokalisierbar innerhalb des Prozesses der Kapitalakkumulation, des Blocks an der Macht und seiner eigenen Struktur eine relative Autonomie gegenüber den einzelnen Kapitalfraktionen, nicht aber gegenüber dem Block an der Macht. Diese Autonomie sei Resultat dessen, „was sich im Staat abspielt“ und zeige sich eben in der Inkohärenz und Wider-

148 Hirsch bringt es auf den Punkt, wenn er formuliert, dass „,die sozialen Formen als in sich selbst widersprüchlicher Ausdruck gesellschaftlicher Widersprüche Institutionalisierungsprozesse begründen, unterstützen und begrenzen, d. h. Ihre Tendenz oder Richtung bestimmen" [Hirsch 1992, S. 213]. 
sprüchlichkeit des staatlichen Handelns. Hier sei zu erkennen, inwieweit die einzelnen Fraktionen des Blocks an der Macht die Politik des Staates (und sei es auch nur rein negativ als oppositionelles Handeln) beeinflussen können [St, S. 125]. Ebenso, wie die staatliche Struktur mit Widersprüchen durchzogen ist, schreiben sich diese Widersprüche aber auch in die Agenten der staatlichen Struktur ein:

Wir haben es hier weniger mit einem einheitlichen und durch einen eindeutigen politischen Willen verbundenem Beamtentum und staatlichen Personal zu tun, sondern eher mit Cliquen, Hochburgen und Gruppierungen, also mit einer Vielzahl verstreuter Mikropolitiken. [St, S. 126]

Diese Mikropolitiken formieren insgesamt die Politik des Staates, aber nicht indem sie einem einheitlichen Dispositiv folgen, sondern - aufgrund der Widersprüchlichkeit der Politiken - indem die Politik des Staates ein Resultat des Aufeinanderprallens dieser Mikropolitiken darstelle. Den Staat als materielle Verdichtung eines Kräfteverhältnis zu begreifen heiße folglich auch, ihn als „strategisches Feld und strategischen Prozess zu fassen“ [ebd.] ${ }^{149}$, als Feld, in dem die verschiedenen Mikropolitiken und Taktiken „sich kreuzen, sich bekämpfen, den Durchbruch zu bestimmten Apparaten finden“" [ebd.]; die Politik des Staates sei somit weniger Resultat der Befolgung eines globalen Planes, sondern Ergebnis einer „konfliktuellen Koordinierung von expliziten und divergierenden Mikropolitiken“ [ebd.].

d) Die Verbindungen/Konfigurationen der verschiedenen Mikropolitiken ist aber in der Konzeption Poulantzas nicht beliebig, sondern diese würden wie die staatlichen Apparate zu einer Einheit organisiert. Der Staat besitze einen einheitlichen Apparat, eine Einheit, „die sich diesmal auf die Staatsmacht, über ihre Risse hinweg, bezieht“" [St, S. 127]. Dies zeige sich, indem die Politik des Staates zugunsten des Interesses der hegemonialen Fraktion innerhalb des Blocks an der Macht arbeite; verursacht aber nicht dadurch, dass der Staat dem Willen dieser Fraktion folge, sondern indem sich die Hegemonie einer Fraktion in die staatliche Struktur als Materialisierung eines Kräfteverhäl-

149 So formuliert z. B. auch Joachim Hirsch ähnlich: „Die heterogene und tendenziell chaotische Struktur des bürgerlichen Staatsapparats ist Voraussetzung dafür, dass er die komplexen Beziehungen zu den verschiedenen Klassen und Klassenfraktionen aufrecht erhalten kann, welche Bedingung seiner Funktionsfähigkeit als Garant der Herrschaft der Bourgeoisie sind" [Hirsch 1974, S. 374 f.]. 
tnisses eingeschrieben habe. Die privilegierte Stellung einer hegemonialen Fraktion im Block an der Macht bewirke die Vereinheitlichung, dies zeige sich beispielsweise im modernen Staat des Monopolkapitalismus:

Die Einheit und Zentralisierung des Staates [...] entsteht [...] in einem komplexen Prozess institutioneller Transformationen des Staates, durch die bestimmte dominante Entscheidungszentren, Dispositive und Knoten ausschließlich für die monopolistischen Interessen durchlässig werden. [ebd.] ${ }^{150}$

Die institutionellen Transformationen würden bewirken, dass innerhalb der Konfiguration der staatlichen Apparate sich dominante Apparate entwickeln, die staatliche Einheit gründe sich daher auf eine ,ganze Kette der Unterordnung bestimmter Apparate unter andere und auf die Herrschaft eines Apparates oder Zweiges des Staates“ [ebd.]. Dieser herrschende Apparat (z. B. Partei, Armee, Ministerium) sei in der Regel der Apparat, der die Interessen der hegemonialen Fraktion par excellence verkörpere ${ }^{151}$. Dieser Prozess beinhalte eine Anzahl von „Nebendeterminationen und Ersetzungen“ von Apparaten, „Verschiebungen von Funktionen und Kompetenzbereichen zwischen den einzelnen Apparaten sowie von konstanten Verlagerungen zwischen der realen und der formalen Macht“ [St, S. 128].

Das heißt für Poulantzas aber auch, dass innerhalb des strategischen Feldes „Staat“ die Orte der realen Macht verschoben werden können; wenn es beispielsweise der Linken gelänge, den Ort der formalen Macht zu erlangen und zahlreiche Apparate des Staates zu besetzen, hieße das nicht, dass sie damit automatisch den Ort der realen Macht kontrolliere. Im Gegenteil seien die reale und die formale Macht in der Lage, selbst ihre staatlichen Orte miteinander zu vertauschen [St, S. 128 f.], ,,die Organisation des bürgerlichen Staates gestattet es ihm, durch sukzessive Verlagerungen und Verschiebungen die Macht der Bourgeoisie von einem zum anderen Apparat zu verlagern“ [St, S. 129]. Das heißt für Poulantzas aber auch, dass die Machtzentren nicht zwangsläufig in den hierarchischen Spitzen der Apparate zu lokalisieren seien, sondern dass es strategische Punkte in den Apparaten gebe, „Knoten“ und „Brennpunkte“ der realen Macht, die es zu besetzen gelte [ebd.].

150 Diese „Duchlässigkeit“ ist analog der „Selektivität“ Offes zu sehen, siehe hierzu Offe 1973, S. $65 \mathrm{ff}$.

151 Siehe hierzu den Abschnitt 2.6 zum autoritären Etatismus. 
Die spezifische Materialität des Staates und die Konfiguration seiner Apparate ergibt sich nach Poulantzas aber nicht nur aus den Kämpfen der Fraktionen innerhalb des Blocks an der Macht, sondern ebenso aus den Klassenkämpfen zwischen dem Block an der Macht und den beherrschten Klassen. Diese Kämpfe sind als politische Kämpfe immer im Staat präsent (und dringen nicht von außen in ihn ein), gleichzeitig gehe der Klassenkampf aber weit über das Feld des Staates hinaus. Aber selbst wenn die Klassenkämpfe auch außerhalb des Staates stattfinden, seien sie dort nicht außerhalb des Feldes der Macht angeordnet, sondern sind in diejenigen

Machtapparate eingeschrieben, die die Kämpfe materialisieren und ebenfalls ein Kräfteverhältnis verdichten. [...] Wegen der komplexen Verkettung des Staates mit der Gesamtheit der Machtdispositive wirken diese Kämpfe immer - diesmal ,aus der Distanz“ - innerhalb des Staates. [St, S. 131] $]^{152}$

Daraus folgert Poulantzas, dass der „Klassenfeind“ immer im Staat anwesend ist, die Struktur des Staates stehe den beherrschten Klassen nicht frontal gegenüber, sondern sei darauf ausgerichtet, „das Verhältnis von HerrschaftUnterordnung im Inneren des Staates aufrechtzuerhalten und zu reproduzieren “ [ebd.]. Dies gelte erst recht vor dem Hintergrund, dass der Staat die Hegemonie der herrschenden Klasse auch durch politische Destabilisierung beherrschter Klassen und durch Herbeiführung von Kassenbündnissen zugunsten der herrschenden Klasse organisieren müsse, dieses würde sich wiederum in die Struktur des Staates einschreiben. Daraus folgert Poulantzas, das auch die beherrschten Klassen innerhalb der materiellen Struktur des Staates Orte besetzen, diese Apparate würden ihnen aber selbst keine Macht verleihen, sondern hätten den Status von Oppositionszentren [St, S. 131 f.], denn vor dem Hintergrund der Konzeption des Staates als materielle Verdichtung eines Kräfteverhältnisses und als strategisches Feld ist natürlich klar, dass der Staat selbst keine Macht haben kann, sondern gesellschaftlicher Ort ist, in dem Macht ausgeübt wird:

Unter Staatsmacht ist nur die Macht bestimmter Klassen [...] d. h. ihre Stellung in Machtbeziehungen gegenüber anderen Klassen [...] zu verstehen. [...] Der Staat ist weder der instrumentale Verwalter (das Objekt) einer Machtessenz, die die herrschende Klasse in Besitz hat, noch ein

152 Ähnlich schreiben auch Deleuze/Guattari - auf Althusser zurückgreifend -, dass der Staat „Resonanzbox für private und öffentliche Mächte“ sei [Deleuze/Guattari 1997b, S. 288]. 
Subjekt, das über genauso viel Macht verfügt, wie sie den Klassen gewaltsam wegnimmt. [...] Er ist ein Ort und ein Zentrum der Machtausübung, besitzt jedoch selbst keine eigene Macht. [St, S. 136]

\subsection{Staat und gesellschaftliche Macht}

Der Staat greift durch seine Aktion und seine Wirkung in alle Machtbeziehungen ein und weist ihnen damit ihren Stellenwert in den Klassenbeziehungen zu.

Nicos Poulantzas

a) In der Entwicklung seiner Machtkonzeption innerhalb seiner Staatstheorie nimmt Poulantzas die Arbeiten Foucaults - wenn auch kritisch - auf. Foucaults Konzeption der Macht geht (unter starkem Einfluss Nietzsches stehend) vor allem davon aus, dass diese nicht auf das Eigentum einer bestimmten Klasse zurückzuführen ist, Macht ist „nicht so sehr das erworbene oder bewahrte Privileg der herrschenden Klasse, sondern vielmehr die Gesamtwirkung ihrer strategischen Positionen“ [ÜuS, S. 38]. Die Existenz von Klassen und Klassenkämpfen wird in dieser Machtkonzeption nicht bestritten [Deleuze 1995, S. 39], vielmehr sind hier die Klassenkämpfe in einem Feld von Machtbeziehungen einzuordnen, das die gesamte Gesellschaft durchzieht, die Machtbeziehungen

reduzieren sich nicht auf das Verhältnis des Staates zu den Bürgern oder auf die Schranke zwischen den Klassen; sie beschränken sich nicht darauf, auf der Ebene der Individuen, der Körper, der Gesten und der Verhaltensweisen die allgemeine Form des Gesetzes oder der Herrschaft zu reproduzieren. [ÜuS, S. 38]

Foucault/Deleuze bestreiten eine „materielle“ Begründung der Macht in dem Sinn, dass sie auf die ökonomische Position einer Klasse zurückzuführen sei: Macht ist, „Macht ist eine Kräfteverhältnis, oder vielmehr jedes Kräfteverhältnis ist ein 'Machtverhältnis'“ [Deleuze 1995, S. 99], Gewalt ist dabei in einem Kräfteverhältnis dessen Begleiterscheinung, nicht aber konstituierend für dieses. Kennzeichnend für die Foucault'sche Machtkonzeption ist somit:

1. Macht ist nicht (grundsätzlich) repressiv, sondern ebenso produktiv ${ }^{153}$

153 „Was bewirkt, dass die Macht Macht ist, dass man sie anerkennt, das liegt doch einfach daran, dass sie die Dinge durchzieht, dass sie Dinge hervorbringt, Freude induziert, 
2. Macht wird nicht besessen, sondern ausgeübt

3. Macht läuft durch Beherrschte wie durch Herrschende hindurch [Deleuze 1995, 100; Foucault 1997c, S. 115]

4. Die Foucault'sche Konzeption von Macht impliziert, dass sowohl Herrschaft als auch Widerstand ausgeübt wird [Foucault 1997c, S. 116].

Von diesem nicht hinterfragbaren Machtbegriff ${ }^{154}$ ausgehend entwickelt Foucault den Begriff der Disziplinargesellschaft, der für die modernen Gesellschaften kennzeichnend ist. Innerhalb dieser Disziplinargesellschaften kann aber Disziplin nicht mit „einer Institution oder einem Apparat identifiziert werden, eben weil sie ein Typus von Macht ist, eine Technologie, die alle Arten von Apparaten und Institutionen durchzieht“" [Deleuze 1995, S. 40]. Die politische Anatomie des gesellschaftlichen Körpers wird folglich gebildet aus einem Netz von Machtbeziehungen, die den verschiedenen gesellschaftlichen Verhältnissen, z. B. Ökonomie, Sexualität, Erkenntnisrelationen nicht äußerlich gegenüberstehen, sondern ihnen immanent sind ${ }^{155}$, die Machtbeziehungen seien sowohl Auswirkungen „von Teilungen, Ungleichheiten und Ungleichgewichten, die in jenen Verhältnissen zustande kommen, und andererseits sind sie die inneren Bedingungen jener Differenzierungen“ [Foucault 1997c, S. 115]. Von dieser Konzeption ausgehend entfalten Deleuze und Foucault eine Kritik am (strukturalistischen wie orthodoxen) Marxismus, für den der Staatsapparat „privilegierter Ort als Quelle der Macht“ [Deleuze 1995, S. 41] darstelle. Der Staat sei demgegenüber aber vielmehr Resultante oder Gesamteffekt von Machtbeziehungen zu begreifen ${ }^{156}$ [ebd., S. 40].

Allerdings ist festzustellen, dass diese Kritik insoweit ihr Ziel verfehlt, als dass „der“ Marxismus nie behauptet hat, der Staat sei „Quelle der Macht“. Vielmehr wurde in den verschiedenen marxistischen „Schulen“ der Staat zwar als „Instrument“, ,,juristischen Überbau“ usw. bezeichnet, die Macht des kapi-

Wissen ausgestaltet, Diskurs produziert; man muss die Macht als ein produktives Netz sehen, das den ganzen Sozialkörper einhüllt“" [Foucault 1978b, S. 80].

154 „Man sollte nicht fragen: 'Was ist die Macht? Und von woher kommt sie?'“ [Deleuze 1995, S. 100]

155 Diese Position wird freilich von Deleuze selbst wiederum eingeschränkt: Die Entwicklung der Disziplinargesellschaft ließe sich mit der ökonomischen Struktur der Gesellschaft allenfalls insoweit in Beziehung setzen, als das „demographischer Druck“ und ein „Wachstum der Produktion“ eine solche bedingen [Deleuze 1995, S. 41].

156 Auch diese Position wird von Deleuze später eingeschränkt, vgl. Deleuze/Guattari 1992, S. $619 \mathrm{ff}$. 
talistischen Staates wurde aber immer auf die Produktionsverhältnisse zurückgeführt. Wenn Foucault als Kritik am Marxismus formuliert, „die Machtbeziehungen bilden nicht den Überbau, der nur eine hemmende oder aufrechterhaltende Rolle spielt - wo sie eine Rolle spielen, wirken sie unmittelbar hervorbringend“" [Foucault 1997c, S. 115], offenbart sich eine z. T. fragwürdige Interpretation des Marxismus: die Identifikation von Überbau und Macht bzw. die Interpretation des Staates als alleinigem Machtverhältnis innerhalb der marxistischen Theorie. Zweifellos übt der Staat in verschiedenen marxistischen Theorien Macht aus, entfaltet vielfältige Machtbeziehungen, allerdings besitzt er nicht die Macht, sondern ist generell Form, in der gesellschaftliche Macht ausgeübt wird. Schon die Anmerkung Marx', nach dem der Staat nur der geschäftsführende Ausschuss sei, der die gemeinsamen Geschäfte der herrschenden Klasse vertrete [MEW, Bd. 4, S. 464], verweist in diese Richtung des Staates als Repräsentationsverhältnis. Auch ist der Staat für den „orthodoxen“ Marxismus nicht die einzige Form, in der Macht ausgeübt wird, der Staat ist in diesem Zusammenhang aber zweifellos von überragender Bedeutung. Wenn Deleuze in seiner Foucault-Monographie ausführt,

die gesamte Ökonomie, zum Beispiel die Werkstatt oder die Fabrik, setzt bereits diese Mechanismen der Macht voraus, die schon von innen auf die Körper und die Seelen und bereits innerhalb des ökonomischen Feldes auf die Produktivkräfte und Produktionsverhältnisse einwirkt [Deleuze 1995, S. 42],

ist das aus Sicht des historischen Materialismus nicht unbedingt eine originelle Ansicht. Weder behauptet der Marxismus, dass sich der Kapitalismus (genauer: die kapitalistische Produktionsweise) ohne Macht- bzw. Gewaltausübung herausgebildet hat [MEW, Bd. 23, S. 741 ff.], noch dass die Produktionsweise im engeren Sinn frei von Macht ist [ebd., S. $371 \mathrm{ff}$.$] :$

Es kostet Jahrhunderte, bis der „freie“ Arbeiter infolge entwickelter kapitalistischer Produktionsweise sich freiwillig dazu versteht, d. h. gesellschaftlich gezwungen ist, für den Preis seiner gewohnheitsmäßigen Lebensmittel seine ganze aktive Lebenszeit, ja seine Arbeitsfähigkeit selbst, seine Erstgeburt für ein Gericht Linsen zu verkaufen. [ebd., S. 287; Hervorhebung S.v.B.]

b) Die von Foucault vorgetragene Kritik nimmt Poulantzas kritisch auf, indem er eine Konzeption der Macht in Bezug auf den Staat entwirft, die nicht auf den 
zentralen Aspekt der marxistischen Theorie - der Dominanz des Klassenkampfs in den gesellschaftlichen Beziehungen - verzichtet:

1. Der Klassenkampf schließe Machtbeziehungen, auch nicht-ökonomische Machtbeziehungen ein, diese Machtbeziehungen seien spezifisch, da sie mit Ausbildungsverhältnissen verknüpft seien und verweisen auf

objektive, in die Arbeitsteilung eingegliederte Stellungen und kennzeichnet die Fähigkeit einer jeden Klasse, ihre spezifischen Interessen im Gegensatz zu den anderen Klassen zu verwirklichen. [...] Diese Machtbeziehungen, die in der Mehrwertproduktion und in deren Beziehung zu den politisch-ideologischen Strukturen verankert sind, sind im übrigen in spezifischen Institutionen und Apparaten materialisiert. [St, S. 33]

2. Macht sei nicht mit den Staat identisch und könne nicht auf diesen reduziert werden, sondern sie erstreckt sich über dessen Bereich hinaus.

3. Der Bereich des Staates sei nicht auf den juristisch definierten, weitgehend mit dem repressiven Apparaten identischen Staat zu reduzieren, wie es nach Ansicht Poulantzas - in den Arbeiten von Foucault geschieht. Folglich sei die Macht in dem erweiterten Staatsbegriff (RSA + ISA) in allen Staatsapparaten existent.

4. Aber die Macht sei auch außerhalb dieses erweiterten Staatsbegriffs existent: Zum einen ließen sich die Machtbefugnisse außerhalb des Staates in den Produktionsverhältnissen finden (auch wenn diese Machtbefugnisse wiederum in einem engen Verhältnis mit der politischen Macht/dem Staat stehen würden). Zum anderen weise die Macht immer über den Staat und seine ideologischen Apparate hinaus, letztere

stellen keine vorrangigen oder erschöpfenden Momente der Reproduktion der ideologischen Herrschafts- und Unterwerfungsbeziehungen dar, genauso wenig wie sie die herrschende Ideologie schaffen. Durch die ideologischen Apparate wird die herrschende Ideologie nur ausgearbeitet und verbreitet. [St, S. 34]

5. Die Machtbeziehungen ließen sich nicht auf die Apparate reduzieren, sondern würden in einer spezifischen Beziehung zu den gesellschaftlichen Kämpfen stehen ${ }^{157}$,

157 Insoweit besteht zwischen Poulantzas und Deleuze/Foucault eine Übereinstimmung, als das Macht ein gesellschaftliches Verhältnis ist, alle gesellschaftlichen Bereiche durchzieht und strukturiert. Eine weitere Differenz ist aber bezüglich der Macht- und Kräfteverhältnis erkennbar: während der Marxismus durch die Beseitigung der - spezifische Machtverhältnisse konstituierende - objektiven Macht- oder „Verblendungsverhältnisse“ (seien es nun die Eigentumsverhältnisse oder der Warenfetischismus) immerhin noch eine Option sieht, „den Menschen“ aus (bestimmten) Machtverhältnissen zu befreien, sind die Macht- 
in der komplexen Beziehung zwischen dem Klassenkampf und den Apparaten kommt den Kämpfen die vorrangige und fundamentale Rolle $z u$. Das Feld dieser (ökonomischen, politischen, ideologischen) Kämpfe stellt bereits auf der Ebene der Ausbeutung und der Produktionsverhältnisse nichts anderes als ein Feld von Machtverhältnissen dar. [ebd.]

Desweiteren habe der Staat auch eine konstitutive Rolle in den Produktionsverhältnissen und den Klassenkämpfen, also den gesellschaftlichen Machtbeziehungen. Eine solche konstitutive Rolle zu behaupten bedeute nicht, die Frage nach einem chronologischem Verlauf zu stellen (,wer war zuerst da, die Produktionsverhältnisse oder der Staat?“), sondern es gelte, das synchronischtheoretische Verhältnis von gesellschaftlicher Macht und Staat zu untersuchen:

Wo es Klassenteilung und daher Kampf und Klassenmacht gibt, gibt es immer schon den Staat, d. h. die institutionalisierte politische Macht. Es gibt keinen Klassenkampf oder keine Klassenmacht vor dem Staat oder ohne den Staat, keinen „Naturzustand“ oder ,gesellschaftlichen Zustand“, der dem Staat vorausgeht. [...] Der Staat steckt von Anfang an das Kampffeld ab, das Feld der Produktionsverhältnisse mitinbegriffen, er organisiert den Markt und die Eigentumsverhältnisse, etabliert die politische Herrschaft und die politisch herrschende Klasse, er markiert und kodifiziert alle Formen der gesellschaftlichen Arbeitsteilung, die gesamte gesellschaftliche Realität im Bezugsrahmen einer Klassengesellschaft. [St, S. 36]

Das bedeutet für Poulantzas nicht weniger, als dass in einer Klassengesellschaft keine gesellschaftliche Realität denkbar ist, die nicht in Beziehung zum Staat und zur Arbeitsteilung steht; selbst wenn die historische Realität einer Gesellschaft angenommen werde, die vor dem Staat existiere, muss diese Gesellschaft und ihre Geschichte zum (abwesenden) Staat in Beziehung gesetzt werden:

Wenn (eine) Geschichte daher die Geschichte des Klassenkampfes ist, wenn die ,primitiven“ Gesellschaften ohne Staat Gesellschaften ohne (diese) Geschichte sind, dann nur deshalb, weil diese Geschichte nicht ohne Staat existiert. [ebd.]

Dementsprechend sei der Staat nicht das historische Ergebnis des Klassenkampfes, sondern die Geschichte des Klassenkampf sei ohne den Staat nicht denkbar (ebenso wenig stelle der Staat die „Eröffnung“ der Geschichte dar) [ebd.]. Die Verbindung des Staates mit dem Klassenkampf bedeute allerdings nicht, dass Macht allein in Bezug auf die Klassenbeziehungen gedacht werden könne, sondern dass die Machtverhältnisse sich auch über den Bereich der

verhältnisse für Foucault endlos und nicht zu überwinden. 
Klassenbeziehungen heraus erstrecken würden. Dabei hätten diese Machtbeziehungen aber grundsätzlich Klassencharakter, da sie zwar auf einer anderen Grundlage als die gesellschaftliche Teilung in Klassen beruhen, aber mit spezifischen Apparaten und Institutionen verknüpft seien (insbesondere die Familie) und in denen sich diese spezifischen Machtverhältnisse reproduzieren würden. Diese Institutionen stehen wiederum mit dem Staat in Beziehung:

Der Staat greift durch seine Aktion und seine Wirkungen in alle Machtbeziehungen ein und weist ihnen damit ihren Stellenwert in den Klassenbeziehungen zu. Der Staat konzentriert auf diese Weise heterogene Machtbeziehungen, die sich zu Relaisstationen und Stützen der (ökonomischen, politischen und ideologischen) Macht der herrschenden Klasse entwickeln. Die Machtverhältnisse in den sexuellen Beziehungen zwischen Mann und Frau, die ohne Zweifel von den Klassenbeziehungen zu unterscheiden sind, werden unter anderem durch den Staat (aber auch durch den Betrieb) als Klassenbeziehungen etabliert und reproduziert; die Klassenmacht durchzieht sie, benutzt sie, verfeinert sie, kurz, sie weist ihnen ihren politischen Stellenwert zu. Der Staat ist nicht allein deshalb ein Klassenstaat, weil er die in den Klassenverhältnissen begründete Macht konzentriert, sondern insofern er tendenziell durch die Aneignung ihrer Mittel auf jede Macht einwirkt, obwohl diese beständig über ihn hinausreicht. [St, S. 40] ${ }^{158}$

Dadurch komme der politischen Macht, auch wenn sie auf ökonomischer Macht basiere, besondere Bedeutung zu, da ihre „Transformation jede wesentliche Modifikation der anderen Machtfelder überwiegend bestimmt“, sie konzentriere und materialisiere sich im zentralen Ort der Ausübung der politischen Macht, dem Staat. [St, S. 41 f.]

Der Staat ist demnach nicht eine institutionelle Integration/Zusammenführung gesellschaftlicher Mikromächte; diese Foucault'sche Konzeption läuft letztendlich darauf hinaus, dass die verschiedenen gesellschaftlichen Machtverhältnisse sich ,gleichberechtigt“, lediglich abhängig von der Stärke der mit ihnen korrespondierenden politischen Bewegungen, innerhalb der staatlichen Apparate materialisieren [vgl. Foucault 1997c, S. 113 ff.; Jäger 1983, S. 138, Fn. 1]. Demgegenüber bilden in der Konzeption Poulantzas' die verschiedenen Machtverhältnisse den Staat, aber nicht als bloße „Anhäufung“ von Machtverhältnissen, sondern als spezifische Konfiguration von Machtverhältnissen, die

158 Die Einbeziehung nicht-ökonomischer Machtverhältnisse in die Theorie und das Zugeständnis deren politischer Bedeutung ist durchaus als Selbstkritik Poulantzas zu werten: in Politische Macht und gesellschaftliche Klassen wird unter dem Begriff der „Politik“ nur der politische Klassenkampf zugelassen und das ,politische Feld“ wird dort allein durch den Staat gebildet [Poulantzas 1980, S. 35 ff.] 
durch ein dem Staat grundlegendes Machtverhältnis (das Klassenverhältnis) transformiert und an dieses angepasst werden und deren Materialität durch den Staat formiert wird. 


\title{
2.5. Die Materialität des Staates
}

\subsubsection{Macht und Wissen}

Der kapitalistische Staat bemächtigt sich der Produktion der Wissenschaft, die damit in ihrer immanenten Struktur zu einer mit den Machtmechanismen verflochtenen Staatswissenschaft wird. Dies gilt nicht nur für die sogenannten „Humanwissenschaften“.

Nicos Poulantzas

\begin{abstract}
Man kauft keine Gelehrten, Techniker und Apparate, um die Wahrheit zu erfahren, sondern um die Macht zu erhalten.
\end{abstract}

Jean-François Lyotard

Von der Frage der Macht ausgehend untersucht Poulantzas die Materialität des Staates, dabei legt er (dies ist wiederum eine Selbstkorrektur früherer Arbeiten) besonderes Augenmerk auf die gesellschaftliche Arbeitsteilung. Diese Arbeitsteilung sei nicht nur innerhalb der ökonomischen Struktur aufzufinden, sondern ebenso in den anderen Strukturen des gesellschaftlichen Ensembles. Bezüglich der gesellschaftlichen Arbeitsteilung sei die Trennung in „Hand“- und „Kopfarbeit" nicht so zu verstehen, dass zwischen denen, die mit dem Kopf, und jenen, die mit der Hand arbeiten, unterschieden wird, sondern die Unterscheidung von Hand- und Kopfarbeit verweise auf „die politisch-ideologischen Beziehungen innerhalb bestimmter Produktionsverhältnisse“ und ebenso auf die Trennung des „Wissens“ von der Produktion sowie der Verbindung dieses Wissens mit der Macht. Die Trennung von Hand- und Kopfarbeit sei gekennzeichnet durch:

a) die spezifische Trennung der intellektuellen Elemente von der vom unmittelbaren Produzenten ausgeführten Arbeit, die in dieser Trennung von der geistigen Arbeit (dem Wissen) die kapitalistische Form der manuellen Arbeit annimmt;

b) die Trennung der Wissenschaft von der manuellen Arbeit, die sich zur unmittelbaren Produktivkraft, wenn auch „,im Dienste des Kapitals“ entwickelt;

c) die Herausbildung von spezifischen Beziehungen zwischen der Wissenschaft/dem Wissen und den ideologischen Verhältnissen bzw. der herrschenden Ideologie [...] im Sinne einer ideologischen Legitimation 
der Macht in der wissenschaftlichen Technik, d. h. der Legitimation der Macht als Resultat einer rationellen wissenschaftlichen Praxis;

d) die organischen Beziehungen zwischen der von der manuellen Arbeit getrennten geistigen Arbeit und der politischen Herrschaft, kurz, zwischen dem kapitalistischen Wissen und der kapitalistischen Macht. [St, S. 48]

Die Trennung von manueller und geistiger Arbeit ist nach Poulantzas zwar nicht für die kapitalistische Gesellschaftsformation spezifisch, allerdings besitze diese eine spezifische Form dieser Trennung, die wiederum auf den Staat verweise und dessen Funktion bezüglich dieser Trennung erkennen lasse:

Der Staat verkörpert in der Gesamtheit seiner Apparate, d. h. nicht nur in seinen ideologischen, sondern auch in seinen repressiven und ökonomischen Apparaten, die geistige Arbeit in ihrer Trennung von der manuellen Arbeit. [St, S. 49]

Diese Trennung von manueller und geistiger Arbeit schreibe sich im kapitalistischen Staat in seine Materialität ein und bestimme die Konstitution und Reproduktion seiner Apparate. Die spezifische Trennung des Staates von den Produktionsverhältnissen und seine politische Funktion schlägt sich in der Spezialisierung sowohl der repressiven wie ideologischen Staatsapparate nieder und steht selbst in Verbindung mit einem „Wissen“: „Diese Apparate [...] schließen die Umsetzung und Beherrschung eines Wissens und eines Diskurses ein [...], von denen die Volksmassen ausgeschlossen sind“ [ebd.]. Dieses Wissen werde somit in den staatlichen Apparaten monopolisiert und innerhalb der Reproduktion dieser Apparate reproduziere sich wiederum die Trennung von geistiger und manueller Arbeit: die geistige Arbeit - verstanden als Wissen um die Organisation und Lenkung des Staates - reproduziere sich in den Apparaten und Agenten des Staates, wohingegen sich die manuelle Arbeit (als Ausschließung/Distanzierung von diesem Wissen) sich in den beherrschten Massen konzentriere und diese von den organisatorischen Funktionen der Staatsapparate ausgeschlossen bleiben würden. Die für die repräsentative Demokratie grundlegenden Institutionen wie Parteien, Parlament usw. würden dementsprechend auf diesem Ausschlussprinzip basieren [ebd.].

Mit dem Begriff des Agenten der staatlichen Apparate, dem innerhalb der Organisation und Lenkung der staatlichen Apparate maßgebliche Bedeutung zukommt, greift Poulantzas eine Konzeption Gramscis auf, der diesen Agenten bereits in seinen Gefängnisheften analysierte und als den modernen Typus des Intellektuellen identifizierte. 


\subsubsection{Gramsci-Exkurs II: Die Intellektuellen}

Im Gegensatz zu bürgerlichen Analysen und der Mehrzahl der marxistischen Autoren, die den Begriff des Intellektuellen möglichst eng fassen, um - basierend auf den sozialen Bedingungen desselben - mögliche Bündnispartner der Arbeiterbewegung zu entdecken, versuchte Gramsci, den Begriff des Intellektuellen aus einer politisch-funktionalen Sicht $\mathrm{zu}$ entwickeln [Priester 1981, S. 91].

Unter Intellektuellen darf man nicht nur jene allgemein mit dieser Bezeichnung erfassten Schichten verstehen, sondern im allgemeinen die gesamte soziale Schicht, die organisatorische Funktionen im weiten Sinne ausübt, sei es auf dem Gebiet der Produktion, auf kulturellem wie auf politisch-administrativen Gebiet: sie entsprechen den Unteroffizieren in der Armee und teilweise auch den höheren Offizieren subalternen Ursprungs. Um die politisch-soziale Funktion der Intellektuellen zu analysieren, muss man ihre psychologische Haltung zu den Grundklassen untersuchen. [zit. nach Priester 1981, S. 91]

Die Arbeitsfelder der Intellektuellen werden hier bereits angedeutet: Ökonomie, Kultur, Politik. Allerdings definiert Gramsci die Intellektuellen nicht über den Inhalt ihrer Tätigkeit, sondern aus ihrer gesellschaftlichen Stellung bezüglich der Klassenverhältnisse [Gh, Bd. 7, S. 1499]. Innerhalb der Analyse Gramscis stellen die Intellektuellen zwar eine soziale Schicht, aber keine eigene Klasse dar. Vielmehr bringe jede (fortschrittliche) Klasse eigene Intellektuelle hervor, die im Interesse der jeweiligen Klasse eine Vermittlungsfunktion zwischen den ökonomischen, kulturellen und politischen Strukturen wahrnehmen.

Jede gesellschaftliche Gruppe schafft sich, während sie auf dem originären Boden einer wesentlichen Funktion in der Welt der ökonomischen Produktion entsteht, zugleich organisch eine oder mehrere Schichten von Intellektuellen, die ihr Homogenität und Bewusstsein der eigenen Funktion nicht nur im ökonomischen, sondern auch im gesellschaftlichen und politischen Bereich geben. [ebd., S. 1497]

Die Entwicklung dieser „organischen Intellektuellen“ ist für Gramsci somit von der ökonomischen Basis der jeweiligen Klasse abhängig, der sie entwachsen. Am Beispiel der besitzenden Klasse konkretisiert Gramsci diese historische Herausbildung der Intellektuellen und entwickelt die ökonomische und gesellschaftliche Funktion der Intellektuellen in Bezug auf die Ökonomie, ,der kapitalistische Unternehmer schafft mit sich den Techniker der Industrie, den Wissenschaftler der politischen Ökonomie, den Organisator einer neuen Kultur, 
eines neuen Rechts usw. usf." [ebd.]. Dieser Herausbildungsprozess auf ökonomischem, juristischem und kulturellem ist eine für die jeweilige Klasse notwendige (intellektuelle) Aufgabe, die wiederum selbst von Repräsentanten oder „Spezialisten“ derselben durchgeführt wird.

Wenn nicht alle Unternehmer, so muss doch zumindest eine Elite derselben eine Fähigkeit als Organisator der Gesellschaft im allgemeinen haben, in ihrem ganzen komplexen Organismus von Dienstleistungen bis hin zum staatlichen Organismus, wegen der Notwendigkeit, die günstigsten Bedingungen für die Ausdehnung der eigenen Klasse zu schaffen; beziehungsweise muss sie zumindest die Fähigkeit besitzen, die „Gehilfen“ (spezialisierte Angestellte) auszuwählen, denen diese Tätigkeit des Organisierens der außerbetrieblichen allgemeinen Verhältnisse anvertraut werden kann. [ebd.]

Zum einen vollzieht sich die Herausbildung von Intellektuellen immer vor dem historischen Hintergrund der Entwicklung der Produktionsverhältnisse, zum anderen findet jede sich entwickelnde Klasse bereits Gruppen von Intellektuellen vor, die „traditionellen Intellektuellen“:

Aber jede „wesentliche“ gesellschaftliche Gruppe, die aus der vorhergehenden ökonomischen Struktur und als Ausdruck einer Entwicklung derselben (dieser Struktur) in der Geschichte auftaucht, hat, zumindest im bisherigen Verlauf der Geschichte, bereits bestehende Gesellschaftskategorien vorgefunden, die geradezu als Repräsentanten einer selbst durch die komplexesten und radikalsten Veränderungen der gesellschaftlichen und politischen Formen nicht unterbrochenen geschichtlichen Kontinuität erschienen. [ebd., S. 1498]

Diese „traditionellen Intellektuellen“ seien vor allem die Personen, die in dem „Überbau“ der alten Gesellschaft tätig sind, welcher von der neu entstehenden Gesellschaftsformation vorgefunden wird, also vor allem Richter, Verwaltungsbeamte usw.; als Vertreter der traditionellen Mittelklassen kommt ihnen erheblicher politischer Einfluss zu [Bischoff 1981, S. 111]. Mitentscheidend für den Erfolg einer Klasse, die versucht, selbst herrschende Klasse zu werden,

ist ihr Kampf um die Assimilierung und ,ideologische“ Eroberung der traditionellen Intellektuellen, eine Assimilierung und Eroberung, die um so schneller und wirksamer ist, je mehr die gegebene Gruppe gleichzeitig ihre eigenen organischen Intellektuellen heranbildet. [Gh, Bd. 7, S. 1500]

Diese Assimilierung oder dieses Bündnis mit den traditionellen Intellektuellen [Kebir 1980, S. 86] sei u.a. dadurch möglich, dass die organischen, fortschrittlichen Intellektuellen eine „Ausstrahlung“ auf die traditionellen Intellektuellen haben würden. Zum anderen herrsche innerhalb der Gruppe der Intellektuellen 
ein ausgeprägtes Standesdünkel, das durch die eigene (falsche) Annahme, von den anderen gesellschaftlichen Klassen unabhängig zu sein, verursacht sei:

Es gibt keine unabhängige Klasse von Intellektuellen, sondern jede soziale Gruppe besitzt eine eigene Schicht von Intellektuellen oder ist bestrebt, sie sich zu schaffen; aber die Intellektuellen der geschichtlich (und tatsächlich) fortschrittlichen Klassen üben unter den jeweiligen Bedingungen eine solche Anziehungskraft aus, dass sie sich schließlich die Intellektuellen der anderen sozialen Gruppen unterordnen und auf diese Weise ein System der Solidarität aller Intellektuellen herbeiführen, deren Bindemittel psychologischer (Eitelkeit usw.) und häufig kastenmäßiger (technisch-juristischer, ständischer usw.) Art sind. [Gh, Bd. 2, S. 279]

Als für Italien prägende Gruppe traditioneller Intellektueller erkannte Gramsci die Kirche. Im Feudalismus habe die Priesterkaste

einige wichtige Dienstleistungen monopolisiert [...]: die religiöse Ideologie, das heißt die Philosophie und die Wissenschaft der Epoche, einschließlich der Schule, des Bildungswesens, der Moral, der Justiz, der Wohltätigkeit, der Fürsorge usw. Die Kategorie der Kirchenmänner kann als die organisch an die grundbesitzende Aristokratie gebundene Intellektuellenkategorie betrachtet werden: sie war juristisch der Aristokratie gleichgestellt, mit der sie sich in die Ausübung des feudalen Eigentums am Boden und in den Genuss der an das Eigentum gebundenen staatlichen Privilegien teilte. [Gh, Bd. 7, S. 1498]

Die historische Entwicklung vom feudalistischen zum bürgerlichen Staat habe in der Folge bewirkt, dass zum einen die Mehrzahl der ehemals durch die Kirche wahrgenommenen Funktionen (Bildung, Justiz usw.) nun vom bürgerlichen Staat wahrgenommen und die „Ideologie“ im engeren Sinn (Philosophie, Wissenschaft) innerhalb der „Zivilgesellschaft“ (also spezifischer Staatsapparate) entwickelt und verbreitet werde. Dieser Entwicklung entsprechend haben sich neue Schichten von Intellektuellen innerhalb der Staatsapparate gebildet. Gleichzeitig würden aber die traditionellen Intellektuellen und ihre Institutionen fortbestehen, wobei sie nicht unbedingt einen Anachronismus darstellen, sondern durch ihre Assimilierung in der Gesellschaftsformation weiterhin eine hegemoniale Funktion ausüben. Vor dem Hintergrund seiner Staatstheorie kann Gramsci auch bezüglich der politischen Herrschaft des Bürgertums die Funktionen der Intellektuellen innerhalb der beiden Sphären des integralen Staates konkret benennen:

Vorläufig lassen sich zwei große superstrukturelle „Ebenen“ festlegen diejenige, die man die Ebene der „Zivilgesellschaft" nennen kann, d. h. des Ensembles der gemeinhin ,privat“ genannten Organismen, und diejenige der „politischen Gesellschaft oder des Staates“ -, die der 
Funktion der „Hegemonie“, welche die herrschende Gruppe in der gesamten Gesellschaft ausübt, und der Funktion der ,direkten Herrschaft" oder des Kommandos, die sich im Staat und in der „formellen“ Regierung ausdrückt, entsprechen. Diese Funktionen sind eben organisierend und verbindend. Die Intellektuellen sind die „Gehilfen“ der herrschenden Gruppe bei der Ausübung der subalternen Funktionen der gesellschaftlichen Hegemonie und der politischen Regierung, nämlich:

1. des „spontanen“ Konsenses, den die großen Massen der Bevölkerung der von der herrschenden grundlegenden Gruppe geprägten Ausrichtung des gesellschaftlichen Lebens geben, eines Konsenses, der ,historisch“ aus dem Prestige (und folglich aus dem Vertrauen) hervorgeht, das der herrschenden Gruppe aus ihrer Stellung und ihrer Funktion in der Welt der Produktion erwächst;

2. des staatlichen Zwangsapparats, der „legal“ die Disziplin derjenigen Gruppen gewährleistet, die weder aktiv noch passiv „,zustimmen“, der aber für die gesamte Gesellschaft in der Voraussicht von Krisenmomenten im Kommando und in der Führung, in denen der spontane Konsens schwindet, eingerichtet ist. [ebd., S. 1502]

Somit muss in der Konzeption Gramscis jede Klasse, die die Hegemonie erlangen will, neben den Intellektuellen, die sie zur Organisierung der ökonomischen Struktur braucht, zwei weitere Typen von Intellektuellen hervorbringen: zum einen die Schicht der Intellektuellen, die den politisch-administrativen Apparat bedient, also vor allem Verwaltungsaufgaben wahrnimmt, zum anderen die Intellektuellen, die den Konsens der beherrschten Massen organisieren: Journalisten, Künstler, Lehrer usw. ${ }^{159}$ Gleichzeitig muss sie versuchen, die traditionellen Intellektuellen zu gewinnen und in die neuen Apparate einzubinden. Die Organisation in den hegemonialen wie den administrativen Apparaten

führt zwar zu einer gewissen Arbeitsteilung und folglich zu einer ganzen Abstufung von Qualifikationen, von denen einige keinerlei Merkmale leitender oder organisierender Art mehr aufweisen: im gesellschaftlichen und staatlichen Führungsapparat gibt es eine ganze Reihe von Beschäftigungen manuellen und instrumentellen Charakters. [...] In der Tat muss die intellektuelle Tätigkeit auch von innen her in Stufen unterschieden werden, Stufen, die in ihren extrem entgegengesetzten Momenten einen regelrechten qualitativen Unterschied ausmachen: auf die höchste Stufe wären die Schöpfer der verschiedenen Wissenschaften, der Philosophie, der Kunst usw. zu stellen; auf die niedrigste die bescheidensten „Verwalter“ und Popularisatoren des bereits vorhandenen, traditionellen, angehäuften intellektuellen Reichtums. [ebd., S. 1502 f.]

159 Der Wirkungsbereich der Intellektuellen ist somit nicht allein auf die Zivilgesellschaft beschränkt, wie von Roth behauptet [Roth 1972, S. 110] 
Die politischen und hegemonialen Aufgaben der Intellektuellen bedingen somit, dass sich die Anzahl derselben nicht mehr allein aus den ökonomischen Bedingungen ergibt, sondern ebenso durch die Notwendigkeit der Besetzung des Staatsapparates wie durch die hegemonialen Funktion der Intellektuellen bestimmt wird. Je mehr die Hegemonie zu schwinden beginnt, um so mehr müssen durch die herrschende Klasse die administrativen und hegemonialen Apparate ausgebaut, neue Intellektuelle herangezogen werden.

\subsubsection{Der Diskurs des Staates}

a) Poulantzas stimmt der dargelegten Analyse Gramscis vollkommen zu, er behauptet wie dieser, dass die Konstitution des Bürgertums als herrschende Klasse von der Herausbildung eines „Korpus organischer Intellektueller“ abhängig sei. Ebenso wie Gramsci konstatiert er die überragende Bedeutung der (organischen wie traditionellen) Intellektuellen bezüglich der Organisation der Hegemonie durch eine Klasse [St, S. 50, 54; vgl. auch Balibar 1978, S. 19].

Nach Poulantzas formieren sich diese Intellektuellen/Agenten der staatlichen Strukturen um einen „offiziellen Diskurs“, den Diskurs des Staates, in welchem zum einen der Staat, seine Praktiken und seine Agenten legitimiert werden $^{160}$. Zum anderen werde innerhalb des offiziellen Diskurses die Wissenschaft in eine spezifische Beziehung zum Staat gesetzt: der Staat bemächtige sich zunehmend der Produktion der Wissenschaft, die damit in ihrer Struktur zunehmend zu einer ,,mit dem Machtmechanismus verflochtenen Staatswissenschaft wird“ [St, S. 50] ${ }^{161}$. Diese „Aneignung“ durch den Staat sei dadurch nicht bloße Instrumentalisierung/Unterwerfung im Dienste des Kapitals, sondern die Beziehung zwischen Staat und Wissenschaft wird zu einem organischen Verhältnis, der Staat formiert „die geistige Arbeit über eine ganze Reihe von Netzen und Kanälen [...] und unterwirft sich den Korpus der Intellektuellen und Wissenschaftler“" [ebd.; vgl. Balibar 1987, S. 19].

160 Diese Legitimation fände aber auch außerhalb dieses Diskurses in von dem Staat selbst produzierten Ideologieformen statt [St, S. 50].

161 Auch hier lassen sich Parallelen zu Foucault ziehen: Die Techniken und Technologien, mit der Menschen regiert werden, werden mit der Entwicklung des Staates auch zum Gegenstand einer akademischen Disziplin, die z. B. an der Universität Göttingen als „Polizeywissenschaft" gelehrt wurde. Diese Universität habe für die politische Entwicklung Europas deswegen erhebliche Bedeutung, da dort wichtige Beamte aus Preußen, Österreich und Russland ausgebildet wurden [Foucault 1999a, S. 210], die Verwaltungswissenschaft wurde sozusagen dort erfunden. 
Aus dieser Perspektive ist die Unterwerfung der Wissenschaft nicht nur eine Frage der Legitimation des Staates, sondern wird (neben der ökonomisch motivierten Unterwerfung der Wissenschaft) zu einer Machttechnik, in dem der Staat durch Verbeamtung (also auch der juridischen Erzwingung von Loyalität) der Wissenschaftler und Intellektuellen einen homogenen Korpus erzeugt (z. B. in den Universitäten, insbesondere aber in der Verwaltung), ein ,spezialisierter und professionalisierter Körper" [St, S. 50 f.], der die gesellschaftliche Hegemonie reproduziert. Durch den gleichen Mechanismus, welcher die Intellektuellen als Träger des (Herrschafts-) Wissen zu Staatsbeamten mache, sind die eigentlichen Beamten des Staates durch ihre Beziehung zu dem Wissen und der Anwendung des Wissens aber auch $\mathrm{zu}$ Intellektuellen geworden [St, S. 51]. Die hegemonialen Funktionen und die Trennung von geistiger und manueller Arbeit manifestieren sich aber nicht nur in den Apparaten der Qualifikation der Arbeitskraft, sondern setzten sich ebenso in der Gesamtheit der Apparate des Staates fort (beispielsweise Parteien, kulturelle Apparate, Massenmedien) [St, S. 53].

Im Anschluss an Poulantzas' Argumentation muss diesbezüglich auch konstatiert werden, dass die Trennung von geistiger und manueller Arbeit aktuell weiterhin vor allem in den staatlichen Apparaten der Qualifikation der Arbeitskraft und den ökonomischen Apparaten sowohl reproduziert als auch verschärft (siehe S. 161 ff.), in den anderen Apparaten dagegen die hegemonialen Funktionen an Bedeutung gewinnen, dies betrifft insbesondere die - in Verbindung mit der Transformation der Parteien (siehe S. 187 ff.) stehende Entpolitisierung, „Nationalisierung“ und Infantilisierung des öffentlichen politischen Diskurses. Ebenso wird die „Aneignung“ (oder Produktion!) eines wissenschaftlichen (insbesondere des juridischen) Diskurses von zentraler Bedeutung, wenn dieser als hegemoniale Funktion erscheint, z. B. um innerhalb des öffentlichen politischen Diskurses Fragestellungen bezüglich politischen Handelns von der Legitimität zugunsten der Legalität zu verschieben (siehe dazu S. 151 ff.).

b) Der Diskurs des Staates ist für Poulantzas durch verschiedene herrschende Ideologien durchzogen, andererseits manifestiere sich in ihm wie gezeigt ein Wissen/eine Wissenschaft, die sich der Staat unterworfen hat. Dieser Diskurs 
besitze aber keine immanente Einheit, sondern er sei ein „,bruchstïckhafter und unvollständiger Diskurs, je nach den strategischen Plänen der Macht und den verschiedenen Klassen, an die er gerichtet ist“ [ebd.]. Der Staat produziere „für die verschiedenen Klassen immer mehrere Diskurse, die in unterschiedlicher Weise je nach der Klassenbestimmung in seinen verschiedenen Apparaten verkörpert sind“ [St, S. 30]. Das Funktionieren dieses Diskurses sei dabei davon abhängig, dass er angehört und verstanden wird, es ist ,,in den verschiedenen diskursiven Codes eine Übercodierung des Staates erforderlich“ [ebd.], die dieses „Verstehen“ garantiere. Die Übercodierung bilde den Rahmen der „Homogenisierung der diskursiven Segmente“, sie werde den Subjekten durch die Vereinheitlichung der Sprache zu einer Nationalsprache und der damit verbundenen Eliminierung anderer Sprachen eingeschärft. Diese Nationalsprache sei zwar schon für die Gründung einer nationalen Ökonomie und eines nationalen Marktes erforderlich, für den Staat als „,nationale“ politische Organisation aber unabdingbar. Dem Staat falle somit die Aufgabe zu, „die diskursiven Verfahren für die Gestaltung der Materialität des Volkes/der Nation zu organisieren sowie die Sprache zu schaffen" ${ }^{162}$ [St, S. 52]. Wie die Sprache sei aber ebenso die Schrift von der Trennung von geistiger und manueller Arbeit betroffen. Mehr noch als in der Sprache/dem Diskurs manifestiere sich in der Schrift diese Arbeitsteilung, jede Aktion innerhalb des Staates dokumentiere sich mit Hilfe der Schrift, eine

anonyme Schrift, die nicht einfach einen Diskurs wiederholt, sondern die einen Weg vorgibt, die bürokratische Orte und Dispositive vorzeichnet, den zentralisierten und hierarchisch gegliederten Raum diese Staates durchzieht und gestaltet. Die Schrift schafft und verräumlicht die linearen und umkehrbaren Abstände in der segmentierten und konsekutiven Kette der Bürokratisierung. [St, S. 52 f.]

Eigentümlich für den kapitalistischen Staat sei dabei, dass er die Schrift nicht wie vorkapitalistischen Staaten - in Verbindung mit dem dominanten ideologischen Apparat, der Kirche - den Massen vorenthält und monopolisiert, wodurch dort schon der Herrschaftscharakter der Schrift erkennbar ist. Im Gegenteil werde die Schrift in den Schulen popularisiert, gleichzeitig aber die Struktur der Schrift, ihre Orthographie und Grammatik vom Staat ,systemati-

162 Ähnlich merken Deleuze/Guattari an, dass der Staat ,nicht nur die Voraussetzung für die Schrift, sondern auch für das Wort, die gesprochene Sprache und das Sprachsystem“ sei [Deleuze/Guattari 1997b, S. 595 f.]. 
siert (wenn nicht gar entdeckt) und dann zu einem Netz von Machtbeziehungen ausgebaut" [St, S. 53]. Indem der Staat aber die Schrift propagiere, verdoppele er sie aber auch: der Staat selbst operiere mit dem offenen, nationalsprachlichen Diskurs, der verstanden werden müsse, gleichzeitig werde das Wissen und die Macht in die Staatsschrift verlagert und von denen die Massen ausgeschlossen bleiben würden [ebd.].

Eine solche Ausschließung und Distanzierung der Massen von dem Wissen sei grundlegend für die verschiedenen Techniken der Machtausübung, sie vollziehe sich über eine „Reihe von Ritualen, Diskursformen, strukturierten Typen der Thematisierung, Formulierung und Behandlung von Problemen durch die Staatsapparate“ [St, S. 53]. Der gesamte Aufbau des Staates und seiner Praktiken folge somit der gesellschaftlichen Arbeitsteilung und stelle die Materialisierung der Beziehungen von Wissen und Macht dar:

Von den hierarchischen, zentralisierten und Disziplinarbeziehungen bis zu den Stufen und Knotenpunkten der Entscheidung und Ausführung, von den Ebenen der Delegation der Autorität bis zu den Formen der Verteilung und Verheimlichung des Wissens je nach der gewählten Ebene (das bürokratische Geheimnis) und den Formen der Qualifikation und Rekrutierung der Staatsagenten [...] verkörpert der Aufbau des kapitalistischen Staates bis in die kleinsten Details die innerhalb der geistigen Arbeit induzierte und verinnerlichte Reproduktion der kapitalistischen Teilung zwischen geistiger und manueller Arbeit. [St, S. 52] 


\subsubsection{Staat und Nation}

Die unmittelbaren Produzenten werden nur vom Boden befreit, um eingerastert zu werden; in den Fabriken natürlich, aber auch in den Familien im modernen Sinne, in den Schulen, der Armee, den Gefängnissen, den Städten und Territorien der Nation.

Nicos Poulantzas

Für Poulantzas ergibt sich im Zusammenhang mit der Materialität des Staates die Frage, in welchem Zusammenhang „Staat“ und „Nation“" stehen. Bezüglich dieses Zusammenhangs konstatiert er, dass alle marxistischen theoretischen Ansätze diesem Verhältnis zu wenig Aufmerksamkeit geschenkt hätten - es somit keine marxistische Theorie der „Nation“ gebe, aber erste Hinweise im marxistischen Diskurs vorhanden seien [St, S. 85].

1. Innerhalb der klassischen Texte des Marxismus lassen sich nach Poulantzas erste Hinweise bezüglich der theoretischen Einordnung der „Nation“ finden. Demnach gebe es einen Begriff der Nation, welcher nicht mit dem der modernen Nation übereinstimme, er sei dadurch gekennzeichnet, dass er eine „Einheit für die Reproduktion des Ensembles der gesellschaftlichen Verhältnisse" darstelle. Das Entstehen dieser Nation korrespondiere nicht mit dem Entstehen des Kapitalismus, sondern deren Konstitution falle mit der Konstitution der Klassengesellschaft zusammen. Allerdings werde in den klassischen Schriften auch die Auffassung vertreten, dass die Nation über das Absterben des Staates hinaus bestehen bleibe, was für Poulantzas ein Kernproblem bei der Rezeption dieser Texte darstellt: einerseits die Konstitution des Begriffs in Bezug auf die Klassenstruktur, andererseits aber die Auffassung, dass das Objekt „Nation“, wenn auch modifiziert, seinen theoretischen Konstitutionsrahmen ,überlebt“ [St, S. 85 f.].

2. Weiterhin sei die Frage des Verhältnisses von Nation und Staat im Kapitalismus in den Arbeiten des Austromarxismus und in den Analysen Lenins angegangen worden. Hierbei stelle sich als Ergebnis eine potenzielle Differenz von Staat und Nation dar, aus der Lenin das politische wie kulturelle „Selbstbestimmungsrecht der Völker“" abgeleitet habe. Danach sei die Nation Legitimation für die Gründung eines souveränen Staates, dieses 
Selbstbestimmungsrecht sei aber durch Stalin faktisch liquidiert worden. [St, S. $86 \mathrm{f}$.

3. Schließlich sei bezüglich der Frage nach der Besonderheit der modernen Nation zu konstatieren, dass in zahlreichen marxistischen Ansätzen die Nation tendenziell mit dem Staat zusammenfalle,

die modernen Nationen weisen selbst die historische Tendenz auf, ihre eigenen Staaten zu bilden. Die Orte und Knotenpunkte der erweiterten Reproduktion der gesellschaftlichen Verhältnisse [...] haben die Tendenz, sich mit den Grenzen des Staates und der Nation zu decken. [St, S. 87]

Bezüglich des letzten Punktes kritisiert Poulantzas die Auffassung, dass die Nation mit der Zirkulationssphäre des Kapitals, dem inneren Markt, in ausschließlicher Beziehung stehe. Nach dieser Argumentation arbeite der Staat daran, innere Hemmnisse der Waren- und Kapitalzirkulation zu beseitigen und so Markt und Nation zur Deckung zu bringen. In die gleiche Richtung laufe die Argumentation, nach der der Staat die gesellschaftlichen Individuen als formell Freie und Gleiche konstituiere, um sie so als gleichberechtigte Warenbesitzer in den Prozess der Kapitalakkumulation einzufügen,

die dazu gegebene Klassenanalyse läuft nach folgendem Muster ab: die Nation ist ganz wie der Staat die Schöpfung des Handelskapitals und geht auf die Handelsbourgeoisie in den Anfängen des Kapitalismus zurück. [St, S. 88]

Diese Konzeption hat nach Poulantzas zahlreiche Mängel, denn erstens könne der Ansatz nicht die Entstehung der modernen Nation klären. Zwar sei es richtig, dass die Durchsetzung der kapitalistischen Produktionsweise die Vereinheitlichung des Marktes erfordere, es sei aber aus diesem theoretischen Ansatz heraus nicht ersichtlich, warum diese Vereinheitlichung innerhalb des Bezugsrahmens der Nation erfolgt, also die Grenzen des Marktes mit den Grenzen der Nation zusammenfallen und wie diese Zuweisung dieser Grenzen vor sich gehe. Zweitens sei diese Konzeption empirisch und positivistisch, denn sie greife auf ein gemeinsames Territorium, eine gemeinsame Sprache, eine gemeinsame Tradition zurück, dabei würden diese Gemeinsamkeiten als „transhistorische Wesenheiten“ begriffen.

Die Entstehung der modernen Nation und ihr spezifisches Verhältnis zum Staat werden dann als Konsequenz eines Prinzips (der Verallgemeinerung des Warentauschs) begriffen, dessen Auswirkung die Addition und Akkumulation dieser verschiedenen Elemente sein soll, die ein inneres Wesen besitzen [...]. Diese Akkumulation wird dann umschlossen vom Nationalstaat, der ihr Ergebnis sein soll. [St, S. 89] 
Dieser Ansatz könne also nicht klären, warum sich Territorium, Sprache und Tradition als Merkmale der Nation zu einer neuen Konfiguration als moderne Nation zusammenfügen und wie die scheinbar transhistorische Wesenheiten sich als moderne Nation artikulieren könnten. Insgesamt berge dieser Ansatz die Gefahr, die Rolle der Nation in der modernen kapitalistischen Gesellschaft zu unterschätzen. Demgegenüber gelte es, die transhistorische Wesenheiten zurückzuweisen und darauf $\mathrm{zu}$ insistieren, dass Territorium und Tradition (Historizität/Geschichte) innerhalb der kapitalistischen Entwicklung eine spezifische Veränderung erlebt haben: der kapitalistische Staat habe sich den gesellschaftlichen Raum und die gesellschaftliche Zeit unterworfen ${ }^{163}$.

Die konstitutiven Elemente der Nation (ökonomische Einheit, Territorium und Tradition) werden durch das direkte Eingreifen des Staates in die materielle Organisation von Raum und Zeit modifiziert. Die moderne Nation fällt tendenziell mit dem Staat zusammen in dem Sinne, dass der Staat sich die Nation einverleibt und die Nation in den Staatsapparaten Gestalt annimmt, denn sie wird zur Verankerung seiner Macht in der Gesellschaft und umreißt ihre Grenzen. Der kapitalistische Staat funktioniert auf der Grundlage der Nation. [St, S. 91]

\subsubsection{Die kapitalistische Raummatrix}

Poulantzas spezifiziert die Raummatrix dahingehend, dass das (nationale) Territorium selbstverständlich nicht „natürlich“ gegeben ist, sondern dass es je nach Produktionsweise spezifische Raummatrizes gebe. Diese Matrizes beschreiben nach Poulantzas nicht einfach eine lineare Folge von Aneignungsformen des Raums, sondern folgen verschiedenen Dispositiven zur Organisation des gesellschaftlichen Raums. Diese Dispositive hätten selbst aber kein „inneres Wesen“, weshalb in der Untersuchung dieser Dispositive vor allem ihre Diskontinuitäten untersucht werden müssen. Diese Diskontinuitäten dürften allerdings nicht, wie nahe liegt, einfach mit den Produktionsverhältnissen in Verbindung gebracht werden, denn dies würde bedeuten, dass sich die Diskontinuitäten/die Transformationen der Dispositive immer auf einen gleichen grundlegenden Gegenstand - den „Raum“ - beziehen würden. Das hieße aber, dass dieser „Raum“ je nach Produktionsweise lediglich unterschiedlich angeeignet, eingegrenzt oder modifiziert werde. Demgegenüber sei aber vielmehr

163 Dieser theoretische Ansatz wird von Hirsch aufgegriffen, vgl. Hirsch 1994a. 
anzunehmen, dass die verschiedenen Produktionsweisen den Raum nicht lediglich verschieden „,behandeln“ - der gesellschaftliche Raum besteht nicht a priori, sondern wird selbst produziert, die Dispositive zur Aneignung des gesellschaftlichen Raums materialisieren die „differenziellen Raummatrizes [...], die schon in ihrem Aufbau vorhanden sind. Die Genealogie der Produktion des Raumes geht der Geschichte seiner Aneignung voraus “ [St, S. 93; Hervorhebung S.v.B.].

Kennzeichnend für die antike Produktionsweise sei beispielsweise, dass sie einen „kontinuierlichen, homogenen, symmetrischen, reversiblen und offenen Raum“ impliziere. Sie besitze ein Zentrum (die Polis), von dem sich der Raum aus homogen entfalte. Dieser Raum habe keine Grenze und definiere dadurch kein „Außen“, der Raum sei weder differenziert noch hierarchisch. Die antiken Reiche hätten sich demzufolge nicht ausgedehnt, indem sie ihre Grenzen immer weiter verschoben hätten, sondern indem sie sich in einem homogenen Feld ausgedehnt hätten (tendenziell würden diese Eigenschaften des gesellschaftlichen Raums auch für den Feudalismus gelten) [St, S. 93 f.].

Im Gegensatz dazu stehe die Produktion und Aneignung des gesellschaftlichen Raums im Kapitalismus, denn hier stehe das Territorium in Verbindung mit der Konstitution der modernen Nation - und natürlich mit den spezifischen Merkmalen der kapitalistischen Produktionsweise. Bei der Untersuchung der Rolle des Territoriums sei daher vor allem davon auszugehen, dass die entwickelte gesellschaftliche Arbeitsteilung innerhalb dieser Produktionsweise eine völlig neue Raummatrix voraussetzt, einen ,seriellen, fraktionierten, diskontinuierlichen, parzellierten, zellenförmigen und irreversiblen Raum, der für die tayloristische Teilung der Fließbandarbeit in der Fabrik charakteristisch ist “164 [St, S. 96]. Indem der Raum parzelliert wird, entstehen Poulantzas zufolge nun erstmals Grenzen im modernen Sinn, die ein Innen und Außen definieren und die ,,auf einem seriellen und diskontinuierlichen Raster verschoben werden können" [ebd.]. Dieses durch die neu entstandene Grenzen abgesteckte Territorium stehe in Beziehung mit den kapitalistischen Produktionsverhältnissen, diese

164 Ähnlich formulieren Deleuze/Guattari: „Schließlich hat der Kapitalismus nicht durch die Stadtform, sondern durch die Staatsform triumphiert" [Deleuze/Guattari 1997b, S. 602]. 
implizieren diesen Raum als Zerstückelung des Arbeitsprozesses in kapitalistische Produktions- und Reproduktionseinheiten. Die ungleiche Entwicklung des Kapitalismus ist in seiner verräumlichten Dimension mit dieser diskontinuierlichen Morphologie wesensgleich [...]. Die Anfänge des Territoriums als konstitutives Element der modernen Nation sind in diese Raummatrix eingeschrieben. [St, S. 97]

Das nationale Territorium sei folglich nicht „natürlicher“ Raum, sondern im wesentlichen politisch, da der Staat die Verfahren zur Organisation des Raumes monopolisiert habe und in seinen Apparaten diese Raummatrix materialisiere und die - der Arbeitsteilung und damit verbunden der territorialen Organisation - unterworfenen Individuen beherrscht.

Denn die Individualisierung des politischen Körpers zu identischen, dem Staat gegenüber jedoch getrennten Monaden beruht auf dem Aufbau des Staates, der in die Raummatrix eingeschrieben ist, die der Arbeitsprozess impliziert. Die modernen Individuen sind die Bestandteile der modernen Staaten und Nationen. Volk und Nation des kapitalistischen Staates stellen die Zielscheibe eines Raums dar, dessen Grenzen die passenden Konturen für die materiellen Eroberungen und Verankerungen der Macht bilden. Die segmentiere Kette dieser individualisierten Orte umschließt das Innen des nationalen Territoriums als staatlichen Abschnitt der Machtausübung. [...] Die unmittelbaren Produzenten werden nur vom Boden befreit, um eingerastert zu werden; in den Fabriken natürlich, aber auch in den Familien im modernen Sinne, in den Schulen, der Armee, den Gefängnissen, den Städten und Territorien der Nation. Das bewahrheitet sich bis hin zu den Modalitäten der Machtausübung im kapitalistischen Ausnahmestaat: Die Konzentrationslager sind auch in dem Sinne eine moderne Erfindung, dass sie dieselbe Raummatrix der Macht materialisieren wie das nationale Territorium. [ebd.]

Das Territorium wie die Grenzen desselben sind nach Poulantzas auch bezüglich der Rolle des Staates zur Organisation der nationalen Einheit von Bedeutung: wenn durch die Territorialisierung Grenzen gezogen werden, vollzieht der Staat eine Homogenisierung des eingeschlossenen Raums und konstituiert mit dieser Vereinheitlichung die moderne Nation, „,der Staat setzt die Grenzen dieses seriellen Raumes in demselben Prozess, indem er das eint und homogenisiert, was diese Grenzen einschließen“ [St, S. 98]. Hier steht die bereits angesprochene Individualisierung im Zusammenhang mit der Gründung der Nation: Der Staat verwirkliche die Einheit der Individuen als „Volk und Nation“, mit der „politisch-öffentlichen Homogenisierung“ setze er aber mit dieser Bewegung gleichzeitig die „private Dissoziation“ durch. Mit der Homogenisierung stehe ebenso der einheitliche nationale Markt in Beziehung: der (abgeschlossene) Markt sei nicht vor dem Staat oder der Nation existent, sondern werde in 
dem Homogenisierungsprozess geschaffen, indem erst in diesem Prozess die Grenzen von Innen und Außen gezogen werden [ebd.].

Die Schaffung von nationalen Grenzen im modernen Sinn und der Abgrenzung eines ,irreversiblen und begrenzten Raums“ impliziere weiterhin, dass zunehmend die Verschiebung dieser Grenzen im Zentrum steht, also insbesondere im Imperialismus die Frage der Ausdehnung der Märkte, der Territorien und des Kapitals im Zentrum des staatlichen Handelns steht: „Diese Grenzen werden erst von dem Augenblick an [...] gesetzt, indem es [...] darum geht, sie zu überschreiten“ [St, S. 99]. Diese Verschiebung der Grenzen, die tendenziell selbst ohne Grenze ist, bedeute im Gegensatz zur Vergangenheit nicht mehr eine Ausbreitung in einem homogenen Raum, der lediglich angefügt wird, sondern eine „Expansion durch Lücken, die man ausfüllt““. Dieses Ausfüllen werde durch die Homogenisierung der Unterschiede und der Vernichtung des „Fremdkörpers“ innerhalb der Nation erreicht, nur so sei der Völkermord als spezifische Erscheinung des modernen Staates zu verstehen: während in der Antike und im Feudalismus sich die Bewegung der territorialen Expansion in einen homogenen und offenen Raum ausgebreitet und dort die Bevölkerung undifferenziert massakriert habe, sei der Völkermord und das Konzentrationslager eine Erfindung des modernen Staates, die Identifizierung und die Umschließung des „Fremdkörpers“ sei erst möglich, indem der nationale Raum definiert werde. Die physische Eliminierung des „Fremdkörpers“ sei charakteristisch für den modernen Totalitarismus:

Trennen und teilen um zu vereinigen, zerstückeln um einzurastern, atomisieren um einzuverleiben, segmentieren um zu totalisieren, einzufrieden um zu homogenisieren, individualisieren, um die Veränderungen und Unterschiede auszumerzen: die Wurzeln des Totalitarismus sind in die Raummatrix eingeschrieben, die der moderne Nationalstaat materialisiert und die schon in seinen Produktionsverhältnissen und der kapitalistischen gesellschaftlichen Arbeitsteilung anwesend sind. [St, S. 100]

\subsubsection{Die kapitalistische Zeitmatrix}

Ebenso wie die Raummatrix ist nach Poulantzas die Zeitmatrix, vor allem als „gemeinsame historische Tradition“ verstanden, in Beziehung zu den Transformationen der Produktionsverhältnisse und der gesellschaftlichen Arbeitsteilung zu setzen. Hierbei sei wiederum der Modus der Reproduktion von entscheidender Bedeutung: während die kapitalistische Gesellschaftsformation auf 
einer erweiterten Reproduktion basiere, seien die vorkapitalistischen Gesellschaftsformationen durch eine einfache Reproduktion gekennzeichnet. Daher seien für diese eine Zeitmatrix der pluralen und singulären Zeiten spezifisch, jede dieser Zeiten sei dabei „kontinuierlich, homogen, reversibel und repetitiv“ [St, S. 100]. Jede der in den vorkapitalistischen Gesellschaftsformationen verschiedenen gesellschaftlichen Praxen vorhandene Zeit sei „flüssig und fließend“, aber nicht messbar, denn es bestehe in diesen Gesellschaftsformationen eben keine Referenz-Zeit, kein universelles Maß, auf die sich eine solche Messung beziehen könnte [ebd.]. Demgegenüber zeichne sich die kapitalistische Zeitmatrix dadurch aus, dass sich die kapitalistische Produktionsweise in diese eingeschrieben hat $^{165}$ :

Maschinerie und große Industrie und die Fließbandarbeit implizieren eine segmentierte, serielle, in gleiche Momente unterteilte, kumulative und irreversible, da auf das Produkt orientierte Zeit; durch das Produkt ist die Zeit auf die erweiterte Reproduktion, die Akkumulation des Kapitals gerichtet. [St, S. 102]

Die kapitalistische Zeit sei somit durch die Aufsichtsagenten des kapitalistischen Produktionsprozess mess- und kontrollierbar und werde so zu einer universellen Zeit, die zwar weiterhin segmentiert und serialisiert ist, aber die jeweiligen anderen gesellschaftlichen Zeiten als differenzielle Zeitformen, als von der Zeit des Produktionsprozesses differente Zeiten, als „Variationen des Rhythmus und der Skandierung einer seriellen, segmentierten, irreversiblen und kumulativen Zeit" setzt [St, S. 103]. Diese Zeitmatrix schreibt sich Poulantzas zufolge wie die Raummatrix in die Materialität des Staates ein und werde Teil der politischen Herrschaft - zum einen, indem diese Zeitmatrix in der Formierung der Subjekte anwesend ist, zum anderen, in dem sie in den Techniken der Macht und den staatlichen Institutionen wie Armee, Schule und Gefängnis anwesend ist. Die Vereinheitlichung der segmentierten Zeit werde selbst zu einer Aufgabe des Staates, so dass dieser Herrschaft und Kontrolle über die Zeit gewinnen müsse. Dies erreiche der Staat durch die Normierung und Vereinheitlichung der Zeit, auf die sich in der Folge alle anderen gesellschaftlichen Zeitformen beziehen. Die ungleichzeitige Entwicklung des Kapitalismus, also die zeitlich differenten Entwicklungen von Ökonomie, Ideologie

165 Auch hier lassen sich bei Foucault Hinweise zu einer Konzeption verschiedener Zeiten und der Verbindung der verschiedenen Zeitformen mit den Techniken der Macht und dem Produktionsprozess finden, siehe ÜuS 186 f., S. 192 ff., 197 ff. 
und Politik, würden so durch den Staat aufeinander bezogen und homogenisiert [St, S. 105].

Laut Poulantzas fällt in diesem Zusammenhang die Nation mit dem Staat in einem doppelten Sinn zusammen: entweder indem sie mit dem bestehenden Staat identisch wird oder sich selbst zum Staat - als Jakobinismus oder Separatismus - konstituiert. Hier wirke dann die Zeitmatrix auf eine neue Art, indem die Tradition/Historizität nicht mehr auf die Erinnerung gerichtet ist, sondern auf das Hier und Jetzt: die Tradition wirke auf den Prozess der Bildung des Staates entweder beschleunigend oder bremsend und „deckt sich mit einer Aufeinanderfolge von Momenten, die eine irreversible, vom Staat skandierte Geschichte produzieren“ [St, S. 106]. Die Nation wie die nationale Tradition/ Geschichte werde vom Staat organisiert und monopolisiert,

der moderne Imperialismus ist auch Homogenisierung der Zeitsequenzen und Assimilierung der Geschichten durch den Nationalstaat. Die Forderungen nach nationaler Autonomie und eigenem Staat im modernen Zeitalter bedeuten in der kapitalistischen Historizität die Forderung nach einer eigenen Geschichte. [ebd.]

Wenn auch der Staat nicht das Subjekt der Geschichte sei, könne über die Zeitmatrix erklärt werden, warum der Staat als Zentrum in der Geschichtsschreibung erscheine. Dass beispielsweise zwar grundsätzlich eine Geschichte des internationalen Proletariats geschrieben werden könnte, de facto aber eine Geschichte des nationalen Proletariats geschrieben werde, sei nicht auf ideologische Mechanismen zurückzuführen, sondern darauf, dass „die Geschichte“ in einem spezifischen Zusammenhang mit dem Staat und der Nation stehe, diese Verbindung sei eine Wurzel des modernen Totalitarismus.

Die Beherrschung und Vereinheitlichung der Zeit und ihre Erhebung zum Machtinstrument, die Totalisierung der Historizitäten durch die Vernichtung der Unterschiede, die Serialisierung und Segmentierung der Momente, um sie auszurichten und zu kumulieren, die Entsakralisierung der Geschichte, um sie in Beschlag zu nehmen, die Homogenisierung von Volk und Nation durch das Fälschen und Auslöschen der eigenen Vergangenheit: all diese Prämissen des modernen Totalitarismus existieren in der in die modernen Staaten eingeschriebenen Zeitmatrix, die schon von den Produktionsverhältnissen und der kapitalistischen gesellschaftlichen Arbeitsteilung impliziert wird. [St, S. 107]

Der Staat verbinde die räumlichen und zeitlichen Matrizes und führe so eine Verbindung von Territorium und Geschichte her. Die Geschichte werde vom 
Staat dadurch totalisiert und kapitalisiert, sie finde nur noch in Bezug auf das eigene Territorium und den Staat selbst statt.

Der kapitalistische Staat setzt die Grenzen, indem er das konstituiert, was innen ist - Volk und Nation [...]. Die nationale Einheit, die moderne Nation, wird so zur Historizität eines Territoriums und zur Territorialisierung einer Geschichte [...]. Die Grenzmarkierungen des Territoriums werden zu Orientierungspunkten der Geschichte, die im Staat vorgezeichnet sind. [ebd.]

Indem der Staat so das Innen und Außen bezüglich des Territoriums und der Geschichte definiert, könne er auch dadurch dazu übergehen, die Fremdkörper innerhalb der Volksnation zu identifizieren und zu liquidieren. Die Völkermorde wie die Konzentrationslager seien somit als eine finale Ausschließung dieser Fremdkörper aus dem nationalen Raum und der nationalen Zeit zu begreifen [ebd. $]^{166}$.

\subsubsection{Diskurs und Nation}

Die Produktion der Ethnizität, das bedeutet auch die Rassisierung der Sprache und die Verbalisierung der Rasse.

Étienne Balibar

Wenn im Zusammenhang von Nation und Staat Poulantzas davon spricht, dass es eine Nation vor dem modernen Nationalstaat gegeben hätte und so eine Position der Klassiker aufrecht erhält, muss dieser Ansicht zum Teil widersprochen werden. Wenn die Nation begriffen wird als etwas vom Staat Differentes (wenn auch sich mit diesem überschneidendes), dem Staat historisch Vorgelagertes und vom Staat (oder einer Klasse) usurpiertes, wird prinzipiell (wenn nicht gleich rassistische Argumentationsmuster herangezogen werden) auf einer kulturellen Identität und auf das durch diese Identität zusammengefasste Volk/kulturelle Ethnizität rekurriert.

Hier scheint es m. E. vielmehr angebracht, von einem nationalen Diskurs zu sprechen, der mit dem Konzept des modernen Staates in Verbindung steht.

166 Der Zusammenhang des modernen Nationalstaats mit Rassismus und Totalitarismus wird so auch anderweitig vertreten, vgl. Balibar 1993, Balibar/Wallerstein 1992, Hirsch 1994a. Hier läßt sich auch wieder eine Parallele zu Foucault ziehen, denn die von ihm analysierten Prozesse der Definition des ,anderen“ in der Medizin verlaufen auch historisch analog der Entwicklung des Nationalstaats. 
Die von Poulantzas identifizierten Elemente der Nation - insbesondere die Sprache ${ }^{167}$ und die (nationalisierte) Geschichtsschreibung - sind als diskursive Praktiken ausgerechnet solche Praktiken, die erst nach der Gründung eines sich auf einer Nation berufenden Staates „vervollständigt“ werden: wie Poulantzas selbst angemerkt hat, wird erst nach der Gründung des Staates eine Nationalsprache im eigentlichen Sinn konstituiert; in den politischen Gemeinschaften der Antike wie des Feudalismus war ein nebeneinander verschiedener Sprachen durchaus üblich [Hobsbawm 1998, S. 33 f., Balibar/Wallerstein 1990, S. 121]. Ebenso wird nach der Staatsgründung eine Geschichtsschreibung durch den Staat skandiert, die den Staat selbst wiederum als Ziel hat und deshalb erst mit der Gründung des Staates „wahr“ wird, sich die Nation „erfüllt“ bzw. erst vollständig konstruiert wird ${ }^{168}$. Sprache und Geschichtsschreibung sind also diskursive Praktiken, in denen denen Elemente der Nation tatsächlich „materiell“ existieren (nämlich als Nationalismus); dabei werden diese Elemente in die Geschichte beliebig projiziert, um als Legitimation des politischen Systems oder als „Zielvorgabe“ eingesetzt zu werden.

Poulantzas ist dahingehend vollkommen zuzustimmen, dass das historische Auftreten der Nation mit der Spaltung der Gesellschaft in Klassen zusammenfällt, dies kann aber vor allem als ein Indiz für den Klassencharakter des nationalen Diskurses gedeutet werden. Dies gilt insbesondere dann, wenn zuungunsten der religiösen Symbolisierung der politischen Herrschaft die säkulare bürgerliche Herrschaft an Bedeutung gewinnt ${ }^{169}$. Der nationale Diskurs ist in dieser Perspektive vor allem als ein strategischer Diskurs aufzufassen, der die in Klassen zerfallende Gesellschaft daran hindert, sich aufzulösen; ein Diskurs, der eine Identität herstellt, an die die gesellschaftliche Macht ihre Botschaften richten kann (die, ggfs. auch potenziellen, Volks-Subjekte anrufen kann) und somit eine neue politische Symbolisierung errichtet. Dieser Diskurs muss dabei nicht einmal verschweigen, dass die Gesellschaft in Klassen gespalten ist, sondern kann dies solange zugeben, wie ein die Klassen-

167 Vgl. Hobsbawm 1998, S. 33 f.

168 Ähnlich behauptet Wallerstein, dass der Staat historisch der Nation voranging [Balibar/ Wallerstein 1990, S. 101].

169 So stellt Hobsbawm fest, dass der Begriff der Nation erst nach der französischen Revolution auftaucht [Hobsbawm 1998, S. 25 ff.]. 
gegensätze überbrückendes politisches (sprich „,nationales“) Ziel definiert werden $\mathrm{kann}^{170}$.

Die Differenz von Staat und Nation/nationalem Diskurs ist somit auch in den verschiedenen ideologischen Mechanismen zu finden. Während der Staat die Subjekte als formal Gleiche und Freie anruft, dabei die sozialen Differenzen der Subjekte soweit möglich in seinem juristischen System einarbeitet und für das Staats-Subjekt ausblendet (s. u.), verschweigt der nationale Diskurs diese Differenzen nicht. Zudem funktioniert der nationale Diskurs ohne und vor dem Staat - wenn der nationale Diskurs entsteht, ist es ein Diskurs, der Staat werden will. Hier ist denn auch der ideologische Kern der bei Linken wie Rechten so beliebten „kulturellen Identität“ zu suchen. Poulantzas hat für die theoretische Einordnung dieser Identität wertvolle Hinweise gegeben: die Schrift, die sich der Saat unterwirft und homogenisiert und die Geschichte, die der Staat skandiert, sind als elementare Elemente der Nation vor allem Gegenstand von politischen Techniken. Es kann also nicht davon gesprochen werden, dass die Nation/die „kulturelle Identität“ von einer Klasse oder dem Staat usurpiert wird, sie wird vielmehr in einem Diskurs konstruiert und erst durch die politischen Techniken des Staates „wahr“. Wenn, wie Poulantzas behauptet, der kapitalistische Staat auf der Grundlage der Nation funktioniert, ist die Nation und die kulturelle Identität (das Volk) der Gründungsmythos des Staates schlechthin.

Hierbei kann - im Anschluss an Balibar - die Verbreitung einer einheitlichen Sprache und Geschichte, also die Konstruktion eines nationalen Diskurses, auch als Konstruktion einer Ethnizität bezeichnet werden; dabei steht diese Konstruktion natürlich auch in engem Zusammenhang mit den ideologischen Staatsapparaten, die eben zu dieser Verbreitung maßgeblich beitragen: die Schule und die Familie ${ }^{171}$. Beide Apparate sind folglich nicht nur funktional bezüglich der Reproduktion der Arbeitskraft zu analysieren; beispielsweise kann die Einführung der allgemeinen Schulpflicht als der „Reproduktion der Bildung einer fiktiven Ethnizität“" dienlich betrachtet werden [Balibar/

170 Balibar weist zurecht darauf hin, das der Nationalismus/die politische Nation-Form die Klassenkämpfe integrieren und auch kontrollieren könne, diesen aber kein Ende setzen kann [Balibar 1993, S. 135].

171 Im Gegensatz hierzu begreift Balibar Schule und Familie als einen einzigen ideologischen Staatsapparat [Balibar/Wallerstein 1990, S. 126]. 
Wallerstein 1990, S. 126]. Balibar weist in diesem Zusammenhang auch darauf hin, dass die (im Gegensatz zur rassistischen Ethnizität gegebenen) prinzipielle Offenheit einer auf einer einheitlichen Sprache basierenden Ethnizität/Nation nur relativ fiktiv vorhanden ist, im Gegenteil „schafft die Zugehörigkeit zu einer Sprachgemeinschaft [...] sogleich Spaltungen, differentielle Normen, die sich ganz massiv mit den Klassenunterschieden decken" und Teil des körperlichen Habitus werden [Balibar/Wallerstein 1990, S. 127]; die auf diesem Habitus basierenden Stigmatisierung insbesondere bezüglich „regionaler“ oder „ausländischer“ Akzentuierungen des Sprechvorgangs führt schließlich zur „Rassisierung der Sprache und der Verbalisierung der Rasse“ [ebd.]. 


\subsubsection{Staat und Individualisierung}

So formiert sich eine Politik der Zwänge, die am Körper arbeiten, seine Elemente, seine Gesten, seine Verhaltensweisen kalkulieren und manipulieren. Der menschliche Körper geht in eine Machtmaschine ein, die ihn durchdringt, zergliedert und wieder zusammensetzt.

Michel Foucault

a) Als nur scheinbar gegenläufige Tendenz einer Zentralisierung und Bürokratisierung des Staates analysiert Poulantzas die zunehmende Individualisierung in den bürgerlichen Gesellschaften. Individualisierung ist in der Konzeption Poulantzas nicht als „Subjektwerdung“ des Individuums zu verstehen, in der das Individuum eine zunehmende Freiheit erfährt, sondern sie ist eine Technik der Macht, in der die beherrschten Massen parzelliert und atomisiert und die einzelnen Individuen subjektiviert werden.

Der (zentralisierte, bürokratisierte etc.) Staat etabliert diese Atomisierung und repräsentiert [...] die Einheit dieses Körpers (die Nation/das Volk), der in formell gleichberechtigte Monaden unterteilt ist. [...] Die Materialität des Staates und seiner Apparate wirkt auf einen fraktionierten Gesellschaftskörper, der in seiner Aufteilung homogen, in der Isolierung seiner Elemente und in seiner Atomisierung einheitlich ist: von der modernen Armee bis zur Verwaltung, der Justiz, dem Gefängnis, der Schule und den Massenmedien könnte man eine lange Liste aufstellen. [St, S. 55 f. $]^{172}$

Der Individualisierungsprozess und die Konstitution der Individuen als Rechtssubjekte ist dabei nach Poulantzas nicht aus der Figur des Warenbesitzers oder aus der Struktur der Produktionsverhältnisse schlechthin abzuleiten, wenngleich auch die Individualisierung in starken Zusammenhang mit den allgemeinen Tauschbeziehungen steht; konzeptionell ist die Individualisierung vor allem im Taylorismus und dessen fragmentierter Raum-Zeit, seiner internen Arbeitsorganisation angelegt ${ }^{173}$.

172 Vgl. ÜuS, S. 192 ff.

173 Mit der Annahme, dass die staatliche Struktur und ihre Macht- und Herrschaftstechniken in enger Beziehung zur Arbeitsorganisation steht, kann sich Poulantzas zu einem gewissen Teil auf Marx stützen: „Die spezifische ökonomische Form, in der unbezahlte Mehrarbeit aus den unmittelbaren Produzenten ausgepumpt wird, bestimmt das Herrschafts- und Knechtschaftsverhältnis, wie es unmittelbar aus der Produktion selbst hervorwächst und seinerseits bestimmend auf sie zurückwirkt. Hierauf aber gründet sich die ganze Gestaltung des ökonomischen, aus den Produktionsverhältnissen selbst hervorwachsenden Gemeinwesens und damit seine spezifische politische Gestalt.“ [MEW, Bd. 25, S. 799] 
Die Konzeption der Individualisierung als Technik der Macht und ihre Verbindung mit der Raum-Zeit innerhalb der ökonomischen Struktur lässt sich auf eine Aufnahme zentraler Thesen Foucaults zurückführen. Dieser führt aus, dass mit dem 18. Jahrhundert zwei Formen und Techniken der Macht auftreten. Diese neue Techniken würden vor allem darauf abzielen, die Bevölkerung zu individualisieren und regulierenden Maßnahmen zu unterwerfen und sich den individualisierten Körper durch verschiedene Disziplinartechniken zu unterwerfen $^{174}$, im Zentrum dieser Disziplinartechniken stehe vor allem die Dressur und Kontrolle von körperlichen Handlungsabläufen/Durchführungsweisen von Tätigkeiten, bis hin zu den kleinsten Gesten [ÜuS, S. 175].

Diese Disziplinierung der Durchführungsweise bestehe „,in einer durchgängigen Zwangsausübung, die über die Vorgänge der Tätigkeit genauer wacht als über das Ergebnis und die Zeit, den Raum, die Bewegungen bis ins kleinste codiert" [ebd.]. Poulantzas greift diese Ausführungen Foucaults offensichtlich auf, für ihn ist die für den entwickelten Kapitalismus charakteristische tayloristische Raum-Zeit

ein genau abgesteckter, in Abschnitte und Zellen aufgeteilter Raum, in dem jede Parzelle (jedes Individuum) ihren Platz hat und in der jeder Platz einer bestimmten Parzelle entspricht, der aber zugleich homogen und einheitlich aussehen muss: eine lineare, aufeinander folgende, sich wiederholende und kumulative Zeit, in der die verschiedenen Momente ineinander integriert sind. [St, S. 57]

Die Individualisierung ist somit nicht ein der Warenbeziehungen und ihrer juristischen Ideologie entsprechender Prozess, sondern ein Resultat der Mechanisierung und ihrer spezifischen Arbeitsteilung. Die der Mechanisierung zugrunde liegenden „,räumlichen und zeitlichen Matrizen“ [St, S. 57] produzieren die Individualisierung, die sich in der institutionellen Materialität des Staates niederschlägt. Zum einen, indem sich die Apparate selbst fraktionieren, zum anderen, indem sich der Staat selbst als über die Individualisierung hinausweisende Einheit der fraktionierten und parzellierten Gesellschaft setzt: als nationaler Repräsentativstaat, als „Nation des Volkes“ [ebd.]. Die Funktionen des modernen Staates und seine Techniken sind folglich im Zusammenhang mit dieser Individualisierung zu sehen:

174 Vgl. Foucault 1999a, S. 183 f. 
Die Apparate dieses Staates [sind] entsprechend der Funktion der Ausübung der Macht über diese Gesamtheit von Beziehungen strukturiert: sie reproduzieren den gleichen materiellen Bezugsrahmen und die gleiche räumlich-zeitliche Matrix, die auch in den Produktionsverhältnissen enthalten sind. Die interne Organisation der Netze und Dispositive der Bürokratie und ihre Verkettung setzt diesen Rahmen voraus, auch wenn er in der bürokratischen Verwaltung und im Despotismus der Fabrik, im Taylorismus und in der Fließbandproduktion unterschiedliche konkrete Gestalt annimmt. [ebd.]

Der Staat und seine Materialität ist demnach nicht lediglich Reflex der Individualisierung, sondern ist selbst „konstitutiver Faktor der Organisation der gesellschaftlichen Teilung der Arbeit“, der Staat „sanktioniert und institutionalisiert diese Individualisierung durch die Transformation der gesellschaftlichökonomischen Monaden in juristisch-politische Individuen-Personen-Subjekte“ [St, S. 58]. Diese Transformation vollziehe sich nicht innerhalb der Apparate der Justiz, sondern vielmehr innerhalb der materiellen ideologischen Praktiken des Staates (hier greift Poulantzas wieder Althussers Ideologiekonzeption auf). Die „Zurichtung“ der Individuen als ,juristisch-politische IndividuenPersonen-Subjekte“ [ebd.] hat dadurch zur folge, dass der Klassencharakter der Gesellschaft wie der der staatlichen Struktur verdeckt wird. Für Poulantzas stellt dies eine „spontane Ideologie“ dar, die selbst aus der gesellschaftlichen Teilung der Arbeit entspringt und sich in die Materialität des Staates und seine Techniken der Machtausübung einschreibt. Demgegenüber sind die Ideologien, die von den organischen Intellektuellen erarbeitet werden (politische Philosophie, Jurisprudenz), nur Ideologien zweiten Grades [ebd.].

b) Im Anschluss an Foucaults Konzeption der Disziplinargesellschaft formuliert Poulantzas, dass der Staat ,zur Produktion dieser Individualität durch eine Gesamtheit von Wissenstechniken (Wissenschaft) und von Praktiken der herrschenden Macht“ [ebd.] beiträgt. Die Technologien der Macht, die auf die Beherrschung und Disziplinierung der politischen Körper abzielen, von Foucault als „Normalisierung“(175 bezeichnet, bilden in der Gesamtheit ihrer Beziehungen eine neue Form der modernen Macht, den Panoptismus (Foucault). Wie der Konstitutionsrahmen der Rechtssubjekte sei hierbei der Konstitutionsrahmen des kapitalistischen Körpers sowie die Beziehung von 
Staat und kapitalistischer Körperlichkeit nicht aus den Warenbeziehungen und dem Warenfetischismus abzuleiten, sondern grundsätzlich auf die gesellschaftliche Arbeitsteilung zurückzuführen, ,die politische Technologie des Körpers hat ihre Basis in dem Bezugsrahmen der Produktionsverhältnisse und der gesellschaftlichen Arbeitsteilung“ $[\text { St, S. 59 }]^{176}$. In Opposition zu Foucault besteht Poulantzas darauf, dass sich in den Praktiken die herrschende Ideologie materialisiert, so dass sich die herrschende Ideologie eben nicht nur in „Ideen“ zeigt, wie Poulantzas Foucault unterstellt ${ }^{177}$. Der Mechanismus der Individualisierung ist demnach nicht auf die materiellen ideologischen Praktiken verstanden als reine Indoktrination der beherrschten Massen - zu begrenzen und der Mechanismus gehe auch über die Funktion der physischen Repression als Herrschaft über Körper hinaus. Vielmehr sei die Individualisierung

die materielle Gestalt der Produktionsverhältnisse und der gesellschaftlichen Arbeitsteilung im kapitalistischen Gesellschaftskörper und zugleich der materielle Effekt der Praktiken und Techniken des Staates, der diesen (politischen) Körper produziert und ihn sich unterwirft. [St, S. 59]

Die Individualisierung (,Vereinzelungseffekt“) ist dabei nicht auf rein ideologische Verhältnisse zurückzuführen, sondern muss auch als materielle Technik der Macht verstanden werden, die sich bis in die einzelnen Körper niederschlägt: die Einführung des Taylorismus ist so nicht nur als „ökonomische Notwendigkeit“ zu verstehen, sondern ebenso als Aktivität der Macht, mit der das Individuum durch Vereinzelung und durch Unterordnung unter der Maschinerie verschärften Machtbeziehungen unterworfen wird.

176 Auch hier lässt sich eine Parallele zu Foucault ziehen, der die Disziplinartechniken mit der Produktion in Verbindung bringt: „So formiert sich eine Politik der Zwänge, die am Körper arbeiten, seine Elemente, seine Gesten, seine Verhaltensweisen kalkulieren und manipulieren. Der menschliche Körper geht in eine Machtmaschine ein, die ihn durchdringt, zergliedert und wieder zusammensetzt. [...] Die Disziplin fabriziert auf diese Weise unterworfene und geübte Körper (um die ökonomische Nützlichkeit zu erhöhen) und schwächt diese selben Kräfte (um sie politisch fügsam zu machen). [...] Wenn die ökonomische Ausbeutung die Arbeitskraft vom Produkt trennt, so können wir sagen, dass der Disziplinarzwang eine gesteigerte Tauglichkeit und eine vertiefte Unterwerfung im Körper miteinander verkettet." [ÜuS, S. 176 f.]

Die Beziehung zwischen Produktion und individuellem Körper hat bereits Balibar in Das Kapital lesen angesprochen: Mit der Durchsetzung der industriellen Produktion hat sich das Verhältnis von Arbeiter zum Arbeitswerkzeug dahin gewandelt, dass die Maschine nicht länger Werkzeug ist, Arbeitskraft und Arbeitsmittel nicht länger eine Einheit bilden, sondern die Maschine nimmt den Platz der Arbeitskraft als „Werkzeugträger“ ein, der Arbeiter wird der maschinellen Produktion angepasst [DKL, Bd. 2, S. 320 f.]. Auch dies stellt einen Aspekt der „reellen Subsumtion der Arbeit unter das Kapital“ (Marx) dar.

177 Dieser Vorwurf scheint ungerechtfertigt, denn Foucault geht es nicht darum, Ideologie zu lokalisieren, sondern er steht in der Entwicklung seiner theoretischen Arbeiten dem gesamten Konzept der Ideologie zunehmend skeptisch gegenüber, vgl. Foucault 1978b, S. 79. 
Mit der Individualisierung geht aber auch eine Privatisierung einher, die Schaffung eines individuell-privaten Raumes durch den Staat. Die Privatisierung verläuft in einer Doppelbewegung, in der der Staat zugleich den individuell-privaten Raum definiert und als Individuelles-Privates von dem öffentlichen Raum trennt, sich selbst aber als Zusammenfassung und Repräsentanten des Individuell-Privaten setzt:

Das Individuell-Private ist eine Schöpfung des Staates, die mit seiner relativen Trennung von der Gesellschaft als öffentlicher Raum einhergeht. Das weist nicht nur darauf hin, dass diese Trennung nur eine spezifische Form der Anwesenheit des Staates in den ökonomischsozialen Verhältnissen ist, sondern auch auf eine niemals vorher erreichte Omnipräsenz des Staates in diesen Verhältnissen. [St, S. 62]

Wenn das Individuell-Private erst durch den Staat gesetzt wird, heißt das auch, dass es „zum ersten Mal in der Geschichte keine rechtliche und prinzipielle Schranke für die Aktivität und die Übergriffe in die Sphäre des IndividuellPrivaten geben kann" [ebd.]. Da der Staat die Definitionsmacht über den privaten Raum innehat, ist somit seine Ausweitung auf diesen Raum ohne Grenze. Wenn durch die Techniken des Staates der Gesellschaftskörper in Individuell-Privates gespalten wird, nimmt der Staat diese Spaltung auf, indem er

diese getrennte Monaden in derselben Bewegung totalisiert und sich in seinem institutionellen Aufbau ihre Einheit einverleibt. Das Private ist nur die Kopie des Öffentlichen, denn der Staat umreißt selbst die Konturen dieser Verdoppelung, die in den Staat eingeschrieben und schon in den Produktionsverhältnissen und der gesellschaftlichen Arbeitsteilung anwesend ist. Das Individuell-Private ist kein inneres Hindernis für das Handeln des Staates, sondern ein Raum, den der moderne Staat schafft, indem er ihn durchläuft. [St, S. 64]

Hierbei besteht Poulantzas darauf, dass im Verhältnis zum Staat gerade die Familie kein privilegierter Ort sei, der die Grundlage des Staates (oder umgekehrt) bilde. Familie und Staat sind nicht zwei verschiedene Räume, die sich gegenseitig begrenzen, ,sondern der Staat umreißt zur selben Zeit, wie er öffentlich wird, den Ort, den er der Familie [...] zuweist“" [ebd.]. Die Relation von Staat und Familie ist somit, wie die Relation von Staat und IndividuellPrivatem schlechthin, durch den Staat disponibel.

Das Individuell-Private ist integraler Bestandteil des strategischen Feldes, das der moderne Staat darstellt, es ist das Ziel, das der Staat sich als Einwirkungspunkt seiner Macht gibt, kurzum, es existiert nur durch diesen Staat. Das kann man deutlich an diesem an sich unbegreiflichen 
Fixpunkt „privates Individuum“ sehen, von dem man annimmt, dass es Subjekt unveräußerlicher Freiheiten und Menschenrechte und Subjekt eines habeas corpus ist, dessen Körper aber vollständig vom Staat und der Gesamtheit der Privatisierungszentren gestaltet wird. [ebd.]

Die Parzellierung des Gesellschaftskörpers in einzelne Monaden sei Grundlage des modernen Totalitarismus, dessen Grundzüge schon in der repräsentativen Demokratie, dem Rechtsstaat angelegt sind; den gerade durch die von dieser Staatsform ,eingeführte Trennung von öffentlich und privat eröffnet ihm [dem Staat] unbeschränkte Machtperspektiven“" [ebd.] ${ }^{178}$.

Die Grenze der staatlichen „Macht“ ist somit nicht innerhalb seiner eigenen Struktur angelegt oder innerhalb seiner eigenen Ideologie zu lokalisieren. Gleichwohl existiert eine reale Grenze der staatlichen „Macht“, die durch die Kräfteverhältnisse innerhalb des Klassenkampfs definiert wird, „denn der Staat ist auch die materielle oder spezifische Verdichtung eines Kräfteverhältnis, das ein Klassenverhältnis ist“" [St, S. 65]. Die Aufklärungsideologie (Menschen- und Bürgerrechte) wird zu einer Schranke des Staates, nicht weil sie diesem immanent ist oder vom Individuum dem Staat abgetrotzt wird, sondern indem diese Rechte von Klassen erkämpft werden und sich als positives Recht materialisieren. Entsprechend ist die Beziehung des in Klassen gespaltenen gesellschaftlichen Körpers und das Parzellieren der Klassen in individuell-private Einheiten und dem Staat zu bestimmen. Der Staat und seine Materialität ist nicht aus dem Individualisierungsprozess „ableitbar“, sondern der Staat hat in dieser Beziehung eine organische Rolle, da in der kapitalistischen Produktionsweise die gesellschaftlichen Klassen offen, also nicht (relativ) geschlossen wie z. B. ein Stand oder eine Kaste sind. Der Staat übernimmt dabei die Aufgabe,

die individualisierten Agenten auf die Klassen [zu] verteilen, er muss die Agenten so formieren und abrichten, qualifizieren und unterwerfen, dass sie diese oder jene Klassenstelle einnehmen können, an die sie nicht von Natur oder Geburt gebunden sind [St, S. 67].

Dementsprechend sei die Operation der Verteilung der Agenten auf die verschiedenen Klassen in die Materialität der staatlichen Apparate (Schule,

178 Dies gelte selbstverständlich auch für die ehemaligen „realsozialistischen“ Staaten, denn auch in diesen bestehe ein Mechanismus der Trennung des Privaten vom Öffentlichen, schon aufgrund der Verwandtschaft ihrer Produktionsverhältnisse mit denen der „westlichen“ kapitalistischen Staaten (gesellschaftliche Arbeitsteilung, Warenproduktion usw.) [St, S. 64 f.]. 
Verwaltung, Armee usw.) eingeschrieben und beherrsche die Techniken ihrer Machtausübung, die Zurichtung der Körper ist in der kapitalistischen Produktionsweise folglich von einem spezifischen Klassencharakter geprägt:

Es gibt eine bürgerliche Individualisierung und eine Arbeiterindividualisierung, einen bürgerlichen Körper und einen Arbeiterkörper als Modalitäten der kapitalistischen Individualisierung und Körperlichkeit, genauso wie es eine bürgerliche Familie und eine Arbeiterfamilie als Modalitäten der auf dem Individualisierungsprozess basierenden kapitalistischen Familie gibt. [ebd.]

\subsubsection{Staat, Gesetz und Terror}

In den Individuen und Subjekten gibt es kein Wissen und keine Wahrheit außerhalb des Gesetzes. Das Gesetz wird zur Verkörperung der Vernunft.

Nicos Poulantzas

a) Poulantzas rückt den entwickelten kapitalistischen Staat in die Nähe des Totalitarismus, was verwundern mag, wird im allgemeinen unter Totalitarismus - erst recht nach dem Erfolg des Geschichtsrevisionismus - doch eine Herrschaft durch Ausübung von (willkürlicher) Gewalt verstanden, die im Gegensatz zur - natürlich auf ,zivilgesellschaftlicher“" Rechtsstaatlichkeit beruhenden - bürgerlichen Demokratie steht. Doch nichts ist nach Poulantzas falscher als eine solche Trennung von Gesetz und Gewalt, „denn dieser Rechtsstaat, der Staat des Gesetzes schlechthin, hat im Gegensatz zu den vorkapitalistischen Staaten das höchste Gewalt- und Terrormonopol inne, das Kriegsmonopol“ [St, S. 68]. Im Gegensatz zu einer Trennung von Gesetz und Gewalt sei vielmehr auf deren Verbindung zu bestehen, denn jede, auch die gewalttätigste Staatsform habe sich einen juristisches System gegeben [ebd.]. Folglich sei das Gesetz bezüglich des Staates grundsätzlich als integraler Bestandteil der repressiven Ordnung zu begreifen, das Gesetz sei die

Organisation der Gewalt, die von jedem Staat ausgeübt wird. Der Staat erlässt die Regel und verkündet das Gesetz und führt dadurch ein erstes Feld von Befehlen, Verboten und Zensur ein. Er schafft so das Anwendungsgebiet und den Gegenstand der Gewalt. Darüber hinaus organisiert das Gesetz die Bedingungen für das Funktionieren der physischen Repression, bestimmt und bezeichnet ihre Modalitäten und gibt 
den Dispositiven, die sie ausüben, einen Rahmen. Das Gesetz ist in diesem Sinne der Kodex der organisierten öffentlichen Gewalt. [St, S. 68 f.]

Diese physische Repression durch den Staat wird nach Poulantzas' Ansicht weitgehend, insbesondere in den Arbeiten Foucaults, unterschätzt. Foucaults Argumentation ziele darauf ab, dass ausgehend von der Annahme, dass das Gesetz immer mit der Ausübung von Gewalt begleitet ist und demnach eine Unterscheidung von Legalität und Terror nicht mehr aufrecht erhalten werden könne, die Ausübung von „nackter“ Repression durch subtilere Techniken ersetzt worden sei. Zwar habe Foucault zu Recht auf die neuen Techniken der Macht hingewiesen, ein ausschließliches Beharren auf der Konzeption der „internalisierten Repression“ laufe aber darauf hinaus, an die Stelle der organisierten modernen Macht, die immer auch auf physischer Gewalt beruhe $^{179}$, ein Konzept der ,,ideologisch-symbolischen Manipulation, der Organisation des Konsensus und der Internalisierung der Repression“ [St, S. 69 f.] zu setzen; die ,repressiven Apparate werden nur als Teilstücke des DisziplinarDispositivs betrachtet, das die Internalisierung der Repression durch die Normalisierung gestaltet“ [St, S. 69]. Es sei zwar vollkommen richtig, die Frage nach dem organisierten Konsens zu stellen, statt diese Frage aber zu beantworten, sei die Repression, verstanden als „todbringender und bewaffneter Zwang auf die Körper“ [St, S. 70] und „Dressur und Kasernierung der Körper“ [St, S. 27], durch eine Konzeption der ,ideologischen Indoktrinierung (symbolischer Gewalt und Internalisierung der Repression)“ [St, S. 70] ersetzt worden ${ }^{180}$.

Im Gegensatz hierzu sei auf die Ausübung physischer Gewalt durch den modernen Staat und deren Legalität zu insistieren. Der Rechtsstaat zeichne sich hierbei vor allem dadurch aus, das er zunehmend „private“, nicht gesetzlich kodifizierte Gewaltverhältnisse aufnehme/transformiere und ihnen damit den Status der legalen öffentlichen Gewalt gebe,

die außergewöhnliche Ansammlung von körperlichen Zwangsmitteln durch den kapitalistischen Staat geht einher mit seinem Rechtsstaatcharakter. [...] Der Grad offener physischer Gewalt, die in den verschie-

179 Hier argumentiert Poulantzas bezüglich der politischen Macht analog Weber [Weber 1984, S. 90] und Luhmann.

180 Diese Reduktion unterstellt Poulantzas nicht nur Foucault, sondern ebenso der „Frankfurter Schule“, Marcuse und Bourdieu [St, S. 70]. Auch hier scheint der Vorwurf Foucault gegenüber ungerechtfertigt, denn dieser ist sich durchaus bewusst, dass Gewalt nicht nur internalisiert, sondern auch ausgeübt wird, vgl. insbesondere Foucault 1997c, S. 163 ff. 
denen Situationen ,privater“ Macht außerhalb des Staates ausgeübt wird - von der Fabrik bis zu den berühmten Mikrosituationen der Macht verringert sich in genau dem Maße, wie der Staat sich das Monopol der legitimen physischen Macht vorbehält. [St. S. 72]

Poulantzas räumt ein, dass selbstverständlich im Vergleich zu vergangenen Gesellschaftsformationen das Maß der tatsächlich ausgeübten physischen Gewalt in einem modernen bürgerlichen Staat rückläufig ist, dies führe aber offenbar zu der Illusion, dass die moderne Herrschaft nicht auf der Ausübung von Gewalt beruhe. Im Gegenteil hierzu sei aber davon auszugehen, dass diese Beziehung stärker den je ist, denn sie sei determinierend in Bezug auf die „Verfahren der Herstellung des Konsensus“ [ebd.]. Konsens und physische Gewalt würden dabei nicht zwei verschiedene Modi der Ausübung von Herrschaft darstellen, die Wahlweise eingesetzt werden, wenn das jeweils andere versagt (diese Auffassung kann z. B. Gramsci unterstellt werden), durch ihre determinierende Rolle seien Gewalt und Terror innerhalb des gesellschaftlichen Körpers immer anwesend,

die vom Staat monopolisierte physische Gewalt umfasst permanent die Techniken der Macht und die Mechanismen des Konsenses; sie ist in das Raster der disziplinarischen und ideologischen Dispositive eingeschrieben und gestaltet die Materialität des gesellschaftlichen Körpers, auf den die Herrschaft einwirkt, selbst wenn diese Gewalt nicht direkt ausgeübt wird. [St, S. 73]

Ideologische Herrschaft, Normalisierung und Repression seien folglich nicht als voneinander gelöste Modalitäten der Ausübung von Macht zu betrachten,

es handelt sich vielmehr darum, die materielle Organisation der Macht als Klassenverhältnis aufzufassen, dessen organisierte physische Gewalt die Existenzbedingung und der Garant der Reproduktion ist. Der Einsatz der Techniken der kapitalistischen Macht, die Konstituierung der DisziplinarDispositive [...] und das Entstehen der ideologisch kulturellen Institutionen (vom Parlament über das allgemeine Wahlrecht bis hin zur Schule) setzen die Monopolisierung dieser Gewalt durch den Staat voraus, die gerade durch die Verschiebung von der Legitimität zur Legalität und durch die Herrschaft des Gesetzes verschleiert wird. [ebd.] ${ }^{181}$

Die Monopolisierung der legalen Gewalt in der Hand des Staates sei auf die neuen Formen des Klassenkampfs in der kapitalistischen Gesellschaftsforma-

181 Die Monopolisierung der Gewalt bedeutet auch, dass der moderne Staat weiterhin auf der Grundlage des Todes arbeitet, ,selbst wenn er nicht hinrichtet (Todesstrafe), nicht tötet und auch nicht damit droht, selbst und gerade dann, wenn er das Sterben verhindert, verwaltet der moderne Staat den Tod, und auch die medizinische Macht ist in das moderne Gesetz eingeschrieben“ [St, S. 73 f.], vgl. dazu Foucault 1997c, S. 170 f. 
tion zurückzuführen. Die „Entmilitarisierung“ der privaten Konflikte bilde zum einen eine Vorbedingung für das Funktionieren der kapitalistischen Ausbeutung, damit verbunden wechsele die Form der politischen Auseinandersetzungen von periodisch auftretenden bewaffneten Konflikten hin zum gewerkschaftlichen Kampf. Durch die Legalisierung der staatlichen Gewalt werde der gewalttätige Widerstand der Massen illegalisiert und diese von der Ausübung von Gewalt ausgeschlossen. Im Gegensatz zu diesen stehe dem Staat (und damit den herrschenden Klassen) die Form der gewalttätigen „Lösung“ von Konflikten weiterhin offen. Gleichzeitig verstärke aber die Monopolisierung der Gewalt innerhalb des Staates die Illusion, dass der Staat „neutrales“ Instrument sei, ein Werkzeug, das formal selbst ermögliche, dass die beherrschten Massen die Macht erlangen. Diese Illusion habe das paradoxe Ergebnis, das durch die Monopolisierung der Gewalt innerhalb des Staates die Ausübung von Gewalt selbst nicht mehr ausreicht, die politische Herrschaft zu reproduzieren, sondern diese politische Herrschaft bedürfe des zusätzlichen Konsens [ebd.]. Die Organisation des Konsenses wird folglich eine Bedingung der Reproduktion der gesellschaftlichen Macht und vollzieht sich innerhalb des Gesetzes,

die Herrschaft des kapitalistischen Gesetzes weist den Mechanismen des Konsenses einschließlich der ideologischen Indoktrination genau in dem Maße ihre Stelle zu, wie sie die Monopolisierung des physischen Gewalt durch den Staat verschleiert. [St, S. 74]

Die Funktion des Gesetzes sei dabei, wie die Macht, nicht durchweg negativdestruktiv (hier schließt sich Poulantzas der Kritik Foucaults an), dies stelle eine Konzeption dar, in der „der Staat nur wirkt, insofern er untersagt, ausschließt, verhindert, auferlegt; oder insofern er betrügt, fälscht, verbirgt oder glauben macht“ " St, S. 28]. Demgegenüber betont Poulantzas im Anschluss an Foucault eine kreative, schaffende Rolle des Staates (vor allem, in dem der Staat den Konsens als „,materielles Substrat“ der beherrschten Massen erzeugt) dahingehend, dass der Staat die Massen nicht (nur) indoktriniert, sondern auch zu Handlungen zwingt. Die repressive Rolle des Gesetzes erhält somit ein Moment der Positivität,

schon seit dem griechisch-römischen Recht ist es eben auch das Gesetz, das positive Anordnungen erlässt: das Gesetz verbietet und duldet nicht nur nach der Maxime, dass alles erlaubt ist, was nicht durch das Gesetz verboten ist, es stellt auch Aufgaben und zwingt zu positiven Handlungen 
gegenüber der Macht und verpflichtet $\mathrm{zu}$ an die Macht gerichteten Diskursen. [St, S. 75]

Repression besteht also nicht nur darin, dass eine Handlung negativ sanktioniert wird, weil sie verboten ist, sondern ebenso in dem negativen Sanktionieren einer unterlassenen Handlung, obwohl diese angeordnet wurde, „das Gesetz erzwingt nicht nur Schweigen und duldet Gesagtes, sondern verpflichtet oft gerade zum Sprechen“ [ebd.]. Auch wenn bezüglich der Repression das Gesetz eine elementare Rolle spielt, sei die Funktion des Gesetzes nicht auf die Repression zu beschränken, denn das Gesetz sei von ebenso großer Bedeutung für die Organisation des Konsenses, indem es die herrschende Ideologie materialisiere und durch seine „Diskursivität und Struktur die politischökonomischen Realitäten“ verdeckt [ebd.].

Das Gesetz sei aber nicht nur Legitimation von Gewalt und materialisierte Ideologie, sondern werde für die gesellschaftlichen Agenten zur objektiven Struktur, die den Agenten ihre Stelle innerhalb des gesellschaftlichen Körpers zuweist. Durch diese ideologische Stellenzuweisung im politischsozialen Netz würden den Agenten Pflichten, aber auch Rechte erwachsen, „,die imaginäre Besetzung der Stelle hat reale Auswirkungen auf die Agenten“ [St, S. 76; Hervorhebung S.v.B.]. Ebenso sei das Gesetz aber auch als Resultat des Klassenkampfs zu begreifen, denn die Kompromisse, die von den beherrschten Klassen erkämpft werden, schreiben sich direkt in das Gesetz ein; auch durch diesen Vorgang erzeuge das Gesetz Konsens.

b) Poulantzas problematisiert weiterhin, in welcher Beziehung der Staat und sein Handeln zum Gesetz stehen. Dass der Staat und sein Handeln nicht auf das positive Recht beschränkt sein kann, ist nach Poulantzas an folgenden Punkten erkennbar:

1. Das Handeln des Staates vollziehe sich nicht immer in der Form des Gesetzes, sondern könne ebenso in Praktiken und Techniken vollzogen werden, die nicht eine juristische Form annehmen, sondern deren Form von den Klassenkämpfen bestimmt und später in eine juristische Form überführt würden [ebd.].

2. Der Staat könne neben und über das Gesetz hinaus handeln und selbst das Gesetz übertreten: 
Jedes juristische System autorisiert in seiner Diskursivität als Variable der Spielregel des von ihm organisierten Spiels die Nichtrespektierung des eigenen Gesetzes durch den Machtstaat. Das nennt sich dann Staatsräson, was eigentlich nicht einfach heißt, dass die Legalität immer durch Nebenzonen der Illegalität ausgeglichen wird, sondern dass die Illegalität des Staates immer in die von ihm eingeführte Legalität eingeschrieben ist. [St, S. $76 \mathrm{f}$.]

Die Gesetzeslücke, die dem Staat ein Handeln neben dem Gesetz ermöglicht, ist also kein „Versehen“, sondern in dem juristischen Diskurs vorgesehenes Dispositiv, eine Bresche, um das Gesetz zu verlassen. Die Gesetzeslücke sei wie der offensichtliche Verstoß des Staates gegen das Gesetz strukturelle Notwendigkeit für das Funktionieren des Staates [St, S. 77].

3. Das Handeln des Staates geht insofern immer über das Gesetz hinaus, in dem er das Gesetz selbst modifizieren kann. Es gebe kein Primat des Gesetzes gegenüber dem Staat, wie die juristische Konzeption des Staates annehme, sondern der Staat habe innerhalb einer Klassengesellschaft als Inhaber der legitimen Gewalt immer Vorrang gegenüber dem Gesetz. Weiterhin basiere das Gesetz immer auf der Funktion der Gewalt/des Zwangs und damit der repressiven Staatsapparate,

denn wenn es stimmt, dass das Gesetz diese Gewalt organisiert, dann gibt es in dieser Gesellschaft kein Gesetz oder Recht ohne eine Apparatur, die seine Anwendung durchsetzt und sein Wirksamkeit, kurz seine gesellschaftliche Existenz sichert. Die Wirksamkeit des Gesetzes ist niemals die des reinen Diskurses des Wortes oder der erlassenen Regel. [St, S. 78]

Das moderne kapitalistische Gesetz zeichnet sich nach Poulantzas vor allem durch seine Abstraktheit, Formalität und Universalität aus. Diese Kennzeichen seien allerdings nicht direkt in Bezug zu der Zirkulation des Kapitals und dem Warentausch zu setzen bzw. aus diesem ,abzuleiten“, sondern vor allem im Hinblick auf die gesellschaftliche Arbeitsteilung in den Produktionsverhältnissen hin zu untersuchen [ebd.]. Wenn die Trennung der unmittelbaren Produzenten von den Produktionsmitteln nicht (mehr) aufgrund direkt innerhalb des Produktionsprozess anwesender Gewalt aufrecht erhalten wird, folge daraus, dass die Produktionsverhältnisse die Rolle der Gewalt außerhalb des Produktionsprozess zuweisen. Genau diese Zuweisung werde innerhalb des Gesetzes kodifiziert:

Dieses axiomatisierte juristische System bildet den formalen Kohäsionsrahmen für Agenten, die ihrer Produktionsmittel total enteignet sind, und 
zeichnet so die Konturen eines staatlichen Raumes, der von den Produktionsverhältnissen relativ getrennt ist. [...] Das moderne Gesetz verkörpert so den Raum und die Zeit, den materiellen Bezugsrahmen des Arbeitsprozesses; Raum und Zeit sind seriell, kumulativ, kontinuierlich und homogen. Dieses Gesetz setzt die Individuen als juristisch-politische Subjekte und Personen ein, indem es ihre Einheit als Volk und Nation repräsentiert. [St, S. 79]

In der „Repräsentation der Einheit“ verdeckt das Gesetz (als positives Recht) nicht (wie oft vertreten) die Ungleichheit der Subjekte durch formal-abstrakte Gleichheitsprinzipien [Demirović 1987, S. 86], sondern im Gegenteil werden die sozialen Differenzierungen kodifiziert, ohne „die politische Einheit der Gesellschaftsformation in Frage zu stellen“ [St, S. 79].

Alle Subjekte sind vor dem Gesetz gleich und frei. Das heißt schon im Diskurs des Gesetzes (es wird nicht einfach durch ihn verschwiegen), dass sie in Wirklichkeit (als Subjekte und Individuen) verschieden sind, aber nur in dem Maße, wie dieser Unterschied in einen homogenen Raum eingeschrieben werden kann. Das kapitalistische Gesetz verschleiert nicht nur, wie häufig gesagt wird, die realen Unterschiede in einem universalen Formalismus. Es trägt vielmehr dazu bei, den (individuellen und Klassen-) Unterschied in seiner Struktur selbst einzuführen und zu sanktionieren, wobei es sich gleichzeitig zum System des Zusammenhalts und zum Organisator der Einheit und Homogenisierung dieser Unterschiede erhebt. [ebd.]

Dieser Einheit und Homogenisierung entspricht nach Poulantzas die Abstraktheit, Universalität und Formalität des Gesetzes. Diese Kriterien setzen voraus, dass die gesellschaftlichen Agenten frei von direkten, persönlichen Abhängigkeits- und Gewaltverhältnissen $\operatorname{sind}^{182}$, also nicht länger in Kasten oder Stände differenziert sind, sondern offenen Klassen angehören. Wie dargelegt führt Poulantzas diese dem Kapitalismus spezifische Individualisierung der gesellschaftlichen Agenten nicht auf die Durchsetzung universaler Menschenrechte durch das Gesetz zurück, auf ein politisch-moralisches Dispositiv, sondern interpretiert diese Individualisierung vor allem als Folge der Organisation der Produktion. Folglich kann das Recht nicht konstitutiv für die offenen Klassen sein, sondern das Gesetz sanktioniert die Individualisierung, indem es „parallel (oder in relativem Widerspruch) zu anderen Techniken und Praktiken des Staates (den Normalisierungsdisziplinen)“ [St, S. 80] arbeitet.

182 Diesen Abhängigkeits- und Gewaltverhältnissen, kennzeichnend für vorkapitalistische Gesellschaftsformationen, entspreche ein anders gearteter rechtlicher „Überbau“: ein auf „Status, Privilegien und Gewohnheiten“ [St, S. 79] basierendes Recht, dessen Klassencharakter offensichtlich ist. 
Indem das Gesetz Volk und Nation verkörpere, verschiebe es bezüglich der Begründung der politischen Macht die Frage von der Legitimität hin zur Legalität. Es beseitige die vorkapitalistische religiöse Legitimation und setze an ihre Stelle eine politisch-juristische Ideologie, wobei das Gesetz die herrschende politische Ideologie materialisiere, Legalität und Legitimität politischer Macht fallen im Gesetz zusammen. Das Gesetz (als reines Zeichensystem) könne dabei die gesellschaftliche Einheit der Agenten zementieren und repräsentieren, ,indem es sie in das gesellschaftliche Imaginäre einlässt und so die Individualisierungsverfahren" [ebd.] festige. Im Gegensatz zu dem kapitalistischen Gesetz als Zeichensystem interpretiert Poulantzas die ideologische Legitimität der vorkapitalistischen Gesellschaftsformation in der Form der religiösen Symbolisierung, der sakralen Legitimation. Die Verschiebung von religiöser Symbolisierung hin zum Zeichensystem ist nach Poulantzas darin zu suchen, dass die Ideologie innerhalb der kapitalistischen Gesellschaftsformation nicht nur die dominierende Rolle habe - was für die vorkapitalistischen Gesellschaftsformationen kennzeichnend gewesen sei -, sondern die ökonomische Ebene determinierend und dominierend sei. Der spezifische kapitalistische Mechanismus zur Erzielung von Mehrwert beseitige die Untersymbolisierungen, die den persönlichen Bindungen der Agenten zugrunde gelegen haben, ,die Herrschaft des kapitalistischen Gesetzes ist in der Leere des Signifikanten in seiner Umgebung begründet" [St, S. 81].

Wenn das Recht zwar „lediglich“ ein Zeichensystem ist, entfalte es doch u. a. eine spezifische Materialität dadurch, indem es sich in die institutionelle Struktur des Staates einschreibt. Das Gesetz definiere dessen Struktur und die Beziehungen der einzelnen Strukturebenen und Apparate bis hin zu den Rekrutierungsmaßnahmen, innerhalb derer die gesellschaftliche Agenten für die staatliche Struktur selektiert und in diese eingesetzt werden. Dabei falle dem juristischen Diskurs die Aufgabe zu,

das abstrakte und formale Gesetz abschnitt- und stufenweise auf seine konkrete Anwendung hin in einer logisch-deduktiven Abfolge (der ,,juristischen Logik") zu konkretisieren, die nur als das Durchlaufen einer Ordnung von Herrschaft und Unterordnung und eines Entscheidungsund Durchführungsweges innerhalb des Staates ist. [ebd.]

c) In diesem Zusammenhang kann nun Poulantzas die spezifische Funktion des Gesetzes in Bezug auf die Verbindung von Macht und Wissen (s. o.) in der 
kapitalistischen Gesellschaft untersuchen. Wenn der Staat innerhalb der gesellschaftlichen Arbeitsteilung die intellektuelle Arbeit innerhalb seiner Struktur organisiert, verwirklicht das Gesetz diese spezifische Verbindung, ,in den Individuen und Subjekten gibt es kein Wissen und keine Wahrheit außerhalb des Gesetzes. Das Gesetz wird zur Verkörperung der Vernunft“ [St, S. 82]. Die gesellschaftlichen Agenten, die diese intellektuelle Arbeit in der staatlichen Struktur ausüben, also den juristischen Diskurs führen, bilden nach Poulantzas die idealtypische Gruppe von Intellektuellen, den „Korpus spezialisierter Juristen“, der das Wissen des Staates einerseits darstellt und vor den nichtstaatlichen Agenten verbirgt, andererseits dieses Wissen mit der Macht in Beziehung bringt, indem er dieses Wissen anwendet ${ }^{183}$.

Diese Juristenschaft im weitesten Sinne repräsentiert als von der Gesellschaft ,,abgetrenntes“ Netz wahrscheinlich am besten die im Staat verkörperte intellektuelle Arbeit. Jeder Vertreter des Staates im weitesten Sinne [...] ist in dem Maße ein Intellektueller, wie er ein Mann des Gesetzes ist, der Gesetze macht, Gesetz und Vorschrift kennt, sie konkretisiert und anwendet. „Jeder kennt das Gesetz" ist die grundlegende Maxime eines modernen juristischen Systems, in dem außer den Repräsentanten des Staates keiner es kennen kann. Diese von jedem Staatsbürger verlangte Kenntnis ist nicht einmal Gegenstand eines besonderen Schulfachs. [....] Diese Maxime drückt so die Abhängigkeit und Unterordnung der Volksmassen in Bezug auf auf die Staatsbeamten [...] aus; die Unkenntnis (das Geheimnis) des Gesetzes bei den Volksmassen ist ein Merkmal dieses Gesetzes und der juristischen Sprache selbst. Das moderne Gesetz ist ein Staatsgeheimnis und begründet ein Wissen, das von der Staatsräson in Beschlag genommen wird. [ebd.]

Wenn das Gesetz die Funktion habe, die Individuen auf die verschiedenen gesellschaftlichen Stellungen im Rahmen der gesellschaftlichen Arbeitsteilung $\mathrm{zu}$ verteilen und so die Arbeit unter das Kapital zu subsumieren, entspreche es „den besonderen Koordinaten der politischen Kämpfe im Kapitalismus“ [St, S. 83]. Während die vorkapitalistischen Gesellschaftsformationen eine „,blinde“ Reproduktion aufgewiesen hätten, sei dem Kapitalismus die erweiterte Reproduktion eigen, die ein gewisses strategisches Kalkül innerhalb des Produktionsprozesses voraussetze. Dieses strategische Kalkül und die damit notwendig verbundene Voraussicht benötige ein System von Regeln der Reproduktion. Genau dieses formalisierte System von Regeln stelle das Recht dar, das somit die Regeln der eigenen Transformation definiere [ebd.].

183 Vgl. Foucault 1978, S. 84. 
Weiterhin definiere das formale System des Rechts die Modi des Zusammenspiels der staatlichen Apparate. Vor dem Hintergrund des Klassenkampfes und des Blocks an der Macht bedeute das, dass durch das Recht die Aufteilung der Macht zwischen den einzelnen Fraktionen des Blocks an der Macht innerhalb des Staates geregelt und kontrolliert wird, die Verschiebungen der Machtverhältnisse innerhalb des Blocks an der Macht werden im Gesetz formalisiert und transformiert, ohne dass es zu politischen Krisen kommt:

Das kapitalistische Gesetz dämpft und kanalisiert in einem gewissen Sinne die politischen Krisen, so dass diese keine tatsächlichen Staatskrisen nach sich ziehen. Allgemeiner ausgedrückt erscheint das kapitalistische Gesetz als die notwendige Form eines Staates, der gegenüber dieser oder jener Fraktion des Blocks an der Macht relativ autonom sein muss, um ihre Einheit unter der Hegemonie einer Klasse oder Fraktion zu organisieren. [St, S. 84]

Genau wie das Recht die Machtverhältnisse innerhalb des Blocks an der Macht reflektiere und die Kompetenz- und Einflussbereiche der verschiedenen Fraktionen definiere, regele es die Ausübung der Macht über die beherrschten Klassen, indem es den Rahmen eines permanenten Kompromissgleichgewichts umreiße, welches den beherrschten Klassen aufgezwungen werde. Hierbei werde auch der Modus der physischen Repression durch das Gesetz geregelt, dies stelle zwar eine (von den beherrschten Klassen erkämpfte) Grenze der Macht der herrschenden Klasse dar, aber nur insoweit, wie es die Strategie der Beherrschung und der Gewalt gegen die beherrschten Klassen modifiziere, da das Gesetz den Widerstand der beherrschten Klassen einkalkuliere [St, S. 84 f.]. 


\subsubsection{Staat und Ökonomie}

Die Axiome des Kapitalismus sind offensichtlich weder theoretische Sätze noch ideologische Formeln, sondern operative Aussagen, die die semiologische Form des Kapitals bilden und als Bestandteil in die Gefüge der Produktion, Zirkulation und Konsumtion eingehen.

Gilles Deleuze/Félix Guattari

a) Dass nach den bisherigen Ausführungen Staat und Ökonomie nicht einander äußerliche Strukturen sind, der Staat aber auch nicht aus der Ökonomie „ableitbar“ ist, liegt auf der Hand. Ebenso ist offensichtlich, dass dem kapitalistischen Staat bezüglich der (erweiterten) Reproduktion des Kapitals erhebliche Bedeutung zukommt. Da diese ökonomische Funktionen schon von den verschiedenen Staatsformen des Monopolkapitalismus wahrgenommen wurden, erscheint es Poulantzas erforderlich, die Spezifik des modernen Staates auch anhand seiner Verbindung mit der ökonomischen Struktur zu untersuchen.

Die Differenz zwischen dem modernen Staat und den Staatsformen des Konkurrenzkapitalismus arbeitet Poulantzas anhand der Anordnung der beiden Räume („Staat“ - Raum der Politik, „Ökonomie“ - Raum der Reproduktion) heraus. Hierbei werden die beiden Räume nicht als aneinandergrenzende Räume gedacht, wobei der politische Raum auf den ökonomischen einwirkt, oder als Räume, die sich zunehmend gegenseitig durchdringen, deren Konturen aber gleich blieben [St, S. 151]. Es sei im Gegenteil davon auszugehen, dass die Struktur und der Inhalt der Räume sich mit den verschiedenen Produktionsweisen ändern. Ebenso sei die Struktur dieser Räume auch von den verschiedenen Stadien einer Produktionsweise abhängig, wenn diese auf einer erweiterten Reproduktion basiere. Die spezifische Trennung der beiden Räume ist somit innerhalb des kapitalistischen Staates nicht konstant, sondern diese Trennung werde von den Phasen der Entwicklung der ökonomischen Struktur transformiert, „wenn sich die Konfiguration dieser Bereiche (Staat und Ökonomie) ändert, reproduziert sich diese Trennung in neuen Formen“ [St, S. 152].

Die Trennung der Räume verlaufe allerdings nicht hierarchisch (wie im Basis-Überbau-Schema), sondern die der kapitalistischen Produktionsweise eigentümliche Trennung von Staat und Ökonomie ist durch die „spezifische Form der Präsenz des Staates in den Produktionsverhältnissen“ erkennbar 
[ebd.; Hervorhebung S.v.B.]. Der Staat interveniert somit nicht (denn dann wäre er der Ökonomie äußerlich und die Unterscheidung der verschiedenen kapitalistischen Staatsformen wie liberaler Staat, Faschismus usw. ließen sich, in polit-ökonomischer Hinsicht, nur anhand des Ausmaßes der Intervention bestimmen), sondern die staatliche Struktur ist in der kapitalistischen Gesellschaftsformation in der ökonomischen Struktur beständig anwesend. Daraus folgert Poulantzas, dass die Veränderungen der Rolle des Staates bezüglich der Akkumulation und Reproduktion des Kapitals selbst eine Verschiebung des politischen und ökonomischen Raums nach sich zieht, sich dabei aber auch die Relation der beiden Räume verändert. Indem die gesellschaftliche Arbeitsteilung, die Reproduktion der Arbeitskraft usw. modifiziert werde, folge darauf eine Verschiebung in den Räumen, so dass bisher untergeordnete Bereiche wie z. B. Städtebau, Verkehrswesen, Umwelt etc. direkt in den Verwertungsraum des Kapitals integriert und angepasst werden und für die Reproduktion des Kapitals von entscheidender Bedeutung werden können. Durch die Notwendigkeit der Integration und Modifikation werde das Verhältnis des staatlichen Raumes dahingehend betroffen, dass Orte des staatlichen Handelns verschoben werden, der Staat selbst zunehmend in den Raum der Kapitalverwertung gezogen werde (oder der Raum der Verwertung sich in den Staat ausweite), bis der Staat selbst „ganze Sektoren der Kapitalverwertung und Reproduktion der Arbeitskraft" [ebd.] übernehme oder diese Sektoren mit ihm verflochten seien. Diese Verflechtung ist Kennzeichen der qualitativen Differenz des modernen Staates vom liberalen Staat, sie tangiere dabei die gesamte (Re-) Organisation des Staates, ,sämtliche Funktionen des Staates, seien sie repressiver, ideologischer oder anderer Natur, können wegen seiner neuen ökonomischen Rolle nicht mehr isoliert betrachtet werden“ [St, S. 153].

Die Verschiebung der Räume in der Entwicklung des kapitalistischen Staates hat sich nach Poulantzas derart vollzogen, dass die ökonomischen Funktionen des Staates im frühen Monopolkapitalismus im Vergleich zu den ideologischen und repressiven Funktionen nur eine untergeordnete Rolle hatte, wenngleich natürlich die Entwicklung des Kapitalismus ohne einen ökonomische Funktionen wahrnehmenden Staat - der als „ideeller Gesamtkapitalist“ (Marx) agierende Staat - nicht denkbar ist. Im Gegensatz dazu zeichne sich der moderne Staat dadurch aus, das seine ökonomische Funktion nun eine 
determinierende und dominante Stellung innehaben. Dem Staat kämen nicht nur neue Aufgaben zu, sondern die gesamte Struktur des Staates werde auf diese Dominanz hin neu ausgerichtet.

Sämtliche Maßnahmen des Staates werden gegenwärtig in Bezug auf seine ökonomische Rolle reorganisiert. Dies gilt über ideologischrepressive Maßnahmen des Staates hinaus für seine Tätigkeiten in der disziplinierenden Normalisierung, der Strukturierung von Raum und Zeit, der Einführung neuer Prozesse der Individualisierung und der kapitalistischen Körperlichkeit sowie der Ausarbeitung strategischer Diskurse und der Wissenschaftsproduktion. [ebd.]

Das bedeute, dass die ideologischen und repressiven nicht von den ökonomischen Funktionen des Staates getrennt erfasst werden können, die Ausübung von Gewalt und die ideologische Indoktrination durch den Staat sei verbunden mit dem „Rhythmus der Akkumulation und Reproduktion des Kapitals“ [ebd.]. Die ideologischen und repressiven Funktionen seien jedoch weiterhin spezifisch für die staatliche Struktur, wesentliche innere Widersprüche des Staates seien somit an dieser Linie zwischen den ökonomischen und politischhegemonialen Funktionen angesiedelt.

Diese Widersprüche seien auf die innere Logik der jeweiligen Räume zurückzuführen: die ökonomischen Funktionen des Staates schaffen „,vom Staat nur schwer zu beherrschende Unruhen“" [St, S. 154], sie sind quer zu den zur Organisierung der Hegemonie erforderlichen Maßnahmen angeordnet und dazu geeignet, das (Selbst-) Verständnis des Staates als „Garant von Wohlstand und Allgemeinwohl“ [ebd.] in Frage zu stellen. Zweifellos seien die ökonomischen Maßnahmen des modernen Staates vor dem Hintergrund des „Rhythmus der Kapitalakkumulation“ unumgänglich, wobei er selbst die interne Logik der Produktionsweise aber nicht in Frage stellen könne. Dadurch ergebe sich für den Staat die Problematik, dass seine ökonomische und seine politische Strategien tendenziell auseinander fallen, die vom Staat ausgehenden Maßnahmen zur Stützung der Kapitalreproduktion hätten somit zur Folge, dass die Hegemonie selbst betroffen wird [ebd.]. Daraus resultierend verschärfen sich die Widersprüche für Poulantzas sowohl innerhalb des Blocks an der Macht als auch die Widersprüche zwischen diesem Block und den beherrschten Massen und würden zu Krisen führen, die nicht allein ökonomische Krisen seien. Da der staatliche Raum zunehmend an die Kapitalreproduktion gebunden ist, ist sein politisches Handlungsfeld zur Organisierung der Hegemonie beschnitten, 
die Ausweitung des Staates ist keine Ausweitung seiner Macht gegenüber der Wirtschaft. Sie vergrößert ganz im Gegenteil seine Abhängigkeit von ihr: Diese Ausweitung entspricht einer Unterordnung aller sozio-ökonomischen Bereiche unter den Akkumulationsprozess des Kapitals. [ebd.]

Das heiße für die Einschätzung des jeweils aktuellen Regierungspolitik, dass die Durchführung bestimmter ökonomischer Maßnahmen nicht auf eben diese aktuelle politische Programmatik zurückgeführt werden kann, dies würde eine Überpolitisierung des staatlichen Handelns darstellen. Umgekehrt könne das staatliche ökonomische Handeln nicht von der politischen Strategie getrennt gesehen oder dieses Handeln als von der Ökonomie bestimmt interpretiert werden, sondern dieses ist immer auch auf die Aufrechterhaltung der Hegemonie gerichtet, so dass sich das ökonomische Handeln des Staates auch als notwenige „Anpassung an die politische Strategie der hegemonialen Fraktion“ [ebd.] darstellt.

In diesem Zusammenhang sei die ideologische Funktion des Staates nicht seiner ökonomischen Funktion untergeordnet, sondern die ökonomischen Maßnahmen des Staates sind selbst „ideologisch“, indem sie sich in der Form des Technokratismus darstellen und die Ideologie des Wohlfahrtsstaates begründen. Daraus schließt Poulantzas, dass die Widersprüche innerhalb der staatlichen Struktur nicht nur zwischen der ideologisch-politischen und der ökonomischen Struktur zu suchen sind, sondern dass die ökonomischen Maßnahmen des Staates in sich selbst widersprüchlich sind. Indem der Staat einerseits den Notwendigkeiten der Kapitalreproduktion Rechnung tragen will, andererseits durch ökonomische Handlungen Kompromisse durchsetzen und die Hegemonie aufrecht erhalten muss, entwickele sich eine äußerst widersprüchliche Wirtschaftspolitik. [St, S. 155]

Aufgrund der ökonomischen Funktion des Staates, die sich zwangsläufig in spezifischen staatlichen Institutionen materialisieren, rückt Poulantzas von der Althusser'schen Konzeption von ISA und RSA tendenziell ab, es gibt in der Konzeption Poulantzas' neben diesen Apparaten (deren Existenz er keineswegs bestreitet) eine Anzahl staatlicher Apparate, die in erster Linie andere Funktionen als die Ausübung von Repression oder die Reproduktion der herrschenden Ideologie wahrnehmen: Die ökonomischen Staatsapparate (wenngleich auch die repressiven und ideologischen Staatsapparate eine ökonomische Funktion innehaben, so vor allem die Armee/Rüstungsproduktion). 
Die Reorganisation, die Ausweitung und die Konsolidierung dieser wirklich ökonomischen Staatsapparatur - also das Restrukturierungsprinzip des staatlichen Raums - lässt sich denn auch nur begreifen, wenn man mit einer analogischen Vorstellung bricht, die die Staatsapparate in einem in sich geschlossenen Feld differenziert. [St, S. 156]

Die Restrukturierung des staatlichen Apparats unter ökonomischen Gesichtspunkten wird nach Poulantzas anhand folgender Tendenzen sichtbar:

1. Die zunehmende Spezialisierung der ökonomischen staatlichen Apparate,

2. eine Spezialisierung nicht-ökonomischer Staatsapparate auf ökonomische Funktionen,

3. die auf ökonomische Ziele gerichtete horizontale „Vernetzung“ der ideologischen, politischen und ökonomischen Staatsapparate [ebd.].

Der auf ökonomische Funktionen spezialisierte Apparat ist nach Poulantzas zum einen vom Rhythmus der Kapitalakkumulation und -reproduktion am meisten betroffen, zum anderen von der jeweiligen Konjunkturpolitik der aktuellen Regierung am unabhängigsten; er folgt einer internen Logik, die in relativem Widerspruch zur (Staats-) Politik steht. Indem er sowohl mit den Widersprüchen des Blocks an der Macht als auch mit den Widersprüchen zwischen dem Block an der Macht und den beherrschten Massen verschränkt ist, „beweist er am deutlichsten die Kontinuität des Staates in diesen Widersprüchen“ [St, S. 157]. Der ökonomische Staatsapparat sei dabei der ,,privilegierte Sitz der monopolistischen Fraktion“" [ebd.], die innerhalb des Blocks an der Macht die Hegemonie inne habe. Da aber dem ökonomische Staatsapparat eine organische Funktion im Reproduktionsprozess des gesamten Kapitals zukomme, sind ebenso andere Fraktionen des Kapitals in ihm vertreten, wodurch sich Widersprüche im ökonomischen Staatsapparat als auch im Block an der Macht bereits abzeichnen. Wenn der ökonomische Staatsapparat aber nicht von den anderen Staatsapparaten getrennt gesehen werden könne, bedeute das in Bezug auf die Dominanz der ökonomischen Funktionen innerhalb des modernen Staates, dass diese Dominanz auch eine institutionelle Verschiebung und Transformation nach sich ziehe, sie verlaufe zuungunsten des Parlaments, der Parteien und anderer Institutionen der parlamentarischen Demokratie und stärke die Regierung und die administrativen Apparate ${ }^{184}$. Der ökonomische Staatsapparat

184 Siehe dazu den Abschnitt 2.6 
partizipiert also - und zwar vollständig - am gesamten politischen Mechanismus des Staates; er konstituiert ein politisches Dispositiv nicht nur weil er zugunsten der Kapitalakkumulation eingesetzt wird, sondern auch weil er in spezifischer Form die politischen Kompromisse und Konflikte ausdrückt, die innerhalb des Staates ausgefochten werden. [St, S. 157 f.]

Die Analyse des ökonomischen Staatsapparates darf nach Poulantzas aber nicht dazu verleiten, innerhalb dieses Apparates eine Trennung zwischen technokratisch-administrativen, politisch „,neutralen“ Apparate und politisch-ökonomischer Apparate anzunehmen, wie eine theoretische Trennung von Produktivkräften und Produktionsverhältnissen nahe legen könnte - also die Annahme, dass sich die Produktivkräfte (relativ) unabhängig von den Produktionsverhältnissen entwickeln könnten.

Wenn die Produktivkräfte eine eigene, nicht zu vernachlässigende Materialität besitzen, existieren sie doch immer nur verbunden mit bestimmten Produktionsverhältnissen und unter deren Primat. Der Klassenkampf findet immer schon im Zentrum des Arbeitsprozesses statt: Der Grundwiderspruch des Kapitalismus ist ein Klassenwiderspruch zwischen der ausbeutenden Klasse und den ausgebeuteten Klassen. Ökonomische Funktionen, die jeder Staat im Hinblick auf die „Produktion im allgemeinen“ erfüllen muss, gibt es nicht. Diese Funktionen werden immer schon im Klassenkampf eingesetzt und haben also politischen Charakter und Bedeutung. Der ökonomische Staatsapparat besitzt in seiner gesamten Konstitution politischen Charakter. [St, S. 158 f.]

b) Die bisher dargestellten theoretischen Ansätze haben nach Ansicht Poulantzas eher deskriptiven Charakter, er ist im Anschluss daran bemüht, die innere organische Verbindung der ökonomischen Funktionen des Staates herzuleiten. Im Zentrum steht für Poulantzas dabei der tendenzielle Fall der Profitrate $^{185}$, hierbei seien die (ökonomischen) Maßnahmen des Staates vor allem als Gegentendenzen zu verstehen, mit denen der Staat auf den tendenziellen Fall der Profitrate reagiere [St, S. 159] ${ }^{186}$. Dabei seien vor allem allem zwei Strategien des Staates auszumachen:

185 Poulantzas geht offensichtlich davon aus, dass die Marx'schen Untersuchungen zum tendenziellen Fall der Profitrate [vgl. dazu MEW Bd. 25, S. 221 ff.] weiterhin Gültigkeit haben. Hirsch stellt diesbezüglich fest, dass es durchaus (relativ kurze) historische Phasen gibt, in denen die Profitrate stabil bleibt oder steigt [Hirsch 1974, S. 104 ff.], allerdings scheint dies nur zu gelingen, wenn die gesellschaftlichen Verwertungsbedingungen des Kapitals (Stand der Klassenkämpfe, massive Rüstungsausgaben des Staates, Wiederaufbau infolge von Kriegen etc.) dafür geeignet sind, der „normale“ technologische Innovationszyklus selbst scheint den tendenziellen Fall der Profitrate nicht kompensieren zu können.

186 So auch Hirsch 1974. 
1. Die Entwertung bestimmter Teile des konstanten Kapitals,

2. Die Erhöhung des Exploitationsgrades durch Innovation und Qualifikation.

Nach Poulantzas kommt der zweiten Gegentendenz die Hauptrolle zu. Zwar sei es richtig, dass der Staat durch Subventionen, staatliche Investitionen usw. Produktionszweige, die negative Profitraten erwirtschaften, aufrecht erhalte, um so die Durchschnittsprofitrate, vor allem des Monopolkapitals, zu stärken. Allerdings seien diese Maßnahmen in erster Linie als Umschichtungen und Redistributionen des Mehrwerts zwischen Teilen des Kapitals zu bewerten [St, S. 160 f.]. Im Gegensatz dazu sei die zweite Gegentendenz, also die Erhöhung der Mehrwertrate und des Exploitationsgrades durch den Staat, die langfristig dominante Strategie und mit dem Klassenkampf in Beziehung stehende Tendenz, die in der Produktion eine Abkehr von der extensiven Ausbeutung der Arbeit (Konzentration auf die Produktion des absoluten Mehrwert) hin zu einer intensiven Ausbeutung durch technologische Innovationen (Konzentration auf die Produktion des relativen Mehrwert) bewirke ${ }^{187}$. Durch diese Verschiebung, die mit der zunehmenden Internationalisierung des Arbeitsprozesses zusammenfalle, würden sich dem Staat wiederum neue Aufgaben stellen, insbesondere hinsichtlich der erweiterten Reproduktion der Arbeitskraft. Diese Aufgaben würden beispielsweise folgende Bereiche betreffen:

1. Qualifikationsprozesse der Arbeitskraft, Schulwesen und Berufsausbildung,

2. wissenschaftliche Forschung,

3. industrielle Umstrukturierung,

4. Verkehrs-, Gesundheits- und Wohnungswesen,

5. kollektive Konsumtion [St, S. 162].

Dass die Maßnahmen des Staates in diesen heterogenen Bereichen auf die Intensivierung des Arbeitsprozesses, auf

die Erhöhung des Exploitationsgrades durch die erweiterte ReproduktionReglementierung der Arbeitskraft zielen, hat wichtige politische Konsequenzen. Dies erlaubt erstens, den direkten politischen Aspekt dieser Interventionen festzustellen. Zweitens lassen sich so ihre ideologischpolitischen Einsätze kennzeichnen. [ebd.]

187 Mandel stellt zur Frage der Technologie fest, dass der Glaube ,an die Allmacht der Technologie“ die für den Spätkapitalismus spezifische Ideologie sei, ,sie proklamiert die Fähigkeit der bestehenden Gesellschaftsordnung, ihre Krisenanfälligkeit allmählich zu beheben, ihre Widersprüche technisch zu lösen“ [Mandel 1974, S. 445]. 
Die Verschiebung des Produktionsprozesses hin zu einer Erhöhung des Exploitationsgrades bedeute aber nicht, dass die Aktivität des Staates bezüglich der Reproduktion der Arbeitskraft lediglich auf die Qualifikation derselben abzielt, sondern sie richte sich immer auf die gesellschaftliche Arbeitsteilung, d. h. sie ist auf die Veränderung der Produktionsverhältnisse zur Erhöhung des relativen Mehrwerts gerichtet.

Diese Maßnahmen machen aus dem Staat den direkten Drahtzieher der Kapitalkonzentration und Zentralisierung. Dieser Prozess ist selbstverständlich weder bloß technischer noch bloß juristischer Natur. Er umfasst vielmehr wichtige Veränderungen der Produktionsverhältnisse: differenzielle Verbindungen von Machtbefugnissen sowie Besitz- und ökonomischen Eigentumsgraden innerhalb der vom Kapital und seinen verschiedenen Trägern zugleich im nationalen und im Weltmaßstab eingenommen Stellung. [St, S. 163]

Die Veränderung der Produktionsverhältnisse beinhalte eine Umgestaltung/ Reorganisation des Arbeitsprozesses: die Schaffung neuer nationaler wie internationaler Produktionseinheiten, die einen ,integrierten Arbeits- und Produktionsprozess ermöglichen“ [ebd.]. Dieser integrierte Produktionsprozess beschleunige die technologische Innovation und ermöglicht die rasche Erhöhung der Produktivität.

Neben diesen allgemeinen Funktionen im Kontext der Produktionsverhältnisse lassen sich nach Poulantzas aber auch die spezifischen Funktionen des Staates im Bereich der Zirkulation und Konsumtion bestimmen. Wenn die Produktion gegenüber der Zirkulation determinierend ist und die Maßnahmen des Staates immer auf die Produktionsverhältnisse gerichtet sind, bedeute dies, dass das Handeln des Staates sich maßgeblich nicht auf individuelle Konsumtion oder auf Begrenzung/Koordination des Marktes richte. Entscheidend sei vielmehr seine Rolle bezüglich der kollektiven Konsumtion, denn durch die Eingriffe in Wohnungs-, Gesundheits-, Verkehrs- und Bildungswesen und deren öffentlicher Finanzierung werde eine Steigerung der Arbeitsproduktivität und damit verbunden eine Steigerung des relativen Mehrwerts erzielt [St, S. 164]. Diese Maßnahmen können wiederum nicht als technisch-administrative, als zu einer bestimmten Entwicklung der Produktivkräfte gehörige interpretiert werden, sondern es gelte, deren spezifisch politischen Charakter zu erfassen.

Selbstverständlich zwingt die Hegemonie des Monopolkapitals der Strategie des Staates eine bestimmte Richtung auf. Insofern diese Interventionen jedoch die Reproduktion der Gesamtheit der Arbeitskraft 
betreffen und auf eine strukturelle Reorganisation der Arbeitsprozesse verweisen, bewirken sie eine nachhaltige Reproduktion der kapitalistischen gesellschaftlichen Arbeitsteilung. Diese effektive VerwaltungReglementierung der Arbeitskraft, einschließlich der neuen Formen der disziplinarischen Normalisierung und der Unterordnung-Unterwerfung [...] unter die kapitalistischen politischen und ideologischen Verhältnisse, scheint in ihrem politischen Inhalt über die einfache monopolistische Hegemonie weit hinauszugehen und immanenter Bestandteil des Kerns der kapitalistischen Produktionsverhältnisse zu werden. [St, S. 165; Hervorhebung S.v.B.] $]^{188}$

c) Im weiteren stellt sich für Poulantzas die Frage, warum die jeweiligen ökonomischen Maßnahmen vom Staat und nicht vom Kapital selbst ausgeführt werden. Hierbei sei festzustellen, dass es prinzipiell keine ökonomische Funktion gebe, die nicht vom Staat wahrgenommen werden könne, vom Aufbau der Infrastruktur bis hin zu Organisation der Kapitalzentralisierung ${ }^{189}$. Die Geschichte dieser ökonomischen Maßnahmen des Staates ist

weder eine homogene Geschichte noch die lineare Geschichte eines Staates, der in sich nach und nach diese oder jene eigentlich ökonomischen Aktivitäten oder Bereiche summiert und sich aneignet: Sie ist eine Geschichte von Vorstößen und Rückzügen, die sich in den verschiedenen Formationen ungleich entwickelt. [St, S. 166]

Da Poulantzas als Theorierahmen den tendenziellen Fall der Profitrate gewählt hat, ergibt sich für ihn als Erklärung dieses Phänomens, dass die Bereiche, die vom Staat in seine ökonomischen Aktivitäten aufgenommen werden, für das private Kapital unrentabel (geworden) seien, also die Profitrate der jeweiligen Bereiche unterhalb der Durchschnittsprofitrate liege [ebd.] ${ }^{190}$. Andererseits beruhe der „Interventionismus“ aber auch auf einer politischen Komponente, da der Staat auch in Bereichen tätig ist, die für das Kapital sehr wohl rentabel $\operatorname{sind}^{191}$. Zum einen beträfe dieses Handeln ökonomische Felder, die für die allgemeine Reproduktion des Kapitals erforderlich seien (z. B. Forschung ${ }^{192}$,

188 Vgl. hierzu die Ausführungen in Tausend Plateaus zur Unterwerfung/Unterjochung [Deleuze/Guattari 1992, S. 633 ff.].

189 Wie der „Staatssozialismus“ gezeigt hat, kann auch der Staat, ironischerweise mit einer „marxistischen“ Ideologie versehen, auch die komplette Strukturierung der Gesellschaft in Klassen selbst hervorbringen.

190 So auch Hirsch 1974, S. 57.

191 Selbstverständlich ist auch die Aktivität in den unrentablen Bereichen (z. B. Sanierung defizitärer Unternehmen) selbst politisch.

192 Hirsch konstatiert ebenso, dass die ,systematische Erzeugung von Wissenschaft und Technologie zu einem wesentlichen Teil Funktionsbereich der staatlichen Administration“ sei [Hirsch 1974, S. 69]. Gerade durch diese Funktionszuweisung sollte aber auch klar sein, dass die Technologie selber politisch ist und dementsprechend nie klassenneutral, 
Kommunikation), die aber, in der Hand einzelner Fraktionen des Kapitals, Risiken sowohl für die Ökonomie im engeren Sinn als auch für die relative Stabilität des politischen Kompromissgleichgewichts im Block an der Macht bergen können. Die Durchführung dieser Funktionen durch den Staat würden also dem Allgemeininteresse der Bourgeoisie in ihrer Gesamtheit folgen [St, S. 167].

Diese Dispositionen des Staates reflektieren dabei selbst wiederum das politische Kräfteverhältnis (und die Widersprüche) im Block an der Macht, so dass die ökonomischen Maßnahmen vor allem der dort dominanten Fraktion, dem Monopolkapital, dienen würden [St, S. 167 f.]. Der politische Charakter der staatlichen Handlungen sei den (ökonomischen) Staatsfunktionen immanent; sowohl die erweiterten Reproduktion der Arbeitskraft als auch die Entwertung bestimmter Teile des Kapitals werde durch das politische Machtverhältnis im Block an der Macht bestimmt: wo die Entwertung bestimmten Kapitals nicht durch die Konkurrenz erzielt werde, nehme der Staat diese Funktion wahr; wenn der Konkurrenzkampf den Reproduktionsprozess des Kapitals selbst gefährdet sei, trete der Staat regulativ auf.

Die staatliche Ausarbeitung von Taktiken erlaubt dem Engagement des Staates eine gewisse politische Kampfesregulierung, (die jedoch immer relativ bleibt: Sie schafft ein instabiles Kompromissgleichgewicht). [St, S. 168]

Wenn also die Funktionen und Maßnahmen des Staates im wesentlichen durch die Hegemonie des Monopolkapitals innerhalb des Blocks an der Macht bestimmt werden, werden dem Staat dadurch Schranken des Handelns gesetzt, dass dieser Block an der Macht nicht widerspruchslos ist, sondern die Interessen der verschiedenen Kapitalfraktionen, die diesen Block bilden, auseinander fallen - der Staat ist folglich nicht vom Monopolkapital ,in Beschlag“ genommen worden [St, S. 168 f.].

Aber das (direkte oder indirekte) ökonomische Handeln des Staates sei natürlich nicht nur politisch im Hinblick auf das Kräfteverhältnis innerhalb des Blocks an der Macht, sondern ebenso in Bezug auf die beherrschten Massen. Zum einen sei das Handeln des Staates dann erforderlich, wenn „die Durch-

sondern als Produktivkraft immer klassenbezogen ist, in die Entwicklung von Technik (jeder Art) schreiben sich sich die Dispositive der Macht (Herrschaft, Kontrolle und Ausbeutung) ein. Das hat natürlich auch Folgen für die Subjektkonstitution, Technologien wie das Fließband oder das Internet ziehen die Maschen der Macht immer enger um die beherrschten Individuen. 
setzung des Ökonomischen den Rückgriff auf den Gebrauch organisierter Gewalt erfordert" [St, S. 169]. Zum zweiten sei das Handeln im Hinblick auf die Ideologie von Bedeutung. Da der Staat eine Ideologie materialisiere, nach der er selbst das „Allgemeinwohl“ repräsentiert, werde der reale Klasseninhalt seiner ökonomischen Handlungen verschleiert; diese ideologische Funktion verlaufe proportional zu dem steigendem Exploitationsgrad. Diese „Verschleierung“ in Form des Wohlfahrtsstaates sei aber keine Mystifizierung der bestehenden Verhältnisse oder ein Betrug der Massen:

Der Staat organisiert und reproduziert die Klassenhegemonie, indem er einen variablen Kompromissbereich zwischen herrschenden und beherrschten Klassen absteckt, und dabei den herrschenden Klassen häufig sogar gewisse kurzfristige materielle Opfer aufzwingt, um langfristig die Reproduktion ihrer Herrschaft zu sichern. [St, S. 170]

D. h. die sozialstaatlichen Funktionen des Staates sind nicht lediglich aus der Basis oder dem jeweils aktuellen Akkumulationsregime abzuleiten, sondern ebenso als Resultat von Klassenkämpfen oder als Maßnahmen des Staates zu begreifen, um diese Klassenkämpfe zu entschärfen (siehe vor allem die Bismarksche Sozialgesetzgebung). Aber auch hier gelte es, der Vorstellung des Staates als neutrales Instrument, dessen sich die verschiedenen Klassen bedienen, vorzubeugen. Die Dispositionen des Staates würden ,in the long run” grundsätzlich einer Strategie zugunsten der erweiterten Akkumulation des Kapitals folgen. Die Handlungen des Staates übernehmen diese Strategie, indem das politische Kräfteverhältnis und die potenziellen Widerstände berücksichtigt werden. Die politischen Erfolge der Massen wie eben die Sozialgesetzgebung sind somit vor allem Modifikationen der Strategie des Staates. Dass der Staat

bestimmte materielle Forderungen des Volkes aufgreift, die in dem Augenblick, in dem sie durchgesetzt werden, eine sehr weitgehende Bedeutung haben können [...], kann langfristig der Klassenhegemonie dienen. Diese „Errungenschaften des Volkes“ können bei einer Veränderung des Kräfteverhältnisses allmählich ihrer ursprünglichen Inhalte und Bedeutungen auf verdeckte und arglistige Weise beraubt werden. [St, S. 171]

Hiervon ausgehend kann nach Poulantzas der politische Inhalt der ökonomischen (wie auch der nicht explizit ökonomischen) Funktionen des Staates bestimmt werden: das Verwalten/Reproduzieren der Arbeitskraft und vor allem die Reproduktion der gesellschaftlichen Arbeitsteilung, „die Reproduktion der Arbeitskraft [ist] eine politische Strategie, bei der politisch-ideologische Ele- 
mente immer konstitutiv mitwirken“ [ebd.]. Diese Strategie schreibe sich auch in das Handeln des Wohlfahrtsstaates ein: die sozialen Netze würden nicht nur der Reproduktion der Arbeitskraft im engeren Sinn dienen, sondern sie seien ebenso die ,politisch-polizeiliche Kontrolle und Verwaltung dieser Arbeitskraft" [ebd.], die verschiedenen materiellen Erscheinungen der sozialstaatlichen Strategie (Sozialwohnung, freie Schulbildung usw.) seien ,politische Orte der juristisch-polizeilichen Kontrolle der Arbeitskraft"“ [ebd.].

Die Durchsetzung dieser Strategie gehe einher mit der Entwicklung der disziplinierenden Normalisierung, wobei die Repression aber keineswegs nur internalisiert werde, sondern um „feingesteuerte Regelkreise der sozialen Kon-

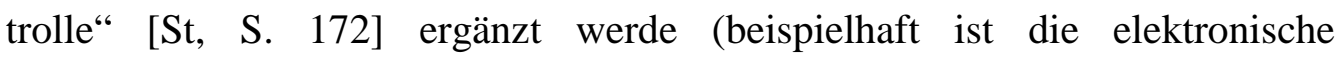
Nachrichtenverarbeitung und -verteilung zwischen den verschieden staatlichen Institutionen zu nennen). Dadurch vollziehe sich eine Verwischung der Grenze zwischen dem „Normalen“ und „Anormalen“ und es folge eine Verschiebung, innerhalb derer die repressive Aktion des Staates von der „Behandlung“ des pathologischen Einzelfalls hin zu einer beständigen Überwachung der gesamten Bevölkerung übergehe ${ }^{193}$ :

In gewisser Hinsicht wird jeder Bürger a priori verdächtig, denn er ist potenziell kriminell. Verdoppelt wird dieser Mechanismus durch die Unterstützung der Polizei durch die Bevölkerung: Durch eine Reihe fortwährender Zeugenaussagen und Denunzierungen (vgl. die diversen moralischen Nachforschungen, die der Sozialhilfe vorangehen) wird jeder Bürger seinerseits zum Überwacher und potenziellen Polizisten. [St, S. $172 \mathrm{f}.]^{194}$

Die Funktionen des Wohlfahrtsstaates seien aber nicht allein auf diese politisch-administrativen zu beschränken: Durch die Qualifizierung und Dequalifizierung von Arbeit vollziehe der Staat weiterhin die Trennung von manueller und intellektueller Arbeit und dränge damit auf eine verschärfte Trennung der gesellschaftlichen Klassen in Sub-Einheiten (Angestellte, Techniker usw.). Gleichzeitig werde die herrschende Ideologie durch den Wohlfahrtsstaat reproduziert, aber nicht nur innerhalb seiner „reinen“ ideologischen Staatsapparate, sondern ebenso habe seine Sozialpolitik eine ideologische Komponente, beispielsweise basiere die Arbeitslosenhilfe

$193 \mathrm{Zu}$ diesem Übergang sind die Arbeiten Foucaults beispielhaft (allerdings lokalisiert Foucault diesen Übergang historisch nicht erst im entwickelten kapitalistischen Staat, sondern weitaus früher, vgl. ÜuS und Foucault 1988).

194 Vgl. hierzu die Ausführungen Gramscis oben. 
unmittelbar auf der Reproduktion der Ideologie kapitalistischer Arbeit: Die Beschränkungen der Arbeitslosenhilfe entstammen nicht nur den ökonomischen Belangen des Kapitals. Sie darf den Empfängern keinesfalls den erniedrigenden und unwürdigen Charakter der Arbeitslosigkeit vergessen lassen. [St, S. 173]

Die neuen Techniken der Normalisierung und Disziplinierung, der Qualifizierung und Entwertung von Arbeit, der expliziten kapitalistischen Körperlichkeit und der Reproduktion der kapitalistischen Ideologie in allen gesellschaftlichen Bereichen verweisen somit auf eine generelle Transformation der kapitalistischen Gesellschaft,

nämlich auf die flexible und feingesteuerte Verbreitung disziplinierender Dispositive unter einer Bevölkerung, die dem Kapital massiv unterworfen ist [...]; die Transformationen der schulischen Prozesse der Ausbildung und die Öffnung/Permeabilität der Familie als Ort einer neuen Arbeitsqualifikation; der Bruch der Barrieren zwischen Normalität und Anormalität in einer Bevölkerung, die einer permanenten strukturellen Arbeitslosigkeit schutzlos ausgesetzt und also potenziell asozial ist; die Reproduktion der Spaltung von Autorität/Entscheidung und Ausführung in der erweiterten intellektuellen Arbeit [...]; schließlich die Ausweitung und Ausbreitung der Immigrantenarbeit auf alle industriellen Branchen und Sektoren, in denen sich entqualifizierte Arbeit konzentriert sowie die Einsetzung zweckdienlicher Kontroll- und Überwachungsnetze. [St, S. $174 \mathrm{f.}]$

d) Wenn auch der Staat vermehrt in die Ökonomie eingreift, gibt es nach Poulantzas doch eine strukturelle Grenze seines Eingreifens. Diese Grenze verschiebe sich zwar in den verschiedenen Phasen des Kapitalismus und in den verschiedenen kapitalistischen Staatsformen, sie sei aber grundsätzlich nicht vom Staat überschreitbar und trenne die Räume des Staates und der Ökonomie. Die Grenze werde in Abhängigkeit des Produktions-, Reproduktions- und Akkumulationsprozesses des Kapitals selbst reproduziert. Innerhalb dieses widersprüchlichen Prozesses wird der Handlungsspielraum des Staates definiert, der selbst durch diese Beschränkung nicht in der Lage ist, sein eigenes Handeln in der Ökonomie wirklich zu beherrschen - seine eigenen ökonomischen Handlungen würden vielmehr selbst zunehmend $\mathrm{zu}$ Ursachen von ökonomischen Krisen werden [St, S. 176].

Der Staat kann heute weder vor noch zurück, er kann sich vom zentralen Kern der Ökonomie nicht fern halten, er kann ihn aber auch nicht kontrollieren. Er muss gleichzeitig sowohl zu viel (Interventionen, die die Krise produzieren) und zu wenig tun (er kann an die tieferen Ursachen der Krise nicht herankommen). [...] Er ist also weniger ein allmächtiger 
Staat, als vielmehr ein Staat, der mit dem Rücken an der Wand und vor einem Abgrund steht. [ebd.]

Hierdurch ergeben sich weitere Schranken des staatlichen ökonomischen Handelns, die die Felder der Zirkulation, Distribution und Konsumtion betreffen. Da der Staat keinen Zugriff auf den harten Kern der kapitalistischen Produktionsverhältnisse hat, seien seine Maßnahmen auf diesen Feldern immer nur ein - von seiner hegemonialen Strategie abhängendes - „reaktives und punktuelles Zusammenbasteln von Maßnahmen gegenüber Bedingungen, die der vom Staat nicht zu beherrschende Verwertungsprozess des Kapitals bereits fixiert hat" [St, S. 177]. Demzufolge sei es auch unmöglich, innerhalb kapitalistischer Produktionsverhältnisse eine staatliche Planung im engeren Sinn durchzuführen, die Maßnahmen des Staates könnten allenfalls als grobe Orientierungslinien begriffen werden, die sich aus den gesellschaftlichen materiellen Ressourcen des Produktionsprozess und den Anforderungen des Akkumulationsprozesses ergeben ${ }^{195}$. Hierbei sind die finanziellen Ressourcen, die der Staat zu Verfügung hat, wiederum abhängig vom Akkumulationsprozess des Kapitals, so dass sich auch hier eine Grenze ergibt: der Staat kann über Steuern nur begrenzt auf das Profiteinkommen aus Kapital zugreifen, andernfalls würde er den Reproduktionsprozess des Kapitals selbst gefährden - der Staat ist in einer permanenten Steuerkrise. [St, S. 177 f.]

e) Die dargestellten theoretischen Positionen Poulantzas erfassen die ökonomischen Aspekte des fordistischen Staates der 70er Jahre in Westeuropa recht genau und kamen zum Teil zu gleichen Ergebnissen wie der sogenannte Neomarxismus in Deutschland. Aber auch für die Untersuchung der ökonomischen Funktionen des kapitalistischen Staates zu Beginn des 21. Jahrhunderts scheinen die theoretischen Annahmen durchaus noch leistungsfähig zu sein.

Poulantzas hat früh die Internationalisierung der kapitalistischen Produktionsweise erkannt [Poulantzas 1973b], ohne allerdings das aktuelle Ausmaß der Internationalisierung der Produktion, Zirkulation und Konsumtion vorher-

$195 \mathrm{Zu}$ einem ähnlichen Ergebnis kommt Hirsch: der bürgerliche Staat könne ,seinem wesentlichen Charakter nach nicht als Regulator des gesellschaftlichen Entwicklungsprozesses auftreten“, sondern müsse ,in seinen konkreten Funktionsbestimmungen als Reaktionsbildung in Bezug auf den fundamental krisenhaften Verlauf des ökonomischen und gesellschaftlichen Reproduktionsprozesses" begriffen werden [Hirsch 1974, S. 370]. 
sehen zu können. Diese Internationalisierung läßt sich vor allem auf folgende Faktoren zurückführen:

1. die Entwicklung in der Informationstechnologie (die noch längst nicht abgeschlossen ist), hat die technologischen Rahmenbedingungen für eine erhöhte nationale wie internationale Arbeitsteilung sowie erhebliche Potenziale zu Erhöhung der Mehrwertrate bereitgestellt,

2. der Untergang des Staatskapitalismus sowjetischen Typs hat zu Folge, dass politische Kompromisse wie der Korporatismus in Westeuropa in Frage gestellt werden und der Klassenkampf - zumindest von einer Seite aus wieder verschärft wird,

3. fallende Profitraten in den kapitalistischen Staaten hat den Wettbewerb sowie den Konkurrenzdruck zunehmend internationalisiert.

Die verschärfte nationale wie internationale Konkurrenz hat vor dem Hintergrund dieser technologischen und politischen Umwälzungen das Ergebnis, dass die Arbeitsteilung zunehmend internationalisiert wird. Ebenso treten die verschiedenen nationalen Produktionsstandorte in eine verschärfte Konkurrenz zueinander. Diese Konkurrenzsituation hat aufgrund der Logik der Kapitalverwertung bezüglich Produktion, Zirkulation und Konsumtion zahlreiche Folgen:

1. Die Trennung von manueller und geistiger Arbeit wird zunehmend internationalisiert: Die produktive Arbeit wird - soweit nicht schon erfolgt - von den kapitalistischen Zentren in diejenigen Teile der Peripherie verlagert, in denen eine optimierte Mehrwertrate erzielt werden kann. In den kapitalistischen Zentren verbleibt vor allem die unproduktive Arbeit (Dienstleistungssektor) sowie die produktive Arbeit der Lenkung und Kontrolle der internationalisierten Arbeitsprozesse; ehemalige Produktionszentren in den Metropolen werden deindustrialisiert. Das bedeutet auch, das in den Zentren die Arbeiterklasse (also die Gesamtheit der produktiven Arbeiter) tendenziell verschwindet und statt dessen die Klasse des ,,neuen Kleinbürgertums“ (vgl. Poulantzas 1975, 180 ff.) stetig wächst.

2. In den Zentren scheinen vor allem jene Zweige der Produktion eine relativ hohe Profitrate zu erwirtschaften, die eine vertiefte Anwendung von wissenschaftlichen oder ingenieurmäßigen Methoden realisieren können, hierbei scheinen vor allem Monopolunternehmen in der Lage $\mathrm{zu}$ sein, diese „Verwissenschaftlichung“ der Produktion zu leisten [Hirsch 1974, S. 174 
ff.]. Auch hier ist die Trennung von manueller und geistiger Arbeit internationalisiert, denn die Forschung und Entwicklung verbleibt in den Zentren.

3. Die Monopolisierungstendenz nimmt weiterhin $\mathrm{zu}$ und internationalisiert sich ebenso.

4. Die Konkurrenz der Standorte verschärft sich auch in den kapitalistischen Zentren selbst entlang des Gefälles der erzielbaren Mehrwertraten.

5. Das traditionelle Kompromissgleichgewicht in den jeweiligen nationalen Blöcken an der Macht wird in Frage gestellt, hier zeigt sich eine Verschiebung des Kräfteverhältnisses zugunsten der Fraktionen des international agierenden Kapitals und zum Nachteil des national operierenden Kapitals.

Die geschilderten Tendenzen erfordern in der Logik der kapitalistischen Produktionsweise aber auch eine drastische Rekonfiguration der politischen, ideologischen und ökonomischen Funktionen des kapitalistischen Staates. Bezüglich der eher ökonomisch orientierten Funktionen des Staates lassen sich dabei empirisch folgende Tendenzen feststellen:

1. Im Zuge der internationalen Konkurrenz haben sich drei ökonomische Zentren (Triade) gebildet, die im Falle der EU auch eine politische Konvergenz der beteiligten Staaten erzeugt: die EU unter Hegemonie Deutschlands, die NAFTA unter Hegemonie der USA und der japanische Wirtschaftraum. Hierbei ist $\mathrm{zu}$ konstatieren, dass die politischen Maßnahmen dieser Organisationen maßgeblich von ökonomischen Erwägungen geprägt sind, Beispiele im Falle der EU sind die Währungs- und Zinspolitik, Struktursteuerung, Preisstabilisierung durch Subventionen, Förderung von Forschung und Entwicklung ${ }^{196}$, regelmäßige Handelskriege mit den USA etc. Es könnte somit davon gesprochen werden, dass mit der Internationalisierung der Arbeitsprozesse eine Internationalisierung der ökonomischen Staatsapparte einhergeht.

2. Die intensive Abhängigkeit der Peripherie - die auch durch internationale Organisationen wie IWF, WTO etc. strukturell gefördert wird - ist von den kapitalistischen Zentren auch weiterhin durch den Einsatz von militärischer

196 So hatten die Ausgaben der EU für Landwirtschaft, F\&E und Strukturförderung im Jahre 1996 einen Anteil von 92\% an den gesamten Ausgaben der EU [EU o.J.]. 
Gewalt abgesichert ${ }^{197}$, wenngleich diese militärischen Operationen nun mit dem Verweis auf Durchsetzung von Menschenrechten ideologisch abgesichert werden ${ }^{198}$. Es ist in diesem Zusammenhang auch durchaus angebracht, die internationale politische und ökonomische Ordnung weiterhin als Imperialismus zu bezeichnen ${ }^{199}$.

3. Aus der verschärften Konkurrenz ergibt sich ebenso das Bestreben, in den Metropolen das bestehende Lohnniveau zu senken. Hier ist in Westeuropa der Staat der entscheidende Hebel, um neben dem noch mehr oder weniger korporatistisch konstituierten „ersten“ Arbeitsmarkt weitere Arbeitsmärkte $\mathrm{zu}$ installieren, welche weitgehend dereguliert sind ${ }^{200}$.

4. Durch die internationale wie nationale Konkurrenz der Produktionsstandorte werden Unternehmen mit hohen direkten und indirekten Subventionen (z. B. Beihilfen, Erlass von Gewerbesteuern) beworben.

5. Aufgrund des Drucks des Kapitals, immer neue Segmente in den Bereich der Kapitalverwertung zu ziehen, werden vom Staat (auch durch permanente Steuerkrisen begünstigt) immer mehr ehemals hoheitliche Aufgaben (insb. Infrastruktur) privatisiert.

197 Die NATO formuliert in bemerkenswerter Deutlichkeit in ihrer Erklärung vom 11.08.1991: "Die Sicherheit des Bündnisses muss jedoch auch den globalen Kontext berücksichtigen. Sicherheitsinteressen des Bündnisses können von anderen Risiken berührt werden, einschließlich der Verbreitung von Massenvernichtungswaffen, der Unterbrechung der Zufuhr lebenswichtiger Ressourcen sowie von Terror- und Sabotageakten“".

198 Da im aktuellen politischen Diskurs „Menschenrechte“ und „Rechtsstaatlichkeit“ synonym mit „Zivilisation“" verwendet wird, knüpft diese ideologische Absicherung bizarrerweise unmittelbar an Legitimationsideologien des Kolonialismus an.

199 So auch Hirsch 2001a.

200 Vor diesem Hintergrund könnte als zweiter Arbeitsmarkt vor allem jener Sektor bezeichnet werden, der aus nichtsozialversicherungspflichtigen Beschäftigten besteht (gering Verdienende und Scheinselbständige). Als dritter Sektor könnte jener Sektor bezeichnet werden, der tendenziell eine Form von Zwangsarbeit (gesetzliche Verpflichtung zur Arbeit bei unterdurchschnittlichen Löhnen) darstellt, z.B. Zivildienst; die Diskussion von Zwangsverpflichtungen von Sozialhilfeempfängern zur Lohnarbeit geht in der BRD in diese Richtung. Schließlich ließe sich noch ein vierter Markt identifizieren, der in einer rechtlichen Grauzone angesiedelt ist (z.B. Sexarbeit) oder ganz kriminalisiert wurde (Schwarzarbeit). Die Senkung des Lohnniveaus erfolgt in der BRD aber auch über die sogenannten Lohnnebenkosten, also über die Sozialversicherungssysteme: während die diesbezüglichen Beiträge für Arbeitgeber und Lohnempfänger gesenkt werden, werden selbstverständlich auch die Leistungen der Sozialversicherungen gekürzt. Um das ursprüngliche Niveau der Versicherungsleistungen zu halten, muss nun einseitig der Lohnempfänger die Differenz über Zusatzversicherungen abdecken. Auch wenn hierbei staatliche Hilfen geleistet werden, liegt immer noch eine Senkung des Lohnniveaus vor. Das hier ein Verteilungskampf zwischen Klassen vorliegt, läßt sich in diesem Zusammenhang auch daran belegen, dass sich der Staat vor allem aus Verbrauchsteuern und Steuern aus Lohneinkommen finanziert: die genannten Beihilfen werden so innerhalb einer Klasse umverteilt 
6. In das Zentrum der Kapitalverwertung rückt zunehmend die Erhöhung der relativen Mehrwertrate; in der Folge wird die gesamte wissenschaftliche Produktion unter den Anforderungen der Ökonomie (re-) organisiert ${ }^{201}$ und so z. B. die Universitäten zu Outsourcing- und Ausbildungsbetrieben umstrukturiert, diese produzieren in der Folge vor allem „operatives Wissen“. Jene wissenschaftliche Produktion, die sich vor diesem Hintergrund (oder dem der politisch-ideologischen Funktion des „Social Engeneering“) nicht legitimieren kann, wird faktisch „stillgelegt“ und das durch das GG garantierte Recht auf Freiheit der Wissenschaft auf kaltem Wege abgeschafft. Ebenso werden in der BRD im Zusammenhang mit modernen Technologien (Bio- und Informationstechnologie) zahlreiche andere Grundrechte (z. B. Menschenwürde, Recht auf informelle Selbstbestimmung) auf dem Prüfstein der Ökonomie seziert.

7. Schließlich übt der Staat aber auch weiterhin die ,traditionellen“ ökonomischen Funktionen aus, insbesondere Infrastrukturpolitik, Steuerung von Migrationsbewegungen etc.

Insgesamt läßt sich diese Rekonfiguration des modernen kapitalistischen Staates bezüglich der historischen Einordnung der aktuellen konkreten kapitalistischen Gesellschaftsformation nutzen: das Kriterium für eine solche Differenzierung hat Poulantzas bereits angedeutet, sie erfolgt nicht an der Art der Produktion/„Praxis“ („Industrieproduktion“, „Dienstleistungsgesellschaft“, „Informationsgesellschaft“ etc.) sondern muss auf die Natur der Mehrwertproduktion und der Reproduktion der Arbeitskraft abzielen und hierbei den Status des Klassenkampfs berücksichtigen. Stand im „Manchester-Kapitalismus“ tendenziell die Erhöhung des absoluten Mehrwerts und im Taylorismus/ Fordismus tendenziell die Erhöhung des relativen Mehrwerts (jeweils bei einfacher Reproduktion der Arbeitskraft und im Falle des Fordismus kombiniert mit durch den Klassenkampf erzwungenen Korporatismus), ist für das derzeitige Stadium moderner kapitalistischer Gesellschaftsformationen die erhöhte Konzentration auf die Erhöhung des relativen Mehrwerts mit hoher internationaler Arbeitsteilung und erweiterter Reproduktion der Arbeitskraft

201 Auch weiterhin kann nicht von einer „Wissenschaft als Produktivkraft“ gesprochen werden, Wissenschaft greift immer nur als ,technologische Anwendung“ (Marx) in die Produktion ein, indem sie sich mit den Produktionsfaktoren (Arbeitskraft, Produktionsmittel) vereinigt [Poulantzas 1975, S. 121]. 
bei gleichzeitiger Aufkündigung des Korporatismus kennzeichnend. Hierbei reduziert sich der Stellenwert der staatlichen Funktionen bezüglich der kollektiven Konsumtion zugunsten der erweiterten Reproduktion der Arbeitskraft, dies erfolgt hinsichtlich der Ausbildung (beständiger Ausbau der wissenschaftlichen Produktion) sowie der Kontrolle und Verwaltung der Arbeitskraft.

„Globalisierung“ und „Neoliberalismus“, begriffen als Strategien, mit denen die Krise des Fordismus überwunden werden soll, haben in dem Sinne tatsächlich eine Liberalisierung bezüglich der ökonomischen Funktionen des Staates zur Folge, dass staatliche Betriebe verkauft, Handel und Kapitalverkehr vereinfacht werden usw. Gleichzeitig scheint aber die „Verzahnung“ von ökonomischer und politischer Struktur immer enger zu werden, die Widersprüche zwischen den kapitalistischen Fraktionen des Blocks an der Macht werden sowohl sichtbarer als auch eklatanter. „Neoliberalismus“ ist somit kein homogenes ökonomisches oder politisches Programm, sondern die widersprüchliche Forderung, dass sich der Staat aus der Ökonomie „,heraushalten“ aber gleichzeitig alle Felder des staatlichen Handelns unter die Dispositive der Ökonomie unterordnen soll. Der proklamierte „,schlanke Staat“ ist zwar in dem Sinne „schlank“, dass er zunehmend seine wohlfahrtsstaatlichen Funktionen reduziert; im Gegenzug aber werden aber seine auf die Kontrolle der eigenen Bevölkerung ausgerichteten repressiven und ideologischen Organe ausgebaut und die Kapitalisierung aller gesellschaftlichen Bereiche weiter vorangetrieben [vgl. Hirsch 1998]. In der Folge der geschilderten Tendenzen wird sich (auch in den kapitalistischen Metropolen) eine zunehmende Differenzierung der sozialen Verhältnisse ergeben und entsprechende soziale Kolateralschäden mit sich bringen. 


\subsection{Der moderne Staat - Autoritärer Etatismus}

Das wahre Objekt der Polizei wird am Ende des 18. Jahrhunderts die Bevölkerung. Sie übt Herrschaft über Lebewesen als Lebewesen aus, und ihre Politik ist deshalb Biopolitik. Da die Bevölkerung nicht mehr ist als das, worum sich der Staat seiner selbst willen kümmert, hat der Staat natürlich das Recht, diese Bevölkerung, falls nötig, auch abzuschlachten.

Michel Foucault

\subsubsection{Autoritärer Etatismus, Totalitarismus, Faschismus}

a) Poulantzas bringt den modernen kapitalistischen Staat mit dem Totalitarismus in Verbindung, setzt die beiden Begriffe aber nicht gleich, sondern begrenzt den Begriff des Totalitarismus, um nicht (wie beispielsweise Maoisten in den 70er Jahren) die bürgerlich-parlamentarische Staatsform mit dem Faschismus gleichzusetzen. Die moderne bürgerlich-parlamentarische Staatsform bezeichnet Poulantzas als autoritären Etatismus, dieser zeichne sich dadurch aus, das einhergehend mit dem zunehmenden Eingreifen des Staates in alle gesellschaftlichen Bereiche die formalen demokratischen Rechte der Individuen als auch die demokratischen politischen Institutionen zusehends eingeschränkt und beschnitten werden [St, S. 185 f.]. Wie der liberale Staat offensichtlich den Produktionsverhältnissen und der Arbeitsteilung des Konkurrenzkapitalismus und der Interventionsstaat den Produktionsverhältnissen des Imperialismus und Monopolkapitalismus „entsprochen“ habe, scheine der moderne Etatismus wiederum auf massive strukturelle Verschiebungen in den Produktionsverhältnissen, der gesellschaftlichen Arbeitsteilung und der Arbeitsprozesse - national wie international - hinzudeuten. Ebenso verweise das Entstehen des autoritären Etatismus auf die weltweit stattfindenden Transformationen in den Klassen und Klassenkämpfen. Das bedeute aber nicht, diese Staatsform als bloßes „Oberflächenphänomen“ zu begreifen, das sich aus einer kurzfristigen politischen Konstellation ergebe, sondern es sei zu vermuten, dass die bisher gekannten politischen Formen des Repräsentativstaates offensichtlich überholt seien [St, S. 186 f.]. Dies sei darauf zurückzuführen, dass der autoritäre Etatismus sowohl mit einer politischen Krise als auch mit einer Krise des Staates in Zusammenhang stehe. Die sich entwickelnde 
Staatsform sei weder als moderner totalitärer Staat zu bezeichnen, der durch einen manipulativen Kapitalismus die Klassenkämpfe durch Integration „stillgelegt" hätte, noch, wie in funktionalistischen oder systemtheoretischen Ansätzen, als selbstregulierendes System, in dem ebenso die Klassenkämpfe verschwunden seien - genauer: in diesen Theorien politische Krisen überhaupt undenkbar seien ${ }^{202}$. Die politische Krise wie die Krise des Staates hätten nicht eine unmittelbare Stärkung des Staates zur Folge, sondern die Auswirkungen auf die Stärke des Staates seien durchaus ambivalent; der Staat sei, „obwohl sein autoritärer Etatismus erschreckend real ist, ein Koloss auf tönernen Füßen, der sich bei seiner Flucht auf schwankendem Boden bewegt“" [St, S. 187].

Die politische Krise, die die entwickelten kapitalistischen Länder erfasst habe, sei aber nicht auf eine ökonomische Krise reduzierbar, ebenso wenig könne die Krise des Staates auf die politische Krise reduziert werden, denn gerade der kapitalistische Staat zeichne sich dadurch aus, politische Krisen „managen“ zu können, so dass diese Krisen nicht zu politischen Staatskrisen (sprich: revolutionären Situationen) wachsen würden. Weiterhin sei für diesen Staat charakteristisch, dass diese Krisen beständig in ihm anwesend seien und zu seinen generischen Elementen gehören würden (ebenso wie die ökonomische Krise generisch zur Ökonomie gehört). Die politische Krise sei dabei mit der ökonomischen Krise verbunden, die Häufung der generischen Elemente sei ein strukturelles Merkmal des Staates, „der autoritäre Etatismus scheint zugleich ein Resultat des Anwachsens dieser Krisenelemente, als auch eine Antwort darauf zu sein“ [St, S. 188 f.].

Die politische Krise, die sich in einer Staatskrise niederschlägt, könne aber nicht a priori mit einem Faschisierungsprozess gleichgesetzt werden.

202 Sicherlich gibt es zwischen dem strukturalistischen Marxismus und der Systemtheorie Ähnlichkeiten, insbesondere in der Annahme der Gliederung der Gesellschaft in verschiedene Instanzen (Subsysteme) und der Determinierung dieser Instanzen untereinander. Allerdings hat Poulantzas darauf hingewiesen, dass in der Systemtheorie (insbesondere in der Konzeptionen Luhmanns und Parsons) Widerspruch in starkem Sinn (als selbstnegatorische Tendenz des gesamten Systems) nicht denkbar ist. Die Abgrenzung von (strukturalistischem) Marxismus und Systemtheorie kann in diesem Zusammenhang erweitert werden: für eine marxistische Theorie der kapitalistischen Gesellschaft sind bestimmte Widersprüche für diese Gesellschaft konstitutiv, die Gesellschaft befindet sich daher immer in einer potenziell krisenhaften Situation. Ebenso hat Offe angemerkt, dass bei Luhmann der Begriff der Herrschaft überhaupt nicht vorkommen kann. Schließlich ist auch anzumerken, dass das Konzept Luhmanns wiederum monistisch aufgebaut ist, indem ein „Prinzip“ (Kommunikation) herangezogen wird, um das theoretische Objekt „Gesellschaft" zu konstituieren. Dadurch ist Luhmann gezwungen, die Begrifflichkeiten so auszuweiten (vgl. Offe 1973, S. 82), dass sie schließlich alles beschreibt. 
Sicherlich seien die Grundzüge des Totalitarismus in den kapitalistischen Produktionsverhältnissen zu suchen (vgl. dazu oben die Ausführungen zur Individualisierung und Gesetz), diese Elemente würden sich aber nicht expressiv entfalten, um sich „den Weg zu ihrer endlichen Verwirklichung im universellen Totalitarismus [zu] bahnen“" [St, S. 189], das Entstehen einer totalitären Staatsform sei immer auch mit den konkreten Klassenbeziehungen verbunden ${ }^{203}$. Aus diesem Grunde könne auch der bürgerliche „Ausnahmestaat“ - der bonapartistische, faschistische oder militärdiktatorische Staat - nicht als für eine bestimmte kapitalistische Phase notwendige Staatsform anerkannt werden ${ }^{204}$. Der Ausnahmestaat erscheine nur, wenn ein spezielle Krise vorliegt: eine Krise, die den Staat durch den Bruch ,mit den regulären Formen der Reproduktion der bürgerlichen politischen Herrschaft“ zu überwinden versucht [St, S. 190].

Von den genannten bürgerlichen Ausnahmestaaten sei der autoritäre Etatismus zu unterscheiden, denn ist die ihm eigene politische Krise qualitativ verschieden, er sei weiterhin ,eine 'demokratische' Form der bürgerlichen Republik“ [St, S. 191]. Im Gegensatz zum faschistischen Staat, der immer einen echten Bruch innerhalb des Staates impliziere und auf einer historischen Niederlage der Arbeiterklasse basiere ${ }^{205}$, existiere bei der Durchsetzung des autoritären Etatismus eine solche Niederlage nicht. Dennoch sei auch das Gegenüberstellen „Liberaler Staat“ - „Ausnahmestaat“ nicht aufrechtzuerhalten. Entgegen den Apologeten des „liberalen“ Staates insistiert Poulantzas auf die Gemeinsamkeiten der bürgerlichen Demokratie/des autoritären Etatismus und dem Totalitarismus. Hierbei sei insbesondere festzuhalten, dass beide Staatsformen zu der selben Phase der kapitalistischen Entwicklung gehören würden und jede kapitalistische demokratische Staatsform totalitäre Tendenzen enthalte [St, S. 191]. Ein Merkmal des autoritären Etatismus sei, dass sich

203 Bei allen Vorbehalten gegenüber sogenannter Totalitarismustheorien: werden die Staaten des ehemaligen „realexistierenden Sozialismus“ als genealogisch mit dem Kapitalismus verbunden eingeordnet (Trennung in Klassen, tayloristische Produktionsorganisation etc.), können so immerhin die „totalitären“ Staatsformen auf einer theoretischen Basis analysiert werden, die nicht auf einem Merkmalskatalog [Friedrich 1957] oder dem Vergleich von Opferzahlen (so z. B. die „,neuen Philosophen“ in Frankreich, vgl. Courtois/Werth/Panne 1999) beruht.

204 Zu Analyse des „Ausnahmestaates“vgl. Poulantzas 1973d sowie Poulantzas 1977.

205 Der Faschismus sei folglich nicht als Reaktion auf eine Zunahme der Volksbewegungen zu begreifen (wie im Marxismus-Leninismus oft behauptet), sondern sei im Gegenteil Resultat des Scheiterns dieser Bewegungen [St, S. 191]. 
angesichts der Klassenkämpfe ein „,institutionelles Präventiv-Dispositiv“ [St, S. 192] aufbaue, ein „Arsenal“, das „nicht immer an vorderster Front der Machtausübung eingesetzt" werde, aber ständig für den Faschisierungsprozess bereitstehen würde [ebd.]. Denn, anders als bei den historischen Faschismen, die den Staat ,auf kaltem Wege“ übernommen hätten, würde ein neuer Faschismus in den westlichen Staaten aus dem Staat selbst heraus entstehen, er wäre ein „Bruch im Inneren des Staates“ entlang von Nahtlinien, „die in seiner gegenwärtigen Konfiguration längst vorgezeichnet sind“" [ebd.].

Der autoritäre Etatismus sei als Staatsform des kapitalistischen Systems natürlich auch nur eine Scheinlösung für die Widersprüche bürgerlicher Herrschaft und kapitalistischer Produktion ${ }^{206}$, den dieser sei ebenso wenig in der Lage, die Widersprüche in der kapitalistischen Gesellschaft zu lösen. Dies zeige sich beispielsweise anhand der Rolle, die der Staat in der Ökonomie zunehmend ausübe. Hierbei seien die Handlungen des Staates zwar Antworten auf bestimmte ökonomische Krisen, zugleich selbst aber ursächlich für weitere Krisen. Das Eingreifen des Staates zugunsten des Kapitals würde dabei aber, insbesondere in der Sozialpolitik, zunehmend ein „,beachtliches Legitimationsdefizit gegenüber den Volksmassen“ [St, S. 195] erkennen lassen, dies könne zu ideologischen Krisen führen, die, soweit sie sich in der Politik als Regionalismus oder Partikularismus äußern, selbst die Einheit des bürgerlichen Staates in Frage stellen können [ebd.].

\subsubsection{Autoritärer Etatismus und Bürokratie}

Die institutionellen Transformationen innerhalb des modernen westlichen Staates führen nach Poulantzas dazu, dass, einhergehend mit dem Abbau der demokratischen Rechte und der Einschränkung der demokratischen Institutionen zugunsten der Exekutive, sich zunehmend eine vom Parlament entkoppelte Staatsbürokratie und -verwaltung entwickelt. Aufgrund der engen Verflechtung

206 Mandel konstatiert ebenso die „Verselbständigung des bürgerlichen Staates“ aufgrund der „erhöhten Schwierigkeit reibungsloser Kapitalverwertung“ [Mandel 1974, S. 435]. Mandel überschätzt aber - nicht nur an dieser Stelle - den im Kapitalismus herrschenden „ökonomischen Automatismus“, der die Reproduktion der Gesellschaft aufrecht erhalte: dieser Automatismus ist nur in der historisch relativ kurzen Epoche des Manchester-Kapitalismus und dem ,laisez-faire“ Staat dominierend, in allen anderen Phasen des Kapitalismus ist die Rolle des Staates zur Aufrechterhaltung der Kapitalakkumulation bedeutender. 
des Staates mit der Ökonomie erreiche dies eine neue Qualität: ist der liberale Staat gekennzeichnet durch „die Kontrolle der Regierung und der Verwaltung“, ein „normative[s] System, das durch die öffentliche Meinung legitimiert wurde“, wird dieses System durch die ,spektakuläre ökonomische Intervention“ des Staates in Frage gestellt ${ }^{207}$ [St, S. 200].

Hierbei sei zum einen festzustellen, dass die Funktion des Parlaments als Gesetzgeber massiv eingeschränkt werde. Dies zum einen dadurch, dass die erlassenen Gesetze faktisch erst in Kraft treten, wenn sie einem „Konkretisierungs- und Spezifizierungsprozess" in der Verwaltung unterworfen werden, also zahlreiche Durchführungsbestimmungen, Verordnungen etc. erlassen werden [ebd.]. Zum anderen würde sich die Gesetze nicht mehr in ein dem parlamentarischen Systems entsprechendes Raster, sondern in ein Raster der „konkreten und kurzfristigen Wirtschaftspolitik“ einschreiben, die im Verwaltungsapparat verkörpert sei [St, S. 200 f.]. Dies führe auch zu neuen Formen der politischen Herrschaft und der Machtausübung,

die von Transformationen in der Verwaltung-Reproduktion der Arbeitskraft abhängen. Die durch allgemeine und universale Normen organisierte soziale Kontrolle [...] verbindet sich mit einer individualisierten Reglementierung, die der „Mentalität“ (der angeblichen Intention) eines jeden Teils des sozialen Körpers nachgebildet ist, der global als verdächtig und potenziell schuldig angesehen wird. Die allgemeine Einschliessung der ,außerhalb des Gesetzes Stehenden“ in Konzentrationslagern (Gefängnisse, Heime usw.) [...] verbindet sich mit dem Durchkämmen der Bevölkerung durch vielfältige und breitgestreute Kreise innerhalb des sozialen Rasters und durch polizeilich-administrative Prozeduren, die auf die Besonderheiten jeder Art von Verdächtigen abgestimmt sind. [St, S. 201]

Die zunehmenden Bedeutung der Verwaltung/Exekutive und die Beschränkung des Parlaments geht nach Poulantzas mit einem Verfall des Gesetzes einher. Dieser „Rückzug des Gesetzes“ [ebd.] sei allerdings nicht unmittelbar auf die ökonomischen Funktionen des Staates zurückzuführen, sondern verweise auf die Kräfteverhältnisse des Blocks an der Macht (und damit auf die hegemoniale Rolle des Monopolkapitals), stehen also in Verbindung mit den Interessen der

207 Die im folgenden dargestellten zuungunsten des Parlaments verlaufenden Transformationen konstatiert zum Teil - wenn auch zwanzig Jahre nach Poulantzas - Ralf Dahrendorf; dieser weist zurecht darauf hin, dass diese Transformationen durch die Gründung und den Ausbau der EU noch beschleunigt werden [Dahrendorf 1999]. Dass diese Transformationen aber auch mit Veränderungen im kapitalistischen Verwertungsprozess zusammenhängen, bleibt bei ihm aber weitgehend unberücksichtigt. 
am Block an der Macht beteiligten Fraktionen. Das instabile Kompromißgleichgewicht innerhalb des Blocks an der Macht als auch bezüglich der beherrschten Massen sei bisher innerhalb der Verwaltung mit Hilfe der Parteien organisiert worden, die Parteien hätten dabei ,als die entscheidenden Vektoren der verschiedenen sozio-ökonomischen Interessen“ agiert [St, S. 203]. Das Zentrum der politischen Prozesse sei somit in den Verwaltungen zu suchen gewesen, den Parlamenten käme immerhin die Funktion der Kontrolle zu und hätte entscheidende Bedeutung in den Legitimationsprozeduren inne gehabt.

Diese Konfiguration werde aber zunehmend dahingehend modifiziert, dass die Exekutive und die Verwaltung die Organisation und Leitung des Staates durchführe und dabei die Aufgabe der ,langfristigen Ausarbeitung des politischen Allgemeininteresses dieses Blocks und der Reproduktion der Hegemonie“ übernehme ${ }^{208}$. Ebenso konzentriere sich in Exekutive und Verwaltung die „Legitimation des Staates gegenüber den beherrschten Klassen“ [ebd.].

Die de jure und vor allem de facto stattfindende massive Verschiebung der Regierungsverantwortlichkeit vom Parlament auf die Spitzen der Exekutive führt zur entscheidenden Einschränkung der parlamentarischen Macht gegenüber der Verwaltung, zur Autonomisierung der Regierung gegenüber dem Parlament und zum wachsenden Abstand der Verwaltung gegenüber der Volksvertretung. [St, S. 204]

Die scheinbare Lösung der Bindung von Regierung und Verwaltung, die scheinbare Autonomie der Verwaltungsbehörden könne nicht darauf zurückgeführt werden, dass Widersprüche zwischen Exekutive und Verwaltung existieren würden, die Widersprüche würden vielmehr quer durch die Verwaltung selbst laufen und das politische System nicht trennen, „sondern organischer Teil der Entscheidungsprozesse“" sein [ebd.],

die Konflikte zwischen der Regierung und der Verwaltung zeugen häufig von Widerständen, die mit der Struktur des Staatsapparats und der bürokratischen Organisation zusammenhängen; Widerstände, die sich auch in der Unbeweglichkeit dieses Apparats gegenüber der Bourgeoisie selbst zeigen. [St, S. 205]

Das Auftreten von Widerständen in der Verwaltung bedeute auch, dass die Spitzen der Exekutive die politische Kontrolle über die Verwaltung erlangen

208 So stellt auch Mandel fest, dass die politische Herrschaft zunehmend in den Spitzen der Verwaltung zu verorten sei [Mandel, 1974, S. 435], Beamtentum und Gewaltenteilung im bürgerlichen Staat seien schlechthin notwendig, um Formen der direkten Demokratie, also direkte Machtausübung durch die beherrschten Massen, zu verhindern [ebd., S. 443]. 
müssen. Die sei auch deshalb notwendig, da die Staatsbürokratie nicht nur Ort der Staatspolitik sei, sondern ,zum prinzipiellen Akteur der Ausarbeitung der staatlichen Politik“ mutiere $[\text { St, S. 206 }]^{209}$. D. h. für Poulantzas, dass die verschiedenen ökonomischen Interessen in den Verwaltungen präsent sind und in eine Hegemoniepolitik übersetzt werden und diese vollzogen wird - die monopolistische Politik werde somit außerhalb des Parlaments definiert und realisiert. Die sich in den Verwaltung bildenden politischen Zentren würden dabei den monopolistischen Dispositiven folgen, die unter Parolen wie ,technologischen Fortschritt“, „industrielle Erfordernisse“ diese Dispositive als ,allgemeine und nationale Interessen“ [St, S. 207] definieren, die Zentren somit eine politisch-ideologische Rolle in der Organisation des Monopolkapitals übernehmen, sie seien ,strukturell als Netzwerke der spezifischen Präsenz hegemonialer Interessen innerhalb des Staates organisiert“ [ebd.]. Dabei sei zu berücksichtigen, dass auch die anderen Fraktionen des Blocks an der Macht ihre „Brückenköpfe und Stützpunkte innerhalb der Verwaltung haben“ [ebd.], ebenso seien die Interessen des Volkes durch die „reformistischen gewerkschaftlichen Vertretung[en]“ präsent; die Gewerkschaften seien „unmittelbar in die Verwaltungsdispositive eingeflochten“ [ebd.], womit die „Integrierung der politischen Richtung dieser Gewerkschaften [...], ihre Quasi-Assimilierung in die institutionelle Materialität des administrativen Dispositivs“ verbunden sei [ebd.]. Indem sich so die wirklichen Orte der politischen Entscheidungen in die Verwaltung verlagern und gleichzeitig sich die Verwaltung zunehmend der Kontrolle der Parlamente entziehe, werde die Politik des Staates „unter dem Siegel des zur permanenten Staatsräson erhobenen Geheimnis ausgearbeitet“ [ebd.], das Öffentlichkeitsprinzip somit strukturell zugunsten der Bürokratie ausgehebelt. Mit der Ausschaltung des Öffentlichkeitsprinzips gehe eine zunehmende Zentralisierung einher, dies sei schon im materiellen Aufbau des Verwaltungsapparats tendenziell angelegt.

Die „unaufhaltsame Verschiebung des Schwerkraftzentrums auf die Staatsbürokratie“ [St, S. 208] bedeute aber auch eine steigende Einschränkung

$209 \mathrm{Zu}$ einem ganz ähnlichen Ergebnis kommt Offe: „Das gemeinsame Interesse der herrschenden Klasse kommt am genauesten in legislatorischen und administrativen Strategien des Staatsapparates zum Ausdruck, die nicht von artikulierten Interessen, 'von außen' also, in die Wege geleitet werde, sondern den eigenen Routinen und Formalstrukturen der staatlichen Organisation entspringen“" [Offe 1975, S. 72]. 
der politischen Freiheiten sowie die Aufhebung der ,im übrigen immer schon fiktiven Gewaltenteilung des bürgerlichen Staates“ [St, S. 209]. Anstelle der Aufteilung der politischen Macht auf verschiedene staatliche Orte trete die „Konzentration der realen Macht in immer eingeschränktere Dispositiven und $\mathrm{zu}$ ihrer tendenziellen Polarisierung auf die Spitzen der Regierung und Verwaltung“" [ebd.]. Poulantzas schränkt ein, dass dieser Prozess immer nur tendenziell vorhanden ist, denn der Staat sei nicht in den Händen des Monopolkapitals, sondern die Widersprüche innerhalb des Blocks an der Macht, die sich durch diesen Prozess noch verschärfen, sind beständig auch in der Materialität des Staates anwesend, der Prozess erzeuge keine echte Homogenisierung des Staates, „sondern ist dessen Antwort auf das Anwachsen seiner inneren Widersprüche“ [St, S. 210]. Die Komplexität des Prozesses,

die Widersprüche zwischen dem Monopolkapital und den anderen Fraktionen des Kapitals und die Widersprüche zwischen dem Blocks an der Macht und den Volksmassen drücken sich auch im inneren des Staates, in seiner Zentralität und seinen Spitzen aus. Diese Widersprüche durchziehen zwangsläufig den Fokus des Staates, den obersten Dienstherren des Exekutive: Es gibt nicht einen Präsidenten, sondern mehrere Präsidenten in einem. Sein zögerndes, unentschlossenes und ungeschicktes Handeln entsteht nicht aufgrund seiner persönlichen Psychologie: Es wird durch diese Situation verursacht. [St, S. 210 f.]

Das Anwachsen des bürokratischen Apparats kann (wie bei Weber oder Habermas) als Rationalisierungsprozess verstanden werden; allerdings ist dies ein Rationalisierungsprozess mit technizistischer Fassade. Durch die Politisierung der Verwaltung und der stattfinden Kämpfe der Fraktionen des Blocks an der Macht innerhalb des Verwaltungsapparats können die Verschiebungen zugunsten der Bürokratie nur als scheinbare Ablösung bestimmter Funktionen vom politischen Prozess gesehen werden.

\subsubsection{Die Staatspartei im autoritären Etatismus}

a) Der oben beschriebene Zentralisationsprozess beinhaltet nach Poulantzas aber auch, dass die Funktion der Parteien sich transformiere, sie seien nun weniger „Orte der politischen Formulierung und Ausarbeitung von Bündnissen und Kompromissen“ [St, S. 211], ebenso seien sie „kaum noch Organismen, die wirkliche repräsentative Beziehungen $\mathrm{zu}$ den gesellschaftlichen Klassen haben“ [ebd.]. Poulantzas begreift die moderne Partei nun vielmehr „Trans- 
missionsriemen für die Entscheidungen der Exekutive“, Popularisieren und Propagieren die Staatspolitik und besitzen somit auch keine Legitimationsfunktion mehr, letztere verlagere sich ,auf plebeszitäre und rein manipulative Regelkreise (die Medien), die von der Verwaltung und der Exekutive beherrscht werden“" [ebd.]. Die Transformationen der politischen Parteien sei u. a. auch daran erkennbar, dass die meisten westlichen Staaten sich tendenziell zu einem Zwei-Parteien-System wandelten; diese Parteien würden mehr oder weniger abwechselnd die Regierung stellen. Hierbei sei festzustellen, dass die Differenz zwischen diesen „Staatsparteien“ zum einen darin liegen, dass sie auf unterschiedliche Methoden die gleiche Politik propagieren würden, dies sei „die berühmte 'Entideologisierung' dieser Parteien“ [St, S. 212]. Zum anderen könnten die Parteien politisch dahingehend differenziert werden, dass ihre Politiken mit den Widersprüchen innerhalb des Blocks an der Macht als auch mit den Widersprüchen in Bezug auf die beherrschten Klassen in Verbindung stehen, aber ihre Politiken lediglich Varianten derselben Politik sind ${ }^{210}$; die Parteien sind

nicht mehr der reale Ort der Austragung dieser Widersprüche. Sie sind Resonanzböden von Widersprüchen, die in dem dominanten Zentrum, der Verwaltung und der Exekutive, wirken. [ebd.]

Das heißt, dass die Parteien die organische Rolle, die sie in den Anfängen der repräsentativen Demokratie gehabt hätten, mit ihrer Transformation nicht mehr Klassenrepräsentanten gegenüber der Spitze der Exekutive seien, sondern die Stellung eines Repräsentanten der Spitzen des Staates gegenüber der Bevölkerung einnehmen würden. Weiterhin bedeute der Transformationsprozess für die Parteien, insbesondere wenn sie eine fundamentale Opposition darstellen, dass sie nicht länger die Rolle des Volksvertreters gegenüber dem administrativen Apparats einnehmen (also beispielsweise eine Kontrollfunktion wahrnehmen können), sondern von dem Zugriff auf die Verwaltung ausgeschlossen werden. Erst indem sie sich - ihre einzelnen Abgeordneten und ihre Politik - ganz der Verwaltung unterwerfen, erhielten sie überhaupt Zugang zu dieser [St, S. 213].

210 Da beide Parteien den gleichen politischen Dispositiven folgen, kommt es nach Poulantzas dazu, dass sich im Staatsapparat ,interparteiliche Netze“ bilden, der zentrale Staatsapparat fungiere als „Forum der Einheitspartei“. Diese „virtuelle Einheitspartei“ (Agnoli) habe gegenüber den nicht-dominanten Parteien eine Kontrollfunktion, indem jede nicht dem Forum zugehörige Partei als revolutionäre Gefahr dargestellt werde, „die Identität dieses Forums der Einheitspartei beruht darauf, dass jede andere Partei zum Feind erklärt wird“ [St, S. 217]. 
Das Begreifen der Parteien als „Transmissionsriemen“ ist in der Perspektive der Transformation der Parteien also durchaus im Lenin'schen Sinn zu verstehen: die Parteien sind nicht länger Artikulationsplattformen von Klassen und Klassenfraktionen, im Mittelpunkt ihrer Tätigkeit steht vielmehr umgekehrt die Popularisierung des politischen Programms der Exekutive, welche von der jeweiligen Partei gestützt wird (gelingt diese Popularisierung nicht, wird dies im aktuellen Diskurs der Politiker als „Vermittlungsproblem“ bezeichnet).

Die institutionellen Transformationen sowie die Mutation der Parteien zum „Transmissionsriemen“ konstatierte Johannes Agnoli (freilich von einem anderen theoretischen Rahmen ausgehend) vor Poulantzas in der BRD. Agnoli erkannte in dem Transformationsprozess einen neuen Herrschaftsmechanismus, in dem die Parteien „sich in dem Modus, nicht in der Substanz“ [Agnoli 1990, S. 51] voneinander unterscheiden. In der Folge ergebe sich für die Parteien zwar ein realer Kampf, dieser sei für die Wähler aber rein illusorisch, da de facto austauschbare Positionen angeboten werden. Diese Austauschbarkeit/ Auswechselbarkeit sei für die moderne Volkspartei auch in ihrem Selbstverständnis und ihrer Selbstdarstellung notwendig, um Wähler anderer Parteien überhaupt für sich gewinnen zu können [ebd., S. 53]. In der Schlussfolgerung ergeben sich für Agnoli ähnliche Konsequenzen wie für Poulantzas:

Verbindet sich die ideologische und organisatorische Form der Volkspartei mit der Formalisierung der Parteienpluralität, so wird ein zweifaches politisch erreicht: Das demokratische Spiel der Kräfte um die Machtverteilung kann fortgeführt und damit die Konstitutionalität aufrechterhalten werden; zugleich wird verbürgt, dass keine wesentlichen Änderungen zu erwarten sind. [ebd.]

In einem anderen Punkt geht Agnoli konsequenter als Poulantzas zu Werke: die Vervielfältigung der Parteien mit einem einheitlichen Programm und dem Streben zum Überwinden der klassenbezogenen Politik, dem (vermeintlichen) klassenübergreifenden Interessenausgleich und der Überwindung der Proletarität stehe in engem Verhältnis mit der faschistischen Einheitspartei [ebd., S. 54], denn sowohl die faschistische Einheitspartei als auch die Volksparteien zielen ungeachtet eines etwaigen klassenmäßigen Auftrags auf die Bildung einer großen Gemeinschaft, in der die Einzelnen der gleichen sittlichen Verpflichtung unterliegen, jedoch einen ungleichen materiellen Anteil an wirtschaftlicher und politischer Macht [...] erhalten. [ebd.] 
b) Die Transformation der dominanten Parteien zu Staatsparteien (von Poulantzas synonym mit ,herrschender Massenpartei“ verwendet [St, S. 214]) und die Verlagerung zahlreicher politischer Prozesse in die Verwaltung hinein beinhaltet nach Poulantzas, dass auch die Verwaltung sich zu einer „realen politischen Partei der gesamten Bourgeoisie unter der Hegemonie des Monopolkapitals innerhalb eines demokratischen Rahmens“ wandelt [St, S. 215], d. h. dass es zu einer gewissen Doppelherrschaft kommt: Die Staatspartei hat nun neben ihrer Funktion als Transmissionsriemen die Aufgabe, den administrativen Apparat zu homogenisieren, ihn auf horizontaler und vertikaler Ebene auf die Einhaltung der Regierungspolitik hin zu kontrollieren. Die dominante Staatspartei „,spielt die Rolle einer Polizei der Verwaltung“ [ebd.], sie „funktioniert also parallel zur administrativ-politischen Kontrolle als Netzwerk der strikten politischen Unterordnung der ganzen Verwaltung unter die Spitzen der Exekutive“ [ebd.]. Dabei sei dieser Prozess selbst wiederum widersprüchlich, die politische Kontrolle von oben stoße auf ständigen und vielfachen Widerstand des bürokratischen Apparats, auch trotz der „disziplinarischen Maßnahmen der Gleichschaltung der Verwaltung" [ebd.]. Die Funktion der dominanten Partei bedinge aber auch, dass sie selbst von der Spitze der Exekutive kontrolliert wird, entweder dadurch, dass die Spitze der Exekutive die Kontrolle über die Partei erlange oder aber, das Spitze der Exekutive selbst historisch eine die Partei kontrollierende Position erlangt habe.

Die Präsenz der Staatsparteien in der Verwaltung bedeute aber nicht, dass die Politisierung der Verwaltung hierauf zurückzuführen sei, denn wie dargelegt sei die Verwaltung schon ,reale Partei“, die Interessen des Monopolkapitals seien unmittelbar in ihr anwesend, ebenso nehme die Verwaltung Aufgaben der Organisation der Hegemonie wahr. Da sie nun unmittelbar mit den sozio-ökonomischen Interessen konfrontiert sei, werde der Schein der Neutralität der Verwaltung zunehmend aufgegeben, die Verwaltung politisiere sich „nun offen und massiv“ [St, S. 216]. Damit einhergehend nehme der Druck der Exekutive zu, indem sie auf der Grundlage ihrer Regierungspolitik das Verwaltungspersonal von oben nach unten austauscht und Hierarchien aufbricht und reorganisiert [ebd.]. Hierbei sei festzustellen, dass immer mehr Beamte sich „,von selbst“ der Staatspartei anschließen würden, es komme zu einer Osmose zwischen dominanter Partei und Verwaltung. Dies könne zum 
einen zur Folge haben, dass es durch die Verflechtung von dominanter Partei und Verwaltung innerhalb des bürokratischen Apparats zu Stockungen der personellen Fluktuation komme und sich dort zunehmend Kalküle der Parteiund Personalpolitik einschreiben. Zum anderen drohe der Staatspartei mit dem Verlust des Regierungmandats auch der personelle Zerfall [St, S. 217]. Die Verbindung von Staat und dominanter Partei sei aber nicht nur auf die Kontrolle der Verwaltung durch diese Partei zurückzuführen, sondern ebenso auf die Legitimationsprozesse, die

Dispositive zur Erzeugung des Konsensus verschieben sich von den politischen Parteien und den bis jetzt für diese Funktion spezialisierten Apparaten (Schule, kultureller Apparat, Familie) auf die staatliche Verwaltung. [St, S. 218]

Dies habe zur folge, dass sich die herrschende Ideologie wie die „Modalitäten seiner Reproduktion und Indoktrination" [ebd.] verändere, der Verwaltung kommen nun selbst ideologische Funktionen zu, allerdings gebe es in dieser Verschiebung strukturelle Grenzen, so dass eine dominante Staatspartei zwar nicht zur „Ausarbeitung dieser Ideologie“ benötigt werde, aber als „Relais und Vehikel der Staatsideologie zu den Volksmassen hin und als Appendix der plebiszitären Legitimierung der staatlichen Verwaltung“ agiere [St, S. 218 f.].

\subsubsection{Autoritärer Etatismus als selbstnegatorischer Prozess?}

a) Der Prozess der Entwicklung des autoritären Etatismus ist nach Poulantzas kein rein institutioneller Prozess, sondern beinhaltet erhebliche Transformationen der bürgerlichen Demokratie selbst: so seien zum einen durch die Verschiebung politischer Prozesse in die Verwaltung zunehmend die Volksmassen von den Staatsapparaten distanziert, gleichzeitig erfasse, zentralisiere und homogenisiere der Staatsapparat alle Bereiche der Gesellschaft. Dies erfolge nicht mittels erhöhter Repression oder ideologischer Indoktrination, sondern durch

den Aufbau neuer Machttechniken und in der Errichtung einer Reihe von Praktiken, Kanälen und Abstützungen, die darauf abzielen, eine neue Materialität des sozialen Körpers zu schaffen, auf den Macht ausgeübt wird" [St, S. 220; Hervorhebung S.v.B.].

Die neue Materialität des sozialen Körpers sei dabei von der der repräsentativen Demokratie spezifischen Materialität - die Trennung von privat und öffent- 
lich und die Spaltung des Volkskörpers in formell freie und gleiche individuellprivate - verschieden. Der soziale Körper werde von einem „etatistisch-autoritären Raster der Machtausübung“ [St, S. 220] überlagert; es entstehe eine „Matrix für neue Formen der gesellschaftlichen Arbeitsteilung“ [St, S. 221], die in allen gesellschaftlichen Beziehungen anwesend ist, sich aber vor allem in den administrativen Dispositiven des Staates ,herausarbeitet und ritualisiert“ [ebd.].

Die Transformation des Staates bedeutet für Poulantzas aber nicht, dass der Staat dadurch eindeutig gestärkt werde, vielmehr beinhalte dieser Prozess auch eine Schwächung des Staates. Zum einen betrifft dies die Politisierung der Verwaltung: indem diese die Leitideologie der „Leistung, des ökonomischen Fortschritts, des Überflusses und des Wohlstands“ [St, S. 222 f.] verkörpere, gerate sie in einen eklatanten Widerspruch zu der eigenen Unfähigkeit, die regelmäßig auftretenden ökonomischen Krisen zu meistern; dies könne zu einer Distanzierung der Massen gegenüber der politischen Hegemonie führen [St, S. 223]. Innerhalb der Verwaltung entstehe zudem die Problematik, dass durch die erweiterte gesellschaftliche Arbeitsteilung sich auch in den Verwaltungsapparaten eine Trennung von manueller und intellektueller Arbeit vollziehe. Dadurch würden in den höheren Organen das „Wissen“ um die Planung und Leitung zunehmend monopolisiert, die untergeordneten Organe würden demgegenüber distanziert und Gegenstand eines ,disziplinarischen Autoritarismus",

hinter ihrer technischen Fassade zielen diese Maßnahmen sowohl auf die Erhöhung der administrativen Arbeitsproduktivität als auch auf die Kontrolle und politische Beherrschung der immensen bürokratischen Maschinerie durch die Spitzen der Exekutive. [St, S. 224]

Diese Distanzierung und die politische Kontrolle der Verwaltung durch die Exekutive sei aber vor allem Resultat der in den Verwaltungsapparaten anwesenden Klassenkämpfe. Insbesondere die „,neue Kleinbourgeoisie“ nehme daran teil, gerade wenn sich die Kämpfe um „die kollektive Konsumtion und die 'Lebensqualität' drehen (Gesundheits-, Wohnungs- und Verkehrswesen, Umweltschutz usw.)“ [ebd.]. Diese Kämpfe seien politisch aber auch deshalb brisant, weil sie sich, im Gegensatz zu den Kämpfen der Arbeiterklasse, direkt in die Verwaltung einschreiben: nicht weil die Beamten der unteren Ränge aus der Kleinbourgeoisie stammen, ,sondern vor allem wegen ihrer Determinie- 
rung als kleinbürgerliche Klasse“" [St, S. 225]. D. h. durch ihre Position in der Verwaltung als Kleinbourgeoisie gekennzeichnet stellt sie durch ihre Kämpfe das Bündnis mit der Bourgeoisie innerhalb des Apparats in Frage, in dem traditionell dieses Bündnis organisiert wird; die Kämpfe der Kleinbourgeoisie bringen einen Riss innerhalb des Bündnisses von Bourgeoisie und Kleinbourgeoisie hervor.

Allerdings richten sich nach Poulantzas auch die anderen gesellschaftlichen Kämpfe beständig auf den Staatsapparat, das administrative Dispositiv werde „,immer offener mit den Forderungen des Volkes konfrontiert“ und es werde damit „,von den Regierungsspitzen und den gesellschaftlichen Kämpfen umklammert" [ebd.]. Durch diese Umklammerung habe das administrative Dispositiv eine Doppelfunktion: zum einen als Vorhut der Macht gegenüber den beherrschten Klassen, zum anderen als politischer Prügelknabe, dem bei politischen Misserfolgen Unmenschlichkeit, Übereifer, bürokratische Schwerfälligkeit usw. vorgeworfen werden könne. Indem die Staatsapparate Zielscheibe der Klassenkämpfe werden, können sie Poulantzas zufolge aber immer weniger den Schein der Neutralität des Staates gegenüber den Klassenkämpfen wahren, die Konsenskrise in den beherrschten Massen „schlägt sich innerhalb des Staatsapparats als induzierte Legitimationskrise nieder“211 [St, S. 226].

Die Schwächung des Staates sieht Poulantzas aber auch bezüglich der Ausarbeitung der Regierungspolitik in der Verwaltung. Trotz der politischen Kontrolle derselben sei es der Verwaltung nicht so effektiv wie der Staatspartei möglich, die Hegemonie zu organisieren. Die Staatspartei sei durch ihre organische Funktion in der Lage, die Kräfteverhältnisse in dem Block an der Macht zu reorganisieren und in der Regierungspolitik zu verdichten. Demgegenüber bedeute die Notwendigkeit der Verlagerung der politischen Prozesse in die Verwaltung, dass diese Prozesse dem administrativen Prozeduren unterworfen werden, die Herstellung von „Kompromisse[n] innerhalb des Blocks“ werde immer ,stockender, verborgener, ruckweiser; durch das unmittelbare Aufeinandertreffen von Unterapparaten und administrativ untergeordneten Bürokraten“ [ebd.] werde die Regierungspolitik inkohärenter; sie sei tendenziell nicht mehr in der Lage, langfristig zu operieren. 
Die hierdurch ausgelösten Widersprüche setzen nach Poulantzas auch einen umgekehrten Prozess in Gang, der diese Widersprüche noch verschärfe: Die Staatsbürokratie politisiere und fraktioniere sich, es komme zur Bildung von „Cliquen, Parteigruppierungen und politischen Hochburgen“ [St, S. 227] in der Verwaltung, die mit ihren Kämpfen die Hegemonie destabilisieren würden. Dieser Prozess erfolge nicht nur in den ,zivilen“ Verwaltungsapparaten, sondern ebenso in den repressiven Apparaten, „die neuen Widersprüche, die die bürgerliche Verwaltung kennzeichnen, schlagen sich so im gesamten Organismus des Staates nieder“ [ebd].

Des Weiteren generiere der autoritäre Etatismus selbst neue Formen des Widerstands in den beherrschten Klassen, so z. B. dem Etatismus entgegengesetzte Formen der Basisdemokratie wie Selbstverwaltungszentren, Bürgerinitiativen und Stadtteilkomitees, diese politischen Formen würden - trotz ihrer relativen Distanz zum Staat - erhebliche Dislozierungseffekte innerhalb des Staates nach sich ziehen. In diesen Zusammenhang stellt Poulantzas auch die in den 70er Jahren „neuen“ Formen der politischen Kämpfe wie Feminismus oder die ökologische Bewegung:

Dem autoritären Etatismus misslingt nicht nur die Erfassung der Massen in seinen disziplinarischen Ketten, d. h. die effektive „Integration“ dieser Massen in seine autoritären Regelkreise. Er provoziert vielmehr eine generelle Forderung nach direkter Basisdemokratie, d. h. das explosive Entstehen demokratischer Ansprüche. [St, S. 228]

b) Aus heutiger Sicht scheint es, dass Poulantzas die Integrationsfähigkeit der ideologischen Staatsapparate gründlich unterschätzt hat, denn eben diese ökologischen und feministischen Bewegungen haben sich nach zwanzig Jahren bestens in den politischen und administrativen Apparat assimiliert, ohne die Reproduktion des Kapitals und die Reproduktion der bürgerlich-administrativen Herrschaft auch nur im mindesten zu gefährden ${ }^{212}$. Offe hat bereits in den 70er Jahren treffend darauf hingewiesen, dass diese Formen der Bürgerinitiativen die Tendenz haben, sich zu genossenschaftlichen Dienstleistungsbetrieben für den gehobenen Mittelstand zu entwickeln und für die politisch-

212 Die Einschätzung der Bürgerinitiativen, die gegen bestimmte Formen der gesellschaftlichen Reproduktion vorgehen (Wohnungs-, Verkehrs- und Umweltpolitik usw.) muss konsequenterweise als politische Artikulationsform der Kleinbourgeoisie erfolgen (so auch Offe 1972, S. 162). 
institutionellen Reproduktionsbedingungen folgenlos bleiben [Offe 1975, S. 162], ,zu Brot und Spielen kommen noch die Bürgerinitiativen hinzu“ [Agnoli 1990, S. 154$]^{213}$.

Ebenso konstatiert Offe aber auch, dass die verschiedenen Bürgerinitiativen nicht zwangsläufig eine Gefahr für den Staatsapparat darstellen, sondern im Gegenteil diesen ergänzen können: sie bilden politische „Frühwarnsysteme“, die „mögliche Konflikte und sich abzeichnende Entwicklungsengpässe rechtzeitig signalisieren und damit Hinweise geben, an welchen Stellen die Administration aktiv werden muss“ [ebd., S. 163]. Rückblickend muss ebenso konstatiert werden, dass Bürgerinitiativen auch kompatible Ergänzungen der Verwaltung bilden können, indem sie, z. B. in der Stadtteilselbstverwaltung, politisch-ideologische Aufgaben der Integration wahrnehmen, die der bürokratische Apparat so nicht leisten kann; diese Organisationsformen nehmen damit den Charakter eines ideologischen Staatsapparats an, ähnliches könnte auch für NGOs behauptet werden.

c) Bezüglich der selbstnegatorischen Tendenzen des autoritären Etatismus muss generell konstatiert werden, dass seit den neunziger Jahren eine Verschiebung hin vom so beschriebenen Sicherheitsstaat zu einem ,nationalen Wettbewerbsstaat“ (Hirsch) vollzieht und eine neue Durchstaatlichung der Gesellschaft stattfindet [vgl. Hirsch 1998]. Hierbei sind bezüglich der Struktur- und Funktionsbestimmung des Staates neben den oben bereits beschriebenen Veränderungen der ökonomischen Funktionen insbesondere zu nennen:

i. Der Staat gibt zum Teil seine regulative Rolle bezüglich des Klassenkompromisses auf. Dies erfolgt sowohl bezüglich seiner ideologisch Positionierung, in dem die staatliche Politik eindeutig vor dem Hintergund der Forderungen des Kapitals formuliert wird, diese allerdings mit einer

213 Auf empirischer Ebene lässt sich bestens die Integrationsfähigkeit der ISA anhand der Geschichte der '68-Bewegung veranschaulichen: griff diese Bewegung in Frankreich den Strukturalismus an, um auf der eigenen Subjektivität als historisch progressive Akteure zu bestehen [Dosse 1999, Bd. 2, S. 145], lassen sich 30 Jahre später die Resultate dieser letzten großen Niederlage der westeuropäischen Linken besichtigen. Die „Subjekte“ dieser Niederlage sind politisch weiterhin auf der politischen Bühne aktiv, allerdings mit ausgetauschtem politischen Programm. So rühmt sich z. B. heute die führende Person der '68-Bewegung in Paris, D. Cohn-Bendit, dass sie im politischen System der BRD bestens „,angekommen“ ist: „Ich bin Verfassungsschutz“ [zit. nach „Konkret“ 10/98, S. 41]. Das aber die ideologische (Re-) Integration durchaus dysfunktional enden kann, zeigen einige ehemaligen Genossen Cohn-Bendits - z. B. Mahler und Langhans - die sich nun als Vordenker der radikalen Rechten versuchen. 
nationalistisch aufgeladenen Standortideologie versieht. Die regulative Rolle wird aber auch materiell aufgegeben, in dem seine wohlfahrtsstaatlichen Transferleistungen ab- und polizeilich-überwachende Maßnahmen aufgebaut werden.

ii. Bezüglich der noch verbliebenen demokratischen Rechte ist zu konstatieren, dass diese auf nationaler Ebene in dem Maße abgebaut werden, wie sie sich als Hemmschuh der kapitalistischen Entfaltung erweisen und sich so der autoritäre Charakter des Nationalstaats weiter entfaltet. Bei internationalen zwischenstaatlichen Organisationen ist die Reichweite demokratischer Mitbestimmung und Kontrolle schon seit Gründung derselben grundsätzlich beschränkt (z. B. Europäisches Parlament) oder gar nicht mehr vorgesehen (z. B. Europäische Zentralbank).

iii. Die globale politische Ordnung muss auch weiterhin wie oben angesprochen als Imperialismus bezeichnet werden, in dem die Triade die Peripherie politisch, ökonomisch und - soweit erforderlich - militärisch beherrscht; der Internationalisierung der Arbeitsteilung folgt eine Internationalisierung der Klassenkämpfe. 


\section{Zusammenfassung und Ausblick}

Ziel dieser Arbeit war, die theoretischen Grundzüge einer Staats- und Ideologietheorie darzustellen, die auf einer strukturalistischen Lesart des Marx'schen Werkes sowie der theoretischen Aneignung der Arbeiten von Gramsci und Foucault basieren. Die Ergebnisse der Arbeit lassen sich thesenhaft wie folgt zusammenfassen:

i. Die (Re-) Konstruktion des Marx'schen Werks anhand strukturalistischer Methoden hat eine der dogmatisierten Lesart entgegengesetzte „Schule“ des Marxismus hervorgebracht. Diese Lesart konnte auch zeigen, dass bestimmte Methoden und Annahmen, die den Strukturalismus prägen, bereits bei Marx selbst zu finden sind. Der strukturalistische Marxismus hat vor allem durch die Arbeiten Althussers, Balibars und Poulantzas' in Frankreich einen ähnlichen Stellenwert wie sie die „Frankfurter Schule“ in Deutschland inne; ebenso wie die „Frankfurter Schule“ hat der strukturalistische Marxismus national und international eine Lesart Marx' etabliert, die heute noch - beispielsweise in den Werken von Bourdieu, Butler, Derrida, Lipietz usw. - von Einfluss ist, wenn z. T. auch nur als Gegenstand der Abgrenzung.

ii. Eine besondere Problematik bei Althusser ergibt sich offenbar aus dem Umstand, dass seine Arbeiten eine große Nähe zum strukturalistischen Denken aufweist und er dadurch immer wieder die Frage bezüglich des Verhältnisses von Wissenschaft und Philosophie anschneiden muss. Hierdurch entsteht für Althusser offenbar die Gefahr, dass er dem revolutionären Marxismus - also auch seinen persönlichen politischen Anschauungen (erst recht denen der PCF) - tendenziell den philosophischen Boden entzieht und das Dilemma dahingehend zu Lösen versucht, in dem er seine eigenen Arbeiten grundsätzlich in Frage stellt.

iii.Die Ideologie- und Subjektkonzeption Althussers ist in der marxistischen Theorie wohl als wegweisend einzustufen. Mit dieser Theorie gelingt es Althusser, sowohl Anschluss an diskurstheoretische Ansätze zu finden als auch die Institutionen zu identifizieren, in denen die ideologische Reproduktion der Gesellschaft organisiert und so die Hegemonie einer Klasse reproduziert wird. Hierbei ist die Konzeption, dass Ideologie nicht als 
„Verblendung“, sondern als gesellschaftliche Praxisform untersucht wird, ein wesentlicher Fortschritt gegenüber den Analysen Gramscis.

iv. Die Lektüre Foucaults und Gramscis durch Poulantzas erweist sich als durchaus fruchtbar, hierdurch erfolgte eine produktive Erweiterung eines marxistischen Staatsbegriffs und stellt insgesamt einen wesentlicher Fortschritt dar gegenüber einem abgeleiteten, „werkzeughaften“, verkürzten Staatsbegriff wie er bei Marx und Engels (insbesondere im Anti-Dühring), vor allem aber bei Lenin und seine Epigonen zu finden ist. Hierbei stellt sich die Konzeptionen des Staates als Verdichtung von Kräfteverhältnissen und die relative Autonomie des Staates als wesentliche theoretische Erweiterungen dar. Hierbei läßt sich zusammenfassend die relative Autonomie des Staates theoretisch mit folgenden Funktionen des Staates begründen:

I. Der als ideeller Gesamtkapitalist handelnde Staat muss Funktionen ausführen, die auch gegen die Interessen einzelner Fraktionen des Kapitals durchgesetzt werden müssen.

II. Der Staat bildet ein (vermeintlich objektives) politisches Feld, in dem die Klassenkämpfe ausgetragen werden können, ohne die Produktionsverhältnisse zwangsläufig selbst in Frage zu stellen.

III.Die hegemonialen Mechanismen gestatten es dem Staat, sich als klassenneutral darzustellen, gleichzeitig sind aber die der kapitalistischen Produktionsweise zugrunde liegenden Machtverhältnisse in seinen Strukturen präsent.

IV.Nur ein relativ autonomer Staat ist in der Lage, eine Kohäsion der einzelnen Apparate zu garantieren und eine institutionelle Parzellierung des Staates zu verhindern.

V. Da die relative Autonomie des Staates historisch variabel ist und vor allem von Klassenkampf bestimmt ist, erlaubt sie es, die verschiedenen Staatsformen der kapitalistischen Produktionsweise (Parlamentarismus, Bonapartismus, Faschismus) anhand der historisch-konkreten Relationen der gesellschaftlichen Strukturen zu erfassen ${ }^{214}$.

214 Hierbei bezieht sich Poulantzas vor allem auf die Analyse des Bonapartismus durch Marx, nach Poulantzas lassen sich schon bei Marx Ansätze einer Theorie der relativen Autonomie des Staates finden [Poulantzas 1980, S. 268 ff.]. 
v. Die daraus folgende Erweiterung des Staatsbegriffs hinsichtlich der ökonomischen Funktionen des Staates ist notwendig, um herzuleiten, wie der Staat den tendenziell krisenhaften Verlauf der kapitalistischen Produktionsweise beeinflussen kann. Indem Poulantzas auch die Schranken der Handlungsmöglichkeiten des Staates bestimmt, kann die Verbindung/Einflussnahme des Staates auf die ökonomische Struktur analysieren werden ohne dabei der Idee eines „organisierten Kapitalismus“ (Habermas) zu verfallen.

vi. Die Ausarbeitungen Poulantzas hinsichtlich des Verhältnisses von Staat und Nation müssen als problematisch bezeichnet werden. Zwar sind seine Analysen zu den Zeit- und Raummatrizes als Bestandteile der Nation fruchtbar, allerdings gelingt es ihm nicht, einen adäquaten Begriff der Nation zu entwerfen und bleibt traditionellen (marxistischen) Konzeptionen verhaftet.

vii.Die Theorien Poulantzas' zum „autoriären Etatismus“ sind von bemerkenswerter Aktualität und werden von der Regulationstheorie ${ }^{215}$ - insbesondere von Hirsch - regelmäßig aufgegriffen. Bei der Lektüre Poulantzas' überrascht weniger der Optimismus, mit dem dieser vor dem Hintergrund der Klassenkämpfe und Studentenrevolten der 60er und 70er Jahre die basis-

215 Die Regulationstheoretiker begreifen sich selbst (zumindest die französischen Vertreter der Regulationstheorie) als „aufsässige Kinder“ (Lipietz) der Althusser'schen „Schule“; es wird aus dieser theoretischen Position aber auch Kritik am strukturalistischen Marxismus formuliert. So behauptet Lipietz, dass zum einen der Widerspruch durch Althusser seiner Bedeutung beraubt wurde, zum anderen, dass gesellschaftlichen Gruppen und Individuen nicht mehr als „strukturtransformierende gesellschaftliche Subjekte“ [Lipietz 1992, S. 11] begriffen werden.

Der Vorwurf bezüglich der begrifflichen Unterminierung des „Widerspruchs“ ist m. E. nur zum Teil begründet, denn ansonsten würde die Denkfigur der „,determinierte Struktur mit Dominante" wenig Sinn machen. Allerdings ist der Vorwurf in dem Sinne berechtigt, wenn er darauf abzielt, dass in der Althusser'schen Konzeption der Widerspruch die Tendenz hat, die Strukturen identisch zu reproduzieren. Hier haben Balibar und Poulantzas aber notwendige (Selbst-) Kritik geleistet; es wird gesellschaftliche Reproduktion auch als nicht-identische Reproduktion gedacht, in dem die Rolle des Klassenkampf stärker gewichtet wird.

Die Kritik an der Rolle des Subjekts wird auch von Hirsch geteilt, so formuliert er, dass eine „Selbstreproduktion gesellschaftlicher Strukturen unabhängig von individuellen oder kollektiven Strategien und Handlungen" [Hirsch 1992, S. 215 f.] fehl leite. Eine solche Interpretation bedeutet natürlich, Althusser gründlich misszuverstehen, denn dessen Problemstellung in Ideologie und ideologische Staatsapparate ist, warum sich die gesellschaftlichen Strukturen auch trotz der individuellen - und erst recht kollektiven Strategien reproduzieren, welchen Einfluss diese Strategien (also vor allem der Klassenkampf) auf die Reproduktion haben und wie die „individuellen“ Strategien überhaupt entstehen. Eventuell ist es dieser Einschätzung geschuldet, wenn Hirsch dem strukturalistischen Marxismus vorwirft, die Geschichte des Kapitalismus als expressives Entfalten der Grundstruktur dieser Gesellschaftsformation zu deuten und dadurch leugnen würden, dass die kapitalistische Gesellschaft, bedingt durch den Klassenkampf, sehr unterschiedliche Zustände kenne [Hirsch 1991, S. 130]. 
demokratischen Bewegungen beurteilte, sondern viel mehr seine Hellsichtigkeit, mit der er die Tendenz der kapitalistischen Staaten vorhersah, nahezu jede Form von (demokratischer) Gegenbewegung zu assimilieren und gleichzeitig zu einer modernen autoritären Staatsform zu mutieren. 


\section{Literaturverzeichnis}

Agnoli, J.

1990: Die Transformation der Demokratie. Freiburg i. Br.

Albers, D. / Altvater, E. / Haug, W. F. (Hrsg.)

1983: Aktualisierung Marx’'. Berlin

Althusser, L.

1968: Für Marx. Frankfurt/M.

1969: Wie sollen wir das Kapital lesen? o. O.

1973a: Marxismus und Ideologie. Berlin

1973b: Antwort an John Lewis. In: Arentz/Bischoff/Jaeggi 1973

1973c: Die Bedingungen der wissenschaftlichen Entdeckung von Marx. In: Arentz/Bischoff/Jaeggi 1973

1973d: Bemerkungen zu einer Kategorie: "Prozeß ohne Subjekt und ohne Ende/Ziel". In: Arentz/Bischoff/Jaeggi 1973

1973e: Anmerkung zur "Kritik des Personenkults". In: Arentz/Bischoff/ Jaeggi 1973

1974a: Lenin und die Philosophie. Reinbeck/Hamburg

1974b: Pour Marx. Paris

1975a: Elemente der Selbstkritik. Berlin

1975b: Versuch über Lenins philosophische Position. In: Lecourt 1975b

1976: Geschichte beendet, endlose Geschichte. In: Lecourt 1976

1977: Ideologie und ideologische Staatsapparate. Hamburg - Berlin

1978a: Die Krise des Marxismus. Hamburg

1978b: Endlich befreit sich etwas lebendiges aus und in der Krise des

Marxismus. In: Alternative Nr. 119

1979: Der Marxismus als endliche Theorie. In: Altvater/Kallscheuer 1979

1983: Marx' Denken im Kapital. In: ProKla Nr. 50

1985: Philosophie und spontane Philosophie der Wissenschaftler. Berlin 1998: Die Zukunft hat Zeit / Die Tatsachen. Frankfurt/M.

Althusser, L. / Balibar, É.

1969: Lire le Capital. Paris

1972: Das Kapital lesen. Reinbeck/Hamburg

Althusser, L. / Tort, M.

1976: Freud und Lacan/Die Psychoanalyse im historischen Materialismus. Berlin

Altvater, E. / Kallscheuer, O. (Hrsg.)

1979: Den Staat diskutieren. Berlin

Anderson, $\mathrm{P}$.

1978: Über den westlichen Marxismus. Frankfurt/M.

1979: Antonio Gramsci: Eine kritische Würdigung. Berlin

Arentz, H. / Bischoff, J. / Jaeggi, U. (Hrsg.)

1973: Was ist revolutionärer Marxismus? Berlin

Autorenkollektiv

1955: Politische Ökonomie. Berlin

Autorenkollektiv

1976: Freiheit der Kritik oder Standpunktlogik-Diskussion in der KPF.

Berlin

Bachelard, G.

1993: Epistemologie. Frankfurt/M. 
Backhaus, H.-G.

1997: Dialektik der Wertform: Untersuchungen zur Marxschen Ökono-

Balibar, É. miekritik. Freiburg i. Br.

1974: Cinq études du matérialisme historique. Paris

1975: Diskussion zur Ideologietheorie. In: Alternative Nr. 104

1977a: Über die Diktatur des Proletariats. Hamburg - Berlin

1977b: Marxismus, Rationalismus, Irrationalismus. In: Alternative Nr. 116

1977c: Über historische Dialektik. Kritische Anmerkungen zu "Lire le Capital". In: Jaeggi/Honneth 1977

1978: Soziale Krise und ideologische Krise. In: Alternative Nr. 118

1979: Fragen zur "Partei außerhalb des Staates". In: Altvater/

Kallscheuer 1979

1993a: La Philosophie de Marx. Paris

1993b: Die Grenzen der Demokratie. Hamburg

1994a: Für Althusser. Mainz

1994b: Strukturale Kausalität, Überdetermination und Antagonismus. In:

Böke/Müller/Reinfeldt 1994

Balibar, É. / Macherey, P.

1974: Thesen zum materialistischen Verfahren. In: Alternative Nr. 98

Balibar, É. / Wallerstein, I.

1990: Rasse. Klasse. Nation. Ambivalente Identitäten. Hamburg

Balibar, R. et. al.

1975: Linguistische Praktiken und Literatur. In: Alternative Nr. 104

Barthes, R.

1966: Die strukturalistische Tätigkeit. In: Kursbuch Nr. 5

Benton, $\mathrm{T}$.

1984: The Rise and Fall of Structural Marxism - Althusser and his influence. London - Basingstoke

Berthold, J.

1992: Althusserlektüren: Lektüre/Ideologie/Didaktik in Louis Althussers Diskurs. Würzburg

Bettelheim, C.

1970a: Über das Fortbestehen von Warenverhältnissen in den „sozialistischen Ländern“. Berlin

1970b: Ökonomischer Kalkül und Eigentumsformen. Berlin

Bettelheim, C. et. al.

1979: Zurückforderung der Zukunft. Macht und Opposition in den nachrevolutionären Gesellschaften. Frankfurt/M.

Bischoff, J.

1981: Einführung Gramsci. Hamburg

Böke, H.

1994: Allgemeinheit und ihre Brüche. Zum Problem der Rationalität und Kritik bei Althusser. In: Böke/Müller/Reinfeldt 1994

Böke, H. / Müller, J. C. / Reinfeldt, S. (Hrsg.)

1994: Denk-Prozesse nach Althusser. Hamburg - Berlin

Bourdieu, $\mathrm{P}$.

1976: Entwurf einer Theorie der Praxis. Frankfurt/M.

1995: Sozialer Raum und Klassen - Leçon sur la leçon. Frankfurt/M., 3. Aufl. 
1997a: Der Tote packt den Lebenden. Hamburg

1997b: Sozialer Sinn: Kritik der theoretischen Vernunft. Frankfurt/M., 2. Aufl.

1999: Die feinen Unterschiede: Kritik der gesellschaftlichen Urteilskraft. Frankfurt/M., 11. Aufl.

Brentel, $\mathrm{H}$.

1989: Soziale Form und ökonomisches Objekt. Studien zum

Gegenstands- und Methodenverständnis der Kritik der politischen Ökonomie. Opladen

Brieler, U. et al

1986: Gramsci, Foucault und die Effekte der Hegemonie. In: kultuRRevolution Nr. 11

Brühmann, $\mathrm{H}$.

1980: "Der Begriff des Hundes bellt nicht". Das Objekt der Geschichte der Wissenschaften bei Bachelard und Althusser. Wiesbaden

Brüsemeister, T. et. al. (Hrsg.)

1991: Die versteinerten Verhältnisse zum Tanzen bringen: Beiträge zur marxistischen Theorie heute. Berlin

Bucharin, N.

1922: Theorie des historischen Materialismus - Gemeinverständliches Lehrbuch der marxistischen Soziologie. Hamburg

Buci-Glucksmann, C.

1981: Gramsci und der Staat. Köln

1983: La gauche, le pouvoire, le socialisme. Hommage à Nicos Poulantzas. Paris

Courtois, S. / Werth, N. / Panne, J.-L.

1999: Schwarzbuch des Kommunismus. München

Dahrendorf, R.

1999: Traurige Parlamente. In: FAZ Nr. 208/1999

Deleuze, G.

1992: Woran erkennt man den Strukturalismus? Berlin

1995: Foucault. Frankfurt/M., 2. Aufl.

Deleuze, G. / Foucault, M.

1977: Der Faden ist gerissen. Berlin

Deleuze, G. / Guattari, F.

1997a: Anti-Ödipus. Kapitalismus und Schizophrenie I. Frankfurt/M., 8. Aufl.

1997b: Tausend Plateaus. Kapitalismus und Schizophrenie II. Berlin

Demirović, A.

1987: Nicos Poulantzas: eine kritische Auseinandersetzung. Hamburg Berlin

1988: Der ungleichzeitige Marxismus Louis Althussers. Assoziationen zur "Krise des Marxismus". In: kultuRRevolution Nr. 20

1992: Regulation und Hegemonie - Intellektuelle, Wissenspraktiken und Akkumulation. In: Demirović/Krebs/Sablowski 1992

1994: Totalität und Immanenz. In: Böke/Müller/Reinfeldt 1994

Demirović, A. / Krebs, H.-P. / Sablowski, T. (Hrsg.)

1992: Hegemonie und Staat. Münster

Derrida, J.

1974: Grammatologie. Frankfurt/M.

1990: Die différance. In: Engelmann 1990 
1991: Gesetzeskraft. Der "mystische Grund der Autorität". Frankfurt/M.

1994: Politik und Freundschaft. Interview mit M. Sprinkler. In: Böke/ Müller/Reinfeldt 1994

1995: Marx' Gespenster. Frankfurt/M.

1998: Ich misstraue der Utopie, ich will das Un-Mögliche. Interview mit T. Assheuer. In: Die Zeit Nr. 11/1998

Descombes, V.

1981: Das Selbe und das Andere. Philosophie in Frankreich 1933-1978. Frankfurt/M.

Donzelot, J. / Meuret, D. / Miller, P. / Rose, N.

1994: Zur Genealogie der Regulation. Mainz

Dosse, F.

1999: Geschichte des Strukturalismus. Hamburg

Eagleton, T.

1993: Ideologie. Stuttgart - Weimar

1997: Die Illusionen der Postmoderne. Stuttgart - Weimar

Elliot, G.

1987: Althusser - The Detour of Theory. London - New York

Euchner, W.

1983: Karl Marx. München

1991: Klassiker des Sozialismus. München

Euchner, W. / Schmidt, A. (Hrsg.)

1972: Kritik der politischen Ökonomie heute. 100 Jahre "Kapital".

Frankfurt/M.

Engelmann, $P$.

1990: Postmoderne und Dekonstruktion. Leipzig

Esser, J. / Görg, C. / Hirsch, J. (Hrsg.)

1994: Politik, Institutionen und Staat. Zur Kritik der Regulationstheorie. Hamburg

EU

o.J.: Der europäische Haushalt. Online in Internet:

http://europa.eu.int/comm/dg10/publications/brochures/move/

finances/budget/txt_de.html\#ch2; Stand 17.12.2001

Fetscher, I.

1967: Karl Marx und der Marxismus - Von der Philosophie des Proletariats zur proletarischen Weltanschauung. München

Fichant, M. / Pêcheux, M.

1977: Überlegungen zur Wissenschaftsgeschichte. Frankfurt/M.

Foucault, M.

1973a: Über verschiedene Arten Geschichte zu Schreiben. Interview mit

R. Bellour. In: Reif 1973

1973b: Strukturalismus und Geschichte. Interview mit J.-P. El Kabasch.

In: Reif 1973

1978a: Dispositive der Macht. Berlin

1978b: Der sogenannte Linksintellektuelle. Gespräch mit M. Fontana. In:

Alternative Nr. 119

1986: Vom Licht des Krieges zur Geburt der Geschichte. Berlin

1987: Von der Subversion des Wissens. Frankfurt/M.

1988: Die Geburt der Klinik. Frankfurt/M.

1994: Überwachen und Strafen. Frankfurt/M.

1996: Wahnsinn und Gesellschaft. Frankfurt/M., 12. Aufl. 
1997a: Archäologie des Wissens. Frankfurt/M., 8. Aufl.

1997b: Die Ordnung der Dinge. Frankfurt/M., 14. Aufl.

1997c: Der Wille zum Wissen - Sexualität und Wahrheit I. Frankfurt/M., 9. Aufl.

1997d: Die Ordnung des Diskurses. Frankfurt/M.

1999a: Botschaften der Macht. Stuttgart

1999b: In Verteidigung der Gesellschaft. Frankfurt/M.

Friedrich, C. J.

1957: Totalitäre Diktatur. Stuttgart

Garaudy, R.

1960: Die materialistische Erkenntnistheorie. Berlin

1969a: Marxismus im 20. Jahrhundert. Hamburg

1969b: Die Aktualität des Marxschen Denkens. Frankfurt/M.

Ghisu, S. F.

1994: Epistemologische Untersuchung zum Verhältnis von historischem Materialismus und Psychoanalyse bei Louis Althusser. Berlin (Diss.)

Giddens, A.

1988: Die Konstitution der Gesellschaft. Frankfurt/M.

De Giovanni, B. / Gerratana, V. / Paggi, L.

1978: Gramsci-Debatte 1 - Hegemonie, Staat und Partei. Hamburg

Godelier, M.

1970: System, Struktur und Widerspruch im "Kapital". Berlin

Goldmann, L.

1971: Gesellschaftswissenschaften und Philosophie. Frankfurt/M.

1984: Die marxistische Erkenntnistheorie und ihre Anwendung auf die

Geschichte des marxistischen Denkens. In: Lenk 1984

Gramsci, A.

1986: Zu Politik, Geschichte und Kultur. Köln

1991 ff.: Gefängnishefte. Hamburg - Berlin

Habermas, J.

o. J.: Briefe aus dem Kerker. Leipzig

1973: Legitimationsprobleme im Spätkapitalismus. Frankfurt/M.

1974: Theorie und Praxis. Frankfurt/M., 3. Aufl.

1976: Zur Rekonstruktion des historischen Materialismus. Frankfurt/M.

1981: Theorie des kommunikativen Handelns. Frankfurt/M.

1985: Die neue Unübersichtlichkeit. Kleine politische Schriften.

Frankfurt/M.

1992: Faktizität und Geltung. Frankfurt/M.

1996: Der philosophische Diskurs der Moderne. Zwölf Vorlesungen. Frankfurt/M., 5. Aufl.

Harms, A.

2000: Warenform und Rechtsform - Zur Rechtstheorie von Eugen Paschukanis. Baden-Baden

Hauck, G.

1992: Einführung in die Ideologiekritik. Hamburg

Haug, W. F.

1983: Notiz zu Michel Pecheux' Gedanken über den "ideologischen

Bewegungskampf". In: Das Argument Nr. 139

Hegel, G. W. F.

1952: Phänomenologie des Geistes. Hamburg 
1955: Grundlinien der Philosophie des Rechts. Hamburg

Heinrich, M.

1991: Die Wissenschaft vom Wert. Die Marxsche Kritik der politischen Ökonomie zwischen wissenschaftlicher Revolution und klassischer Tradition. Hamburg

Hirsch, J.

1974: Staatsapparat und Reproduktion des Kapitals. Frankfurt/M.

1983: Nach der "Staatsableitung". Bemerkungen zur Reformulierung einer materialistischen Staatstheorie. In: Albers/Altvater/Haug 1983

1991: Das nеue Gesicht des Kapitalismus. In: Brüsemeister 1991

1992: Regulation, Staat und Hegemonie. In: Demirović/Krebs/Sablowski 1992

1993: Internationale Regulation. Bedingungen von Dominanz, Abhängigkeit und Entwicklung im globalen Kapitalismus. In: Das Argument Nr. 198

1994a: Vom fordistischen Sicherheitsstaat zum nationalen Wettbewerbsstaat. In: Das Argument Nr. 203

1994b: Politische Form, politische Institutionen und Staat. In: Esser et. al. 1994

1995: Der nationale Wettbewerbsstaat. Amsterdam - Berlin

1998: Vom Sicherheitsstaat zum nationalen Wettbewerbsstaat. Berlin 1999: Geht die Arbeit wirklich aus? In: jungle world Nr. 24/1999

2000a: Krise als Chance. In: jungle world Nr. 8/2000

2000b: Voll normal. In: jungle world Nr. 15/2000

2001a: Der Imperialismus ist umgezogen. In: jungle world Nr. 11/2001

2001b: Globalisierung und Terror. Online in Internet: http://www.linksnetz.de/K_texte/K_hirsch_terror.html; Stand 24.12.2001

Hobsbawm, E.

1998: Nationen und Nationalismus. München, 2. Aufl.

Honneth, A.

1977: Geschichte und Interaktionsverhältnisse. Zur strukturalistischen

Deutung des Historischen Marxismus. In: Jaeggi/Honneth 1977

Horkheimer, M. / Adorno, T.

1988: Dialektik der Aufklärung. Frankfurt/M.

Hund, W. D.

1973: Strukturalismus, Ideologie und Dogmengeschichte. Darmstadt und Neuwied

Jäger, $M$.

1983: Kommunismus kommt von kommunal. In: Albers/Altvater/Haug 1983

Jaeggi, U.

1968: Ordnung und Chaos - Strukturalismus als Methode und Mode. Frankfurt/M.

1975: Theorie der Geschichte: Geschichte der Theorie? In: Das Argument Nr. 94

1976: Theoretische Praxis. Probleme eines strukturalistischen Marxismus. Frankfurt/M.

Jaeggi, U. / Honneth A. (Hrsg.)

1977: Theorien des historischen Materialismus. Frankfurt/M.

Jessop, B.

1982: The capitalist state: Marxist theories and methods. Oxford 
1985: Nicos Poulantzas. Marxist theory and political strategy. London

1992: Regulation und Politik - Integrale Ökonomie und integraler Staat.

Kallscheuer, O.

In: Demirović/Krebs/Sablowski 1992

1974: "Anti-Hegelianismus" innerhalb der Arbeiterbewegung.

Hypothesen zur Althusser- und Della-Volpe-Schule. In: Alternative Nr. 97

Kaminski, F. / Karuscheit, H. / Winter, K.

1982: Antonio Gramsci - Philosophie und Praxis. Frankfurt/M.

Kammler, C. / Plumpe, G. / Schöttler, P.

1978: Philosophie der Ideologie oder Theorie des ideologischen Klassenkampfs. In: Alternative Nr. 118

Karsz, S.

1976: Theorie und Politik: Louis Althusser. Frankfurt/M. - Berlin - Wien

Kebir, S.

1980: Die Kulturkonzeption Antonio Gramscis. München

1991: Gramscis Zivilgesellschaft. Hamburg

Kojève, A.

1975: Hegel. Eine Vergegenwärtigung seines Denkens. Kommentar zur

"Phänomenologie des Geistes". Frankfurt/M.

Krahl, H.-J.

1971: Konstitution und Klassenkampf. Frankfurt/M., 4. Aufl.

Kühnl, R.

1971: Formen bürgerlicher Herrschaft. Reinbeck/Hamburg

Kurz, R.

1999: Die Welt als Wille und Design. Postmoderne, Lifestyle-Linke und die Ästhetisierung der Krise. Berlin

Labica, G.

1976: Auf jeden Fall: Marx lesen. In: Autorenkollektiv 1976

1986: Der Marxismus-Leninismus: Elemente einer Kritik. Berlin

1998: Karl Marx - Thesen über Feuerbach. Hamburg - Berlin

Lacan, J.

1980: Schriften. Olten

Laclau, E.

1981: Politik und Ideologie im Marxismus. Hamburg - Berlin

1988: Die Politik als Konstruktion des Undenkbaren. In:

kultuRRevolution Nr. 17/18

Lecourt, D.

1975a: Kritik der Wissenschaftstheorie. Marxismus und Epistemolgie.

Berlin

1975b: Lenins philosophische Strategie. Frankfurt/M.

1976: Proletarische Wissenschaft? Der Fall Lyssenko und der Lyssenkoismus. Hamburg

1985: Jaques Lacan. In: Widerspruch Nr. 9

1994: Abschied von Lacan. Für einen marxistischen Neubeginn jenseits der Sackgasse. In: Böke/Müller/Reinfeldt 1994

Lefèbvre, $\mathrm{H}$.

1966: Der dialektische Materialismus. Frankfurt/M.

Lenin, I.

1962 ff.: Werke. Berlin 
Lenk, K. (Hrsg.)

1984: Ideologie: Ideologiekritik und Wissenssoziologie. Neuwied und Berlin, 9. Aufl.

Lévi-Strauss, C.

1971: Strukturale Anthropologie I. Frankfurt/M.

1996: Traurige Tropen. Frankfurt/M., 10. Aufl.

1997: Das wilde Denken. Frankfurt/M., 10. Aufl.

Lichtmann, R.

1990: Die Produktion des Unterbewußten: die Integration der Psychoanalyse in die marxistische Theorie. Hamburg - Berlin

Link, J.

1988a: Über Kollektivsymbolik im politischen Diskurs und ihren Anteil an totalitären Tendenzen. In: kultuRRevolution Nr. 18/19

1988b: Wie funktioniert "Überdetermination" - Zu einem Grundbegriff Althussers. In: kultuRRevolution Nr. 20

Lipietz, A.

1985: Akkumulation, Krise und Auswege aus der Krise. Einige methodologische Anmerkungen zum Begriff der Regulation. In: ProKla Nr. 82

1992a: Vom Althusserismus zur "Theorie der Regulation". In:

Demirović/Krebs/Sablowski 1992

1992b: Allgemeine und konjunkturelle Merkmale der ökonomischen

Staatsintervention. In: Demirović/Krebs/Sablowski 1992

Luhmann, N.

1998: Die Gesellschaft der Gesellschaft. Frankfurt/M.

Lukács, G.

1970: Geschichte und Klassenbewußtsein. Neuwied - Berlin

Lyotard, J.-F.

1990a: Beantwortung der Frage: Was ist postmodern? In: Engelmann 1990

1990b: Randbemerkungen zu den Erzählungen. In: Engelmann 1990

1994: Das postmoderne Wissen. Wien

Machery, P.

1973: Lenin. Kritik an Tolstoij. In: Alternative Nr. 92

1988: Eins teilt sich in Zwei. In: kultuRRevolution Nr. 20

Mandel, E.

1974: Der Spätkapitalismus. Frankfurt/M.

Marcuse, $\mathrm{H}$.

1964: Der eindimensionale Mensch. Neuwied

Marx, K. / Engels, F.

1956 ff.: Werke. Berlin

1975 ff.: Marx-Engels-Gesamtausgabe. Berlin

Merleau-Ponty, M.

1966a: Humanismus und Terror. Frankfurt/M.

1966b: Phänomenologie der Wahrnehmung. Berlin

1968: Die Abenteuer der Dialektik. Frankfurt/M.

Miliband, R.

1975: Der Staat in der kapitalistischen Gesellschaft. Frankfurt/M.

Mouffe, C.

1988: Hegemonie und neue politische Subjekte. Eine neue Konzeption von Demokratie. In: kultuRRevolution Nr. 17/18 
Müller, J. C.

1994: Gesetz ist Gesetz. In: Böke/Müller/Reinfeldt 1994

Müller, J. C. et. al.

1994: Der Staat in den Köpfen. Anschlüsse an Louis Althusser und Nicos Poulantzas. Mainz

Offe, C.

1975: Strukturprobleme des kapitalistischen Staates. Frankfurt/M., 3. Aufl.

Parsons, T.

1972: Das System moderner Gesellschaften. München

Paschukanis, E.

1991: Allgemeine Rechtslehre und Marxismus. Berlin - Freiburg

Pêcheux, M.

1978: Zum theoretischen Status der Semiologie. In: Alternative Nr. 118

1982: Language, Semantics and Ideology. Houndmills, Basingstoke, Hampshire and London

1983: Ideologie - Festung oder paradoxer Raum? In: Das Argument Nr. 139

1984: $\mathrm{Zu}$ rebellieren und zu denken wagen! Ideologien, Widerstände, Klassenkampf. In: kultuRRevolution Nr. 5/6

1988: Sind die Massen ein beseeltes Objekt? In: kultuRRevolution Nr. $17 / 18$

Pêcheux, M. / Fuchs, C.

1975: Das Subjekt und der Sinn. Zur Neuformulierung des Erkenntnisgegenstandes der Sprache. In: Alternative Nr. 104

Pfaller, R.

1997: Althusser - Das Schweigen im Text. München

Poster, M.

1984: Foucault, Marxism and history: mode of production versus mode of information. Cambridge

Poulantzas, N.

1972a: Aus Anlass der marxistischen Rechtstheorie. In: Reich 1972

1972b: Theorie und Geschichte. Kurze Bemerkungen über den Gegenstand des "Kapitals". In: Euchner/Schmidt 1972

1973a: Zum marxistischen Klassenbegriff. Berlin

1973b: Die Internationalisierung der kapitalistischen Produktionsverhältnisse und der Nationalstaat. Berlin

1973c: Klassenkampf und Repression - Einige Hauptzüge des kapitalistischen Staates. In: Kursbuch Nr. 31

1973d: Faschismus und Diktatur. München

1975: Klassen im Kapitalismus - heute. Berlin

1976: La crise de l'État. Paris

1977: Die Krise der Diktaturen. Frankfurt/M.

1978a: Staatstheorie: politischer Überbau, Ideologie, sozialistische

Demokratie. Hamburg

1978b: Der "starke Staat" und seine Schwächen. In: Alternative Nr. 119

1980: Politische Macht und gesellschaftliche Klassen. Frankfurt/M.

1983: Une revolution copernicienne dans la politique. In: Buci-

Glucksmann 1983 
Poulantzas, N. / Miliband, R.

1976: Kontroverse über den kapitalistischen Staat. Mit einem Beitrag von Ernesto Laclau. Berlin

Priester, K.

1981: Studien zur Staatstheorie des italienischen Marxismus: Gramsci und Della Volpe. Frankfurt/M. - New York

Projekt Ideologie-Theorie

1982: Theorien über Ideologie. Berlin, 2. Auflage

1984: Die camera obscura der Ideologie. Berlin

Projekt Klassenanalyse

1975: Louis Althusser - Marxistische Kritik am Stalinismus? Berlin

Rancière, J.

1972: Der Begriff der Kritik und die Kritik der politischen Ökonomie.

Berlin

1975: Wider den akademischen Marxismus. Berlin

1994: Althusser: Die Szene des Textes. In: kultuRRevolution Nr. 29

Reich, N. (Hrsg.)

1972: Marxistische und sozialistische Rechtstheorie. Frankfurt/M.

Reichelt, $\mathrm{H}$.

1973: Zur logischen Struktur des Kapitalbegriffs bei Karl Marx. Frankfurt/M., 4. Aufl.

Reif, A.

1973: Antworten der Strukturalisten: Roland Barthes - Michel Foucault -

François Jacob - Roman Jakobson - Claude Lévi-Strauss.

Hamburg

Resch, R. P.

1992: Althusser and the Renewal of Marxist Social Theory. Berkley

Rheinberger, H. J.

1975: Die erkenntnistheoretischen Auffassungen Althussers. In: Das

Argument Nr. 94

Riechers, C.

1970: Antonio Gramsci - Marxismus in Italien. Frankfurt/M.

Rodriguez-Lorez, J.

1971: Die Grundstruktur des Marxismus. Gramsci und die Philosophie der Praxis. Frankfurt/M.

Roth, G.

1972: Gramscis Philosophie der Praxis - Eine neue Deutung des Marxismus. Düsseldorf

Rudel, G.

1981: Die Entwicklung der marxistischen Staatstheorie in der Bundesrepublik. Frankfurt/M. - New York

Sartre, J.-P.

1967: Marxismus und Existentialismus. Reinbeck

de Saussure, F.

1931: Grundfragen der allgemeinen Sprachwissenschaft. Berlin -

Schaff, A. Leipzig

1974: Strukturalismus und Marxismus. Wien

Schenkel, L. / de Vries, S. J.

1989: Umleitung oder: Wie heißt Bruno mit Nachnamen? Marginalien zu Althusser-Deleuze - Foucault. Gießen 
Schmidt, A.

1969: Beiträge zur marxistischen Erkenntnistheorie. Frankfurt/M.

1972a: Zum Erkenntnisbegriff der Kritik der politischen Ökonomie. In:

Euchner/Schmidt 1972

1972b: Geschichte und Struktur. Fragen einer marxistischen Historik.

München

Schmidt, W.

1980: Probleme einer Metakritik der Anthropologie: über Althussers

Versuch einer ahumanistischen Neuinterpretation der marxistischen Theorie. Bochum

Schoch, B.

1980: Marxismus in Frankreich seit 1945. Frankfurt/M. - New York

Schöttler, P.

1974: Philosophie/Politik/Wissenschaft. Bemerkungen zum Wandel der theoretischen Problematik bei Louis Althusser. In: Alternative Nr. 97

1988: Althusser und die Geschichtsschreibung der "Annales" - Ein unmöglicher Dialog. In: kultuRRevolution Nr. 20

Schweicher, R.

1980: Philosophie und Wissenschaft bei Louis Althusser. Köln

Sebag, L.

1970: Marxismus und Strukturalismus. Frankfurt/M.

Sève, L.

1972: Marxismus und Theorie der Persönlichkeit. Frankfurt/M.

1976: Über die materialistische Dialektik. Frankfurt/M.

Smart, B.

1985: Foucault, marxism and critique. London

Smith, S. B.

1984: Reading Althusser. Ithaca - London

Spiegel, $\mathrm{H}$.

1983: Gramsci und Althusser - Eine Kritik der Althusserschen Rezeption von Gramscis Philosophie. Hamburg - Berlin

Terray, E.

1974: Zur politischen Ökonomie der "primitiven" Gesellschaften. Frankfurt/M.

Thieme, $\mathrm{K}$.

1972: Zur sogenannten "strukturalistischen" Marx-Interpretation. In:

Althusser/Balibar 1972

1982: Althusser zur Einführung. Hamburg

Trein, F.

1977: Die Autonomie der Theorie bei L. Althusser in ihrer rationalistischen Begründung. Berlin (Diss.)

Trenkle, $\mathrm{N}$.

1999: Brothers in Arms - Über die heimliche Verwandtschaft von

Traditionsmarxismus und Postmodernismus. Online in Internet: http://www.giga.or.at/others/krisis/n-trenkle_Brothers-inArms jungle-world-1999.html; Stand 17.12.2001

Turchetto, M.

1994: Für die Kritik einer Selbstkritik. In: Böke/Müller/Reinfeldt 1994

Weber, M.

1984: Soziologische Grundbegriffe. Tübingen, 6. Aufl. 
Wolf, F. O.

1983: Diesseits oder Jenseits der "Staats-Politik"? In:

Albers/Altvater/Haug 1983

1988: Auf der Suche nach dem ideologischen Klassenkampf diesseits von imaginärer Klassenpolitik und symbolischen Münchhauseniaden. In: kultuRRevolution Nr. 18/19

Zizek, S.

1988: Das Subjekt vor der Subjektwerdung. In: kultuRRevolution Nr. 20 2001: Die Tücke des Subjekts. Frankfurt/M. 
Ich versichere, dass ich die eingereichte Dissertation „Zur Staats- und Ideologietheorie im strukturalistischen Marxismus" selbständig und ohne unerlaubte Hilfsmittel verfasst habe. Anderer als der von mir angegeben Hilfsmittel und Schriften habe ich mich nicht bedient. Alle wörtlich oder sinngemäß den Schriften anderer Autoren entnommen Stellen habe ich kenntlich gemacht.

Stefan von Brauk 


\section{Lebenslauf}

Name: $\quad$ Stefan von Brauk

Geb.-Datum: $\quad$ 23.12.1967

Geb.-Ort: Lübbecke/Westfalen

Staatsangehörigkeit: Deutsch

schulischer Werdegang

$\begin{array}{ll}1974-1978 & \text { Grundschule Lübbecke } \\ 1978-1984 & \text { Jahn-Realschule Lübbecke } \\ 1988-1991 & \text { Oberstufe der Georg-Christoph-Lichtenberg } \\ & \text { Gesamtschule Göttingen }\end{array}$

wissenschaftlicher Werdegang

1991 - 1992 Studium der Physik an der Universität Göttingen

1992 - 1997 Studium der Sozialwissenschaften (Politikwissenschaft, Publizistik und Kommunikationswissenschaft, VWL, Öffentliches Recht) an der Universität Göttingen, Abschluss als Diplom-Sozialwirt $1997-2002$ Promotion

beruflicher Werdegang

\begin{tabular}{|c|c|}
\hline $1984-1988$ & Polizeivollzugsbeamter im Bundesgrenzschutz \\
\hline $1994-1997$ & Wissenschaftliche Hilfskraft am Institut für \\
\hline & Wirtschaftsinformatik II der Universität Göttingen \\
\hline $997-2000$ & $\begin{array}{l}\text { Softwarearchitekt und Projektleiter bei der Prof. } \\
\text { Schumann } \mathrm{GmbH} \text {, Göttingen }\end{array}$ \\
\hline $000-2001$ & $\begin{array}{l}\text { Niederlassungsleiter bei der Prof. Schumann } \\
\text { GmbH, Niederlassung Köln }\end{array}$ \\
\hline eit 2001 & $\begin{array}{l}\text { Projektleiter bei der eVision-Ventures AG, } \\
\text { Leverkusen }\end{array}$ \\
\hline
\end{tabular}

